\title{
Ambulatory urodynamics : from physiological research to daily practice
}

Citation for published version (APA):

van Waalwijk va Doorn, E. S. C. (1993). Ambulatory urodynamics : from physiological research to daily practice. [Doctoral Thesis, Maastricht University]. Rijksuniversiteit Limburg.

https://doi.org/10.26481/dis.19930416ew

Document status and date:

Published: 01/01/1993

DOI:

10.26481/dis.19930416ew

Document Version:

Publisher's PDF, also known as Version of record

\section{Please check the document version of this publication:}

- A submitted manuscript is the version of the article upon submission and before peer-review. There can be important differences between the submitted version and the official published version of record.

People interested in the research are advised to contact the author for the final version of the publication, or visit the DOI to the publisher's website.

- The final author version and the galley proof are versions of the publication after peer review.

- The final published version features the final layout of the paper including the volume, issue and page numbers.

Link to publication

\footnotetext{
General rights rights.

- You may freely distribute the URL identifying the publication in the public portal. please follow below link for the End User Agreement:

www.umlib.nl/taverne-license

Take down policy

If you believe that this document breaches copyright please contact us at:

repository@maastrichtuniversity.nl

providing details and we will investigate your claim.
}

Copyright and moral rights for the publications made accessible in the public portal are retained by the authors and/or other copyright owners and it is a condition of accessing publications that users recognise and abide by the legal requirements associated with these

- Users may download and print one copy of any publication from the public portal for the purpose of private study or research.

- You may not further distribute the material or use it for any profit-making activity or commercial gain

If the publication is distributed under the terms of Article $25 \mathrm{fa}$ of the Dutch Copyright Act, indicated by the "Taverne" license above, 


\section{Ambulatory Urodynamics}

FROM PHYSIOLOGICAL RESEARCH TO DAILY PRACTICE

\section{PROEFSCHRIFT}

ter verkrijging van de graad van doctor

aan de Rijksuniversiteit Limburg te Maastricht, op gezag van de Rector Magnificus Prof. Mr. M.J. Cohen, volgens het besluit van het College van Dekanen, in het openbaar te verdedigen op vrijdag, 16 april 1993 om 14.00 uur

door

Ir. Ernst Stefan Christiaan van Waalwijk van Doorn

geboren op 8 februari 1954 te Eindhoven 
Promotor:

Beoordelingscommissie: Prof. Dr. R.S. Reneman (voorzitter)

Prof. Dr. H.J.A. Mensink

Prof. Dr. F. Spaans

Prof. Dr. E.H.M.A. Marres

Dr. J.B.D.M. van Gool

\section{CIP-DATA KONINKLIJKE BIBLIOTHEEK, DEN HAAG}

Waalwijk van Doorn, Ernst Stefan Christaan van

Ambulatory Urodynamics : from physiological research to daily practice / Ernst Stefan Christaan van Waalwijk van Doorn.

- [S.1. : s.n.]

Thesis Maastricht. - With ref. - With summary in Dutch.

ISBN 90-9006004-9

SISO 604.3

SISO 605.8

Subject headings: Urodynamics / Incontinence.

Produktie, layout en druk:

ASKA tekst + druk bv - Alphen aan den Rijn

The printing of this thesis was sponsored by:

Applied Medical Technics bv

ASKA tekst + druk bv

Bayer AG.

Bio Interface bv

Byk Nederland bv

Dräger bv (former Honeywell-Philips)

Gaeltec Ltd.

KABI Pharmacia bv

Medical Measurement Systems bv

Stichting Fysiologic

Stichting WAMU 


\section{Preface}

The research, described in this thesis, was performed at two locations. The patient materials used in chapters 2,3 , and 4 originate from the department of Urology of the University Hospital Nijmegen, the patient materials used for chapters 5-8 originate from the department of Urology of the University Hospital Maastricht. Since I changed jobs during the progress of this research, I am very grateful to Ir. W.C.M. van Lieshout, previous chairman of the Board of Governors of the University of Nijmegen, who enabled me to use the data for this thesis. Also, I want to thank my former colleagues at the department of Instrumentation end the department of Urology of the St Radboud hospital; especially Wil Hermans, Theo Schoester and Benny Hendriks, who always supported me enthusiastically. Furthermore, I want to express my gratitude to all my colleagues of the department of Urology at the University Hospital Maastricht, who all showed interest and gave support to my work; especially Theo Vanspauwen and Sabine Geurts, who spent many saturdays to investigate volunteers and who performed most of the urodynamic investigations with the essential quality. I thank Obe Veldman, who was responsable for the technical development of the Urodec 500 system and Ageeth Remmers for her support with the analysis of the data. I am grateful to Judith Bakker, who re-edited my english. Finally, I want to thank Karl Delaere, who introduced me into urodynamics and Rudi Janknegt for his great support and confidence during the second part of this research. And last but not least, I want everybody to know that this thesis would not exist, if my wife Irene would not have been so patient with me and always prepared to listen to my problems and to read the results. 
To: my parents and

my wife Irene

NEMO COGNOSCITUR NISI PER AMICITIAM. 


\section{Table of contents}

Chapter I Introduction

page $9-14$

1.1 Introduction

1.2 Aims of this study

1.3 Study set-up

1.4 References

Chapter II Sensitivity and specificity of conventional urodynamics with respect to urinary incontinence

2.1 Introduction

2.2 Materials and methods

2.2.1 Conventional urodynamic investigation (CUI)

2.2.2 Patient groups

2.3 Results

2.4 Discussion

2.4.1 Reliability of symptomatic preclassification of incontinence

2.4.2 Incontinence proven in different incontinence groups

2.4.3 Discrimination by the conventional urodynamic investigation (CUI) between the main three categories of incontinence

2.5 Review of literature:

Results of other studies investigating correlation of classification according to symptoms and urodynamic diagnosis compared with the present study

2.6 Conclusions

2.7 Comment

2.8 References 
Chapter III A telemetric ambulatory method to investigate the lower urinary trac function

E.S.C.van Waalwijk van Doorn, R. A. Janknegt Dept. of Urology, University Hospital

Maastricht, The Netherlands.

Submitted for publication.

Chapter IV Ambulatory monitoring to assess the efficacy of oxybutynin chloride in patients with mixed incontinence

E.S.C. van Waalwijk van Doorn, W. Zwiers

Dept. of Urology, University Hospital

Maastricht and dept. of Urology,

St. Josef Hospital Eindhoven, The Netherlands.

Published in European Urology, 18: 49, 1990.

Chapter V Computerised Ambulatory

Urodynamics

E.S.C. van Waalwijk van Doorn, R.A. Janknegt Dept. of Urology, University

Hospital Maastricht, The Netherlands.

A summary of this chapter was published in Neurourology and Urodynamics Volume 6. Number 3, july 1987.

Chapter VI Extramural ambulatory urodynamic monitoring during natural filling and normal daily activities: evaluation of one hundred patients

E. S.C. van Waalwijk van Doorn, A. Remmers, R. A. Janknegt

Dept. of Urology, University Hospital

Maastricht, The Netherlands.

Published in the Journal of Urology, 146: 124, 1991. 
Chapter VII Conventional and extramural ambulatory urodynamic testing of the lower urinary tract in female volunteers

E.S.C. van Waalwijk van Doorn, A. Remmers, R. A. Janknegt

Dept. of Urology, University Hospital

Maastricht, The Netherlands.

Published in the Journal of Urology, 147: 1319, 1992.

Chapter VIII Detrusor Activity Index

Quantification of detrusor overactivity by means of ambulatory monitoring.

E.S.C. van Waalwijk van Doorn, A. Remmers, A.W. Ambergen*, R. A. Janknegt Dept. of Urology, University Hospital Maastricht, ${ }^{*}$ Dept. of Medical Informatics and Statistics, University of Limburg, The Netherlands.

Submitted for publication.

Summary page 199-202

Samenvatting page 203-206

Appendix page 207

Curriculum vitae page 209 



\section{Chapter I - Introduction}

\subsection{Introduction}

Urinary incontinence is a major health problem which, although not directly related to mortality, often is a serious handicap. Nowadays a reliable diagnosis of the causes of urinary incontinence is not possible without the application of quantitative conventional urodynamic investigations like uroflowmetry, urethral profilometry, filling cystometry and pressure/flow tests. For this reason the understanding and mastering of these tests are basic demands to specialists working in a urological or gynaecological practice.

As equipment is expensive and the investigations are time consuming, the need for efficiency and reliability when using these tools is obvious. All aforementioned conventional clinical tests are performed while the patient is bound to the clinical laboratory and therefore limited. The functioning of the lower urinary tract as a urine storage and evacuation system is normally characterized by time constants, varying from seconds to hours. This causes the occurrence of symptoms during the short conventional quantitative urodynamic tests to be uncertain.

For this reason it may be that conventional urodynamic investigations give doubtful results and frequently do not result in a reliable functional diagnosis, while very often clinical questions remain unanswered.

The long and complex medical history of many patients may be added to illustrate the poor results of former therapies, which largely relied on the outcome of urodynamic diagnostics. Since the quantitative and qualitative results of urodynamic tests are used to justify surgical therapy, which is always irriversable, it goes without saying that quantitative urodynamic testing methods need to be reliable.

Based on his urodynamic experiences in 1002 male and 1901 female patients, Abrams (1) stated that urodynamic investigations can help the clinician to improve diagnosis and treatment in four main ways:

- the investigations may (author: should) assist in the evaluation of an individual case, providing objective evidence on which to base decisions.

- the analyses of groups of patients may, over a time, improve both the understanding of pathophysiology and the selection of patients for treatment.

- urodynamic testing may provide objective information before and after therapeutic intervention, allowing the 
clinician to monitor the results of treatment more accurately.

- the urodynamic testing assists the continuing education of the clinicians themselves.

As the clinician becomes more experienced in the urodynamic investigation of patients his confidence in his diagnostic ability as to the significance of complaints increases. This increase of confidence is only partially justified (1).

With the last part of this statement, Abrams already indicates the limitations of the urodynamic tests.

Particularly for the judgement of reliability of existing clinical urodynamic diagnostic techniques, which have evolved within daily practice, an increase in knowledge of normal and abnormal behaviour of the lower urinary tract under non-laboratory daily conditions seems to be important.

Ambulatory monitoring might serve as a promising tool to gain more knowledge about this behaviour under normal conditions.

That this would even lead to a new generation of urodynamic diagnostic systems which record the lower urinary tract functioning under non-clinical, normal conditions was not expected in advance.

\subsection{Aims of this study}

- to quantify the limitations of the nowadays commonly applied urodynamic tests performed according to the standards suggested by the International Continence Society $(2,3,4)$.

- to develop ambulatory urodynamic methods to learn about detrusor and sphincter behaviour under normal daily conditions and during an extended period both in patients and normal volunteers

- to compare ambulatory urodynamic testing with the conventional investigative methods to evaluate its possible clinical applicability and value.

\section{$1.3 \quad$ Study set-up}

- In chapter II the limitations of conventional urodynamic tests are studied through a correlation between "preclassification according to medical history" and "final urodynamic diagnosis" in a group of 608 patients. Results 
will be compared with studies by other authors. which are sparsely found in literature.

- In chapter III, IV, V, VI and VII the evolution of ambulatory urodynamic measuring is described as follows:

- In chapter III an ambulatory urodynamic investigation method is described, which was developed to study patients on-line. An eight channel telemetry system was used. In this way different activities and events during ambulatory recording could be studied and interpreted with the help of direct questioning of the patient.

A study to compare this ambulatory method with the conventional investigation is presented and discussed.

- In chapter IV an ambulatory method will be described for 24 hour "intramural" urodynamic investigation of detrusor activity using an analog miniaturized tape recorder system (Oxford Instruments). A clinical trial using this holter method will be presented to demonstrate the efficacy of Oxybutynin Chloride to suppress detrusor activity. This study is also performed to demonstrate the clinical applicability of 24 hour ambulatory urodynamic monitoring.

- In chapter $V$ an "extramural" ambulatory method will be described using a processor based miniaturized holter system (URODEC 500), which was developed for this study.

- In chapter VI a clinical study is presented to compare conventional urodynamic testing with ambulatory extramural urodynamic monitoring, as described in chapter $\mathrm{V}$, in a group of 100 patients with complaints of urinary incontinence.

- Because of the major differences between conventional urodynamic findings and those after ambulatory monitoring the need for urodynamic reference values in asymptomatic subjects occurred. In chapter VII the results of a urodynamic study in a group of 50 asymptomatic volunteers are presented. Both detrusorand urethral sphincter activity were investigated with the URODEC 500 system, using the method described in chapter $\mathrm{V}$. 
- In chapter VIII the Detrusor Activity Index (DAI) is presented. This quantitative index was developed, based on the experience and results presented in the previous two chapters. The DAI is a new urodynamic parameter which enables the quantitative interpretation of detrusor overactivity in an individual patient.

- Chapter IX will summarize the most important results and conclusions obtained from the study.

- Since this study was performed partly at the Catholic University of Nijmegen and partly at the University Hospital of Maastricht, appendix will show the origin of the patient data. 


\section{$1.4 \quad$ References}

1. Abrams P., Feneley R., Torrens M.: The clinical contribution of urodynamics.

Urodynamics, chapter 5, edited by Mundy A.R. et al.: 118, 1983.

2. International Continence Society; Standardisation Committee: The Standardisation of Terminology of lower urinary tract function.

Draft 14/1/87.

3. International Continence Society: Urodynamic equipment, technical aspects.

Journal of Medical Engineering \& Technology: 11; $\mathrm{Nr} 2$ : 57-64, 1987.

4. International Continence Society; Standardisation Committee: The Standardisation of Terminology of lower urinary tract function.

Scand. J. Urol. Nephrol, Supplementum 114: 5-19, 1988. 



\section{Chapter II - Sensitivity and specificity of conventional urodynamics with respect to urinary incontinence}

\section{$2.1 \quad$ Introduction}

To quantify the subjective experience of the limitations of the urodynamic clinical tests as they were performed at the urodynamic unit of the university of Nijmegen, a comparison was made between preclassification according to medical history taking on the one hand and the diagnosis based on the urodynamic clinical testing results on the other. Occurrence of symptoms during the quantitative diagnostic tests, is regarded to be essential for a conclusive diagnosis and with respect to possible therapeutic consequences.

"The conventional urodynamic investigation (CUI)" is described. This clinical investigation was performed according to the suggestions made by the "Standardisation Committee" of the International Continence Society (ICS) $(5,6,7)$. Conclusions are drawn on the sensitivity and specificity of the described conventional urodynamic investigation with a special emphasis on the diagnosis "urinary incontinence".

\section{$2.2 \quad$ Materials and methods}

During a period of 14 months all patients with complaints of urinary incontinence and/or micturition problems, visiting the outpatient clinic of the department of urology, were pre-classified according to medical history taking and then investigated and evaluated urodynamically.

\subsubsection{Conventional Urodynamic Investigation (SUI)}

A SUI has to be considered as a functional test of the filling and evacuation phases of the lower urinary tract system. SUI consists of a FREE UROFLOWMETRY to test on the evacuation phase, followed by URETHRAL PROFILOMETRY and the FILLING CYSTOMETRY to test on the storage phase and finally a PRESSURE/FLOW STUDY to test again on the evacuation phase. In the next paragraphs the different urodynamic test are described and examples originating from a MMS urodynamic laboratory system are shown (fig. 1-6). Analyses of the different curves are partially performed automatically and partly semi-automatically by puting markers with the help of a 
cursor at certain positions in the curves. The programm calculates then the different urodynamic parameters.

\subsubsection{Free uroflowmetry}

The uroflowmetry is used to get a first quantitative and qualitative impression of the evacuation function of the lower urinary tract.

The patient is asked to come with a full bladder. "Full" means "full, according to the subjective judgement of the patient". The test is performed in a private toilet, where the patient can void under normal circumstances; momentary flow and volume of the urine are registered. Figure 1 shows as an example an initial flow recording. From these curves maximum (Qmax) and mean flowrate (Qave), flow time, voiding time and time to peak flowrate are deduced; curves are also interpreted and qualitatively with respect to the shape.

\subsubsection{Urethral pressure profilometry (UPP)}

The UPP test is applied to obtain quantitave information on the closure function of the urethral sphincter mechanism. During the UPP test a urethral pressure profile with respect to bladder pressure is recorded. A dual sensor catheter is inserted transurethrally. One sensor is positioned at the tip, the other $50 \mathrm{~mm}$ distally. After insertion of both sensors into the bladder, the catheter is connected to an automatic puller and the distal pressure sensor is pulled with a constant speed of $1 \mathrm{~mm} / \mathrm{sec}$ through the urethra. The tip pressure sensor remains in the bladder. In this way a urethral pressure profile relative to the bladder pressure is obtained. Anatomical length, functional length and maximal closure pressure of the urethral sphincter mechanism can be obtained. Figure 2 demonstrates an example of a UPP with the calculated parameters. This procedure can be repeated in different positions of the body and under conditions of physical stress like coughing. A recording of a UPP while the patient coughs is called a "stress profile". With the help of this procedure "transmission ratio" can be calculated; i.e. how well sudden pressure changes, like caused by coughing, are transmitted to the region of the sphincter mechanism. Figure 3 shows an example of a stress profile with calculated transmission ratio.

Instead of using a dual sensor catheter a 4 sensor catheter was used mainly during this study. This has no advantages for the UPP test, but will be discussed under 'filling cystometry'. Figure 4 shows an example of a UPP applying a 4 sensor catheter. 


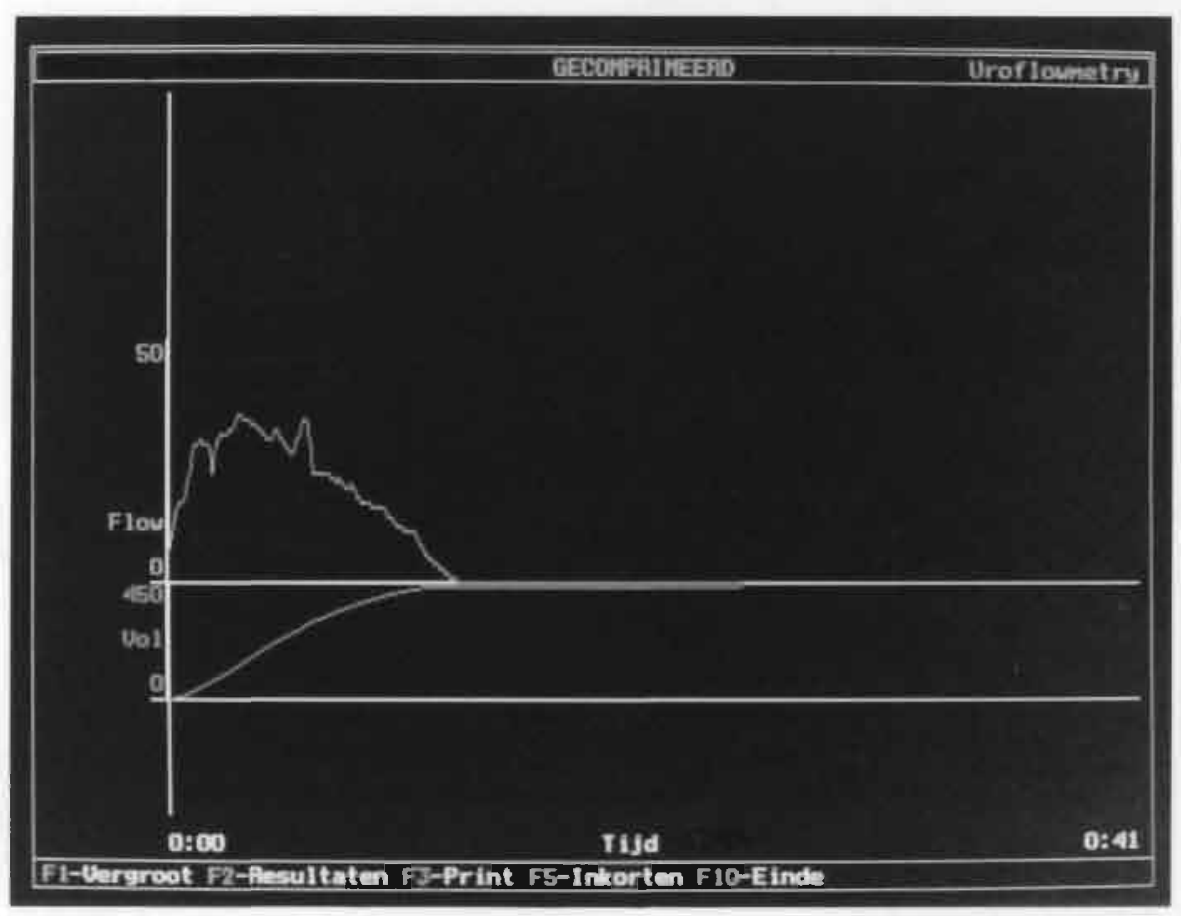

Figure 1. Free uroflowmetry of a female patient recorded with a MMS system; the horizontal axis represents time (sec), the vertical axis flow (mil) sec) respectively volume (ml); results are calculated automatically; Peak. flow $35 \mathrm{ml} / \mathrm{sec}$, Time to peakflow $5 \mathrm{sec}$, Voided volume $440 \mathrm{ml}$, Flow time $21 \mathrm{sec}$, Voiding time $21 \mathrm{sec}$, Mean flowrate $21 \mathrm{ml} / \mathrm{sec}$, Normal voiding (like at home) YES, Straining NO. 



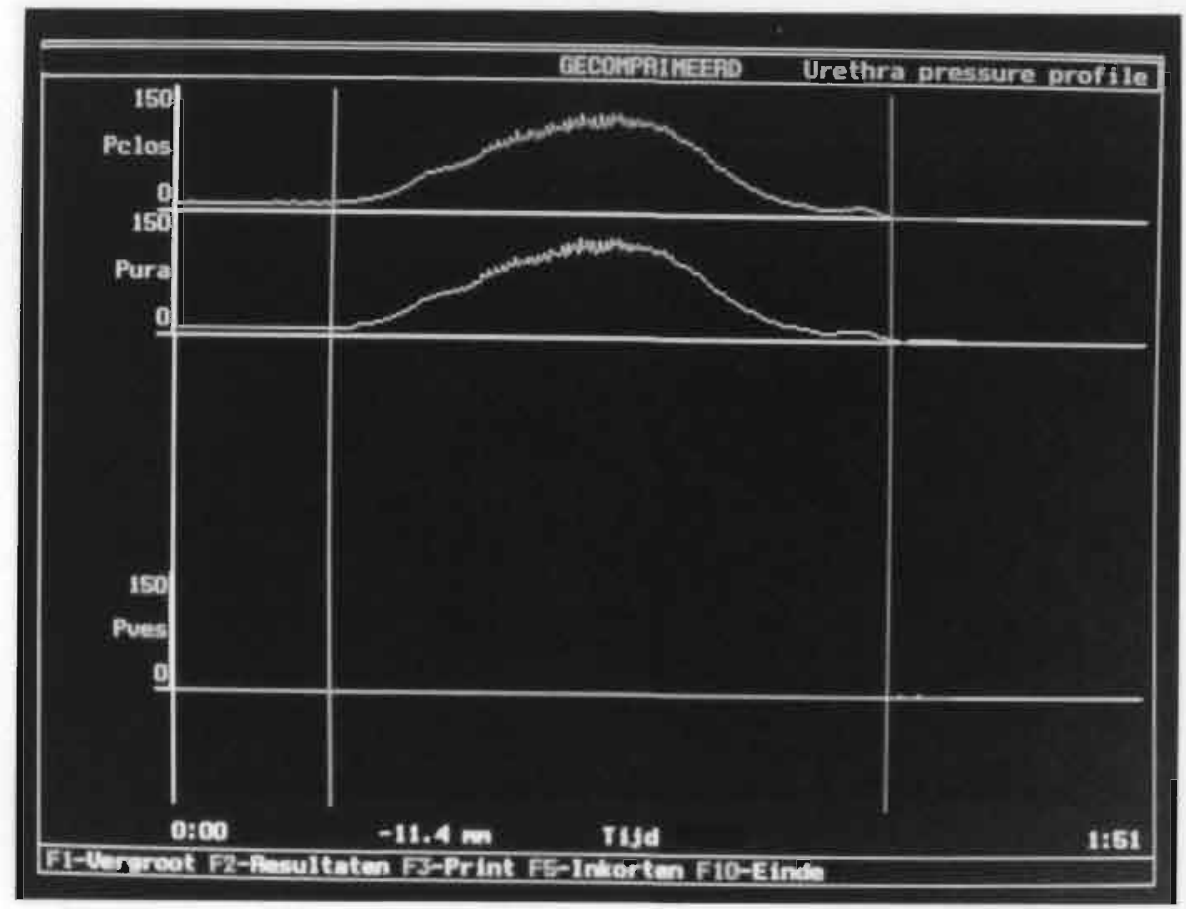

Figure 2. Urethral Pressure Profilometry in a female patient; the horizontal axis represents time ( $\mathrm{sec}$ ), the vertical axis pressure ( $\mathrm{cmH}_{2} \mathrm{O}$ ); results are calculated automatically; Puller speed $0.5 \mathrm{~mm} / \mathrm{sec}$, Maximum. Urethral Closure pressure $114 \mathrm{cmH}_{2} \mathrm{O}$, Functional Length $38 \mathrm{~mm}$, Anatomical Length $40 \mathrm{~mm}$; in the mid region one can see the pressure pulses due to turgescence of the urethral arteris. 


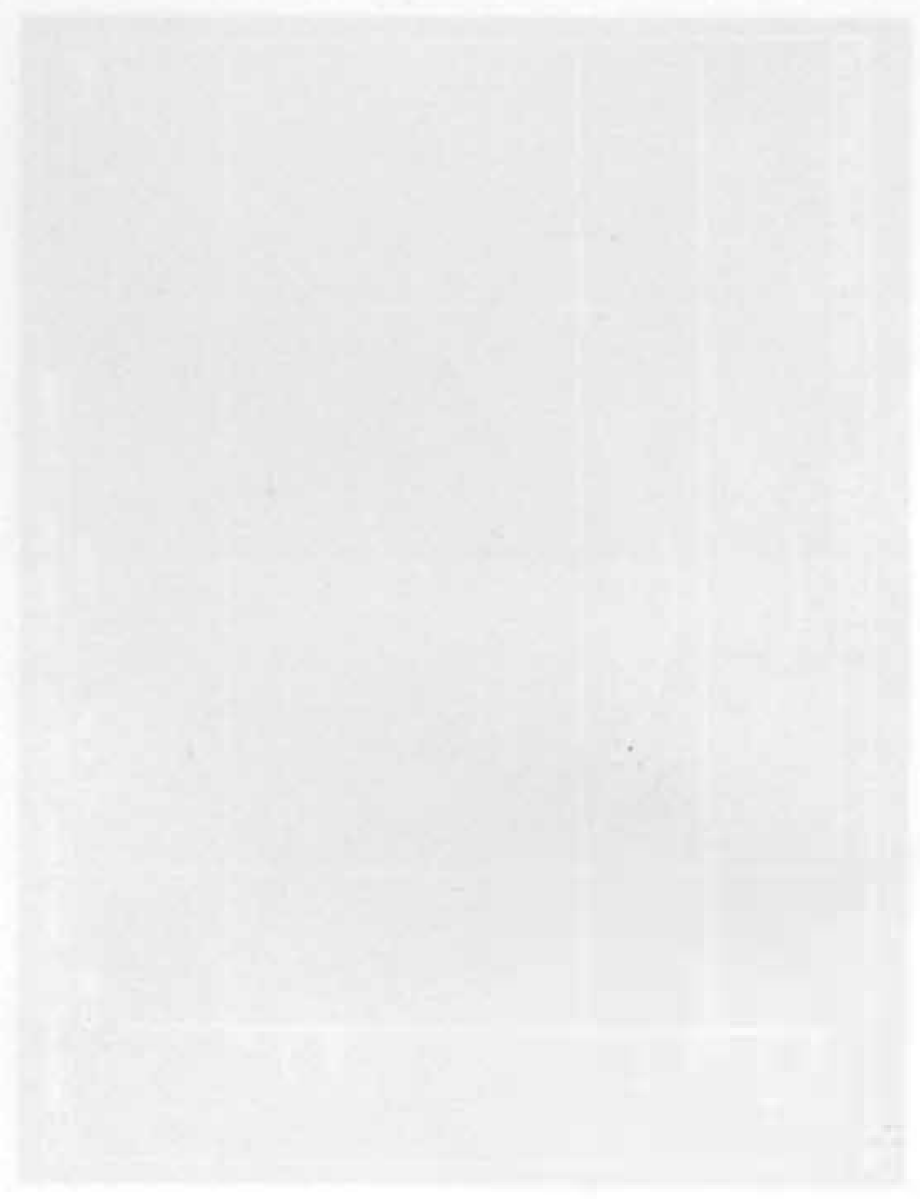




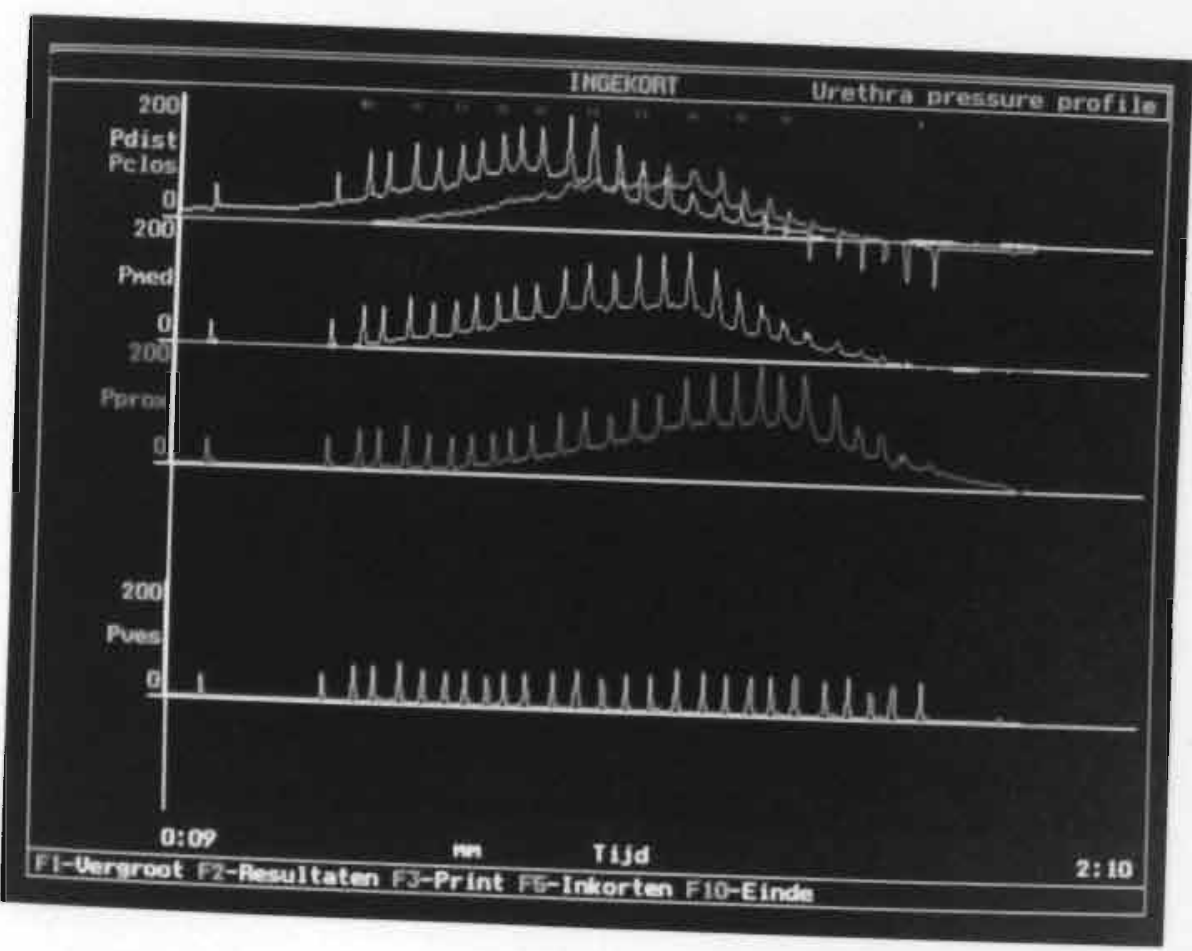
Figure 3. Dynamic Urethral Pressure Profilometry in a female patient using an 8 french catheter with 3 urethral pressure transducers; the horizontal
axis represents time ( $\mathrm{sec})$, the vertical axis pressure $\left(\mathrm{cmH}_{2} \mathrm{O}\right)$; results are calculated automatically from the $\mathrm{P}_{\text {mid }}$ curve; Puller speed 0.5
$\mathrm{~mm} / \mathrm{sec}$, Profile Length $39 \mathrm{~mm}$; Transmission Ratio in the proximal wo third of the $(* 100 \%)$ of the pressure peaks due to coughing of the urethral and the intraves the urethra $\geq 100 \%$; Transmission ratio represents the ratio 


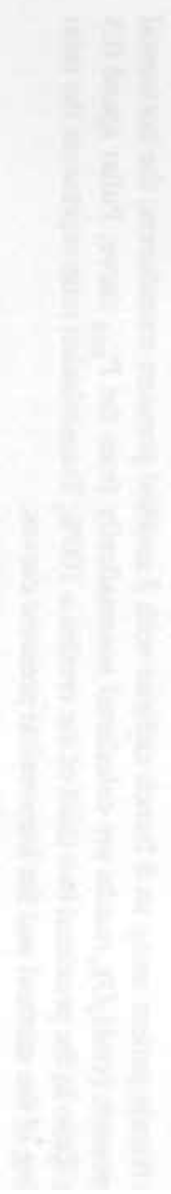




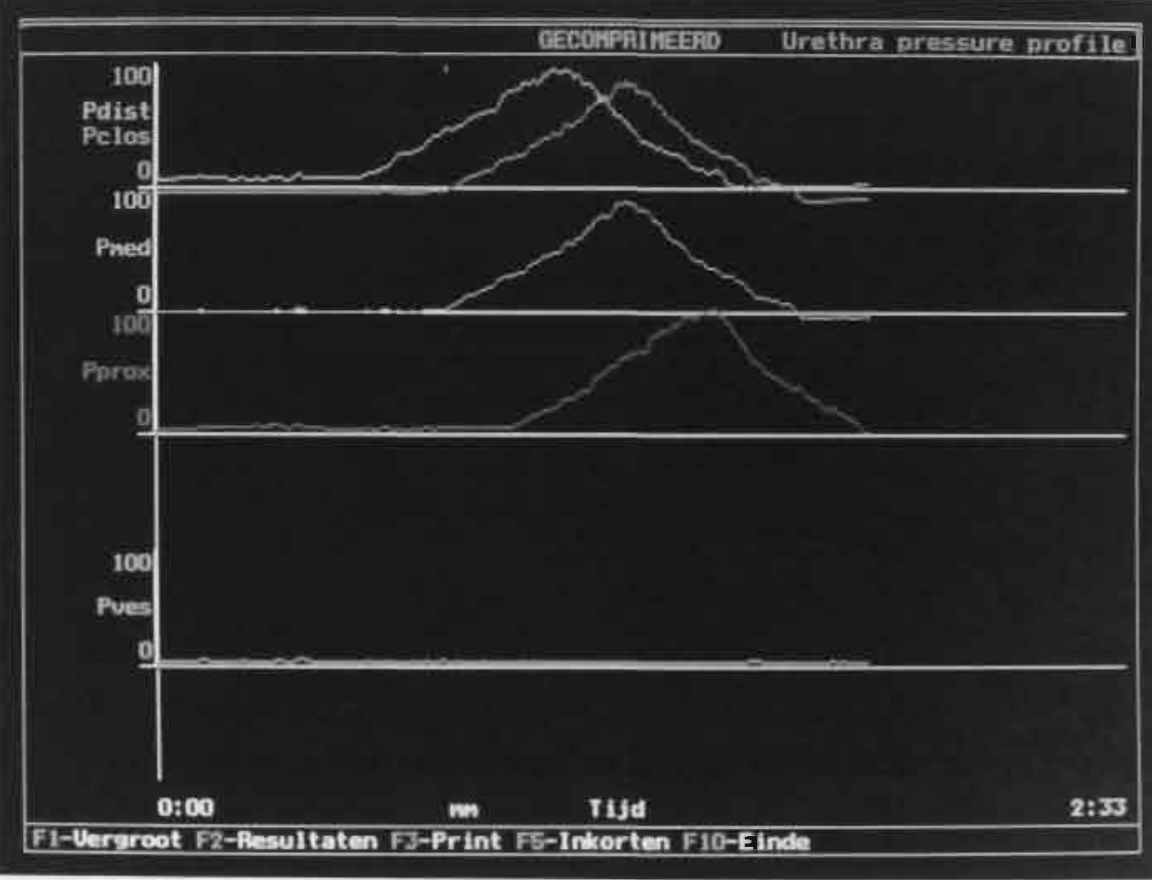

Figure 4. Urethral Pressure Profilometry in a female patient using an 8 french catheter with 3 urethral pressure transducers; the horizontal axis represents time ( $\mathrm{sec}$ ), the vertical axis pressure $\left(\mathrm{cmH}_{2} \mathrm{O}\right)$; results are calculated automatically from the $\mathrm{P}_{\text {mid }}$ curve; Puller speed $0.5 \mathrm{~mm} /$ sec, Maximum Urethral Closure pressure $89 \mathrm{cmH}_{2} \mathrm{O}$, Functional Length $37 \mathrm{~mm}$, Anatomical Length $37 \mathrm{~mm}$. 


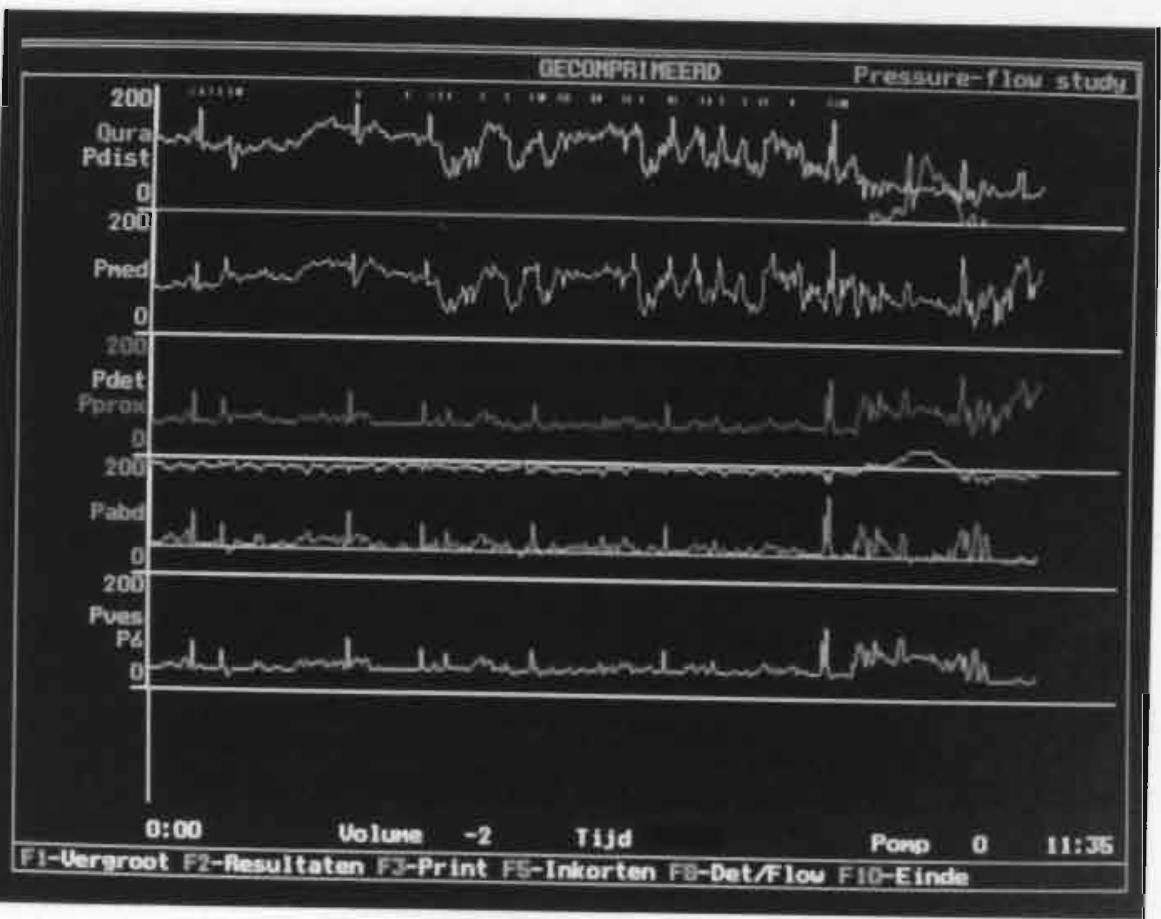

Figure 5. Filling Cystometry followed by Pressure/Flowstudy in a female patient; the horizontal axis represents time (sec), the vertical axis pressure $\left(\mathrm{cmH}_{2} \mathrm{O}\right)$ respectively flow $(\mathrm{ml} / \mathrm{sec})$; results are calculated automatically applying an 8 french catheter with 3 urethrally positioned pressure transducers. The proximal transducer lays in the bladderneck; the mid and distal transducers show pressure variations due to urethral sphincter activity (relaxations and contractions (squeezing). During voiding urethral relaxation can be recognized; also a peak in the flowrate caused by straining can be seen. At the end of the flow the urethral sphincter mechanisme closes again resulting in a pressure rise
in the urethre. 



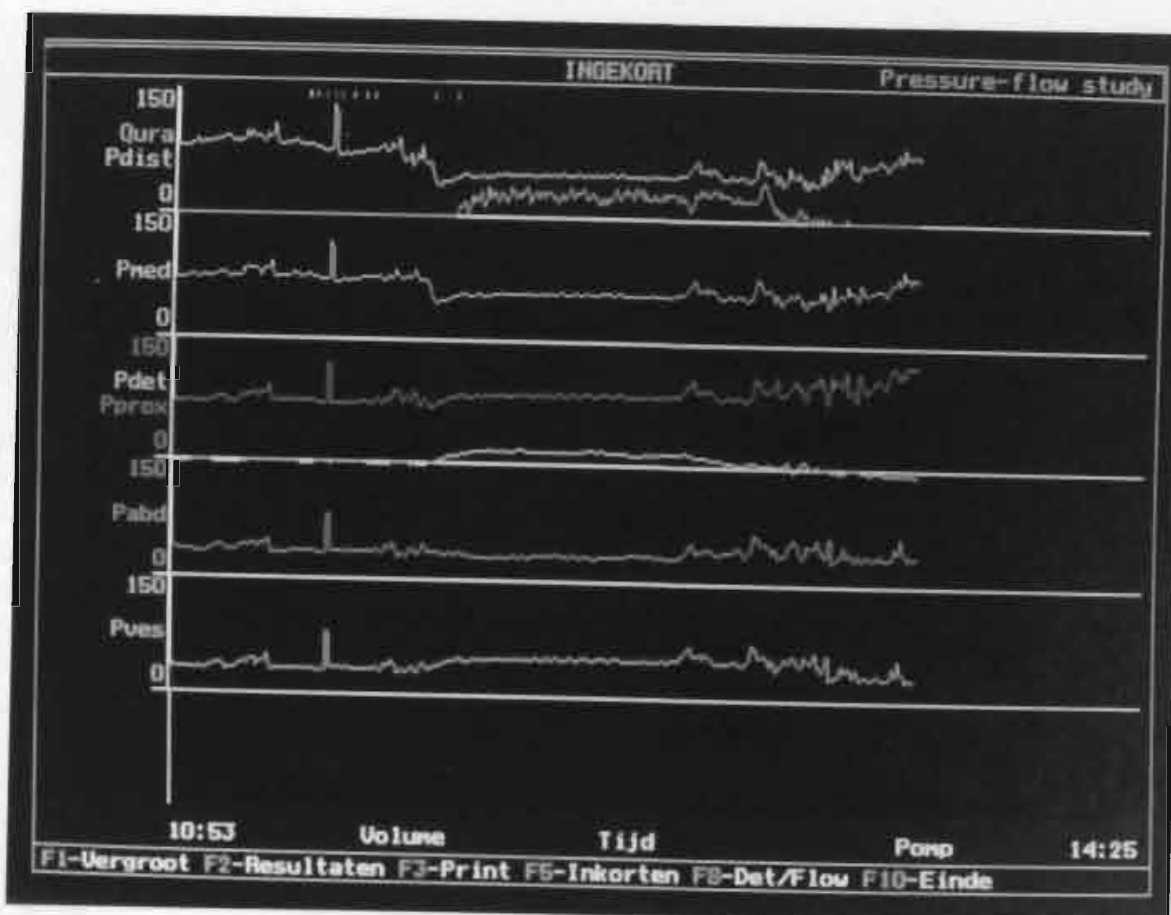

Figure 6. Pressure/Flowstudy in a female patient applying an 8 french catheter with 3 urethrally positioned pressure transducers. Results: Cystometric Bladder Capacity: 453, Opening pressure Pves: $45 \mathrm{cmH}_{2} \mathrm{O}$, Opening time: $6.4 \mathrm{sec}$, Maximum detrusor pressure: $19 \mathrm{cmH}_{2} \mathrm{O}$, Peak flowrate: voiding?: NO; this last aswer of he plime: $104 \mathrm{sec}$, Mean flowrate: $4 \mathrm{ml} / \mathrm{sec}$, residual urine: $0 \mathrm{ml}$, Straining during voiding?: NO. Normal 



\subsubsection{Filling cystometry}

With the special 4 sensor catheter used with profilometry the urethral pressure is also recorded during filling cystometry. The three pressure transducer positioned proximally, medially and distally in the urethra enable us to identify the position and movement of the transducers using the UPP curve as a reference. To draw conclusions on detrusor activity it is necessary to record also intra-abdominal pressure as a reference. The abdominal pressure is recorded by a one sensor catheter, which is inserted approximately $10 \mathrm{~cm}$ rectally. An extra catheter to empty and fill the bladder is inserted transurethrally to measure residual urine after free uroflowmetry and to fill the bladder. All catheters are fixed and the bladder is filled with water or saline at room temperature at a filling rate of $30-50 \mathrm{ml} / \mathrm{min}$ via the extra catheter. Several subjective events like FIRST SENSATION, VOIDING SENSATION, URGE SENSATION, BLADDER CAPACITY as a function of the filling volume are registered. Also pain, uninhibited detrusor contractions, leakage, compliance and, if present, urethral relaxations are marked in the recordings. All occurring events are correlated with the monitored curves to judge the storage function of the detrusor and urethral sphincter mechanism.

The filling cystometry is started with the patient in supine position, which is changed to standing position after "first sensation" or "voiding sensation" is indicated by the patient. At maximal cystometric bladder capacity the filling is stopped, the filling catheter is removed, followed by different exercises, like coughing, straining, bending, squatting and jumping to provoke urine loss. Figure 5 shows an example of a filling cystometric recording using a 4 sensor catheter to monitor detrusor and urethral sphincter activity.

\subsubsection{Pressure/flow study}

Like the initial flowmetry, the pressure/flow study concerns the evacuation phase. The test is performed directly after the filling cystometry. The filling catheter is removed and the patient is asked to void on a flowmeter, while the pressure transducers are still recording detrusor and sphincter activity. After voiding the residual urine volume is measured. The flow curve can be compared with the free uroflowmetry to judge the influence of the unphysiological circumstances. The patient must judge his voiding to be normal to accept the curves as representative.

The pressure/flow study provides information on detrusor contractility, 
synergia of the detrusor/sphincter activity, micturition mechanism (detrusor contraction, straining or both), maximum and mean flowrates, flowtime, voiding time, urethral resistance and residual urine. Figure 6 gives an example of the curves monitored during a pressure/ flow study.

\subsubsection{Patient groups}

In all patients with complaints of incontinence and/or micturition problems a conventional urodynamic investigation was performed. In advance, each patient was tested on urinary infections and, if necessary, treated before the urodynamic investigation. Because of the differences in anatomy of the female and male lower urinary tract both groups were studied seperately. In both groups, five subgroups were defined according to the ICS terminology $(5,7)$ and established only with the help of a standardized questionaire.

\subsubsection{Definitions preclassification patients (ICS)}

STRESS INCONTINENCE as a symptom indicates the patient's statement of involuntary loss of urine during physical exertion.

URGE INCONTINENCE as a symptom indicates the patient's statement of involuntary loss of urine associated with a strong desire to void (Urgency).

MIXED INCONTINENCE as a symptom indicates the patient's statement of involuntary loss of urine both during physical exertion and associated with a strong desire to void.

OTHER INCONTINENCE (not according to ICS terminology) as a classification indicates that the patient complains of involuntary loss of urine and can not be classified as STRESS-, URGE- or MIXED incontinence.

MICTURITION COMPLAINTS as classification indicates the patient's statement of having problems not involving incontinence but mainly related to the evacuation phase (no micturition, frequency, urgency, nycturia, hesitation, dysuria, stranguria, intermittent flow, substantial terminal dribbling).

In case of a combination of urinary incontinence and micturition problems, the incontinence prevailed in the preclassification. 
Based only on the results of the SUI investigation patients were diagnosed. The different diagnoses are again defined in accordance with the ICS terminology.

\subsubsection{Diagnostic classification according to ICS terminology}

STRESS INC.: This diagnosis indicates that during the urodynamic investigation, involuntary urine loss during physical exertion in the absence of detrusor activity was proven. This dysfunction of the urethral closure mechanism was caused by a low transmission ratio of sudden pressure rises during the exertion and/or an incompetent sphincter mechanism.

URGE INC.: This diagnosis indicates that involuntary urine loss was proven to be caused by an uninhibited detrusor contraction. This contraction could be preceded by a relaxation of the urethral sphincter mechanism.

MIXED INC.: This diagnosis indicates that involuntary urine loss was proven both during physical exertion in the absence of detrusor activity and caused by an uninhibited detrusor contraction.

MOTOR URGE: This diagnosis indicates that uninhibited detrusor contractions without urine loss were demonstrated; no stress incontinence was proven.

SENSORY URGE ONLY: This diagnosis indicates that during filling cystometry the patient was complaining of a continuous desire to void in the absence of any demonstrable uninhibited detrusor contractions and without urine loss.

OTHER ABNORMALITIES as a diagnostic classification indicates that neither incontinence, nor motor urge or sensory urge only was proven, but that the investigation demonstrated phenomena like urethral pressure variations, low compliance of the detrusor, pain, no filling sensation, obstructive flow, hypo-active detrusor during voiding, etc.

NORMAL as a diagnostic classification indicates that during the investigation a normal detrusor function and a normal urethral closure mechanism were demonstrated. During the filling phase the bladder contents increased in volume without a significant rise in pressure, no involuntary contractions 
occurred despite provocation. During the evacuation phase normal voiding was achieved by a voluntarily initiated detrusor contraction that is sustained and can be suppressed voluntarily. The normal urethral closure mechanism maintained a clear positive urethral closure pressure (Purethra - Pintravesical) during filling, even in the presence of increased abdominal pressure. During micturition the normal closure pressure decreased to allow flow (synergia). The normal closure mechanism was capable of interrupting urination voluntarily (this "stop test" was not performed in all patients).

Other forms of incontinence, like enuresis nocturna without detrusor instability during the conventional urodynamic investigation, overflow incontinence, the absence of any sphincter function or when no classification could be made, were gathered in one group; this was done because these subgroups were too small to draw any specific conclusions per subgroup.

\section{$2.3 \quad$ Results}

In total 450 female patients with a mean age of 40,7 years (3-79y.) and 158 male paticnt with a mean age of 44,4 years $(5-84 \mathrm{y}$.) entered the study (lables 1 and 2 ).

\begin{tabular}{|c|c|c|}
\hline stress inc. & 98 & $(28 \%)$ \\
\hline urge inc. & 78 & $(22 \%)$ \\
\hline mixed inc. & 129 & $(37 \%)$ \\
\hline other inc. & 43 & $(12 \%)$ \\
\hline total inc. & 348 & $(100 \%)$ \\
\hline
\end{tabular}

symptomatically only micturition problems

$102(23 \%)$

total micturition problems

$102(100 \%)$

total number of female patients

$450(100 \%)$

Table 1. Preclassification of femalc patients according to their urological history ( $N=450$, mean age $40.7 y_{\text {, }}$ range $3-79 y$.). 


\begin{tabular}{lrr} 
stress inc. & 13 & $(16 \%)$ \\
urge inc. & 31 & $(37 \%)$ \\
mixed inc. & 5 & $(6 \%)$ \\
other inc. & 34 & $(41 \%)$ \\
& & \\
\cline { 2 - 3 } total inc. & 83 & $(100 \%)$
\end{tabular}

symptomatically only micturition problems

$75(47 \%)$

total micturition problems

$75(100 \%)$

total number of male patients

$158(100 \%)$

Table 2 Preclassification of male patients $(\mathrm{N}=158)$ according to their urological history $(\mathrm{N}=158$, mean age $44.4 \mathrm{y}$., range $5-84 \mathrm{y}$.).

Table 3 and 4 show how often incontinence was actually demonstrated in the differently preclassified groups.

\begin{tabular}{lccccccc}
\hline RESULTS & $\begin{array}{c}\text { INCONTINENCE } \\
\text { PROVEN DURING } \\
\text { COMPLAINTS }\end{array}$ & $\begin{array}{c}\text { NORMAL } \\
\text { INVESTIGATION }\end{array}$ & $\begin{array}{c}\text { ABNORMAL } \\
\text { INVESTIGATION }\end{array}$ & $\begin{array}{c}\text { SITHOUT } \\
\text { INCONTINENCE }\end{array}$ & \\
\hline STRESS INC. & 58 & $59 \%$ & 30 & $31 \%$ & 10 & $10 \%$ & 98 \\
URGE INC. & 28 & $36 \%$ & 31 & $40 \%$ & 19 & $24 \%$ & 78 \\
MIXED INC. & 68 & $53 \%$ & 34 & $26 \%$ & 27 & $21 \%$ & 129 \\
OTHER INC. & 10 & $23 \%$ & 18 & $42 \%$ & 15 & $35 \%$ & 43 \\
\hline SUM INC. & 164 & $47 \%$ & 113 & $33 \%$ & 71 & $20 \%$ & 348 \\
MICTURITION & 6 & $6 \%$ & 59 & $58 \%$ & 37 & $36 \%$ & 102 \\
\hline SUM & 170 & $38 \%$ & 172 & $38 \%$ & 108 & $24 \%$ & 450 \\
\hline
\end{tabular}

Table 3: Female patients with complaints of incontinence: Pre-classification versus occurrence of complaints and abnormalities during conventional urodynamics. 


\begin{tabular}{|c|c|c|c|c|c|c|c|}
\hline \multirow{2}{*}{$\begin{array}{l}\text { RESULTS } \\
\text { COMPLAINTS } \\
\text { STRESS INC. }\end{array}$} & \multicolumn{2}{|c|}{$\begin{array}{l}\text { INCONTINENCE } \\
\text { PROVEN DURING } \\
\text { INVESTIGATION }\end{array}$} & \multicolumn{2}{|c|}{$\begin{array}{c}\text { NORMAL } \\
\text { DURING } \\
\text { INVESTIGATION }\end{array}$} & \multicolumn{2}{|c|}{$\begin{array}{c}\text { ABNORMAL } \\
\text { WITHOUT } \\
\text { INCONTINENCE }\end{array}$} & SUM \\
\hline & 6 & & 6 & & 1 & & 13 \\
\hline URGE INC. & 15 & & 9 & & 7 & & 31 \\
\hline MIXED INC. & 1 & & 2 & & 2 & & 5 \\
\hline OTHER INC. & 9 & & 10 & & 15 & & 34 \\
\hline SUM INC. & 31 & $37 \%$ & 27 & $33 \%$ & 25 & $30 \%$ & 83 \\
\hline MICTURITION & 4 & $5 \%$ & 38 & $51 \%$ & 33 & $44 \%$ & 75 \\
\hline SUM & 35 & $22 \%$ & 65 & $41 \%$ & 58 & $37 \%$ & 158 \\
\hline
\end{tabular}

Table 4: Male patients with complaints of incontinence: Pre-classification versus occurrence of complaints and abnormalities during conventional urodynamics.

Tables 5 and 6 give the results of the urodynamically found diagnosis versus the symptomatic preclassification for both the female and the male group.

\begin{tabular}{lrrrrrrrrr}
\hline $\begin{array}{c}\text { diagnosis } \\
\text { complaints }\end{array}$ & $\begin{array}{c}\text { Stress } \\
\text { inc. }\end{array}$ & $\begin{array}{c}\text { Urge } \\
\text { inc. }\end{array}$ & $\begin{array}{c}\text { Mixed } \\
\text { inc. }\end{array}$ & $\begin{array}{c}\text { Other } \\
\text { inc. }\end{array}$ & $\begin{array}{c}\text { Motor } \\
\text { urge }\end{array}$ & $\begin{array}{c}\text { Sensory } \\
\text { urge only }\end{array}$ & $\begin{array}{c}\text { Other } \\
\text { abnorm. }\end{array}$ & $\begin{array}{c}\text { Norma } \\
1\end{array}$ & Sum \\
\hline STRESS INC. & 52 & 4 & 2 & 0 & 1 & 4 & 5 & 30 & 98 \\
URGE INC. & 2 & 25 & 1 & 0 & 6 & 10 & 3 & 31 & 78 \\
MIXED INC. & 32 & 19 & 17 & 0 & 12 & 10 & 5 & 34 & 129 \\
OTHER INC. & 4 & 6 & 0 & 0 & 6 & 2 & 7 & 18 & 43 \\
\hline SUM INC. & 90 & 54 & 20 & 0 & 25 & 26 & 20 & 113 & 348 \\
VOIDING & 2 & 4 & 0 & 0 & 10 & 15 & 12 & 59 & 102 \\
\hline TOTAL SUM & 92 & 58 & 20 & 0 & 35 & 41 & 32 & 172 & 450 \\
\hline
\end{tabular}

Table 5: Preclassification versus urodynamic diagnosis of female patients after conventional urodynamic evaluation. 


\begin{tabular}{lccccccccc}
\hline $\begin{array}{c}\text { diagnosis } \\
\text { complaints }\end{array}$ & $\begin{array}{c}\text { Stress } \\
\text { inc. }\end{array}$ & $\begin{array}{c}\text { Urge } \\
\text { inc. }\end{array}$ & $\begin{array}{c}\text { Mixed } \\
\text { inc. }\end{array}$ & $\begin{array}{c}\text { Other } \\
\text { inc. }\end{array}$ & $\begin{array}{c}\text { Motor } \\
\text { urge }\end{array}$ & $\begin{array}{c}\text { Sensory } \\
\text { urge only }\end{array}$ & $\begin{array}{c}\text { Other } \\
\text { abnorm. }\end{array}$ & Normal & Sum. \\
\hline STRESS INC. & 4 & 2 & 0 & 0 & 0 & 0 & 1 & 6 & 13 \\
URGE INC. & 0 & 15 & 0 & 0 & 5 & 0 & 2 & 9 & 31 \\
MIXED INC. & 0 & 1 & 0 & 0 & 2 & 0 & 0 & 2 & 5 \\
OTHER INC. & 1 & 7 & 1 & 0 & 11 & 0 & 4 & 10 & 34 \\
\hline SUM INC. & 5 & 25 & 1 & 0 & 18 & 0 & 7 & 27 & 83 \\
VOIDING & 0 & 4 & 0 & 0 & 11 & 5 & 17 & 38 & 75 \\
\hline TOTAL SUM & 5 & 29 & 1 & 0 & 29 & 5 & 24 & 65 & 158 \\
\hline
\end{tabular}

Table 6: Preclassification versus urodynamic diagnosis of male patients after conventional urodynamic evaluation.

\subsection{Discussion}

In principle, the data presented in section 2.3 can provide answers to the following three questions:

1. how reliable is the preclassification according to the urologic history?

2. does conventional urodynamic investigation separate patients with from patients without urinary incontinence?

3. can the conventional urodynamic investigation discriminate between the different categories of incontinence?

\subsubsection{Reliability of symptomatic preclassification of incontinence.}

In our groups of patients the medical history was taken by specialized physicians. However, it is not possible to have an objective reference group to judge the sensitivity and specificity of "medical history taking". Nevertheless, as the only available option the preclassification was chosen as the standard to judge the sensitivity and specificity of the conventional urodynamic method with respect to incontinence.

Although no reference group was available to test on the reliability of the symptomatic preclassification, there are some arguments to support the hypothesis, that in this study the preclassification of at least STRESS-, URGE- and MIXED incontinence are reliable and can therefore be used as a standard. If stress- or urge incontinence are urodynamically proven, then this is an objective result. If only the group of patients is considered in which incontinence appeared during the conventional investigation, tables 7 and 8 can be obtained from the 
results presented in tables 5 and 6 . On the diagonal a high correlation between preclassification and urodynamic diagnosis for both STRESSand URGE incontinence is found. If we consider the percentages of proven urge inc. ( $\mathrm{N}=4$ out of 58$)$ and mixed inc. ( $\mathrm{N}=2$ out of 58$)$ in the symptomatic STRESS inc. group, which are respectively $7 \%$ and $3 \%$, the symptomatic classification of STRESS inc. shows a high correlation (52/58 means $90 \%$ ) with the urodynamic diagnosis. If the symptomatic classification of URGE inc. is considered, the same small percentages in that group for proven stress inc. ( $\mathrm{N}=2$ out of 28$)$ and mixed inc. ( $\mathrm{N}=1$ out of 28 ) of respectively $7 \%$ and $4 \%$ are found. Therefore the symptomatic classification of URGE inc. also shows a high correlation (25/28 means $89 \%$ ) with the urodynamic diagnosis. The correlation of the symptomatic classification of MIXED inc. with the urodynamic result is very poor $(17 / 68=25 \%)$ as one can see in table 7. Nevertheless it can be imagined that the physician, who is able to classify between STRESS- and URGE inc., can also tell when both symptoms are involved. Therefore it can be concluded from these results that if a patient is preclassified as STRESS- or URGE inc., there is a $90 \%$ probability that the preclassification is confirmed by the urodynamic investigation.

\begin{tabular}{lrrrrr}
\hline $\begin{array}{l}\text { urodynamic diagnosis } \\
\text { symptomatic classification }\end{array}$ & Stress inc. & Urge inc. & Mixed inc. & Total \\
\hline STRESS INC. & $52(90 \%)$ & $4(7 \%)$ & $2(3 \%)$ & 58 & $100 \%$ \\
URGE INC. & $2(7 \%)$ & $25(89 \%)$ & $1(4 \%)$ & 28 & $100 \%$ \\
MIXED INC. & $32(47 \%)$ & $19(28 \%)$ & $17(25 \%)$ & 68 & $100 \%$ \\
\hline TOTAL & 86 & 48 & 20 & 154 & \\
\hline
\end{tabular}

Table 7: Preclassification versus diagnosis of female patients in which incontinence was proven during the conventional urodynamic evaluation.

\begin{tabular}{llccc}
\hline $\begin{array}{l}\text { urodynamic diagnosis } \\
\text { symptomatic classification }\end{array}$ & Stress inc. & Urge inc. & Mixed inc. & Total \\
\hline STRESS INC. & 4 & 2 & 0 & 6 \\
URGE INC. & 0 & 15 & 0 & 15 \\
MIXED INC. & 0 & 1 & 0 & 1 \\
\hline TOTAL & 4 & 18 & 0 & 22 \\
\hline
\end{tabular}

Table 8: Preclassification versus diagnosis of male patients in which incontinence was proven during the conventional urodynamic evaluation. 


\subsubsection{Incontinence proven in different incontinence groups}

As the urodynamic investigation is used as a tool to investigate the function of the lower urinary tract it must be stipulated that:

The diagnosis that should result from the urodynamic investigation, must be based on the occurrence of complaints during the investigation in combination with the objectively recorded dysfunction of the lower urinary tract.

To answer the second question of section 2.4 , the data presented in tables 3 and 4 are evaluated. The analysis mainly concerns the diagnostic capability of the SUI, when urinary incontinence is involved. The actual occurrence of this complaint during the urodynamic investigation is essential.

Table 3 shows that in only $47 \%(\mathrm{~N}=164)$ of 348 female patients with complaints of urinary incontinence, this symptom could be proven objectively during the SUI. In the male patient group this was $37 \%$ $(\mathrm{N}=31$ out of 83 ).

2.4.2.1 Sensitivity and specificity of the conventional urodynamic test with respect to objectifying incontinence

A urodynamic investigation has to be considered as a functional test of the filling and evacuation phase of the lower urinary tract system. This study was limited to patients. Therefore the answering of the second question of section 2.4 concerns only the sensitivity and specificity of the conventional urodynamic investigation with respect to objectifying incontinence.

Sensitivity is defined as the probability that the conventional urodynamic investigation, as described before, objectifies urinary incontinence in patients who are symptomatic with respect to incontinence.

Sensitivity of the conventional urodynamic investigation can be calculated for both females and males. For the female group with symptomatic incontinence the sensitivity $=164 / 348=47 \%$; for the male group the sensitivity $=31 / 83=37 \%$.

Specificity is defined as the probability that the conventional urodynamic investigation, as described before, demonstrates no urinary incontinence in patients who are asymptomatic with respect to incontinence. 
Possible false positive test results are distinguished from patients who are asymptomatic for urinary incontinence according to their medical history; in this study the group of patients with only micturition problems is therefore used as reference group.

The specificity of the conventional investigation can be calculated for both the female and the male patient groups with only micturition problems without incontinence. For the female group $(n=102)$ specificity $=96 / 102=94 \%$; for the male group $(n=75)$ specificity $=$ $71 / 75=95 \%$.

If the sensitivity equals 1 , this means that the conventional urodynamic investigation will in every patient with urinary incontinence confirm this incontinence. If the specificity equals 1 , this means that if no incontinence is involved, this will neither be found during the conventional urodynamic investigation. In tables 9 and 10 the sensitivity and specificity of the conventional urodynamic investigation with respect to the specific form of incontinence is also calculated for the three major incontinence sub-groups for both the females and the males.

\begin{tabular}{lcccc}
\hline $\begin{array}{l}\text { symptomatic } \\
\text { classification }\end{array}$ & $\begin{array}{c}\text { SENSITIVITY } \\
\%\end{array}$ & $\mathrm{~N}$ & $\begin{array}{c}\text { SPECIFICITY } \\
\%\end{array}$ & $\mathrm{~N}$ \\
\hline STRESS INC. & 53.1 & 98 & 98.0 & 102 \\
URGE INC. & 32.1 & 78 & 96.1 & 102 \\
MIXED INC. & 13.2 & 129 & 100 & 102 \\
\hline
\end{tabular}

Table 9: Sensitivity and specificity of the conventional urodynamic investigation in the female patient group classified as stress, urge or mixed incontinent.

\begin{tabular}{lcccc}
\hline $\begin{array}{l}\text { symptomatic } \\
\text { classification }\end{array}$ & $\begin{array}{c}\text { SENSITIVITY } \\
\%\end{array}$ & $\mathrm{~N}$ & $\begin{array}{c}\text { SPECIFICTTY } \\
\%\end{array}$ & $\mathrm{~N}$ \\
\hline STRESS INC. & 30.8 & 13 & 100 & 75 \\
URGE INC. & 48.4 & 31 & 94.7 & 75 \\
MIXED INC. & 0 & 5 & 100 & 75 \\
\hline
\end{tabular}

Table 10: Sensitivity and specificity of the conventional urodynamic investigation in the male patient group classified as stress, urge or mixed incontinent. 
2.4.2.2 Conclusions on sensitivity and specificity of the conventional urodynamic investigation with respect to incontinence

For the male group it would be dubious to draw conclusions from table 10 because of the relatively small numbers. For the female group table 9 shows clearly that the sensitivity for stress inc. is higher than for urge inc. and that, as may be expected, the sensitivity for mixed inc. is the lowest, because in this case both the urge and stress component must be demonstrated during the short conventional investigation. The sensitivity of the conventional urodynamic investigation is the best for stress inc. but extremely low for mixed inc. (13.2\%). The specificity of the main three incontinence groups is high (mean 98.3\%). The low sensitivity causes a major pitfall in treatment of the mixed group, because the stress aspect of the incontinence is often elucidated by the urodynamic investigation, while the urge component remains hidden. Treatment of only the stress aspect can lead to an unexpected and more serious urge incontinence. Every patient will be disappointed if this is the result of the surgical therapy.

Considering the incontinent female groups one can see in table 5, that in $31 \%(\mathrm{~N}=30$ out of 98$)$ of the patients preclassified with the stress inc. symptom, in $40 \%(\mathrm{~N}=31$ out of 78$)$ of those preclassified with the urge inc. symptom and in $26 \%(\mathrm{~N}=34$ out of 129$)$ of those preclassified with the mixed inc. symptoms, the urodynamic investigation did not only demonstrate no incontinence, but was also completely normal. In the complete female group with urinary incontinence the urodynamic investigation failed to determine any dysfunction of the lower urinary tract in $33 \%(\mathrm{~N}=113$ out of 348$)$, in the group with "micturition problems only", this was $58 \%(\mathrm{~N}=59$ out of 102$)$.

Considering the incontinent male group one can see (table 6), that in $46 \%(\mathrm{~N}=6$ out of 13 ) classified with the stress inc. symptom, in $29 \%$ $(\mathrm{N}=9$ out of 31$))$ classified with the urge inc. symptom and in $40 \%$ $(\mathrm{N}=2$ out of 5) classified with the mixed inc. symptoms, the urodynamic investigation did not only demonstrate no incontinence, but was also completely normal. In the whole male group with urinary incontinence the urodynamic investigation failed to determine any dysfunction of the lower urinary tract in $33 \%$ ( $N=27$ out of 83 ), in the group with micturition problems, this was $51 \%(\mathrm{~N}=38$ out of 75$)$. 
2.4.3 Discrimination by the conventional urodynamic investigation (CUI) between the main three categories of incontinence

The third question (2.4) is answered by evaluating the data presented in tables 5 and 6 from section (2.4.1). If the correlation between the symptomatic classification and urodynamic diagnosis for the complete female patient group is considered, the results are a lot worse. In the female group with STRESS inc. $(\mathrm{N}=98)$ the conventional investigation does confirm this objectively in $53 \%$, for URGE inc. $(\mathrm{N}=78)$ in $32 \%$ and for MIXED inc. $(\mathrm{N}=129)$ in only $13 \%$.

If the complete patient group including the male group is considered these percentages are respectively $50 \%$ for STRESS inc., $37 \%$ for URGE inc. and also only $13 \%$ for MIXED inc. These results demonstrate on the one hand that, if the symptom incontinence is demonstrated objectively during the urodynamic investigation, the investigation results correlate well with the preclassification for stress and urge incontinence but poorly for mixed incontinence. On the other hand it must be concluded that the probability of objectifying incontinence during the conventional investigation is rather poor.

\subsection{Review of literature:}

Results of other studies investigating correlation of classification according to symptoms and urodynamic diagnosis compared with the present study

Several authors studied the correlation between symptomatic classification and urodynamic diagnosis. It is difficult to compare the different studies because of the great variety in symptomatic analyses and urodynamic testing methods. Studies are discussed in a chronological sequence. If possible, results will be compared with the present study.

Gaudenz et al. (4) used a questionaire (45 questions) to classify their patients and correlated the answers with the outcome of the urodynamic test (filling cystometry). Their main conclusions concern two groups of patients:

- Patients with incontinence only during coughing and sneezing, which developed during some years, who can interrupt micturition and do not have frequency, nycturia or residual urine, are with a high probability diagnosed as "stress incontinent" after urodynamic testing. 
- Patients with incontinence, developed during a short period, who have frequency, nycturia, can poorly intirrupt micturition and do have a sensation of residual urine after micturition, have a high probability to show uninhibited detrusor contractions during urodynamic testing.

Drutz et al. (3) evaluated 188 female patients with urinary incontinence and/or micturition problems clinically and urodynamically; in 145 patients incontinence was involved. They found that the complaint "wet all the time" correlated with the urodynamic diagnosis "stress incontinent" in $87.0 \%$ but in $21.7 \%$ uninhibited detrusor contractions were seen during testing. All their other questions did not correlate significantly with the urodynamic diagnosis. This result may partly be due to the fact that they did not include the symptomatic classification nor the diagnosis "mixed incontinence" in their analysis.

Karl et al. (8) found in their evaluation of 118 female patients a positive correlation between symptomatic classification and urodynamic diagnosis in $52 \%$ (Table I). The very low percentage of normals (10\%) and the fact that there is no urodynamic diagnosis group "abnormal without incontinence" is caused by the fact that, in this study, incontinence did not have to be objectified during urodynamic testing; urethral closure pressure below $50 \mathrm{cmH} 2 \mathrm{O}$ and the absence of uninhibited detrusor contractions led to the urodynamic diagnosis stress incontinence, uninhibited detrusor contractions $>15 \mathrm{cmH} 2 \mathrm{O}$ led to the diagnosis urge incontinence. Therefore these results show a higher success rate than the present study (Table 11,12).

\begin{tabular}{|c|c|c|c|c|c|}
\hline urodynamic diagnosis & Stress inc. & Urge inc. & Mixed inc. & & Total \\
\hline STRESS INC. & $34(79 \%)$ & 7 & 2 & 43 & $100 \%$ \\
\hline URGE INC. & 10 & $14(52 \%)$ & 3 & 27 & $100 \%$ \\
\hline MIXED INC. & 20 & 9 & $7 \quad(19 \%)$ & 36 & $100 \%$ \\
\hline TOTAL & 64 & 30 & 12 & 106 & $(90 \%)$ \\
\hline
\end{tabular}

Table 11: Correlation between symptomatic classification and urodynamic results found by Karl et al. (8) evaluating 118 female patients. In 12 patients (10\%) no abnormalities could be demonstrated. 


\begin{tabular}{lcccccc}
\hline $\begin{array}{l}\text { urodynamic diagnosis } \\
\text { symptomatic classification }\end{array}$ & Stress inc. & Urge inc. & Mixed inc. & Total \\
\cline { 1 - 4 } STRESS INC. & $56(50 \%)$ & 6 & 2 & 111 & $100 \%$ \\
URGE INC. & 2 & 40 & $(37 \%)$ & 1 & 109 & $100 \%$ \\
MIXED INC. & 32 & 20 & 17 & $(13 \%)$ & 134 & $100 \%$ \\
\hline TOTAL & 90 & 56 & 20 & $166(38.5 \%)$ \\
\hline
\end{tabular}

Table 12: Correlation between symptomatic classification and urodynamic results found in the present study evaluating 348 female and 83 male patients with symptomatic urinary incontinence ( $\mathrm{N}=431$ ). In 140 patients (32.5\%) no abnormalities could be demonstrated. In 96 patients (22.3\%) abnormalities without incontinence were demonstrated. In 166 patients (38.5\%) incontinence was proven during the investigation.

If the correlation of both studies is compared in general with respect to incontinence, a correlation between symptomatic classification and urodynamic diagnosis is found in $26.2 \%$ for this study and in $46.6 \%$ for the study of Karl et al. These two figures may not be compared because objectified incontinence during urodynamic testing was, unlike in the present study, not mandatory in the study by Karl et al.

Awad et al. (1) studied factors which influence the incidence of uninhibited detrusor contractions in women with symptomatic urge incontinence. Comparing supine and standing filling cystometry in a group of 40 patients complaining of urgency and urge incontinence, they found a higher incidence of detrusor instability during the standing cystometry (25/40) compared to a supine position (12/40). Evaluating a group of 99 patients with a urodynamically proven urge incontinence, a correlation with the symptoms was found in 81 patients (82\%). They conclude that the conventional urodynamic study is not "foolproof" to detect detrusor instability; $30 \%$ during supine respectively $61 \%$ during standing cystometry. In the present study a correlation was found in 92\% (103/112; table 5 and 6; 112 patients demonstrated uninhibited detrusor contractions of which 103 were classified as urge or mixed incontinence; the group classified as "OTHER INC" cannot be included in this calculation). As in the present study, it is stated that the conventional urodynamic study is not "foolproof" to detect detrusor instability.

Katz et al. (9) present a group of 142 patients with storage problems of which the majority has urinary incontinence. In $20 \%$ urodynamic testing did not demonstrate any abnormalities. As the present study does, it is stated that if symptoms are not reproduced during the urodynamic 
investigation the obtained data is of little value and may provide misleading information. They also suggest, that the environmental constraints of the urodynamic facility could cause symptoms not to be reproducable during the urodynamic investigation.

Webster et al. (12) also found that provocative cystometry (fast filling, standing position, exercises) reveals uninhibited detrusor activity more frequently than filling cystometry with the patient in supine position. A group of 133 female patients with urinary incontinence, including 51 patients who had undergone unsuccessful surgical therapy, were evaluated urodynamically. In 55\% (73) uninhibited detrusor activity was demonstrated during the investigation. In 38 patients (52\%) provocation by erect fast fill and other provocative manoeuvers were necessary to unmask abnormal detrusor activity. It was also noted that patients history did not accurately predict uninhibited detrusor activity.

Torrens (11) stated that in the best ordinary clinical situation the accuracy of prediction of an unstable filling cystometry from the symptomatology ranges between $31-48 \%$; in the present study uninhibited detrusor contractions during filling cystometry are predicted accurately in $42 \%(103 / 243)$. In $8 \%(9 / 111)$ of the patients with symptomatic stress inc. uninhibited detrusor contractions were found while they were not expected according to medical history taking.

Massey et al. (10) evaluated the correlation between symptomatic classification and urodynamic diagnosis in 1806 consecutive female patients. They found no abnormalities during urodynamic evaluation in $24 \%$ of their cases; in the present study this was $32 \%$ for the complete group with incontinence.

Busch et al. (2) presented a group of 175 incontinent female patients (153 with symptomatic stress, 16 with urge and 3 with mixed incontinence). Their symptomatic classification correlated with the urodynamic result in $87.4 \%$. This result must be criticized, because the criterium for the urodynamic diagnosis of stress incontinence was the absence of uninhibited detrusor contractions during filling cystometry.

Loss of urine was not an essential criterium to decide for a diagnosis. Their standardised procedure consisted of an intravenous urography (IVU) and cystometrogram followed by the urodynamic investigation. This is an unreliable sequence for investigating a patient with urinary incontinence because of the disturbance of the system by the first two tests. 
When considering all previous studies it becomes clear that the first item mentioned in chapter 1 to be fulfilled by the urodynamic investigation:

- the investigations may (should) assist in the evaluation of an individual case, providing objective evidence on which to base decisions,

is still very poorly realized. Nevertheless, these studies do, as the present study does, show the need for improved and more reliable urodynamic tests with a special respect to abnormal detrusor behaviour.

In general one can conclude from the presented results:

- that urinary incontinence is often not seen during conventional urodynamic investigation,

- that it is more difficult to objectify urge incontinence than stress incontinence,

- that, if incontinence is objectified during the investigation, there is a high correlation with the medical history in case of stress or urge incontinence,

- that the ability of the conventional investigation to objectify mixed incontinence is extremely poor, with all consequences if surgical treatment is considered.

\subsection{Comment}

Reading this chapter one may question whether it is meaningful to perform conventional urodynamics if the diagnostic method so frequently fails to clarify the complete functional disorder in case of urinary incontinence. However, it must be stated here and in this context, that conventional urodynamic investigations are meaningful, because there is not only a need to objectively demonstrate incontinence and clarify the category of functional disorder, but within each category there is a wide range of differences between the severeness of symptoms. Especially in symptomatic stress incontinence the sensitivity of the conventional investigation is acceptable (53\%) and the percentage of false positive results for this category is minimal (2\%); but if urgency and frequency are involved the reminder should be "safety first"! 
This aspect should be taken into account before deciding on therapy. It is for these reasons that we continued to improve our diagnostic possibilities.

Reading this chapter one must also realize that the patient group which is presented originates from a university department, which means that in general they have a longer and more complex uro-gynaecological history than normally encountered in a peripheral practice. 


\section{$2.8 \quad$ References}

1. Awad, S.A. and McGinnis, R.H.: Factors that influence the incidence of detrusor instability in women.

J. Urol., 130: 114, 1983.

2. Busch, R. and Kuhlencordt, R.: Stellenwert der urodynamischen Untersuchung bei der Abklärung der weiblichen Harninkontinenz. Urol. int., 40: 235, 1985.

3. Drutz, H.P. and Mandel, F.: Urodynamic analysis of urinary incontinence symptoms in women.

Amer. J. Obst. Gynec., 134: 789, 1979.

4. Gaudenz, R. and Richter, R.: Die Bedeutung der Anamnese für die Diagnostik der Harninkontinenz der Frau.

Schweiz. Rundschau Med., 66: 602, 1977.

5. International Continence Society Standardisation Committee: The Standardisation of Terminology of lower urinary tract function.

Annual International Continence Society meeting, 1987.

6. International Continence Society Working Party on Urodynamic Equipment: technical aspects.

J. Med. Eng. Tech., 11: 57, 1987.

7. International Continence Society; Standardisation Committee: The Standardisation of Terminology of lower urinary tract function.

Scand. J. Urol. Nephrol., Suppl., 114: 5, 1988.

8. Karl, C. and Hannappel, J.: Anamnese und urodynamischer Befund bei inkontinenten Frauen.

Geburtsh. u. Frauenheilk., 43: 377, 1983.

9. Katz, G.P. and Blaivas, J.G.: A diagnostic dilemma: when urodynamic findings differ from the clinical impression. J. Urol., 129: 1170, 1983.

10. Massey, A. and Abrams, P.: Urodynamics of the Female lower Urinary Tract. Urologic Clinics of North America, vol. 12, No. 2: 231-246, 1985. 
11. Torrens, M.J.: A critique of urodynamics.

Urodynamics, chapter 6, edited by Mundy A.R. et al.: pp. 62-68, 1984.

12. Webster, G.D., Sihelnik, S.A., Stone, A.R.: Female urinary incontinence: the incidence, identification, and characteristics of detrusor instability.

Neurourol. Urodynam., 3: 235, 1984. 



\section{Chapter III}

\section{Introduction}

The results presented in chapter II lead the developement of methodology and technology to improve the urodynamic tools to investigate the lower urinary tract. The equipment was derived from an existing system applied in physiologic research in sportsmen at the university of Nijmegen (1).

Accepted for publication in Urodinamica.

\section{References}

1. IJsenbrandt, H.J.B., Kimmich, H.P. and Akker, A.J. v.d.: Single to seven channel lightweight biotelemetry system. Biotelemetry, Meander Leiden, pp. 57-64,1972. 
, 


\title{
A telemetric ambulatory method to investigate the lower urinary tract function
}

\author{
E.S.C. van Waalwijk van Doorn, R. A. Janknegt \\ Dept. of Urology, University Hospital Maastricht, The Netherlands.
}

\begin{abstract}
Most biological systems functioning with a long time constant, are difficult to investigate during short-time examinations under unphysiological circumstances. This is especially true for the clinical setup of a urodynamic laboratory, where urinary bladder and urethral sphincter functions are tested while the patient is in lithotomy position or sitting on a toilet chair. To improve the low sensitivity $(<50 \%)$ of the conventional urodynamic tests to objectify incontinence, the application of radio telemetry was introduced clinically. An eight channel telemetry system combined with a standardized clinical test procedure was evaluated in 80 patients with complaints of urinary incontinence. Comparison of the results of both the conventional and the ambulatory telemetry method demonstrated an improvement in sensitivity to identify abnormal lower urinary tract function from $68 \%$ to $96 \%$. The sensitivity to objectify incontinence improved from $39 \%$ to $76 \%$ by application of radio telemetry.
\end{abstract}

Keywords lower urinary tract, urinary incontinence, voiding disorders, telemetry, ambulatory, urodynamics, diagnostics, telemetry. 


\section{Introduction}

Most of the biological systems functioning with a long time constant, are difficult to investigate during short-time examinations under unphysiological circumstances. This is especially true for the clinical setup of a urodynamic laboratory, where urinary bladder and urethral sphincter functions are tested while the patient is in lithotomy position or sitting on a toilet chair. In the past the limitations of this conventional urodynamic investigation were evaluated by comparing the objective results from clinical urodynamic tests with predicted diagnosis based on a thorough medical history taking.

A large group of 450 female and 158 male patients with complaints of urinary incontinence and/or voiding problems was evaluated. Using the specific urological history taking as a reference standard, the sensitivity and specificity of the conventional urodynamic investigation for diagnosing different types of urinary incontinence were calculated. Results showed a sensitivity for objectifying incontinence of $47 \%$ in the female and $37 \%$ in the male group. Specificity, tested in the patient groups without urinary incontinence, was $94 \%$ respectively $95 \%$.

The poor sensitivity of the conventional urodynamic investigation caused us to look for improvement in both methodology and technology. An improvement in the sensitivity of the investigation was expected by realising an investigative test with the following characteristics:

- free moving patient

- natural filling of the bladder

- extended measuring period

- no laboratory circumstances

- possibility for exercises

- objective urineloss measurement

For this purpose a miniaturized eight channel urodynamic telemetry system was built. A standardized clinical procedure was established to realise optimal investigative circumstances. The clinical procedure had to be matched with the structure of the hospital building, had to create optimal physiological conditions for the patient and had to fit with the personnel structure of the department of urology. After this technique was introduced clinically, the method was tested in a protocol by comparing results of the conventional urodynamic investigation with this new method. For this purpose a group of 80 female patients with complaints of incontinence and/or micturition problems were urody- 
namically evaluated by means of both the conventional tests and this new ambulatory method.

\section{Materials and methods}

Urodynamic telemetry system:

- Bladder activity is recorded through the application of catheter mounted micro transducers (Philips-Honeywell) positioned intravesically and rectally. The latter is used as a reference signal to distinguish bladder activity from abdominal pressure changes, which are reflected in both signals.

- Activity of the urethral sphincter mechanism is recorded from three pressure transducers, mounted on the same catheter as the vesical transducer and positioned longitudinally with a spacing of $7 \mathrm{~mm}$ in the region of the urethral sphincter mechanism (fig. 1).

- First occurrence of urineloss is recorded by means of a self-constructed electronic nappy. At the end of the investigation the total urineloss is established by weighing the absorbing tissue of the nappy.

- uroflow during micturition is recorded by a Dantec uroflowmeter.

All transducers except the uroflowmeter are connected to a miniaturized transmitter (fig. 2). The signals are transmitted to a receiver, which is connected to a Gould chartrecorder. Both the receiver and chartrecorder are placed in a trolley, to enable easy transportation of the complete system, to different measuring areas (fig. 3). The uroflowmeter was only connected with the chartrecorder at the beginning and at the end of the investigation.

\section{Clinical procedure}

Patients are asked to come with a full bladder. The investigation starts with an initial uroflowmetry on the Dantec flowmeter, which was built into a private toilet in the urodynamic department. After the uroflowmetry the patient undresses partially and is catheterised transurethrally and rectally with the 8 french catheters with micro pressure transducers. Then a filling catheter is brought in transurethrally; firstly to measure residual urine after the initial flowmetry and secondly for a rapid fillingcystometry. The rapid filling cystometry, with an inflow of about $100 \mathrm{ml} /$ minute of saline solution (room temperature), is done to have an extra provocative test on possible 
detrusor instability. During this test the bladder volume at "First Sensation" is registered, to be able to empty the bladder at the end of the cystometry to a volume just under the first sensation volume. This is done to prevent mechanical stimulation of the bladder wall by the catheter and to shorten the period of natural bladder filling. The patient is also given $40 \mathrm{mgr}$. of furosemide orally to stimulate urine production during the ambulatory part of the investigation. The patient gets dressed again and the electronic nappy, surrounded by absorbing tissue, is positioned. After a final check of all signals the patient leaves the urodynamic laboratory. The ambulatory part of the investigation takes place at the department of physiotherapy, which is fully equipped for exercising and relaxing. The patients experience this department as less hospitallike. There is a quiet waiting room and the exercising area, which includes normal stairs is in an open corridor. There is also a routing for walking, while the patient stays within the range of the receiver. The ambulatory part of the investigation is devided in several activities:

- Standard exercises:

At the physiotherapy department the trolley with the receiver and chartrecorder is connected to the mains again. Then the patient is taken to the exercising area and explained how to perform each exercise; walking up and down the stairs twice, turning a wheel with a mechanical resistance (strength) during two minutes (estimated by the patient to withdraw attention from catheters etc.), accelerating another wheel, step back and concentrate on the markers to see them move into the wrong direction, jumping 3 times from a 30 or $15 \mathrm{~cm}$ hight, pulling weights ten times followed by walking and listening to running water. Each p atient is asked to do these exercises at her own pace. Some of these exercises are done to distract the patient's thoughts from the bladder and sphincter function, others to provoke incontinence.

- Relaxing period:

At a coffee corner the patient is served a cup of coffee. Then, as if the investigation is interrupted the patient relaxes and sits down for about ten minutes to drink coffee and read some magazines. 


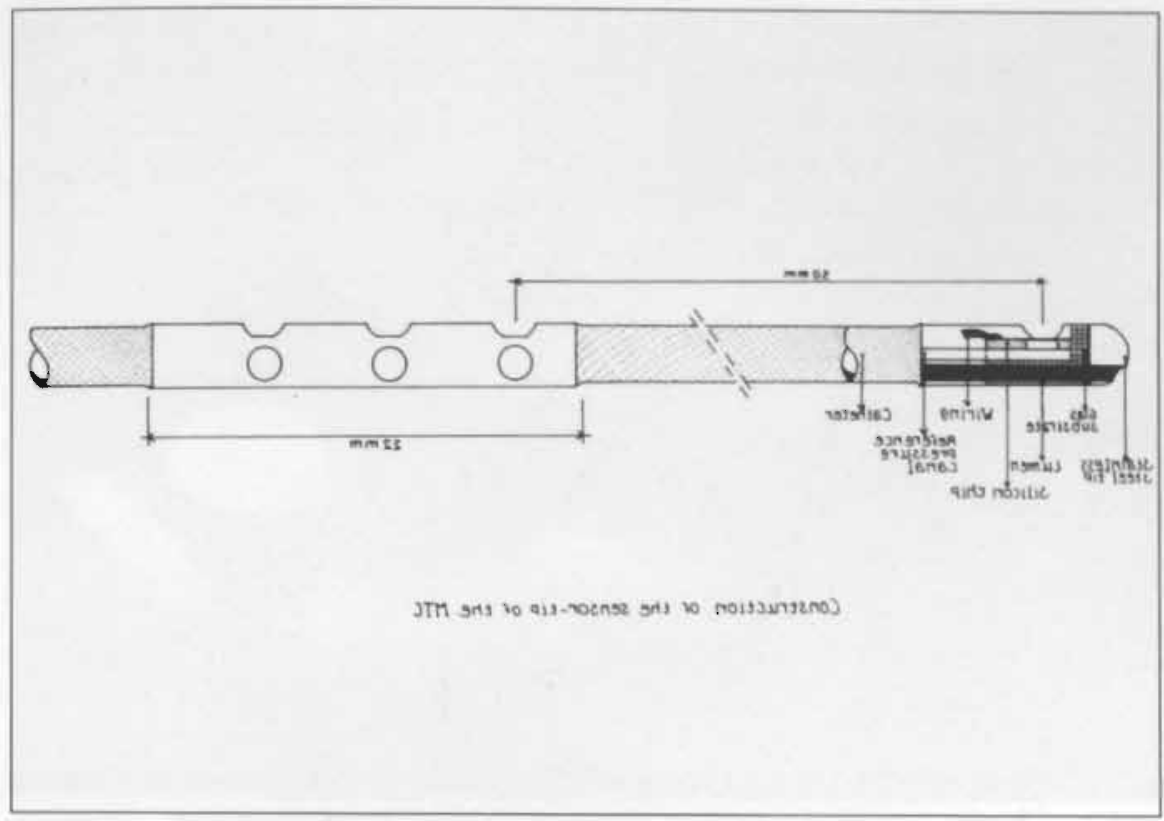

a

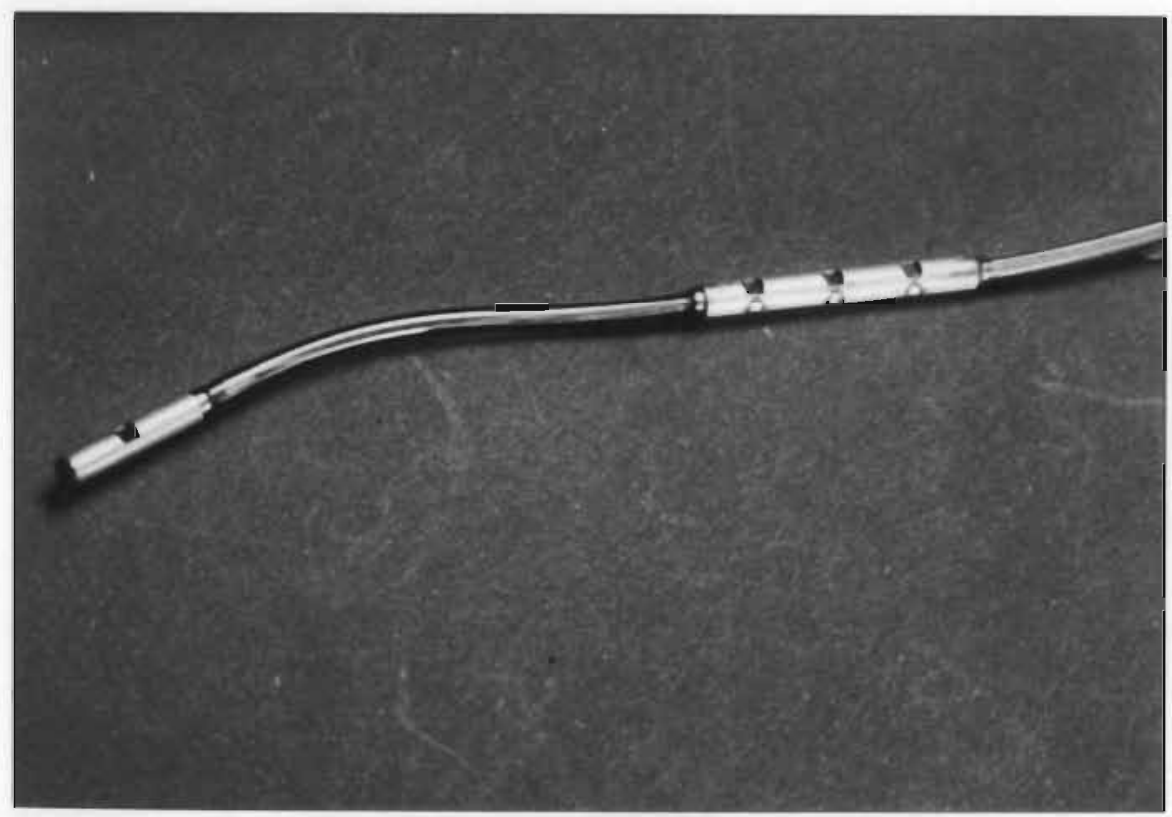

b

Figure 1. a) Construction of the catheter with 4 pressure transducers (MTC, PhilipsHoneywell) as, was applied during a telemetric ambulatory investigation.

b) The actual catheter with pressure transducers. 



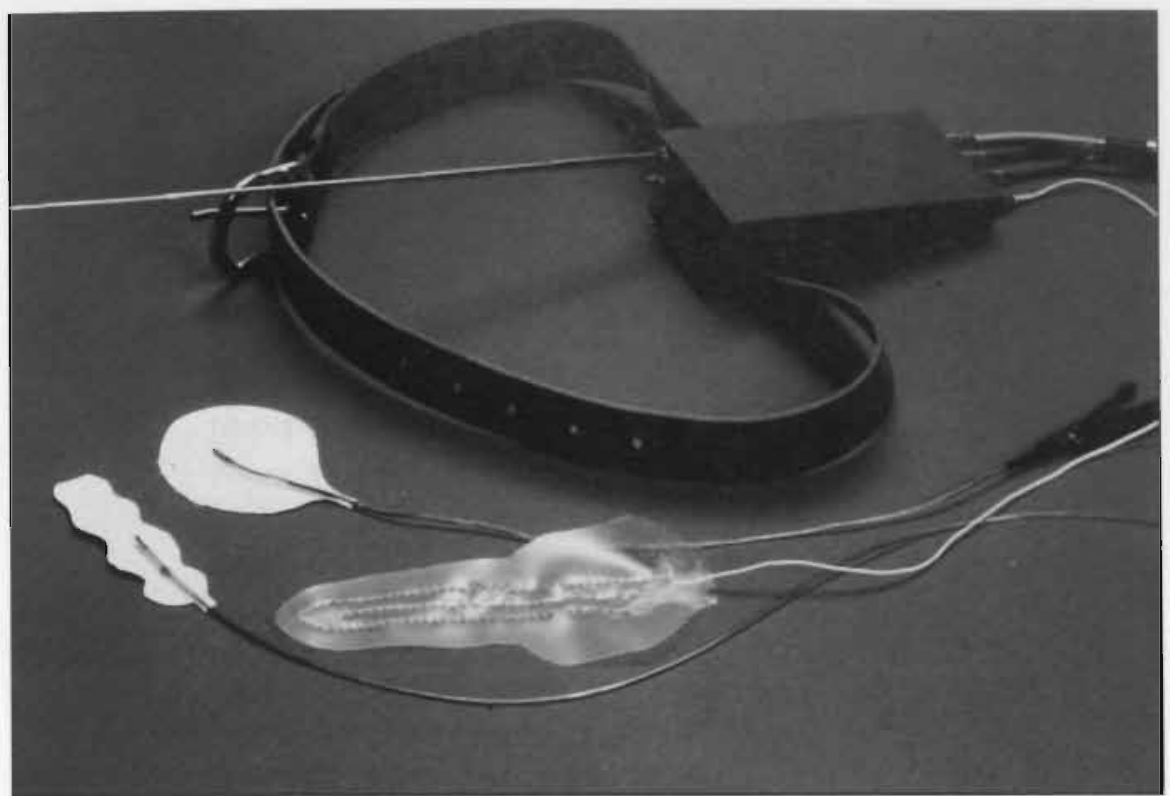

Figure 2. The miniaturized battery powered transmitter with the two catheters and the electronic nappy to detect urineloss.

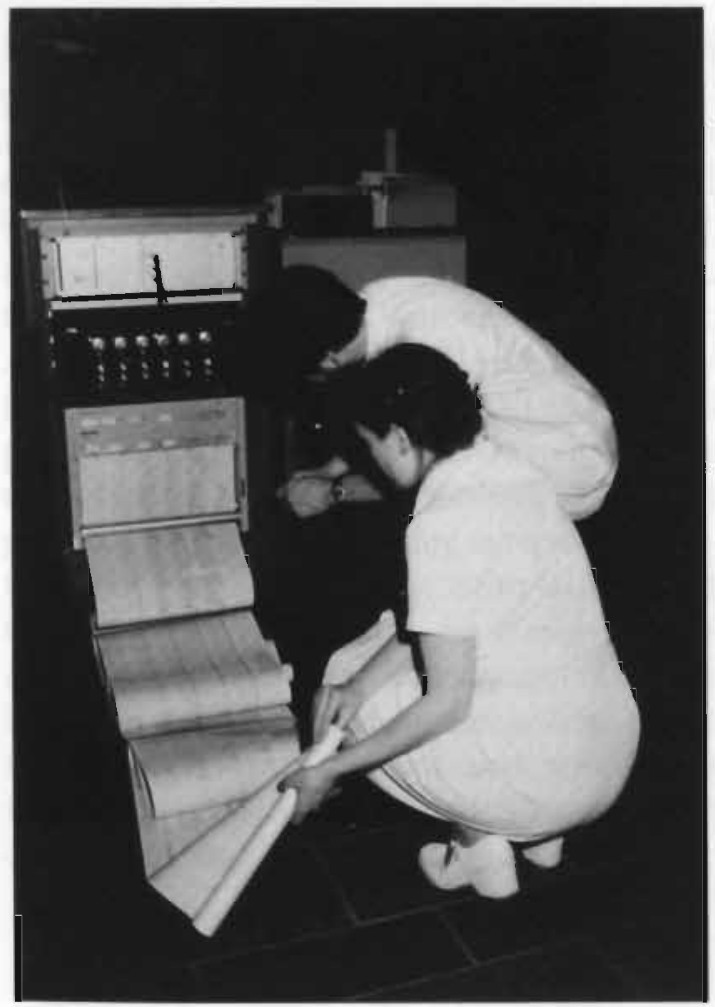

Figure 3.

Trolley with the receiver and the Gould chartrecorder. 
- Specific exercises:

Back in the exercising area the patient is asked under what kind of circumstances the complaints appear. These situations are imitated within the bounds of possibility of the physiotherapy department.

- Second relaxing period:

Again, as if the investigation is interrupted a resting period of about $10-15$ minutes is taken. The patient is also asked to report any desire to void.

Normally the patients want to micturate before or at the end of the second relaxing period. In a few cases the ambulatory period is extended. In other cases massive loss of urine causes to stop the investigation at an earlier stage.

- Pressure/flow study:

For the pressure/flow study we go back to the urodynamic laboratory, where the patient voids with all pressure transducers still in position, on the same private toilet as with the free flowmetry.

In general, most patients have no difficulty in undergoing this procedure. If physical problems are present the ambulatory program is adapted to the circumstances. The complete procedure lasts between $60-120$ minutes (fig. 4 time schedule). To illustrate the difference between a patient investigated in the urodynamic laboratory and the telemetric investigation, figures 5-6 present the different locations of the ambulatory method with examples of the urodynamic curves.

As the final structure and method for the telemetric ambulatory investigation was established and tested clinically, 80 patients entered a protocol to evaluate the telemetric method in comparison with the conventional urodynamic method, consisting of free flowmetry, urethral pressure profilometry, filling cystometry and pressure/flow study.

Only patients with at least complaints of urinary incontinence entered the study. In 26 patients no abnormalities were observed during the conventional urodynamic investigation. In 43 there was a contradiction between the classification according to the medical history and the findings after the conventional investigation. Finally 11 patients in whom the urodynamic investigation result was in accordance with their complaints also entered the study. 
time (minutes)

5

uroflowmetry

15

filling

cystometry

10

standard

exercises

15

relaxing

drinking

10

specific

exercises

15

relaxing

drinking

pressure

flowstudy

10

10

evaluation

90

Figure 4. Diagram of the ambulatory telemetric investigation. 


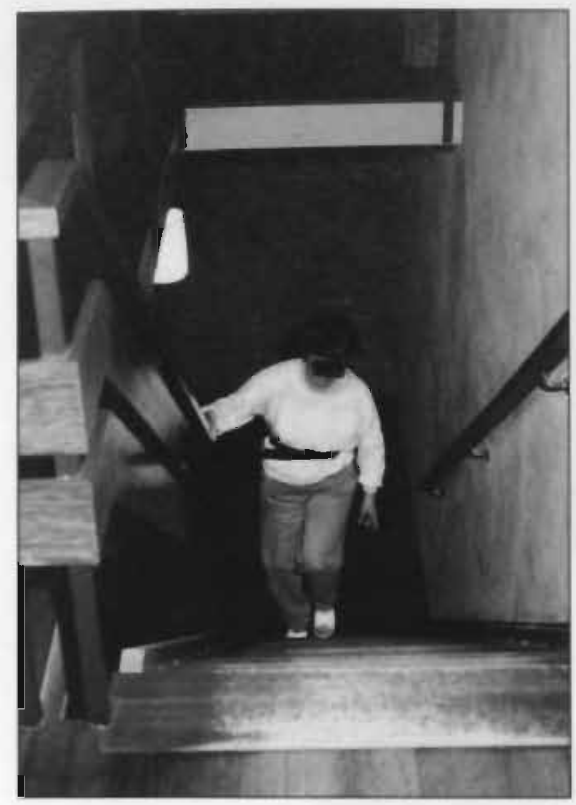

a

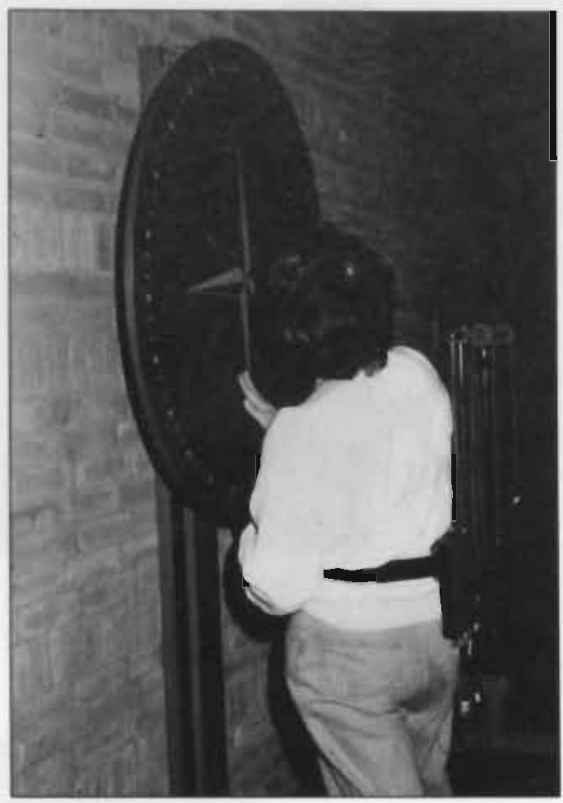

c

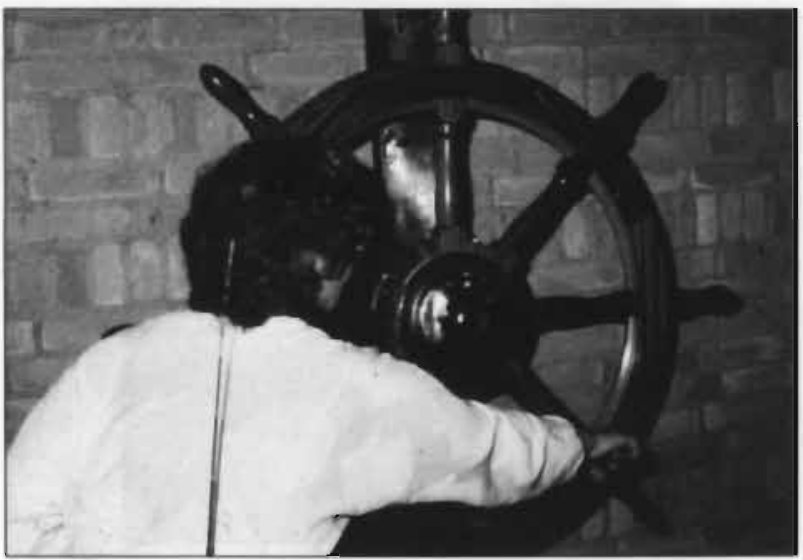

b

Figure 5. a) Patient walking stairs.

b) Patient turning a wheel with a build-in mechanical resistance.

c) Patient accelerates a wheel with markers, steps backwards and concentrates till she can report seeing the markers turn the wrong direction 


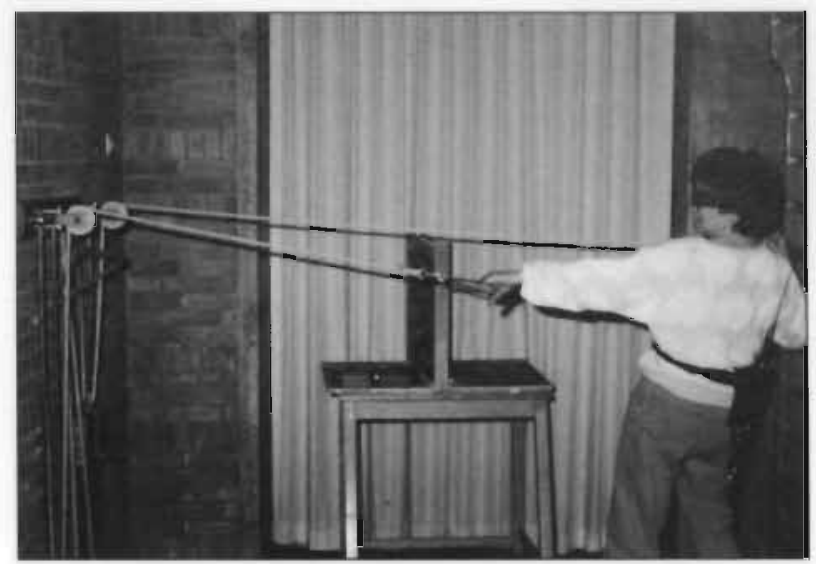

d

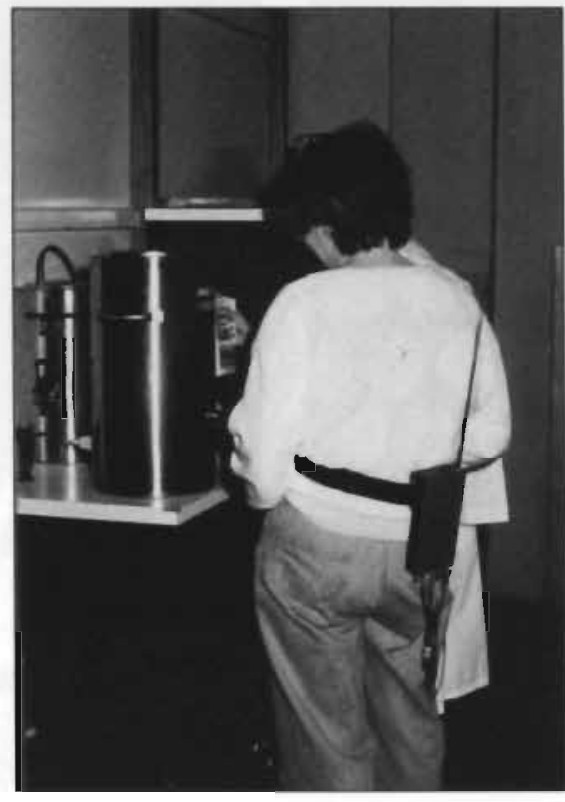

e

Figure 5. d) Patient exercising by pulling weights.

e) The patient is offered coffee before relaxing period. 


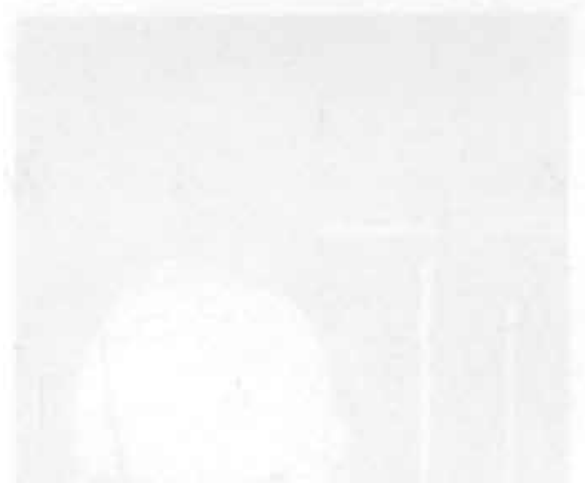




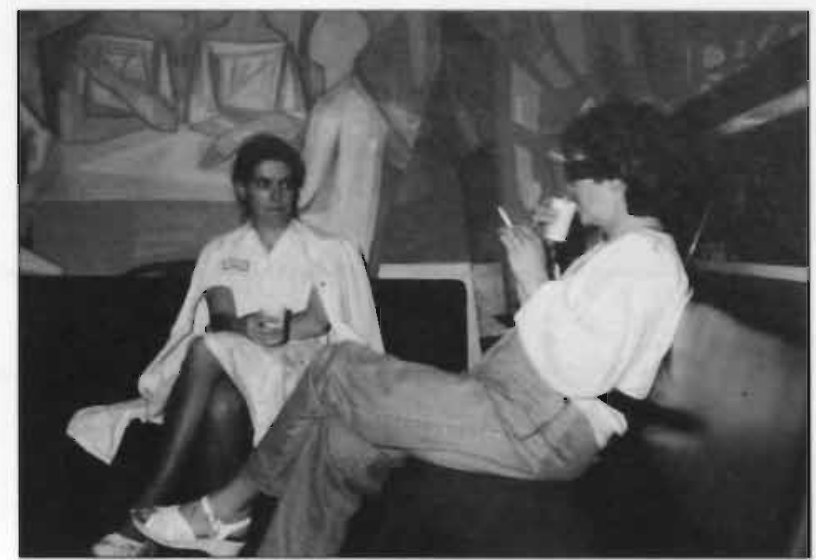

f

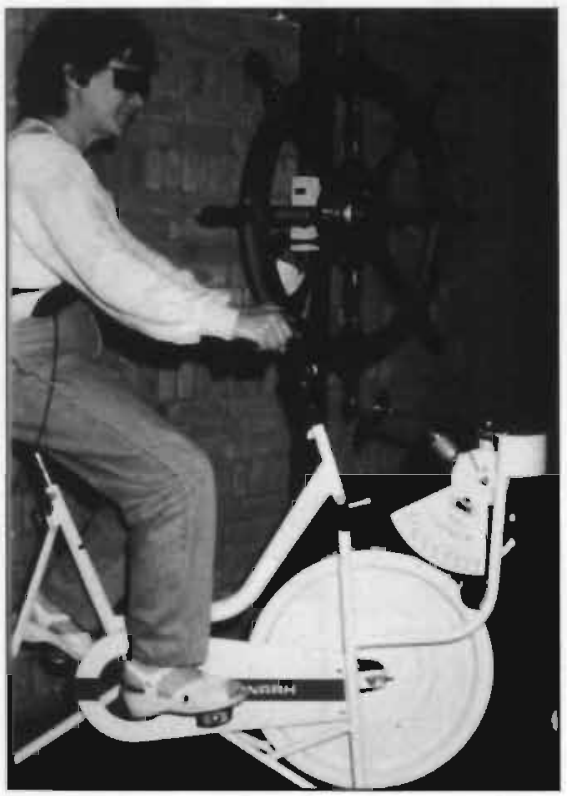

g

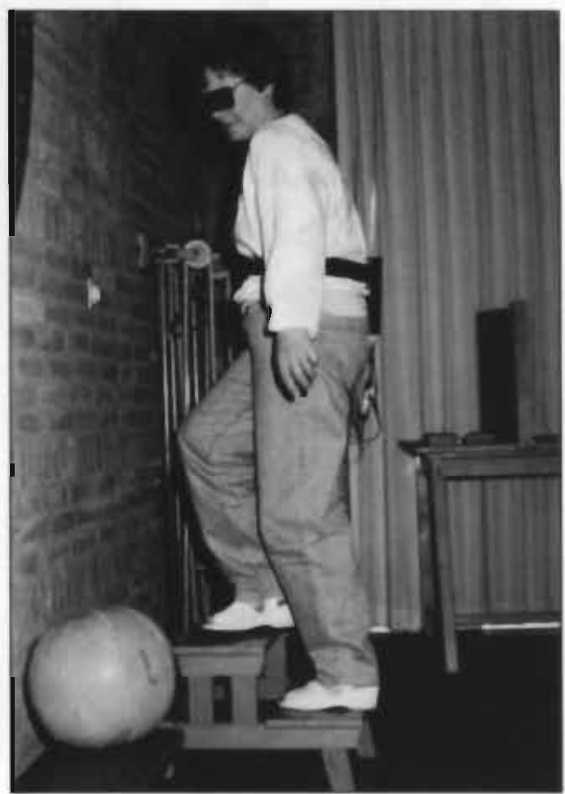

h

Figure 5. f) Patient relaxing.

g) One of the specific exercises, was cycling.

h) If possible Patients jumped from these stairs. The exercises are distracting the patient's attention from the test and at the same time incontinence is provoked. 


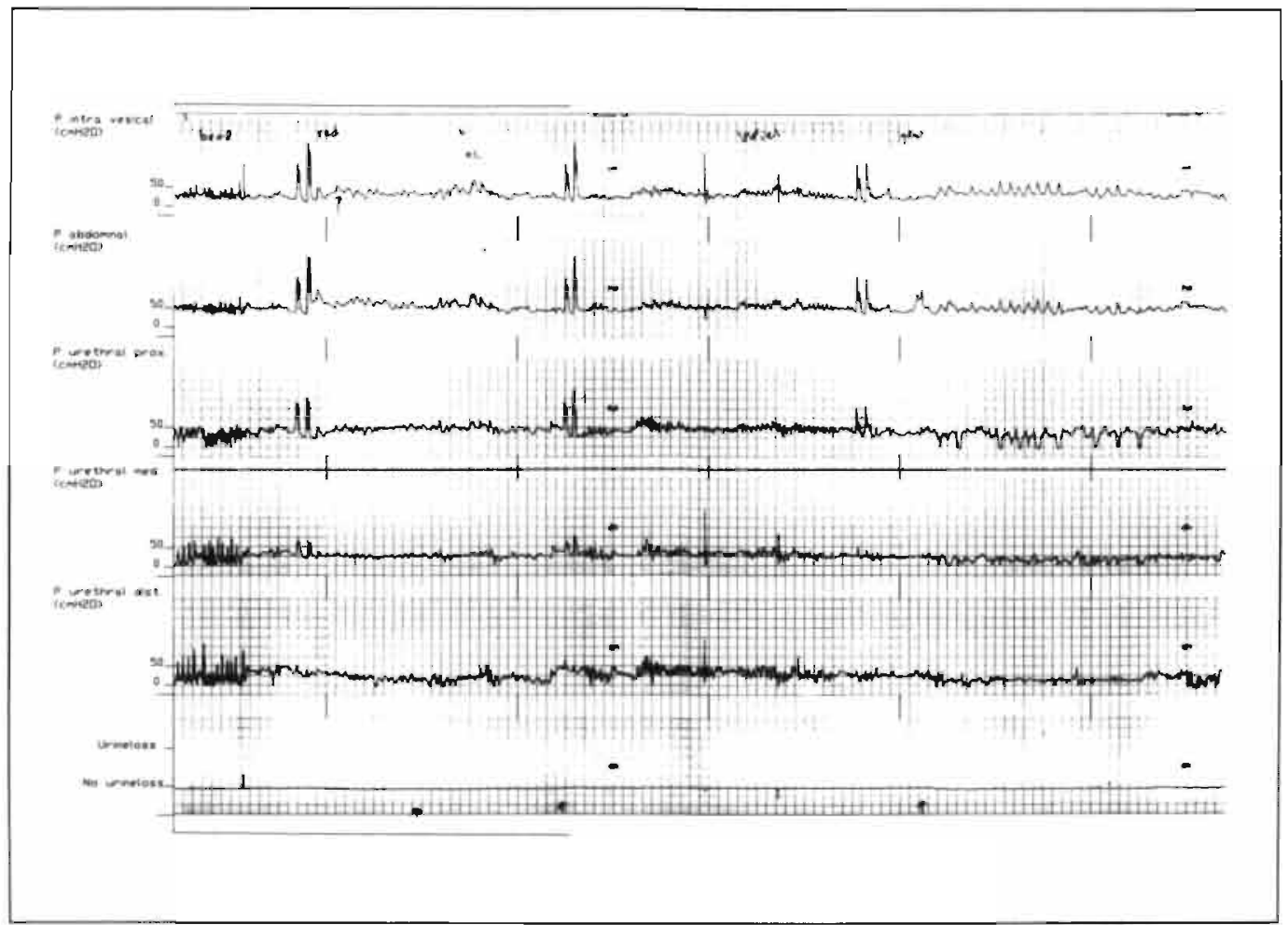

Figure 6a. Curves during the standard exercises. After each exercise the patient is asked to cough. On the midline the time scaling is shown indicating seconds. 


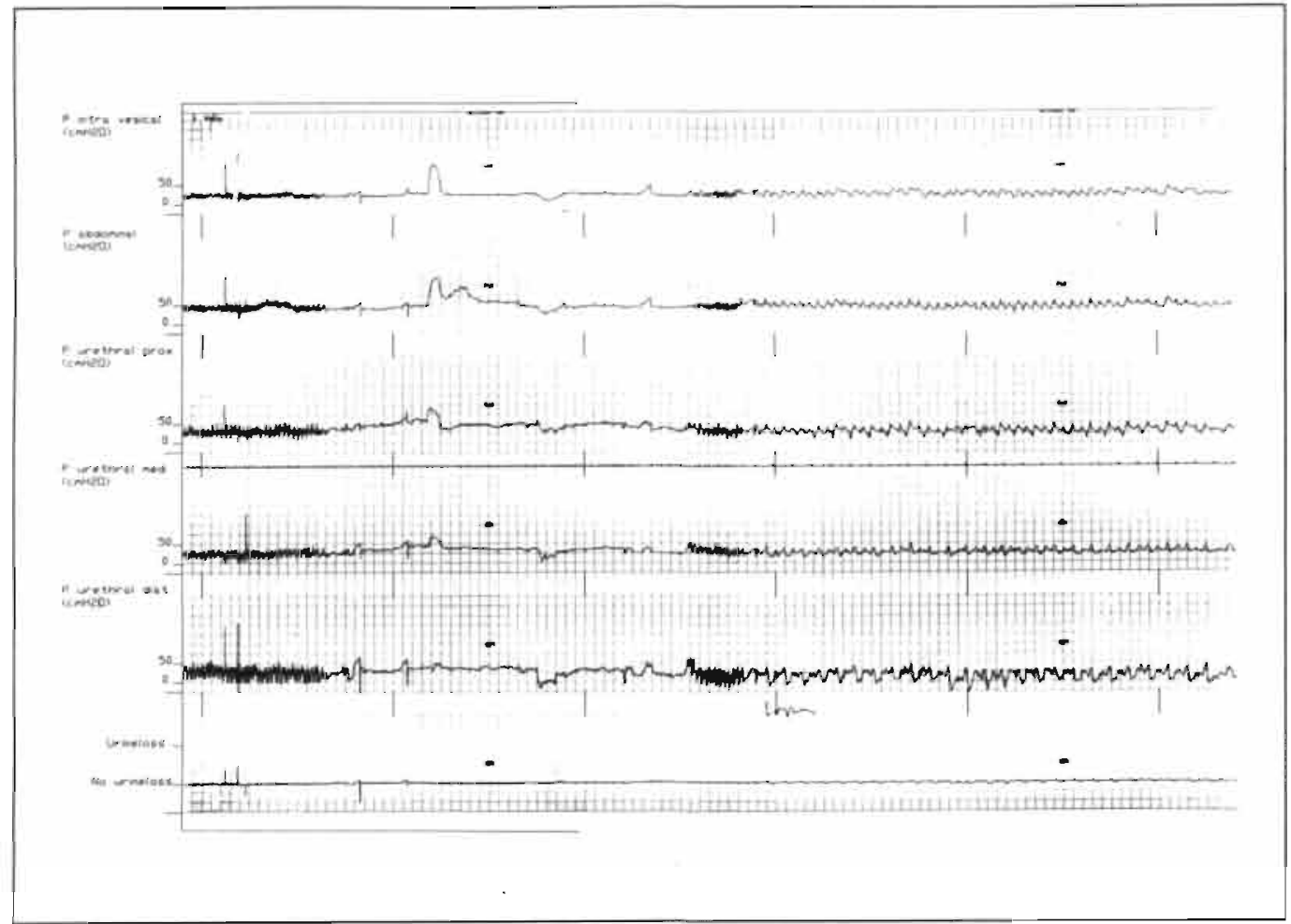

Figure 6b. This part of the curves corresponds with walking to the coffee corner and back to the relaxing area; the right half shows the curves on a higher paper speed. 


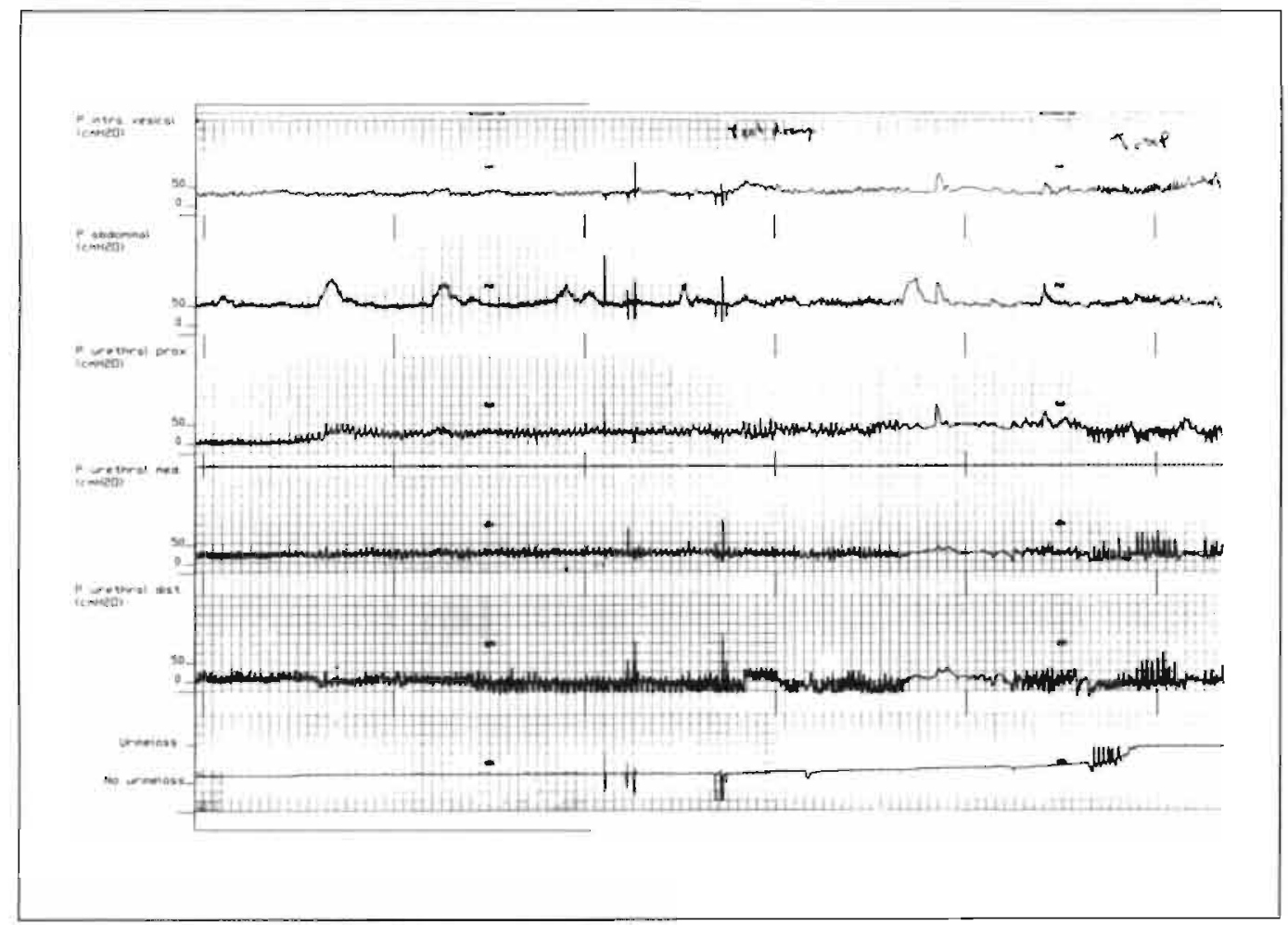

Figure 6c. Patient relaxes, some rectal activity can be recognized; at the beginning of the right half as the patient reports urgency ("veel drang") a small unstable detrusor contraction combined with sqeezing of the pelvic floor occurs; then, as she stands up another unstable contraction causes urine loss, that is shortly later registered on the bottom curve 


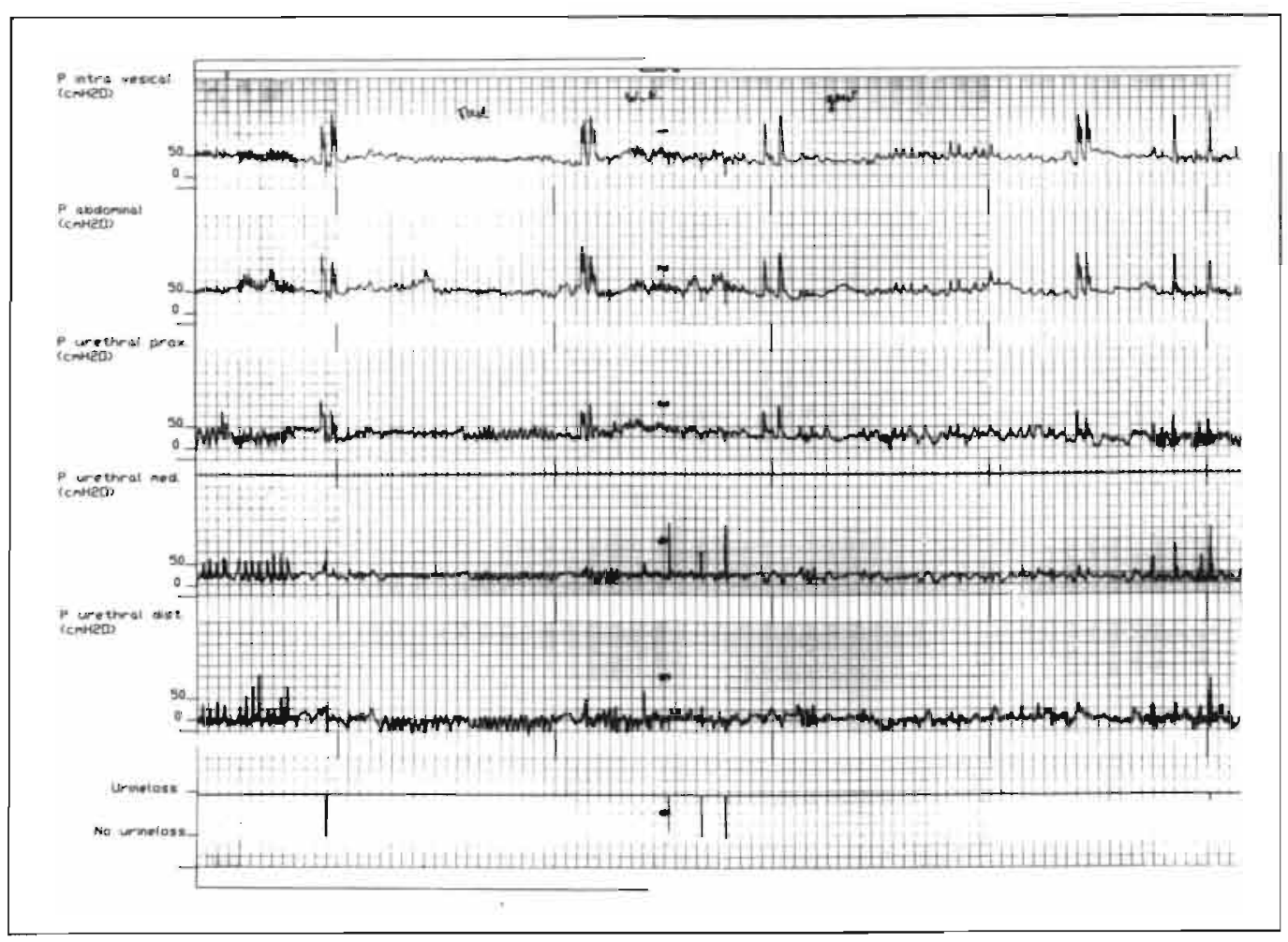

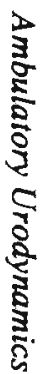

Figure 6d. To see if this rather small unstable contraction can be reproduced, the exercises are continued; after pulling weights again ("gew.") the patient coughs twice, which provokes another unstable bladder contraction. 


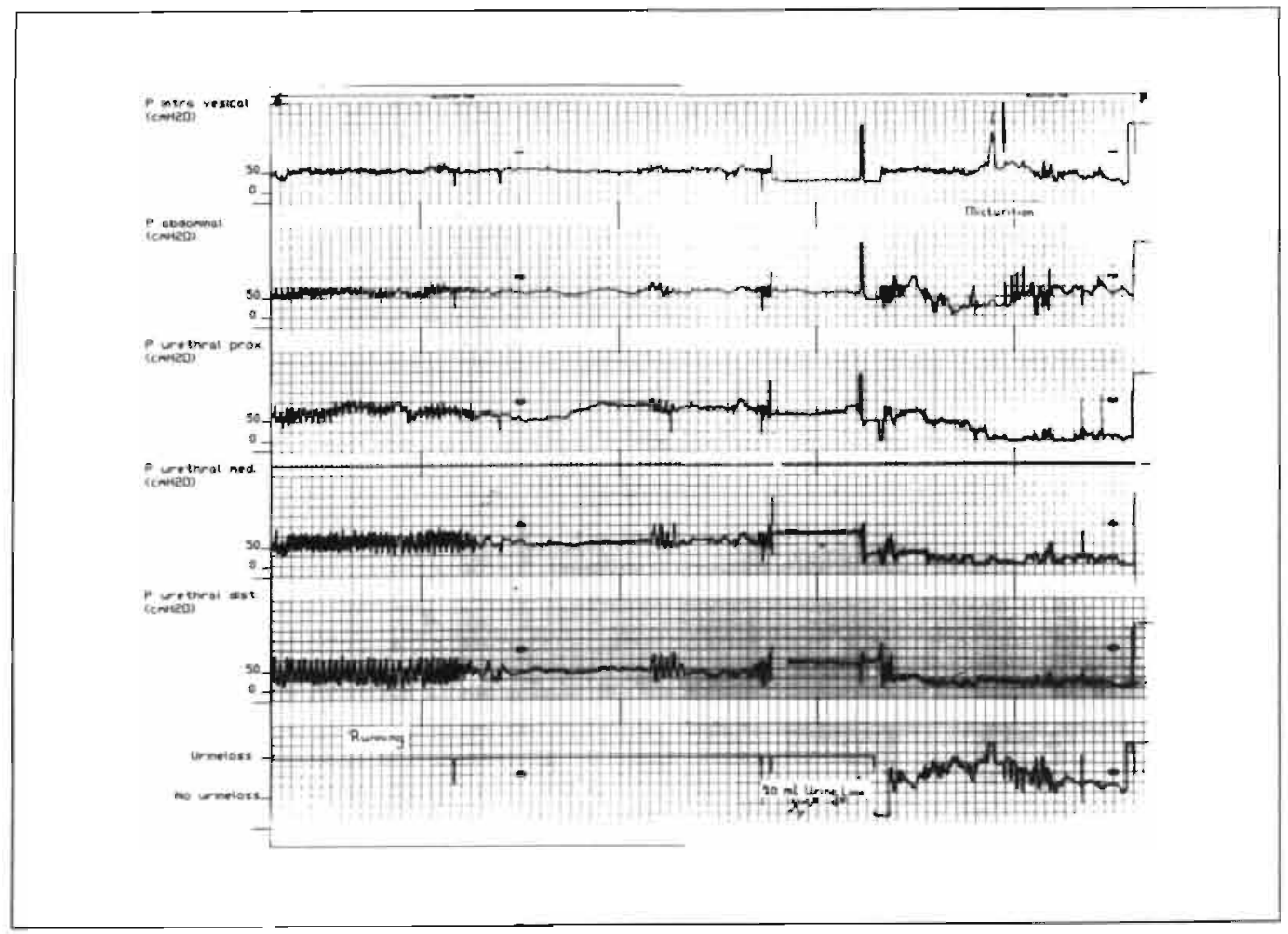

Figure 6e. After some running the ambulatory part of the test is stopped and the patient returns to the urodynamic laboratory for voiding; the urineloss sensor is disconnected and the bottom channel is changed into substracted detrusor pressure. Weighing of the pad reveals a total of $20 \mathrm{ml}$ urineloss. 


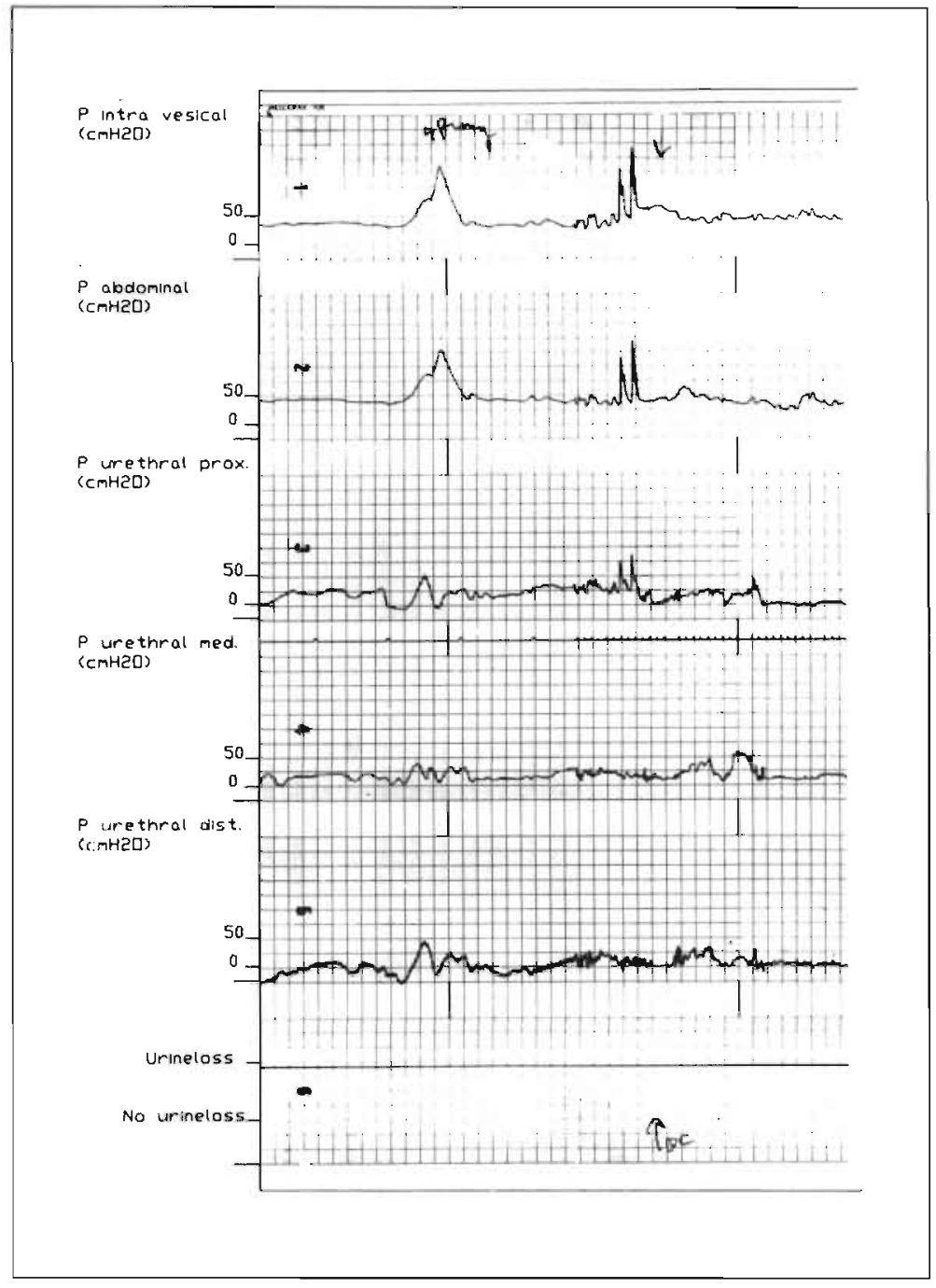

Figure 6f. This part of the curve shows the pressure pattern during a jump (high paper speed) followed by coughing, which evoked another unstable detrusor contraction (O.C.). Also the low transmission ratio can be seen (no pressure peaks due to the coughs in the medial and distal urethral pressure curves). Combining the already demonstrated stress incontinence during the conventional investigation with the results of the telemetric test led to the diagnosis of mixed incontinence. 


\section{Results}

In tables $1-4$ the general results of this female patient group, with at least complaints of urinary incontinence, after conventional and after ambulatory telemetric urodynamic investigation are shown.

A comparison between tables 1 and 2 shows a general improvement of the sensitivity of the ambulatory telemetric method from $54 / 80(68 \%)$ to $77 / 80(96 \%)$ in identifying a patient as abnormal; in the same way there is an improvement in sensitivity in objectifying the symptomatic incontinence from $31 / 80(39 \%)$ to $61 / 80(76 \%)$.

When comparing tables 3 and 4 an improvement is seen in the sensitivity for symptomatic "stress incontinence" from $7 / 17$ to $8 / 17$; these values must be changed to $7 / 11(64 \%)$ and $8 / 11(73 \%)$, because the 6 patients that were diagnosed as urge incontinent after the ambulatory investigation, were all patients preclassified as symptomatic stress incontinent, but turned out to have "pseudo stress incontinence". They showed provoked detrusor instability with urine leakage during exercises.

The sensitivity for symptomatic urge incontinence with the ambulatory test improved from $2 / 9(22 \%)$ to $8 / 9(89 \%)$.

The tables show an improvement for the sensitivity for symptomatic mixed incontinence from $2 / 46(4 \%)$ to $9 / 46(20 \%)$.

For 11 patients the result of the conventional investigation was in accordance with the anamnestic classification; for 8 of these 11 patients the results of the telemetric investigation were the same. For 27 out of 80 patients $(34 \%)$ the results of the conventional urodynamic investigation were equal to the results after ambulatory measurement. If we consider the group of patients that entered the protocol because no incontinence was proven or because of a contradiction between medical history and urodynamic findings $(80-11=69)$, the results of the conventional investigation and the ambulatory investigation did agree in 19 patients (28\%); in 11 patients (58\% out of 19 ; or $16 \%$ out of 69 patients) of this group no incontinence was proven during either investigations, but the results were still the same ( 4 motor urge, 1 sensory urge, 3 other abnormalities, 3 normal).

\section{Discussion}

The idea of bladder activity telemetry is not new. Gleason et al. (1) already described electronic devices and indications for this technique. Thüroff et al. (4) studied the applicability of telemetry in urodynamics again ( 4 channel system; intra vesical, abdominal, differential pressures and electromyography of the pelvic floor musculature (EMG)). They 


\begin{tabular}{lcccc}
\hline $\begin{array}{c}\text { results } \\
\text { complaints }\end{array}$ & $\begin{array}{c}\text { incontinence } \\
\text { proven }\end{array}$ & $\begin{array}{c}\text { normal during } \\
\text { investigation }\end{array}$ & $\begin{array}{c}\text { abnormal without } \\
\text { incontinence }\end{array}$ & sum \\
\hline stress inc. & 7 & 8 & 2 & 17 \\
urge inc. & 3 & 3 & 3 & 9 \\
mixed inc. & 21 & 13 & 6 & 46 \\
other inc. & 0 & 2 & 23 & 80 \\
\hline sum inc. & 31 & 26 & 82 & 8 \\
\hline
\end{tabular}

Table 1. Female patients with complaints of incontinence: occurrence of complaints and abnormalities during conventional urodynamics.

\begin{tabular}{lcccc}
\hline $\begin{array}{c}\text { results } \\
\text { complaints }\end{array}$ & $\begin{array}{c}\text { incontinence } \\
\text { proven }\end{array}$ & $\begin{array}{c}\text { normal during } \\
\text { investigation }\end{array}$ & $\begin{array}{c}\text { abnormal without } \\
\text { incontinence }\end{array}$ & sum \\
\hline stress inc. & 14 & 1 & 2 & 17 \\
urge inc. & 8 & 0 & 1 & 9 \\
mixed inc. & 34 & 2 & 10 & 46 \\
other inc. & 5 & 0 & 3 & 8 \\
\hline sum inc. & 61 & 3 & 16 & 80 \\
\hline
\end{tabular}

Table 2. Female patients with complaints of incontinence: occurrence of complaints and abnormalities during ambulatory telemetric urodynamics.

\begin{tabular}{lccccccccc}
\hline $\begin{array}{r}\text { resuits } \\
\text { complaints }\end{array}$ & $\begin{array}{c}\text { stress } \\
\text { inc. }\end{array}$ & $\begin{array}{c}\text { urge } \\
\text { inc. }\end{array}$ & $\begin{array}{c}\text { mixed } \\
\text { inc. }\end{array}$ & $\begin{array}{c}\text { other } \\
\text { inc. }\end{array}$ & $\begin{array}{c}\text { motor } \\
\text { urge }\end{array}$ & $\begin{array}{c}\text { sensory } \\
\text { urge only }\end{array}$ & $\begin{array}{c}\text { other } \\
\text { abnorm. }\end{array}$ & normal & sum \\
\hline stress inc. & 7 & 0 & 0 & 0 & 1 & 0 & 1 & 8 & 17 \\
urge inc. & 1 & 2 & 0 & 0 & 2 & 0 & 1 & 3 & 9 \\
mixed inc. & 17 & 2 & 2 & 0 & 6 & 2 & 4 & 13 & 46 \\
other inc. & 0 & 0 & 0 & 0 & 3 & 2 & 1 & 2 & 8 \\
\hline sum inc. & 25 & 4 & 2 & 0 & 12 & 4 & 7 & 26 & 80 \\
\hline
\end{tabular}

Table 3. Preclassification and diagnoses of female patients after conventional urodynamic evaluation

\begin{tabular}{lccccccccc}
\hline $\begin{array}{r}\text { results } \\
\text { complaints }\end{array}$ & $\begin{array}{c}\text { stress } \\
\text { inc. }\end{array}$ & $\begin{array}{c}\text { urge } \\
\text { inc. }\end{array}$ & $\begin{array}{c}\text { mixed } \\
\text { inc. }\end{array}$ & $\begin{array}{c}\text { other } \\
\text { inc. }\end{array}$ & $\begin{array}{c}\text { motor } \\
\text { urge }\end{array}$ & $\begin{array}{c}\text { sensory } \\
\text { urge only }\end{array}$ & $\begin{array}{c}\text { other } \\
\text { abnorm. }\end{array}$ & normal & sum \\
\hline stress inc. & 8 & 6 & 0 & 0 & 1 & 0 & 1 & 1 & 17 \\
urge inc. & 0 & 8 & 0 & 0 & 1 & 0 & 0 & 0 & 9 \\
mixed inc. & 11 & 14 & 9 & 0 & 5 & 1 & 4 & 2 & 46 \\
other inc. & 2 & 3 & 0 & 0 & 2 & 1 & 0 & 0 & 8 \\
\hline sum inc. & 21 & 31 & 9 & 0 & 9 & 2 & 5 & 3 & 80 \\
\hline
\end{tabular}

Table 4. Preclassification and diagnoses of female patients after ambulatory telemetric evaluation 
tested their clinical methodology on 10 healthy male patients. They state that the advantages of telemetric urodynamic investigations are: (a) simulation of several stress conditions owing to the patient's independence of stationary laboratory equipment; (b) lowered psychogenic stress as the patient is left undisturbed and can urinate in a normal position and (c) 24-hour investigations. The ambulatory investigation is indicated in case of (a) incontinence if no urine loss can be detected through regular cystometry; (b) micturition disorders if psychogenic inhibition of micturition is suspected and (c) enuresis if 24-hour investigations are desired. They performed their telemetry in one room, tailing the patient with a video camera, while a prescribed sequence of exercises and voidings were performed. During the telemetric investigation bladder filling was accelerated by forced oral fluids and $40 \mathrm{mg}$ of furosemide. They found uninhibited detrusor contractions twice in their group of symptom-free volunteers during normal cystometry and in 6 volunteers during the telemetry procedure. They suggest that the frequent change in position and the irritation of the urethral catheter is suspect to provoke the unexpected detrusor instabilities. It is surprising that they give as a first indication for their telemetric urodynamic investigation "not objectified incontinence" while no testing of females is described.

Vereecken et al. (6) described some case reports in which they applied telemetry ( 3 channels; intravesical pressure suprapubically, abdominal pressure and electronic napkin for urine loss). As indications for this technique they summarize: (a) repeated pressure/flow studies, both in obstruction and in experimental work; (b) cases in which urge incontinence is expected based on the patients history but conventional cystometry reveals a stable detrusor; (c) enuresis nocturna and psychogenic voiding disorders; (d) evaluation of therapy. To demonstrate this last indication Vereecken et al. (7) presented a patient diagnosed with the Shy-Drager syndrome, in which they objectively showed the positive effect of anal electrical stimulation on detrusor instability.

Miyagawa et al. (3) described a one channel telemetry system (intravesical pressure with a fluid-filled epidurally placed tube $(1 \mathrm{~mm})$, ending in the bladder, connected to an external pressure transducer fixed at the level of the symphysis. After investigating only 4 male patients with obstructive micturition symptoms they conclude that they obtain more information on the intra-vesical pressure changes and that micturition disorders are evaluated more accurately with the telemetric data transmission than through conventional cystometry.

The present study presents more patients. The majority of our group has a long and complex urinary tract history. In 69 patients the conven- 
tional urodynamic investigation(s) did not clarify the functional behaviour and functional disorders of their lower urinary tract satisfactorily. Telemetric urodynamic testing according to the described clinical procedure demonstrated an improved sensitivity for incontinence, a better score on sensitivity to demonstrate stress incontinence, motor urge, motor urge incontinence and mixed incontinence. The diagnosis of sensory urge and motor urge often changed into motor urge incontinence. The question occurs if this improved sensitivity of the ambulatory investigation is due to the ambulatory aspect or due to other aspects like the $40 \mathrm{mg}$ of orally administrated furosemide or catheter irritation. Van Venrooij et al. (5) compared conventional filling cystometry with diuresis cystometry (furosemide intramuscular; $0.5 \mathrm{mg} / \mathrm{kg}$ body weight). They found no significant difference in the prevalence of uninhibited detrusor contractions comparing conventional cystometry $(n=16)$ with diurese cystometry $(n=37)$ in the asymptomatic groups (see table 5). Nevertheless they found uninhibited contractions in both asymptomatic groups, which makes the medical history dubious since they give no description of "asymptomatic". If we compare this with the present study (see tables 3 and 4 ) we see that in only one patient in the symptom category "stress incontinence", which can be defined as asymptomatic for detrusor instability, uninhibited detrusor contractions were found during the conventional investigation. During the ambulatory investigation 7 patients were found to have uninhibited detrusor contractions in this group; 6 were diagnosed as "motor urge incontinent" because physical exercises provoked urethral relaxation combined with an unihibited detrusor contraction (pseudo stress incontinence).

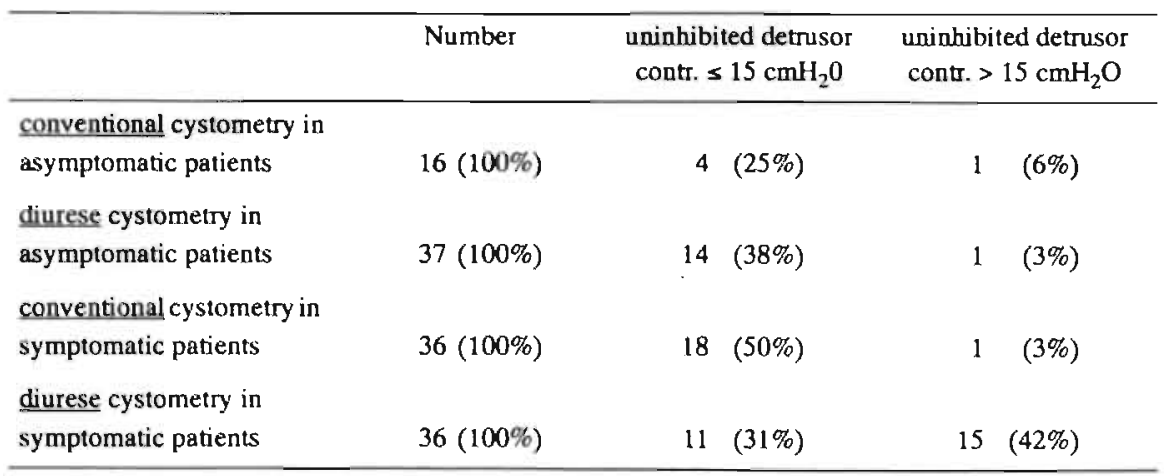

Table 5. Results presented by van Venrooij s comparing conventional filling cystometry and diurese cystometry $(0.5 \mathrm{mg} . / \mathrm{kg}$. body weight furosemide intramuscular). 
If we compare van Venrooij's results (see table 5) in the symptomatic group $(\mathrm{n}=36)$, he demonstrates uninhibited detrusor contractions during conventional filling cystometry in 19 patients (53\%) and during diurese cystometry in 26 (73\%) patients; in 1 during the conventional test and in 15 patients during diurese cystometry detrusor contractions exceeding $15 \mathrm{cmH} 2 \mathrm{O}$ were found. In the present study not the amplitude of the detrusor contraction was considered more important but the contraction in combination with or without urineloss and indicated urge sensation. For the symptomatic patient group presented in this chapter uninhibited detrusor activity was demonstrated in 8 (15\%) during the conventional test and in $37(67 \%)$ out of 55 female patients with a symptomatic urge aspect during the ambulatory test. The symptomatic patient group described by van Venrooij can not be compared with the group in this study because in 69 out of the 80 patients a doubtful result of the conventional investigation was used as a selection criterion. However, one can compare the improvement in both studies to demonstrate detrusor instability. Van Venrooij's result shows an improvement in sensitivity of the diuresis cystometry for patients with urge symptoms from $53 \%$ to $73 \%$; the present study from $25 \%$ to $67 \%$ out of the 55 patients presented in this study. It is also relevant to present a personal communication with drs M.C. de Jonge (1989) on a pilot study he performed to find out if patients with unobjectified urge symptoms during conventional cystometry would show uninhibited detrusor behaviour during diurese cystometry. He used catheter mounted micro pressure transducers; one transurethrally, one vaginally. Eight female patients with complaints involving at least two of the following complaints were evaluated: urgency, urge incontinence, frequency $(>7 x)$, nycturia $(>1 x)$; not involved were: stress incontinence, neurological diseases like diabetes mellitus etc.

The test started with a conventional filling cystometry with saline at a filling rate of $100 \mathrm{ml} / \mathrm{min}$ and the patient in standing position; the filling was stopped when detrusor activity was found or at cystometric bladder capacity (strong desire to void).

If bladder capacity was reached in absence of any detrusor activity, a clinical diurese cystometry in standing position was performed after the pressure/flow study. The patient was given $40 \mathrm{mg}$ of furosemide intravascularly and $500 \mathrm{ml}$ water orally. The investigation was stopped when uninhibited detrusor activity or the stage of strong desire to void was reached. All eight patients were without detrusor instability during the diurese cystometry as they were during the conventional cystometry. Although eight patients is a small number, it was reasonable to expect that at least some detrusor instability would have been demonstrable. 
Apart from these facts, the present study does demonstrate an increase in sensitivity for objectifying incontinence in general and improvement of the sensitivity is not only found for urge incontinence but also for stress and mixed incontinence. 


\section{References}

1. Gleason, D.M., Lattimer, J.K. and Bauxbaum, C.: Bladder pressure telemetry. J. Urol. 94: 252, 1965.

2. James E. D.: Ambulatory monitoring in urodynamics.

In: Urodynamics, edited by Mundy, A.R., Stephenson, T.P., Wein, A.J.: pp. 120-126, New York, 1984.

3. Miyagawa, I., Nakamura, I., Ueda, M., Nishida, H., Nakashita, E. and Goto, H.: Telemetric Cystometry.

Urol. int., 41: 263, 1986.

4. Thüroff, J.W., Jonas, U., Frohneberg, D., Petri, E. and Hohenfellner, R.: Telemetric Urodynamic Investigations in normal Males. Urol. int., 35: 427, 1980.

5. van Venrooij, G.E.P.M., Kamphuis, E.T. and Wolfhagen, M.J.H.M.: Diuresis cystometry in patients with frequency, urgency, and/or urge incontinence complaints.

Neurourol. Urodynam., 6: 29, 1987.

6. Vereecken, R.L., Puers, B. and Das, J.: Continuous telemetric monitoring of bladder function. Urol. Res., 11: 15, 1983.

7. Vereecken, R.L., Goovaerts, J., Knockaert, D., Joossens, J. and Sansen, W.: Urological aspects of the Shy-Drager Syndrome: A Urodynamic and Telemetric Investigation. Eur. Urol., 11: 65, 1985. 



\section{Chapter IV}

\section{Introduction}

Because the telemetric equipment used in chapter III was sensitive to technical problems and demanded too much technical support and also extra personnel, the telemetric investigation could only be performed in a minority of the patients. Therefore it was decided to use also a more simple holter system making use of a portable tape recorder to store intravesical and abdominal pressure signals (fig.1-5). Advantage of this system is an extended monitoring period without demanding more personnel. A study was started to test the applicability of such a method and to test if therapies influencing bladder activity could be evaluated quantitatively.

The results of this study are published in European Urology, 18: 49, 1990. 


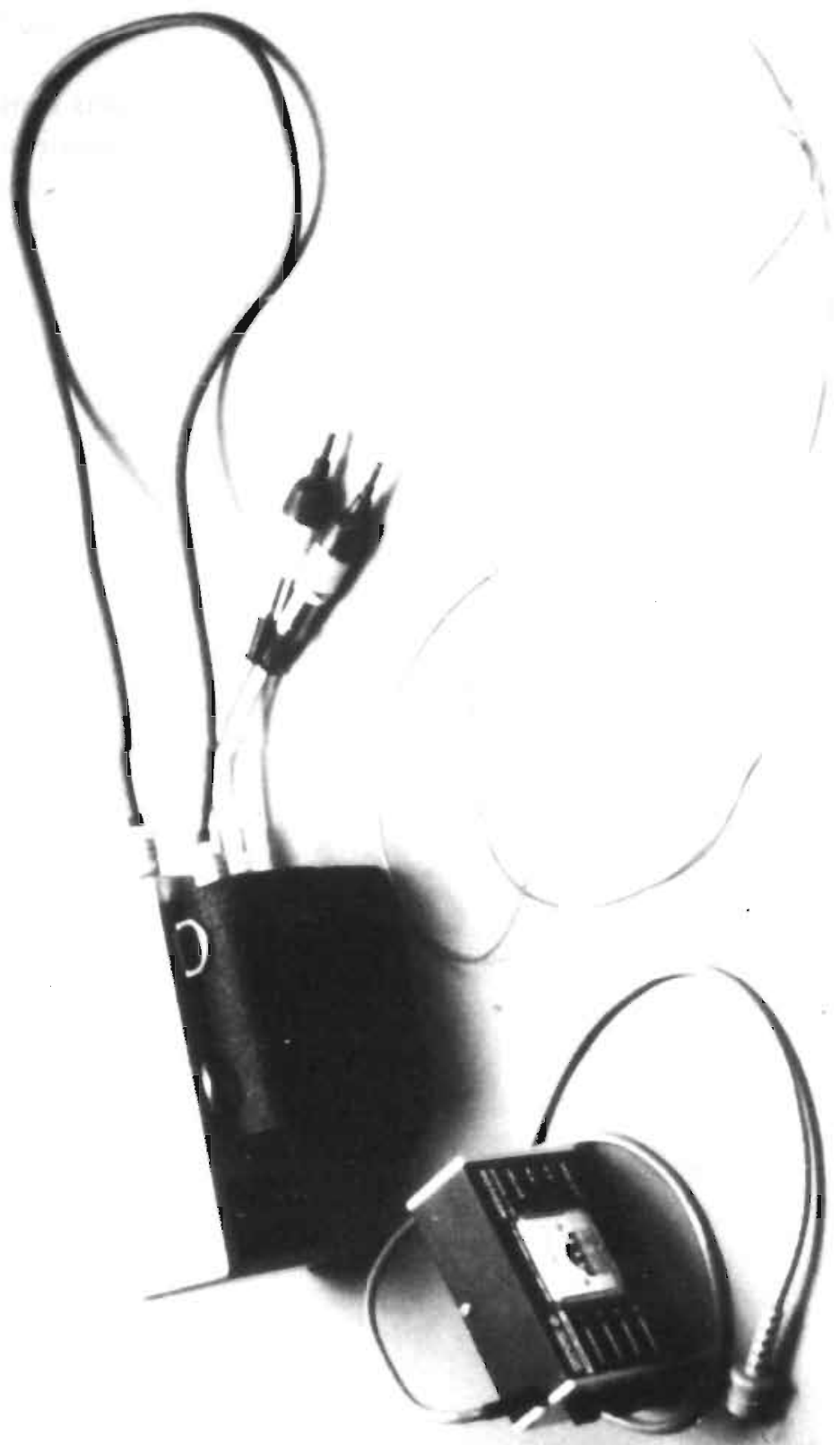

Figure 1. The recording system for 24-hour ambulatory monitoring exists of a set of catheters (Honeywell; 8 french), a box with battery powered amplifiers and a miniaturized taperecorder to store the signals. On the left we see a test box to check batteries and signals. 


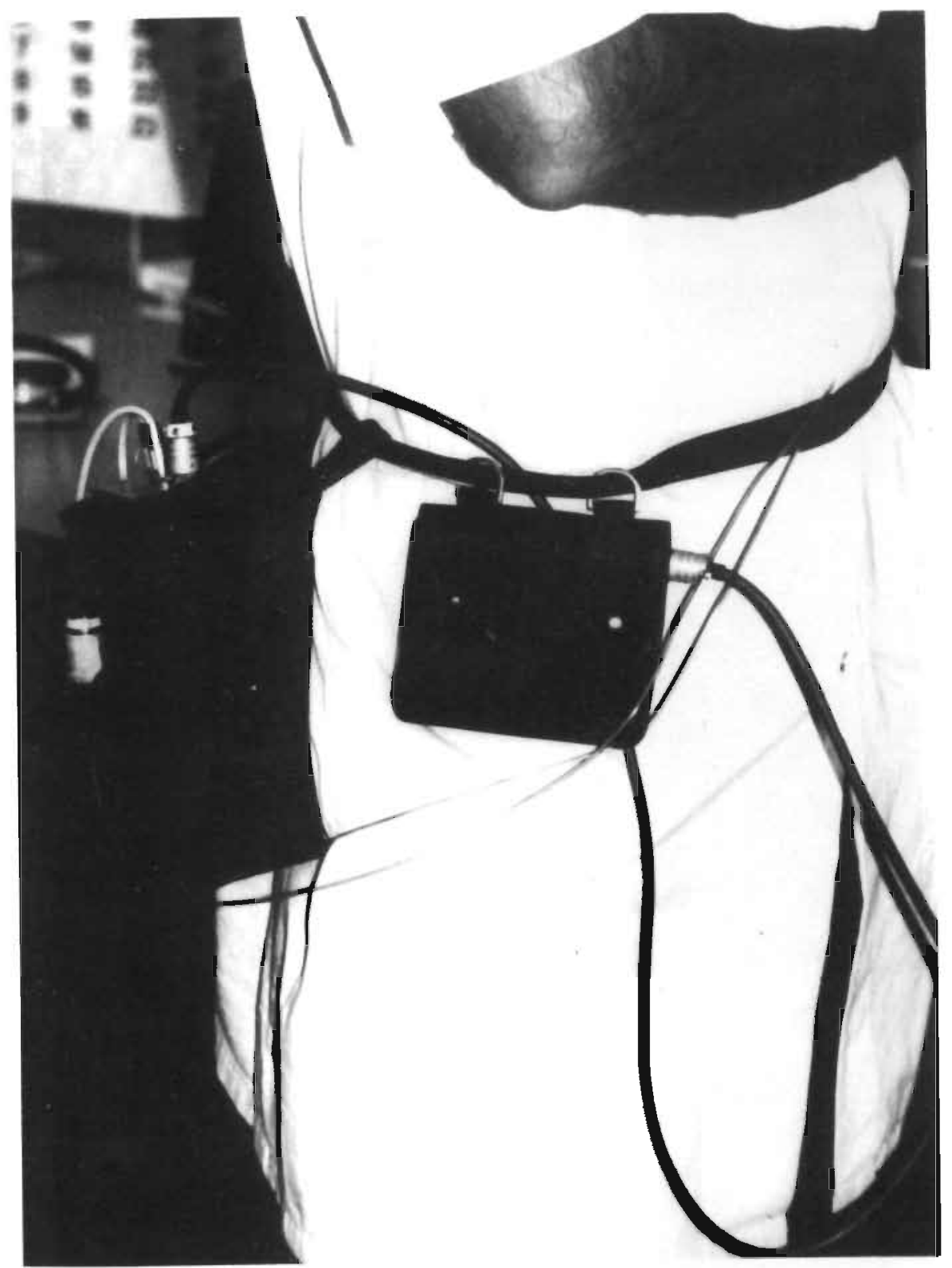

Figure 2. Person wearing the holter system. 


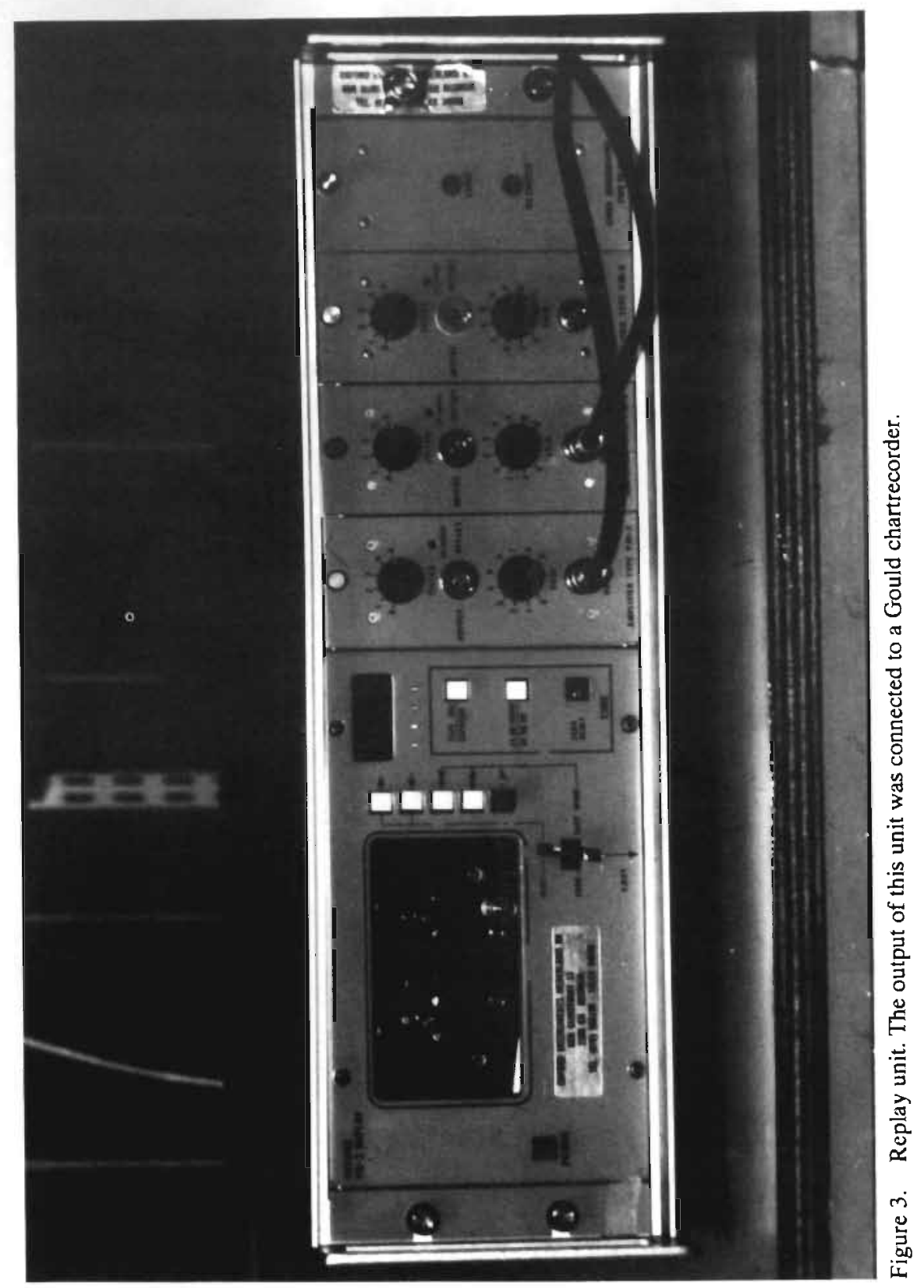




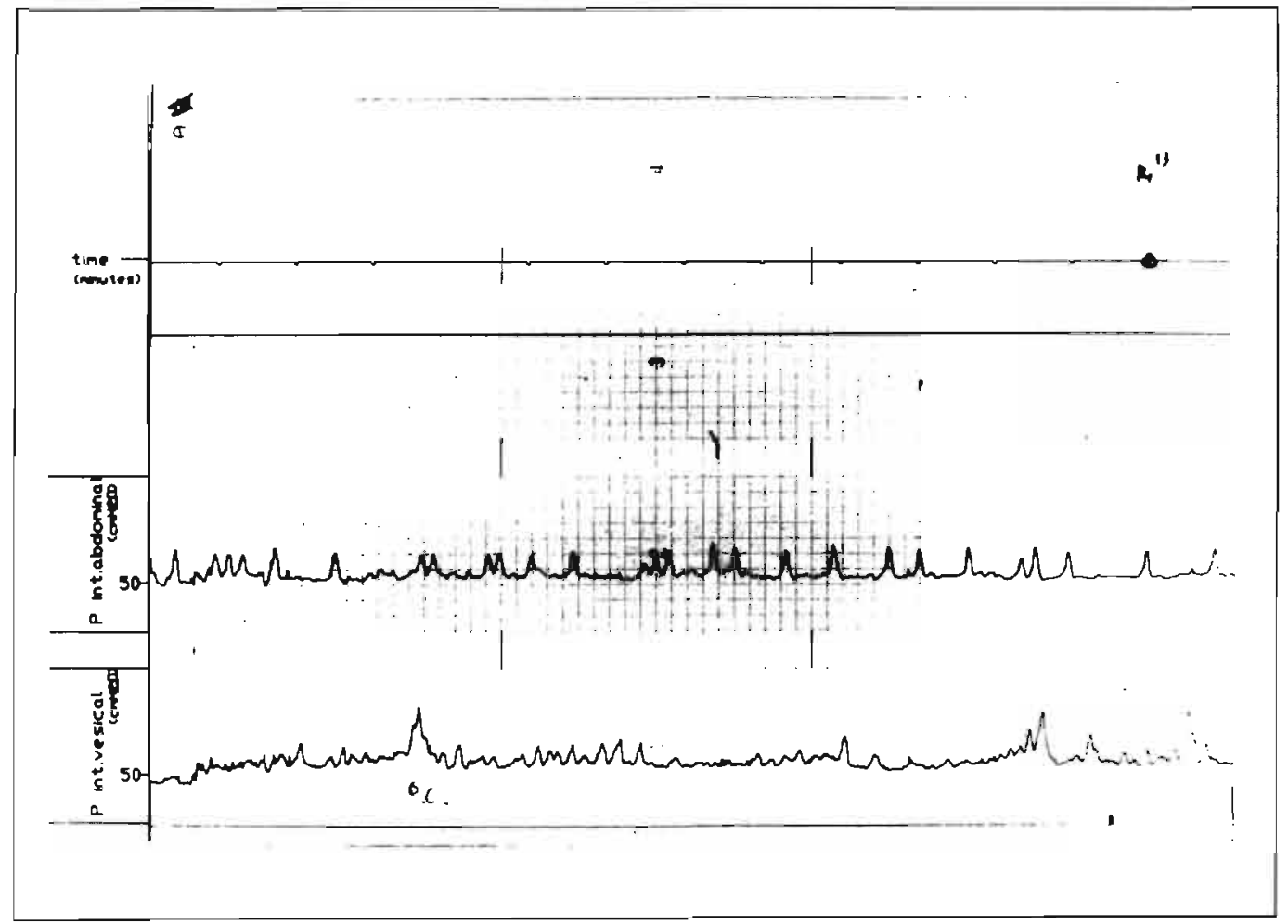

Figure 4. Especially in patients with primary enuresis nocturna it is important to know, whether they suffer from serious detrusor overactivity or they have only an uncontrolled voiding reflexes during the night. These curves were recorded with the holter system in a 11 year old female patient with enuresis nocrurna. Her cystometry was completely normal. Ambulatory testing revealed severe detrusor over activity without incontinence during day-time (2:13 P.M. $\left.=14^{13}\right)$. The horizontal axis represents time (upper line with a marker each minute). 


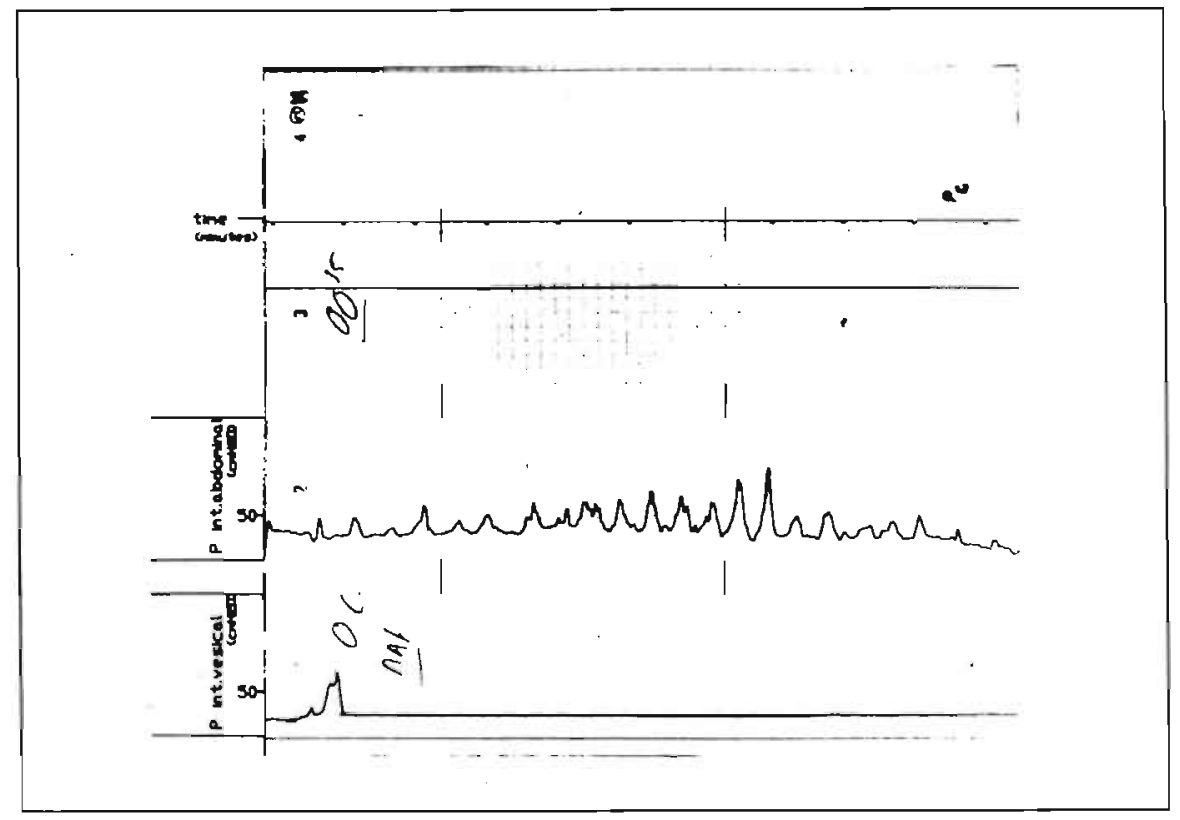

Figure 5. Patients kept a diary to inform us about events of incontinence and voiding. Here one can see the uninhibited detrusor contraction causing incontinence during sleep (00:27 A.M.). The intra-abdominal pressure curve demonstrates perstaltic activity in the rectum. The horizontal axis represents time (upper line with a marker each minute). 


\title{
Ambulatory monitoring to assess the efficacy of oxybutynin chloride in patients with mixed incontinence
}

\author{
E.S.C. van Waalwijk van Doorn, W. Zwiers \\ Department of Urology, University Hospital Maastricht, and Department of \\ Urology, St. Jozef Hospital, Eindhoven, The Netherlands.
}

\begin{abstract}
Objective parameters show the efficacy of oxybutynin chloride on uninhibited detrusor behavior. In the 24-hour ambulatory monitoring method, intravesical and abdominal pressure are recorded. This enables quantification of amplitude, duration, and frequency of uninhibited detrusor contractions. It is even possible to show the efficacy of this drug objectively in patients with severe mixed incontinence.
\end{abstract}

Keywords Urodynamics, Lower urinary tract, Diagnostics, Ambulatory, Urinary incontinence, Anticholinergic 


\section{Introduction}

Urodynamic investigations play a central role in the diagnosis of incontinence. The same is true when establishing the efficacy of anticholinergic/antispasmodic agents in the therapy of motor urge incontinence. However, only subjective parameters like frequency, urgency and incontinence are measured.

Another limiting factor in testing anticholinergic drugs is the fact that the results, as reported by the patient, or assessed by weighing perineal pads, may be influenced by coexisting stress incontinence. Patients with mixed incontinence may not only develop a higher micturition frequency because of motor urge, but also because of stress incontinence. In this group of patients, it is important to know whether the motor urge component can be influenced sufficiently before a suspension operation is taken into consideration. In this respect, it is important to be able to monitor and to quantify those parameters that are influenced by the drug tested. In assessing the effects objectively, most investigators use parameters of basic urodynamic evaluation methods like "first desire to void" and the intravesical volume at the first uninhibited contraction $(1,2)$. Nevertheless, a conventional urodynamic investigation is of limited duration and performed under unphysiological circumstances. Precise quantification of other urodynamic parameters to assess the efficacy of anticholinergic agents, like the number of unstable contractions during a longer period, has not been made.

For these reasons we developed a method for ambulatory 24-hour registration of bladder and rectal pressure. Two very flexible 8 -French polyurethane catheters with built-in micro transducers were applied. The pressure signals were recorded on a portable tape recorder and after 24 -hours the recording was replayed and analyzed in combination with the micturition diary card.

The technical aspects of this method were reported previously (3). Here, we report the results of a study on the efficacy of oxybutynin chloride using ambulatory monitoring.

\section{Materials and methods}

To perform a 24-hour monitoring, the patient was catheterized transurethrally and rectally with 8 -French flexible polyurethane catheters, each equipped with one micro pressure transducer at the tip (PPG-Hellige). Both catheters were connected to a small box containing the amplifiers and the battery power supply. This box was connected to a miniaturized tape recorder (Oxford Instruments). With a control box, that could be connected to the tape recorder, each pressure channel could be checked, e.g. by requesting the patient to cough. On a diary 
form, the start time of the procedure and the events like micturition time and volume, drinking, imperative urge, urine loss, and remarks were noted. Urine loss was measured by pad weighing during 24-hours. The patients remained inside the hospital during the investigation. They were completely ambulant. They could walk around, eat and drink as under normal conditions. In case of defecation, the rectal catheter was removed temporarily. The tape-recorded pressure signals were replayed on an Oxford Instrument replay unit and recorded on a Gould chart recorder. Analyses were done by correlating the events from the diary form with the replayed-tape recorded curves on paper from bladder and abdominal activity. During 1986, 50 patients, aged between 20 and 62 years (the mean being 41 years), with complaints of mixed incontinence, entered the research program. There were 44 woman and 6 men. Before entering this trial all patients had a conventional urodynamic evaluation according to the ICS standards, consisting of initial flowmetry, profilometry, filling cystometry and pressure flow study. All patients had a negative urine culture at the time of all urodynamic investigations.

After the conventional urodynamic investigation, a first 24-hour ambulatory monitoring was performed. During this measurement, no medication was taken that could have effect on bladder behaviour.

Then a second 24-hour monitoring of bladder and micturition took place during a period in which the patient was taking oxybutynin $5 \mathrm{mg}$ orally three times daily.

The following parameters were evaluated:

1. number of uninhibited bladder contractions

2. amplitude of the strongest uninhibited contraction

3. duration of the longest uninhibited contraction

4. reported micturition frequency

5. urine loss

Patients also reported side effects on the micturition diary form. Perineal pads were worn and changed after each micturition and after serious urine loss. The urine loss was established by weighing the pads. Also micturition was recorded on the diary form. The results of both monitoring periods were compared. The Wilcoxon signed ranktest was used to test the efficacy of oxybutynin on detrusor instability. 


\section{Results}

The micturition frequency did not differ significantly between the two recordings. Urineloss showed no significant improvement during drug treatment. A significant difference could be demonstrated in the frequency of uninhibited bladder contractions as well as in the maximal amplitude and the duration of the recorded uninhibited bladder contractions (table 1).

Twenty-nine patients reported a dry mouth, and 16 patients had complaints of blurred vision and/or nausea.

\begin{tabular}{lccc}
\hline & Without Oxybutynin & With Oxybutynin & P. Value \\
\hline Micturition Frequency in $24 \mathrm{~h}$ & 11 & 10 & 0.33 \\
Frequency U.C. in 24 h & 8.7 & 3.4 & $\mathbf{5} 0.001^{*}$ \\
Max. Amplitude U.C., $\mathrm{cmH}_{2} \mathrm{O}$ & 32 & 22 & $\leq 0.01^{*}$ \\
Max. Duration U.C.'s & 90 & 60 & $\mathbf{s} 0.05^{*}$ \\
\hline
\end{tabular}

Table 1. Measured parameters during both 24-hour ambulant monitoring periods.

"statistically significant using the Wilcoxon signed ranktest $(\mathrm{N}=50)$.

\section{Discussion}

Our results clearly show the strong spasmolytic effect on the detrusor muscle of oxybutynin chloride. The uninhibited bladder contractions were significantly shorter and less frequent. Also, the maximum amplitude of the unstable contractions was significantly lower. The anticholinergic effect is also reflected by the reported side effects.

Yet, we found no significant effect on the urine loss. This is in contradiction to the $74-95 \%$ improvement in other reported series $(4,5)$. This can be explained by the fact that these patients suffer from mixed incontinence. Since we serve as a referral center for complicated incontinence, many of our patients have a long medical history of failed incontinence surgery. Therefore, in quantifying the results of the efficacy of anticholinergic medication, we do not rely upon conventional urodynamic testing before deciding to perform major surgical therapy.

The ambulatory monitoring method is now used in our clinic as a standard procedure. This method enables us to quantify the effects of anticholinergic agents even in patients with mixed incontinence.

In conclusion, this study not only shows a statistically significant effect of oxybutynin on bladder instability, but it also demonstrates the diagnostic value of the 24-hour ambulatory monitoring method. 
The 24-hour ambulatory monitoring method is a very objective way to demonstrate the efficacy of all forms of anticholinergic drugs that affect bladder instability. The method gives objective results. Even when mixed incontinence is involved, this method shows the effect on detrusor behavior clearly. 


\section{References}

1. Riva, D. and Casolati, E: Oxybutynin chloride in the treatment of female idiopathic bladder instability: Results from double-blind treatment.

2. Thompson, I.M. and Lauvetx, R.: Oxybutynin in bladder spasm, neurogenic bladder, and enuresis. Urology, 8: 452, 1976.

3. Waalwijk van Doorn, E.S.C. van, Bouwmeister, P.P., van Oostendorp, M.E. and Debruyne, F.M.J.: 24h-ambulant monitoring, a reliable method to test on detrusor instability. Proceedings of the European Association of Urology 7th Congress 1986.

4. Moisy, C.U., Stephenson, T.P. and Brendler, C.B.: The urodynamic and subjective results of treatment of detrusor instability with oxybutynin chloride. Br j Urol, 52: 472, 1980.

5. Zanallo, A., Catanzaro, F. and Marino, V.: Therapeutic efficacy of oxybutynin in the hyperreflexic bladder. Urologia, 49: $788,1982$. 


\title{
Chapter V - Computerised Ambulatory Urodynamics
}

\author{
E.S.C. van Waalwijk van Doorn, R.A. Janknegt \\ Dept. of Urology, University Hospital Maastricht, The Netherlands.
}

A summary of this chapter was published in Neurourology and Urodynamics Volume 6, Number 3, july 1987.

Abstract Because conventional urodynamics are often associated with numerous pitfalls, that may interfere with accurate diagnostics, there is a need for improved techniques for routine clinical use. A computerised recording system for clinical and Extramural Ambulatory Urodynamics (EAM) is introduced. Aim of this study is to show, that EAM can easely be used as a routine investigation and that EAM adds an essential diagnostic tool to the conventional urodynamic investigation.

Keywords Urodynamics, ambulantory, telemetry, diagnostics, incontinence, urine, urinary. 


\section{Introduction}

Like most of the biological systems, which perform functions with a long time-constant, disfunction is difficult to investigate during short time examinations under unphysiological laboratory circumstances. The lower urinary tract with its storage and evacuation phase is a clear example of such a system.

Conventional urodynamics comprises UROFLOWMETRY, PROFILOMETRY, FILLING CYSTOMETRY AND PRESSURE/ FLOW STUDY. The uroflowmetry and pressure/flow study are intended to examine the evacuation phase of the urinary bladder; the profilometry and the filling cystometry should clarify disfunction concerning the storage phase. The conventional standard urodynamic investigation is performed under laboratory circumstances and within a very limited period of time (ca. $40 \mathrm{~min}$.). The investigation results are very much depending on the expertise and experience of the personel setting. Optimal test results are depending on pleasant surroundings, congenial and well trained personel in combination with proper patient preparation. Nevertheless it was demonstrated (2), that especially in an academical practice, with numerous cases of complex incontinence, the standard investigation alone was not at all reliable (less than 50\%).

That telemetry can increase the reliability of urodynamic diagnostics quite a lot, was demonstrated in chapter $3(3,4)$. That ambulatory urodynamic monitoring during 24 -hours is feasable was shown in chapter 4 (5).

These results supported the aim to develop an easy to use miniaturised holter system for routine ambulatory urodynamics.

\section{Materials and methods}

The system for extramural ambulatory monitoring (EAM) consists of a set of two flexible siliconrubber catheters with micro pressure transducers (fig. 1a). They are connected to a microprocessor-based recorder (sizes $155^{*} 90 * 45 \mathrm{~mm}$; weight $390 \mathrm{gr}$ ) carried on a belt (fig. $1 \mathrm{~b}-\mathrm{c})$. The system continuously stores intravesical, abdominal and if indicated urethral pressure signals up to 24 -hours. A button (fig. 1d) can be operated to mark those events, that are of clinical interest. All transducers must be connected before the recorder is started for automatic offset compensation of each pressure transducer. A battery is inserted to start. After one minute for automatically checking and zeroing of the transducers, the catheters can be inserted. Abdominal pressure is measured with a flexible single pressure transducer catheter ( 5 French, Gaeltec) inserted rectally or vaginally. If a dual transducer catheter is applied to monitor bladder and urethral pressure signals, this catheter ( 5 French, Gaeltec) is inserted transurethrally. The urethral 

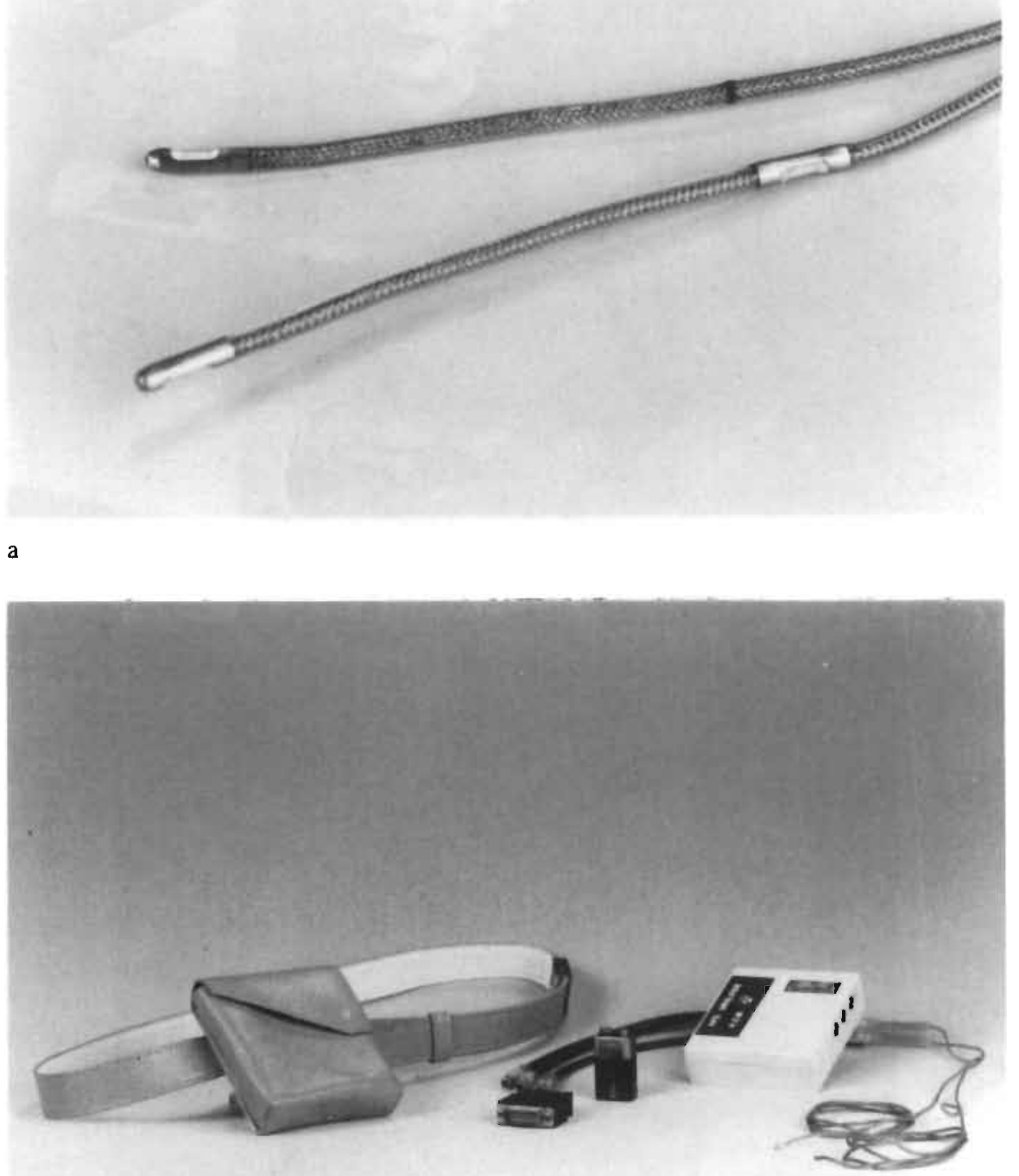

b

Figure 1. a) One catheter mounted pressure transducer (Gaeltec; 5 french) is positioned rectally or vaginally to register abdominal activity. A two transducer catheter (5 french) is used to monitor detrusor and urethral pressures. b) The Urodec 500 monitor (Bio Interface) with Catheters, 9 Volt battery, belt and Control-key. 


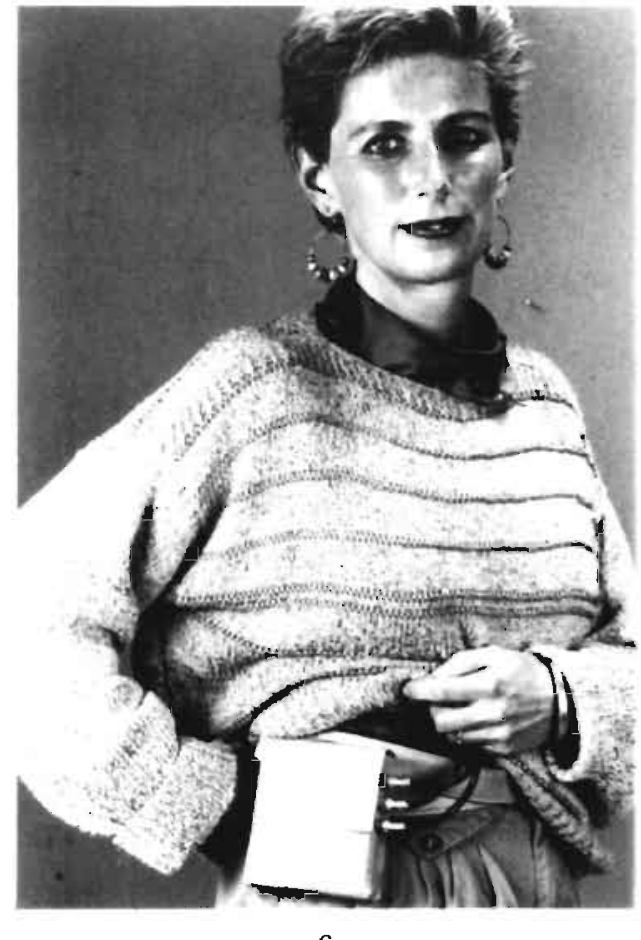

C

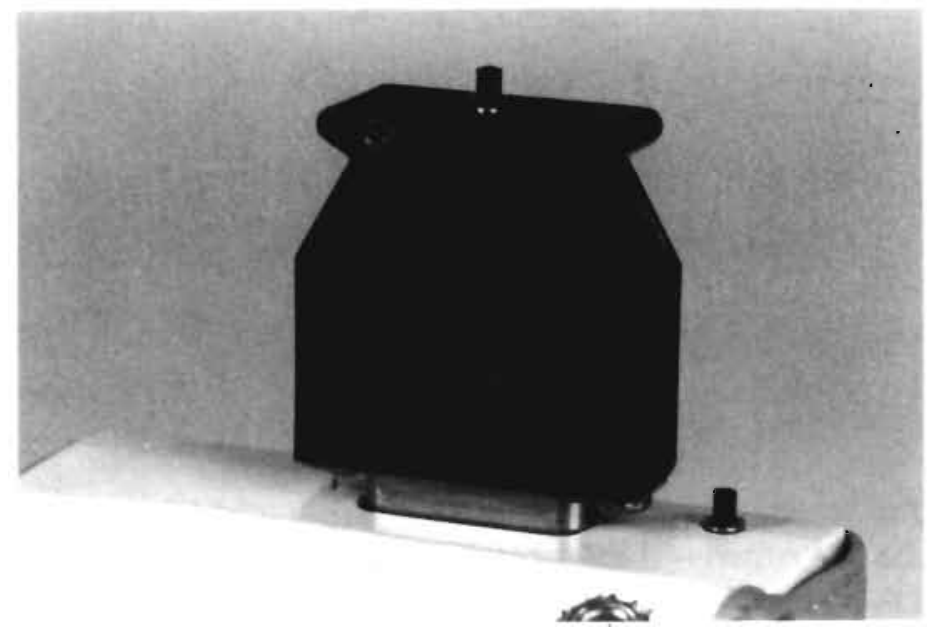

d

Figure 1. c) A female wearing the Holter Recorder (monitor). d) A close-up of the monitor with on the right side the Event-button and in the middle the Controlkey. With this key the signal level of each pressure channel can be checked seperately. 

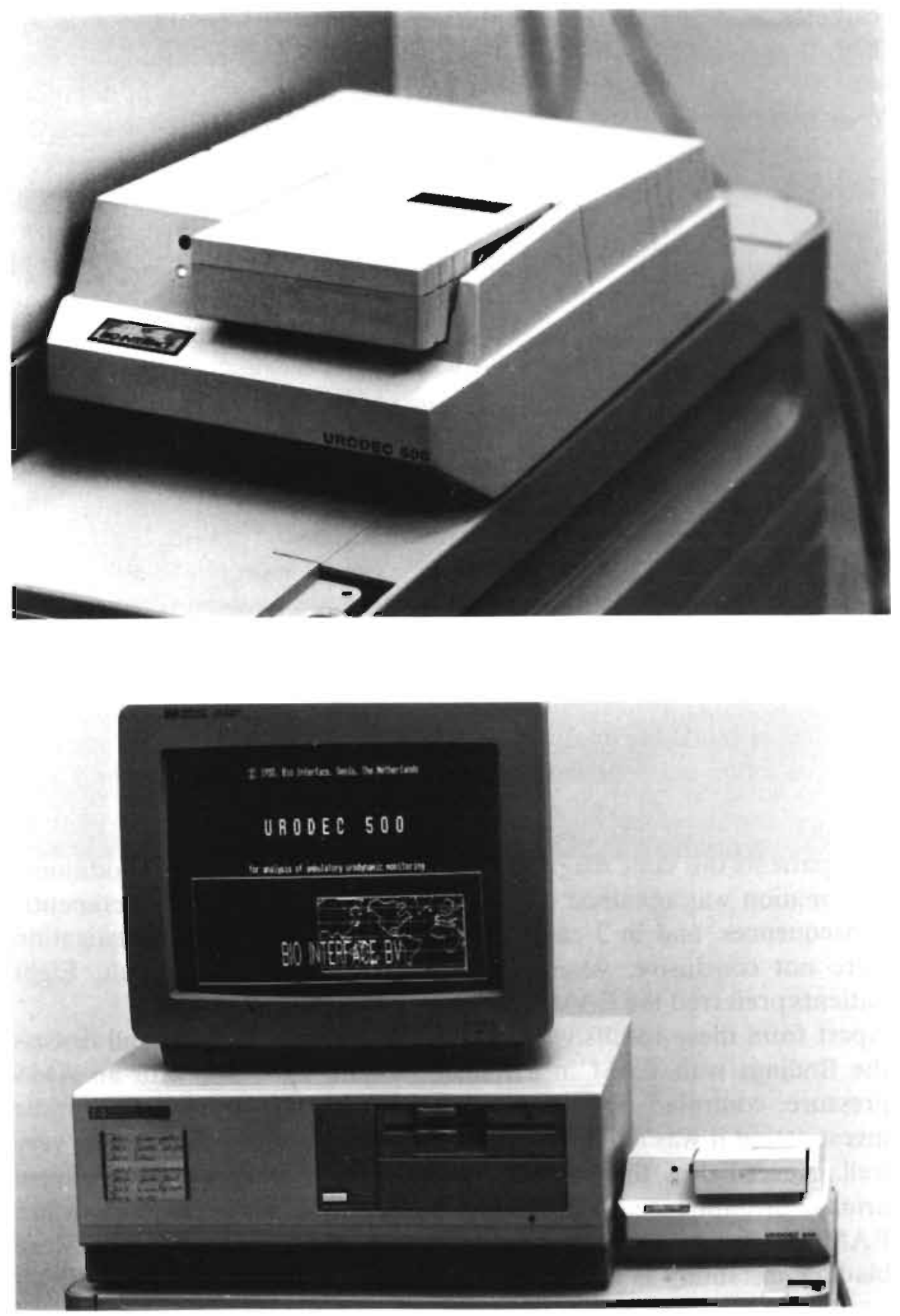

Figure 2. After the monitoring period the recorder is connected to the interface box. The data is then transmitted to the computer system for further analysis. 
catheter is drawn back for positioning the distal transducer at the highest pressure region in the urethral sphincter mechanism. All signals can be checked with a control key (fig. 1d), inserted in the topconnector of the recorder: each channel can be scanned by a switch; the signal level is then displayed by a number of leds on the control key. This key can be used at any moment during the monitoring period. Fixation of the catheter with tape is in most patients sufficient.

During EAM a diary is kept with micturition, urgency, urine loss and drinking events. After defining the operation of the event-button the patient can leave the clinic. After a period up to 24-hours the patient returns to the hospital, where the recorder and catheters are removed. In this study the measuring period was 7-8 hours during daytime. The EAM procedure ends by transmitting the recorded signals to a personal computer, where also the diary data are entered for further processing and analysis (fig. 2). Computer aided analysis of an EAM investigation takes about 10-15 minutes for an 8 hour monitoring period.

Ambulant patients with incontinence problems, visiting our out-patient clinic were asked to take part in this study. In a pilot study 10 patients were evaluated by means of conventional urodynamics and EAM, both at the same day. 9 Female and 1 male patient (aged: 15-62) took part. The findings of the conventional and the EAM method are compared. Also one special case of a patient with an AMS sphincter prosthesis will be discussed in detail to demonstrate the potentials of this system.

\section{Results}

In 6 patients the same diagnosis was determined; in 1 patient additional information was obtained after EAM with diagnostic and therapeutic consequences; and in 3 cases the results of the standard investigation were not conclusive, where the EAM showed a clear result. Eight patients preferred the EAM method above standard method.

Apart from these results we want, as an example, to show and discuss the findings with EAM in a female patient, aged 30, with an AMS pressure controled sphincter prosthesis (fig. 3). During the static investigation it was demonstrated that the implant was functioning very well. Nevertheless this young patient was still complaining of severe urinary incontinence. Two very interesting aspects can be seen in her EAM curves. Although her prosthesis is working fine (fig.4), severe bladder instability is causing pressure rises inside the bladder, which exceed the closure pressure inside the sphincter mechanism (fig. 5). This is causing incontinence. Also it can be seen that, if the urethral pressure transducer is placed and fixed at the right position, sphincter activity can be monitored effectively and there are only minor measuring artefacts (fig. 5). Particulary during the pressure rise in the bladder 

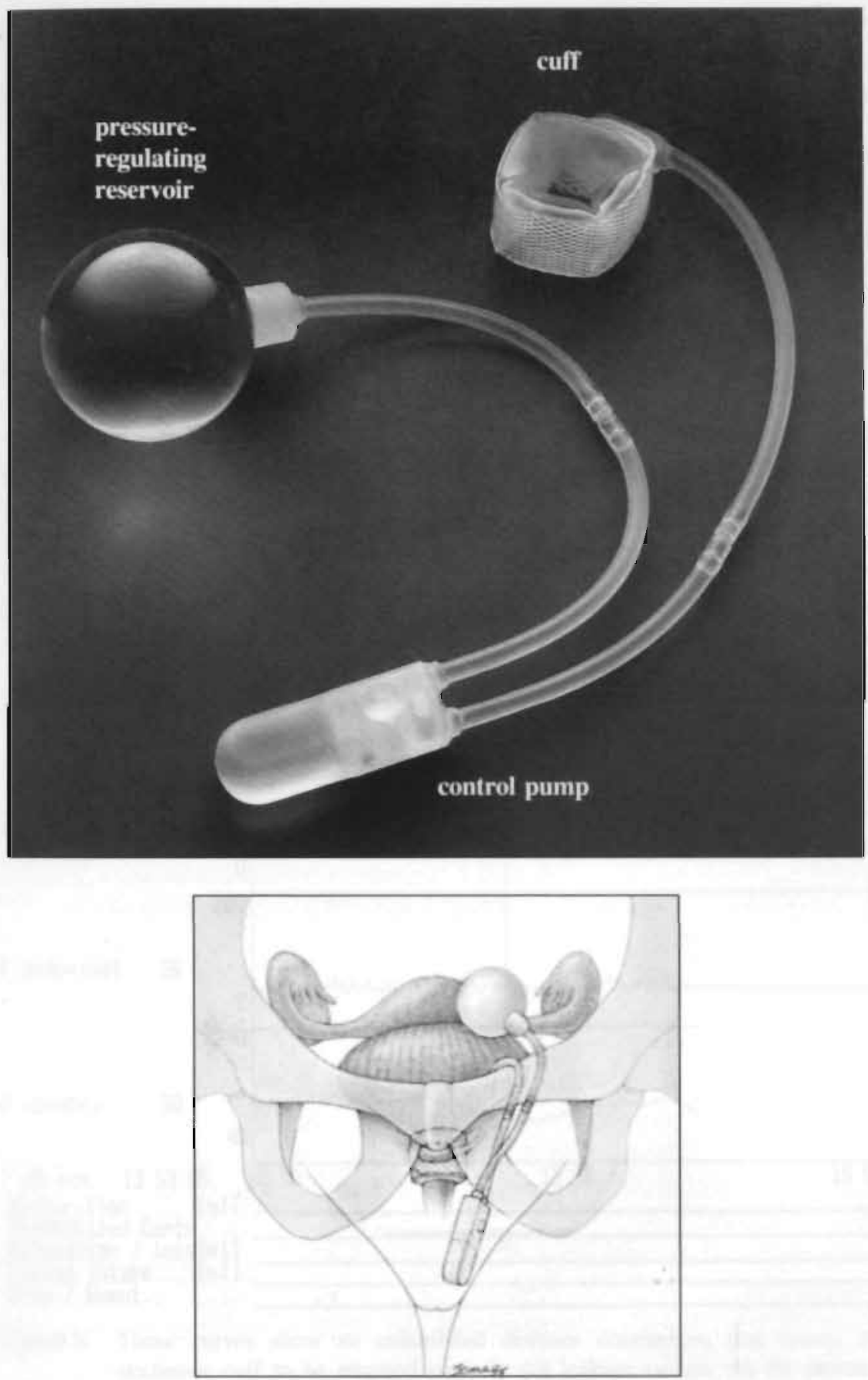

Figure 3. The AMS 800 pressure controled sphincter prosthesis. The pressure inside the occlusive cuff can not exceed the pressure in the pressure regulating balloon. 



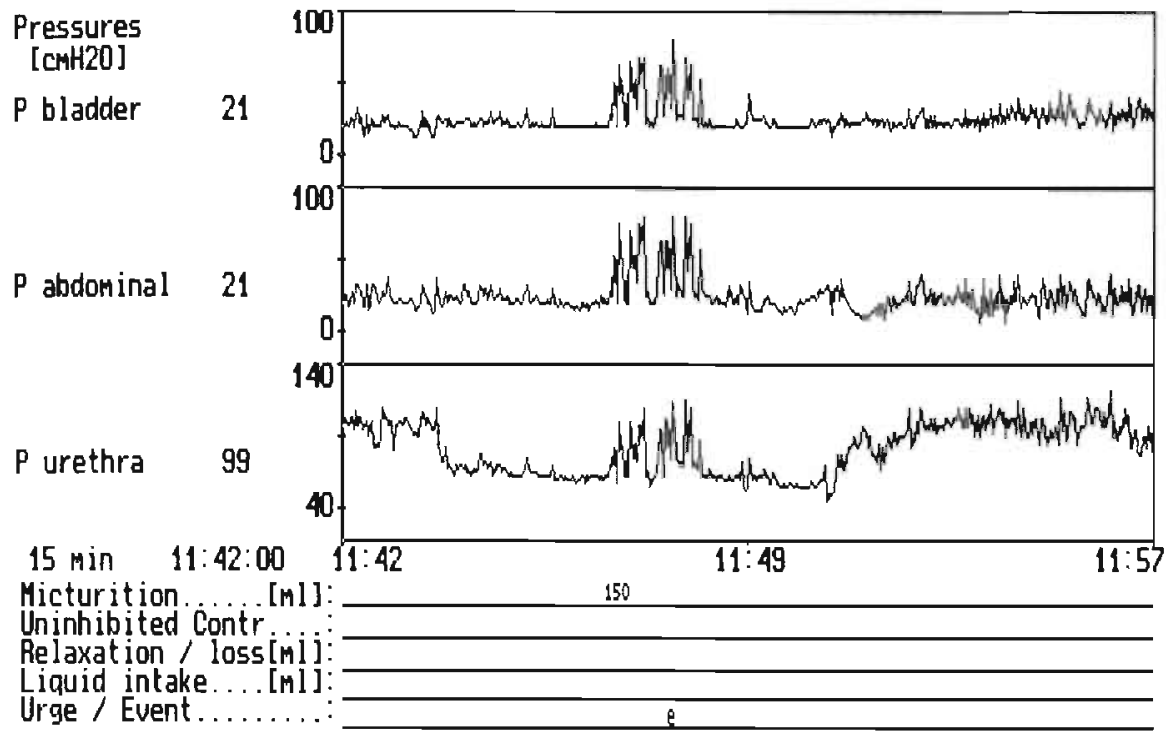

Figure 4. The third curve shows a drop in urethral pressure when the female patient opens the AMS sphincter prosthesis; then she empties her bladder by pressing the abdomen. Then the occlusive cuff is refilled automatically and the urethra closes again.

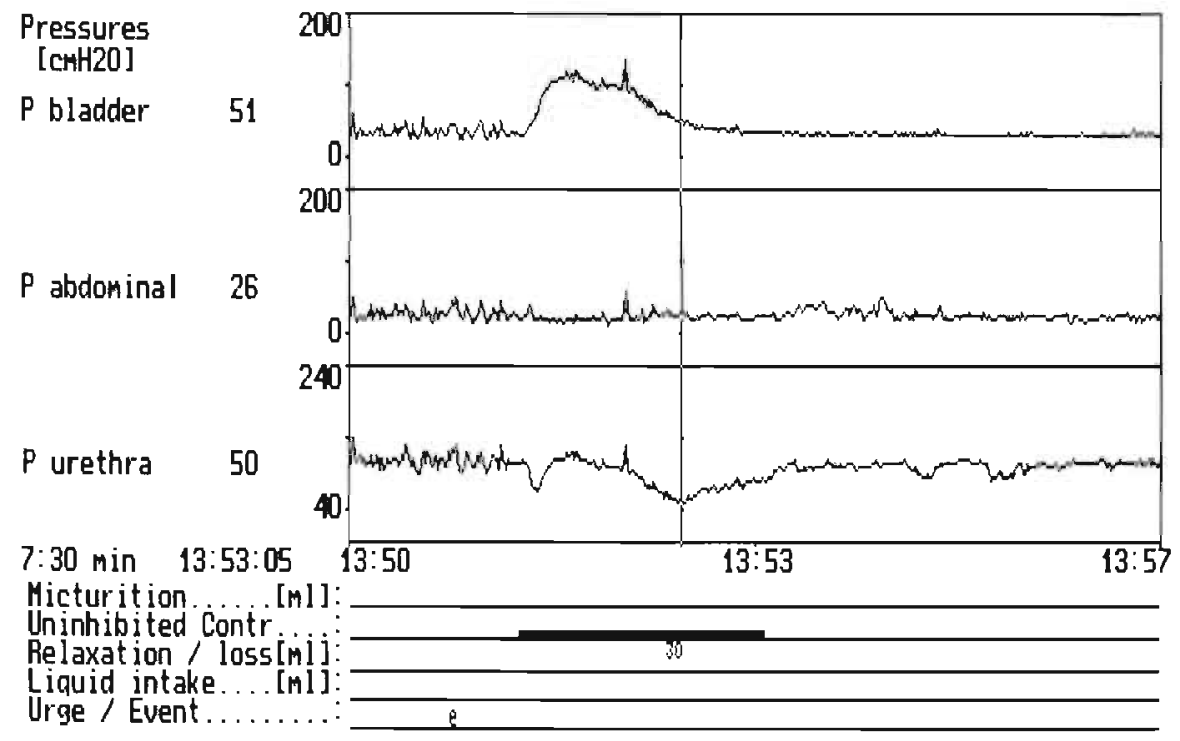

Figure 5. These curves show an uninhibited detrusor contraction, that causes the occlusive cuff to be emptied partially till leakage occurs. As the detrusor contraction decreases the cuff refills slowly again. At this cursor position the intravesical and urethral pressure are equal. This recording shows the possibility of reliable urethral pressure measurements. 
one can see when this unstable contraction opens the cuff around the urethra. When the bladder pressure decreases again under the maximum cuff pressure of the pressure controled prosthesis the cuff is slowly refilled again up to the maximum closure pressure. All these phenomena are monitored under normal conditions outside the clinic and occur repeatedly (fig.6).

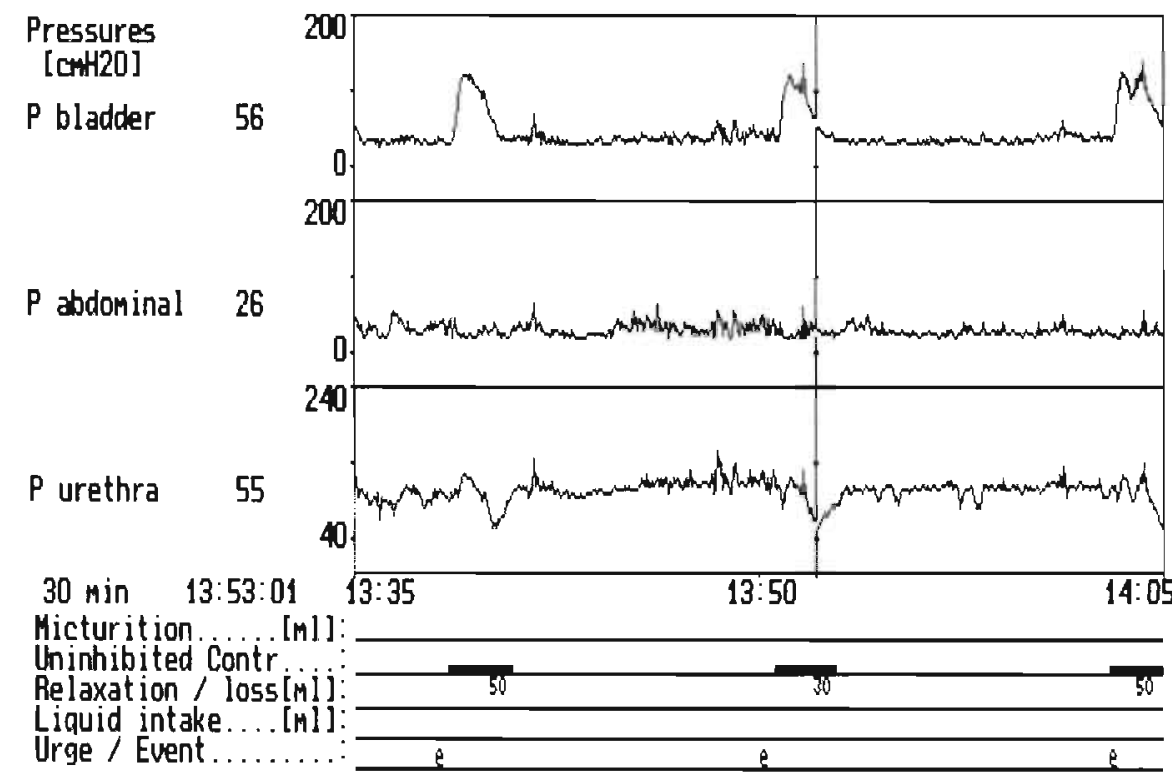

Figure 6. Notice that these curves have a time scale of 30 minutes as the previous figures. It can be seen that the overactive detrusor behaviour occurs repeatedly.

\section{Discussion and conclusions}

The EAM procedure increases the diagnostic reliability essentially, because this ambulant method examines functional behaviour under physiological circumstances (f.i. at home). The filling and evacuation phase are also monitored repeatedly and under physiological conditions. Bladder behaviour can also be correlated with drinking and micturition habits.

Both the clinician and the patient judged EAM as a feasible routine investigation.

Nevertheless, both the system and the method have to be evaluated further in a larger study. 


\section{References}

1. van Waalwijk van Doorn, E.S.C. and Janknegt, R.A.: Computerised ambulatory urodynamics.

Neurourol. Urodynam., 6: 210, 1987.

2. van Waalwijk van Doorn, E.S.C., Zwiers, W., Wetzels, L.L.A.N. and Debruyne, F.M.J.: A comparative study between standard and ambulant urodynamics.

Neurourol. Urodynam., 6: 159, 1987.

3. Delaere, K.P.J., Kimmich, H.P., van Waalwijk van Doorn, E.S.C., Valcke, A.A.P. and Debruyne, F.M.J.: Basic principles of telemetric urodynamic monitoring.

In: Biotelemetry VIII, Edited by H.P. Kimmich and H.J. Klewe. Braunschweig: Doering-Druck, pp. 313-318, 1986.

4. van Waalwijk van Doorn, E.S.C., Bouwmeister, P.P.M., van Oostendorp, M.E., Kimmich, H.P. and Debruyne, F.M.J.:

A retrospective study of the clinical value of telemetric urodynamics compared with standard urodynamics in patients with urinary incontinence. In: Biotelemetry IX. Edited by H.P. Kimmich and M.R. Neuman. Braunschweig: Doering-Druck, pp. 159-160, 1987.

5. van Waalwijk van Doorn, E.S.C. and Zwiers, W.: Ambulant monitoring to assess the efficacy of oxybutynin chloride in patients with mixed incontinence. Eur. Urol., 18: 49, 1990. 



\section{Chapter VI}

\section{Introduction}

Based on the preliminary results with the new system for ambulatory monitoring described in chapter IV, we performed a study in 100 patients to evaluate this method and system more extensively.

The results of this study are published in the Journal of Urology, 146: $124,1991$. 



\title{
Extramural ambulatory urodynamic monitoring during natural filling and normal daily activities: evaluation of one hundred patients
}

\author{
E. S.C. van Waalwijk van Doorn, A. Remmers, R.A. Janknegt \\ Department of Urology, University Hospital Maastricht, The Netherlands.
}

Abstract Conventional urodynamic tests are short and performed under non-physiological circumstances. The introduction of ambulatory urodynamic tests is a promising improvement of our diagnostic abilities with respect to these disadvantages. To test the value of our ambulatory urodynamic method we evaluated 100 patients with urinary incontinence and/or voiding problems with both diagnostic methods. Preclassification according to medical history was compared with the urodynamic diagnosis obtained from the conventional and extramural ambulatory monitoring methods, and the combination of both techniques in patients with urinary incontinence. The conventional method showed no abnormalities in $32 \%$ of the patients compared to only $3 \%$ with the ambulatory method. The conventional method confirmed preclassified stress incontinence in $36 \%$ of the patients, compared to only $14 \%$ by extramural ambulatory monitoring. Combining both methods preclassified stress incontinence was confirmed in $43 \%$ of the patients. Preclassified urge incontinence was confirmed in $47 \%, 59 \%$ and $84 \%$, and preclassified mixed incontinence was confirmed $23 \%, 29 \%$ and $55 \%$ of the patients using the conventional, extramural ambulatory monitoring and combined methods, respectively. An overall correlation with the preclassification in the incontinent group was found in $34 \%$ with the conventional method and in $43 \%$ with the extramural ambulatory monitoring. Combining both diagnostic tools showed a correlation with the preclassification in $67 \%$ of the patients.

These results show the very promising impact of ambulatory urodynamic testing in the near future.

Keywords Urinary tract, urinary incontinence, urination, urodynamics, urethra 


\section{Introduction}

Urodynamic investigations are an essential part of the evaluation of many patients with lower urinary tract disorders. Conventional urodynamic investigations consist of uroflowmetry, filling cystometry, pressure-flow study and profilometry. The investigation is performed under laboratory circumstances, with nonphysiological bladder filling. The entire investigation normally is completed within approximately 45 minutes. Therefore, it seems likely that during a test under normal conditions, which means that the bladder is filled naturally, differences are to be found between such an ambulatory test and the conventional short urodynamic test.

Attempts have been made to assess bladder function under more physiological circumstances, using diuresis cystometry with conventional urodynamic equipment (1) or natural bladder filling by telemetric monitoring (2-7) or Holter monitoring (8-12). The reports show, for example, that detrusor overactivity is detected more frequently and that incontinence is quantified better than during conventional cystometry. Differences in micturition contractions between the ambulatory and conventional tests have also been shown in the same patients $(10,12)$. Some physicians have also managed to monitor urethral activity under ambulatory circumstances (10-11).

In view of these potentials and our previous experiences with on-line eight channel ambulatory telemetry, which already revealed the therapeutic consequences of such a diagnostic tool, a patient, friendly and easy to use miniaturized system for full ambulatory testing of patients in their own daily environment was developed (13). We assessed the use of our extramural investigative method, and the technical performance of the measuring system and microtransducers catheters. Diagnostic results of the extramural ambulatory monitoring (EAM) method and the conventional urodynamic investigation (CUI) were compared with the preclassification according to medical history.

\section{Materials and methods}

Patients with urinary incontinence and/or micturition problems were investigated. To evaluate extramural ambulatory monitoring, the patient history was first taken by the physician. Then, urinary tract infection as a cause for the complaints was excluded. When a urine-culture was positive the infection was treated. Subsequently, a preclassification was made according to International Continence Society terminology (14) after a medical history was obtained. The categories were defined as stress incontinence, urge incontinence, mixed incontinence, other incontinence (including nocturnal enuresis), urgency and other micturition problems. In case of combined incontinence and micturition 
problems, the incontinence prevailed in establishing the preclassification.

A full conventional urodynamic investigation then was performed, according to International Continence Society standards, to evaluate the complaints and to reveal functional disorders $(14,15)$. This investigation included initial flowmetry, urethral pressure profilometry, filling cystometry (30 to $50 \mathrm{ml}$. per sec) and a pressure-flow study. Incontinence was evaluated visually during filling cystometry with or without detrusor activity (urge incontinence), respectivily, with or without stress provocation (coughing, Valsalva manoeuvre, abdominal straining, and so forth - stress incontinence). The same catheters with microtip transducers that were used for the conventional urodynamic investigation were used for the extramural ambulatory monitoring.

Urodynamic diagnoses made after the conventional urodynamic investigation were normal, motor urge incontinence, stress incontinence, mixed incontinence and motor urge.

Definitions of urodynamic diagnoses were those established by the International Continence Society, unless indicated otherwise (14).

Based on the medical history and the results of the conventional test a decision was made whether to perform extramural ambulatory monitoring.

Inclusion criteria for extramural ambulatory monitoring were contradiction between urological history and urodynamic result (this often occurs when complaints of urgency and urge incontinence are involved). stress incontinence in which a previous corrective operation had failed, nocturnal enuresis and/or nightly micturition problems (in these cases measurements were extended overnight) and exclusion of detrusor overactivity when placement of an artificial sphincter mechanism was being considered.

Patients. We analyzed 100 consecutive patients (87 women and 13 men) who met the aforementioned conditions by extramural ambulatory monitoring. Mean age was 43.5 years (range $17-78$ years) in the women and 45.8 years (range $22-77$ years) in the men.

Extramural ambulatory recording system. The extramural ambulatory monitoring system (Urodec 500) is based on the use of cathetermounted, micro-pressure transducers, connected to microprocessor controlled drivers and pre-amplifiers. The signals are digitized by an 8 bit analogue to digital converter. The three pressure channels are each sampled at $50 \mathrm{~Hz}$. The data are preprocessed and then stored at one sample per second per channel. A miniaturized low power microprocessor circuit takes care of the analogue to digital conversion, the 
preprocessing and the storage of all pressure signals with a relative accuracy of plus or minus $2 \mathrm{~cm}$. water. The memory in the recorder is sufficient for up to 24-hours ambulatory measuring. At the end of the investigation the stored data are transferred to a personal computer for definitive storage, processing and the plotting of a clinical report and traces.

Figure 1 shows a block diagram of the ambulatory recorder, pressure catheters and control key for on-line testing.

Three Gaeltec micro-pressure transducers, mounted on two 6F silicon catheters, monitor intravesical, abdominal and urethral pressures: 1 catheter transurethrally and 1 rectally. Vaginal pressure monitoring, to obtain a reference abdominal pressure also was done. This is preferable in some cases, when problems are to be expected with defecation. Measurement of intravesical pressure with an external pressure transducer connected to a suprapubic catheter also is applied succesfully in some patients, if urethral activity is of no interest. A button on the monitor can be used by the patient to indicate certain events, for example micturition, urge sensation and urine loss. All pressure transducers are connected to the battery powered ambulatory recorder (sizes $90 * 105 * 29 \mathrm{~mm}$., weight 230 gram, including battery).

Extramural ambulatory monitoring measuring method. Previous to the ambulatory investigation, patients receive an extensive information sheet describing the test and the necessary preparation. Especially with regard to bowel movement, the patient is advised to empty the bowel prior to the investigation. In case of 24 -hour monitoring the patient is hospitalized.

Installing the ambulatory monitor begins with the patient in supine position. The rectal catheter is inserted first and the microtip should penetrate into the rectum approximately $10 \mathrm{~cm}$, then, a dual transducer catheter (transducers 5 or $6 \mathrm{~cm}$ apart) is inserted. With 2 transducers in the bladder and 1 in the rectum, the patient is asked to relax and lie still for one minute. The pressure transducers are zeroed automatically by placing a battery in the battery compartment of the recorder. The second transducer of the urethral catheter then is positioned in the region of maximum urethral pressure. This can be done with the help of a urethral pressure profile, which is made previously, or with the help of a control key. With the control key, which can be connected to the monitor, each pressure channel can be examined, for example by asking the patient to cough. The catheters are fixed to the perineum or the penis with the help of brown plaster. This method works satisfactorily. The starting time and end of the procedure are registered. Patients are 


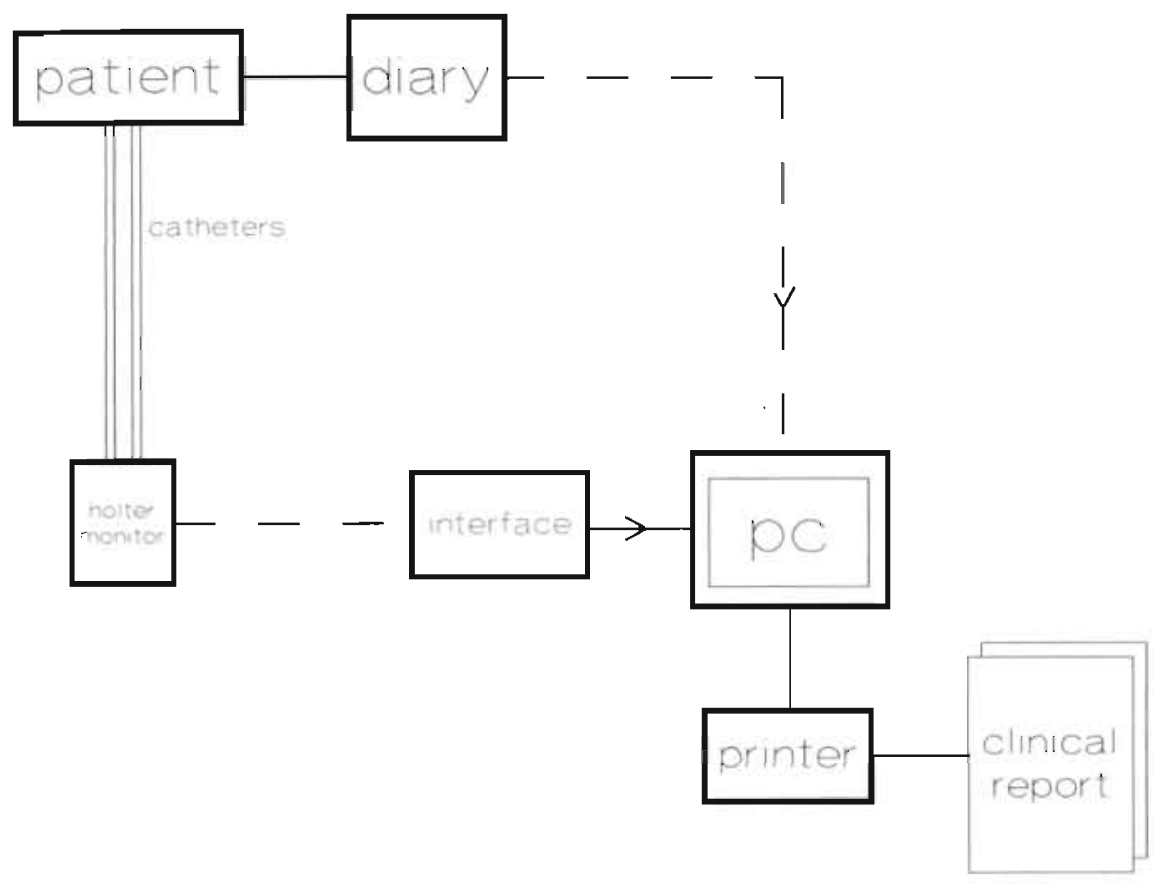

Fig. 1. Block diagram of the ambulatory recorder, pressurc catheters and control key for on-line testing. 

asked to keep a diary of important events such as micturition (time and volume), drinking (time and volume), urge sensations, time and severity of urine loss, and remarks. The severity of the urine loss is categorized as drops, dashes and massive loss. In this study the event button is used to indicate the start of the voiding procedure. The patient is asked to push the button when entering the toilet. This is of considerable importance in recognizing detrusor overactivity just before voiding. After careful instruction, the patient leaves the hospital and returns to normal daily activities. They are strongly advised to drink plenty of fluid so as to have two or more micturitions during the investigation period. At the end of the test period the patient returns to the hospital and the catheters are removed. To obtain the measured data, the monitor is connected to a personal computer by means of an interface unit. With the help of a software package the data from the monitor memory are transmitted to the personal computer. The patient and diary data are entered via the keyboard. Then, the curves are analysed, which means that diary data and events are correlated with the measured curves.

When analysing the curves one must be aware of several physical factors influencing the recorded pressure signals. The zero reference point for a microtip catheter is the atmospheric pressure at the level of the sensing membrane. The same pressure is working on the entire body. If all three catheter mounted transducers are zeroed while positioned in the bladder and the rectum, respectively, while the patient is in the supine position, there will be a relative difference between the two zero points that is roughly equal to the vertical distance between the transducers. When the patient stands the vertical distance between rectal and bladder transducer position generally decreases. In addition, the weight of the urine above the bladder transducer can cause a slow increase of recorded intravesical pressure. The same can happen during withdrawal of the urethral transducer from the bladder into the urethra. For example a bladder filled with $500 \mathrm{ml}$. can cause a maximal pressure change of approximately $10 \mathrm{~cm}$. water.

The actual pressure discrepancies that can occur because of these physical phenomena can be up to approximately $20 \mathrm{~cm}$. water. Nevertheless, since we fix the urethral catheter close to the meatus the position of the intravesical transducer is stable. Analysing the urethral curves, one must realize that urethral pressure measurement differs from intravesical pressure measurement basically because the urethra is not filled with fluid most of the time. Furthermore, the rigidity of the catheter causes deformation of the urethra and therefore, a reaction force (action equals reaction) of the urethral wall on the sensing membrane. Measuring in different orientations in the urethra with a 
rigid catheter shows variations in pressure amplitude. This effect disappears when thin flexible catheters are applied. Change of position can cause artifacts in the recorded pressure by movement of the urethral tissue along the sensing membrane. Most of the time these changes in urethral pressure are also reflected in the intravesical and rectal pressure, for example change from supine to sitting position, walking or cycling. Change in abdominal pressure and intravesical pressure during urine passage also influence the urethral pressure. The extreme shapes of the voiding can be recognized; one with a complete urethral pressure decrease in combination with a detrusor contraction, while the other on the contrary shows the intravesical pressure also in the urethral pressure curve. Any shape in between also is possible. We suggest that the character of the curves is dependent on the obstructive influence of the urethral catheter. A pressure transducer in a narrow urethra with scar tissue will show intravesical pressure during voiding. A flexible well relaxed urethra will show a clear pressure decrease during voiding (fig 2.b, just after the event, which indicates voiding).

Uninhibited detrusor contractions are identified with the help of a cursor. Contractions correlated with registered urine loss are diagnosed as motor urge incontinence. Registered urine loss in the absence of detrusor activity is diagnosed as stress incontinence. The same is done with urethral pressure decreases (urethra relaxations) but only in combination with detrusor activity and/or indicated urge sensation, or if the urethral pressure temporarily decreases to or below the intravesical pressure. Amplitude and duration of the uninhibited detrusor contractions and urethral relaxations are automatically calculated. Finally, a clinical report is generated with a summary of drinking and micturition behaviour, urine loss and analysed detrusor overactivity and sphincter activity (fig. 2 and 3, and tables 1 and 2).

Based on the results of extramural ambulatory monitoring, a new urodynamic diagnosis is established, independently of previous results. The occurrence of incontinence and urodynamic abnormalities, such as detrusor overactivity and sphincter insufficiency during extramural ambulatory monitoring and the conventional urodynamic investigation, are analysed. Preclassifications, conventional urodynamic diagnosis and extramural ambulatory monitoring urodynamic diagnosis are compared. The performances of methodology and recording systems are assessed.

Statistical analysis.

To compare the data obtained from the different groups mean values were calculated. To prove whether the differences in the preclassified groups were significant the Wilcoxon rank test was used. 

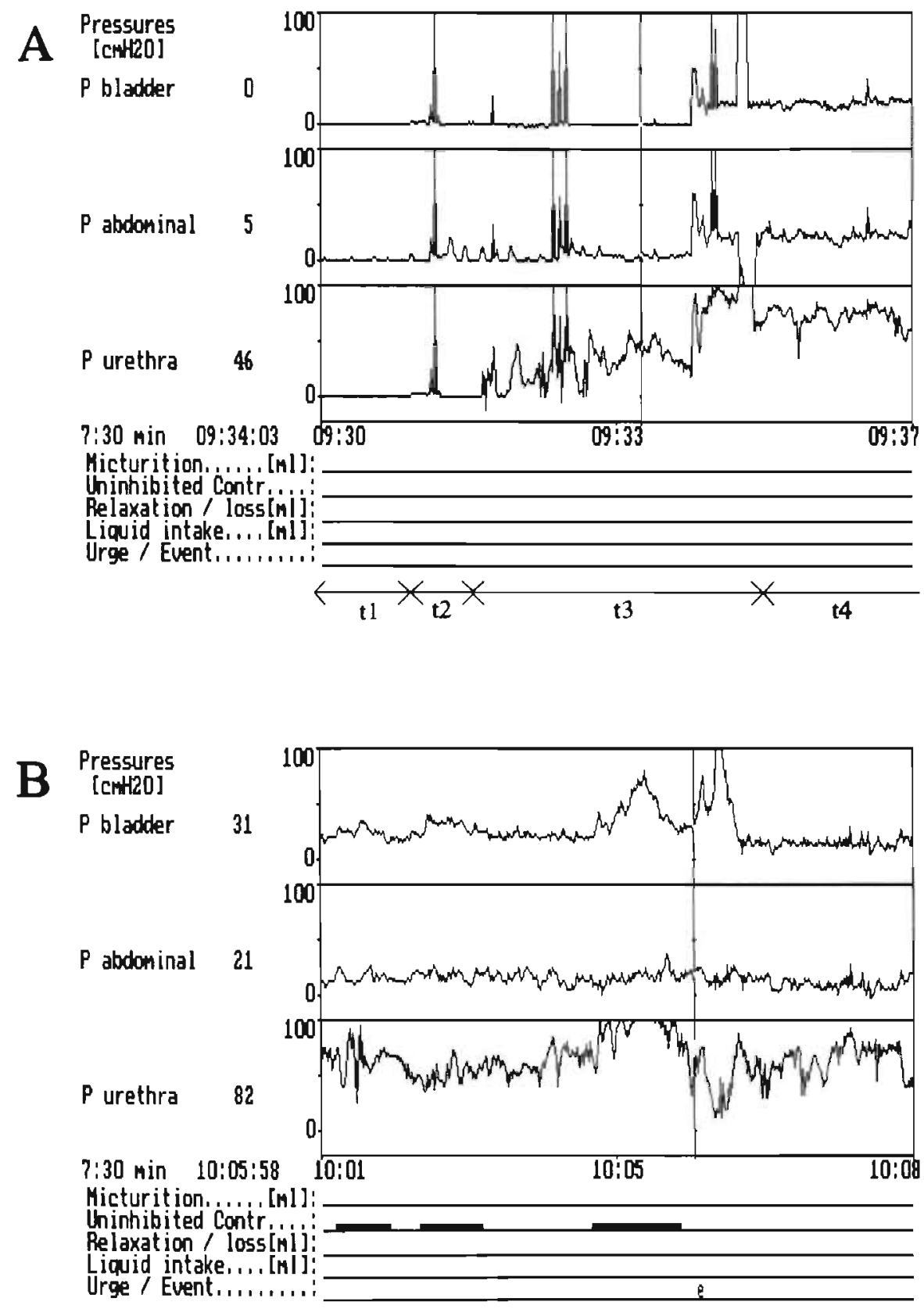

Figure 2. A, beginning of investigation period. $t l$, automatic zeroing period. $t 2$, cough test. $\boldsymbol{t} 3$, positioning and fixation urethral catheter. $\mathbf{t 4}$, start of monitoring period.

B, micturition preceded by uninhibited detrusor contraction and squeezing of the urethra. 


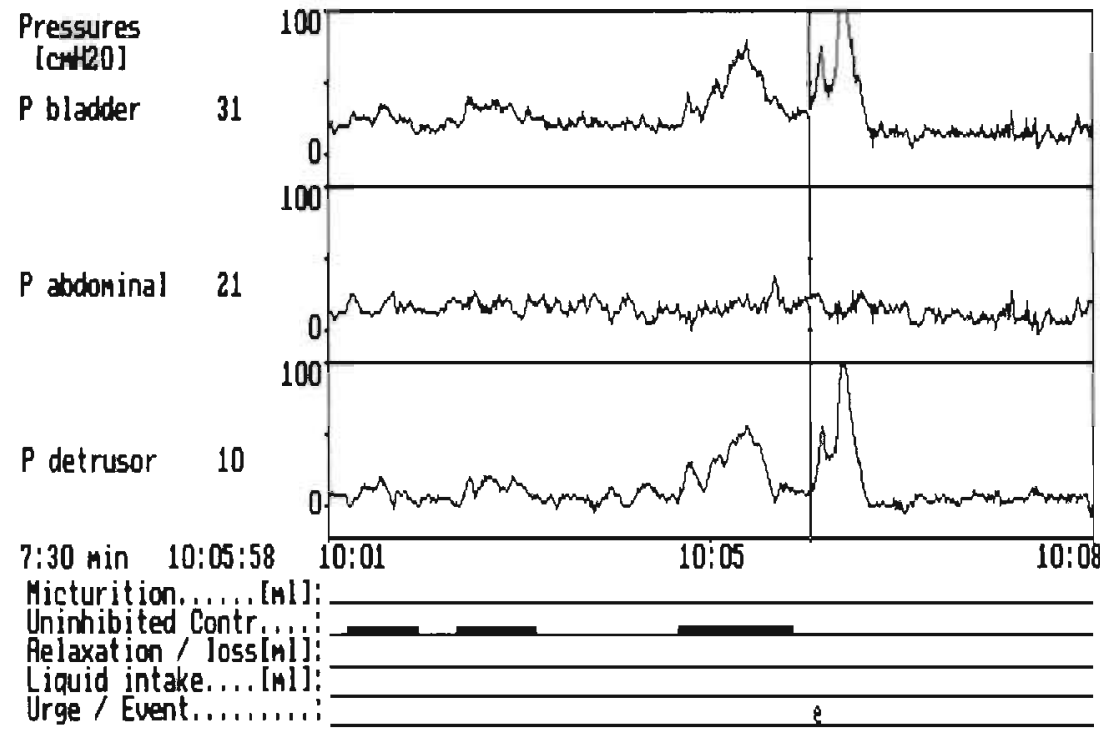

$D \begin{gathered}\text { Pressures } \\ {[\text { crH20] }} \\ P \text { bladder }\end{gathered}$

33

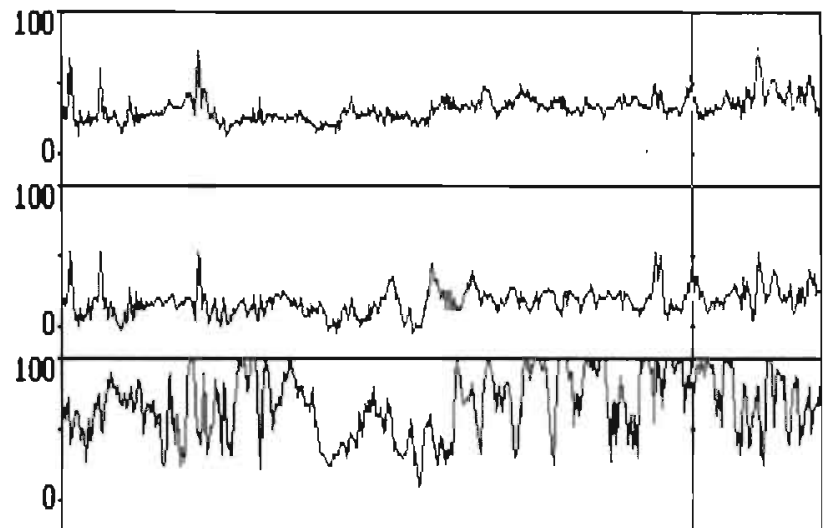

P urethra

90

$10: 5 ?$

$11: 01$

$7: 30$ min $10: 59: 59$
Micturition..... [nll:

Uninhibited Contr.....

Relaxation / loss[MI]:

Liquid intake.... [mi]:

Urge / Event...........

Figure 2. C, detrusor trace from same example as in part B. D, urethral relaxation with urine loss $(I) . e$, event, in this case start of micturition. $u$, urge sensation. 


\section{MICTLRITIOHS}

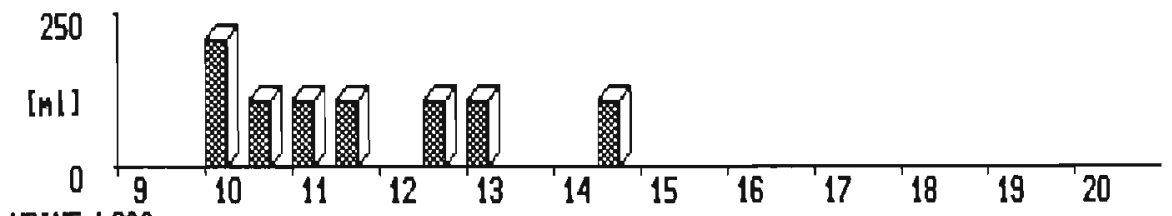

URIKE LOSS

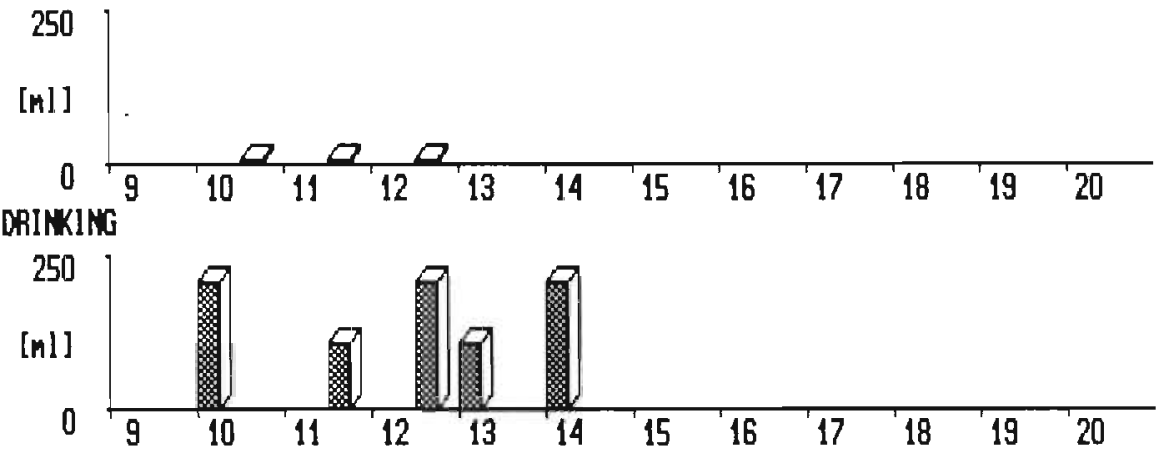

UNIHIBITED CONTRACTIONS

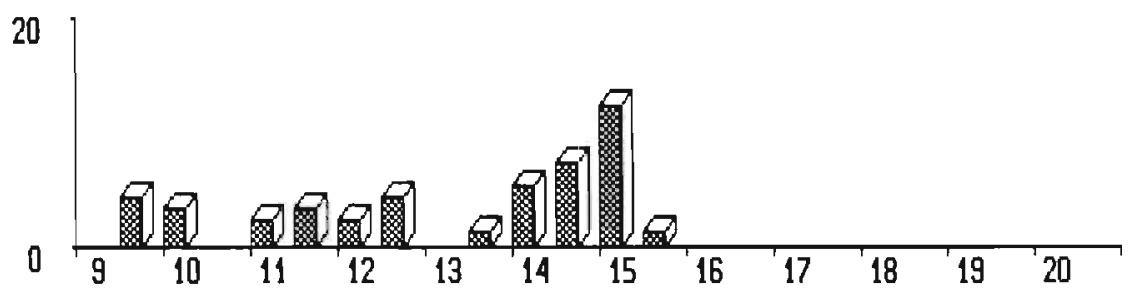

\section{UAETHAA RELAXATIONS}

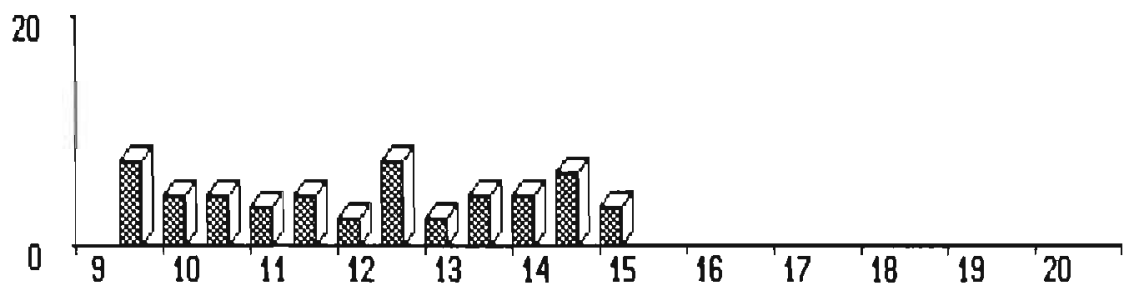

Figure 3. Occurrence of events during investigation period visualized graphically on time axis. 


\section{Clinical Report - Ambulatory Urodynamic Investigation}

Name

: GM

Start investigation ......: $09: 30$

Initials

: $\mathbf{f}$

End investigation:

$15: 36$

Day of birth

1933

Date of investigation.....: Sept. 8, 1988

Investigator

: van Waalwijk van Doorn

Diagnosis and comments

Conclusions: motor urge incontinence, urethral relaxations, hyperreflexia.

Totals

Micturitions:

No. 6

total vol. (ml.)

700

Uninhibited contractions:

No. 43

Max. amplitude $\left(\mathrm{cmH}_{2} \mathrm{O}\right)$ 71

Max. duration (mins.:sec)

01:39

Urethral relaxations:

No. 50

Max. amplitude $\left(\mathrm{cmH}_{2} \mathrm{O}\right)$

118

Max. duration (mins.:sec)

03:05.

No. events

9

Urine loss:

No. 4

Total vol. (ml.)

Urge (No.)

Drinking:

No.

Total vol. (ml.)

800

Table 1. Example of clinical report - patient data and general overview of events. 


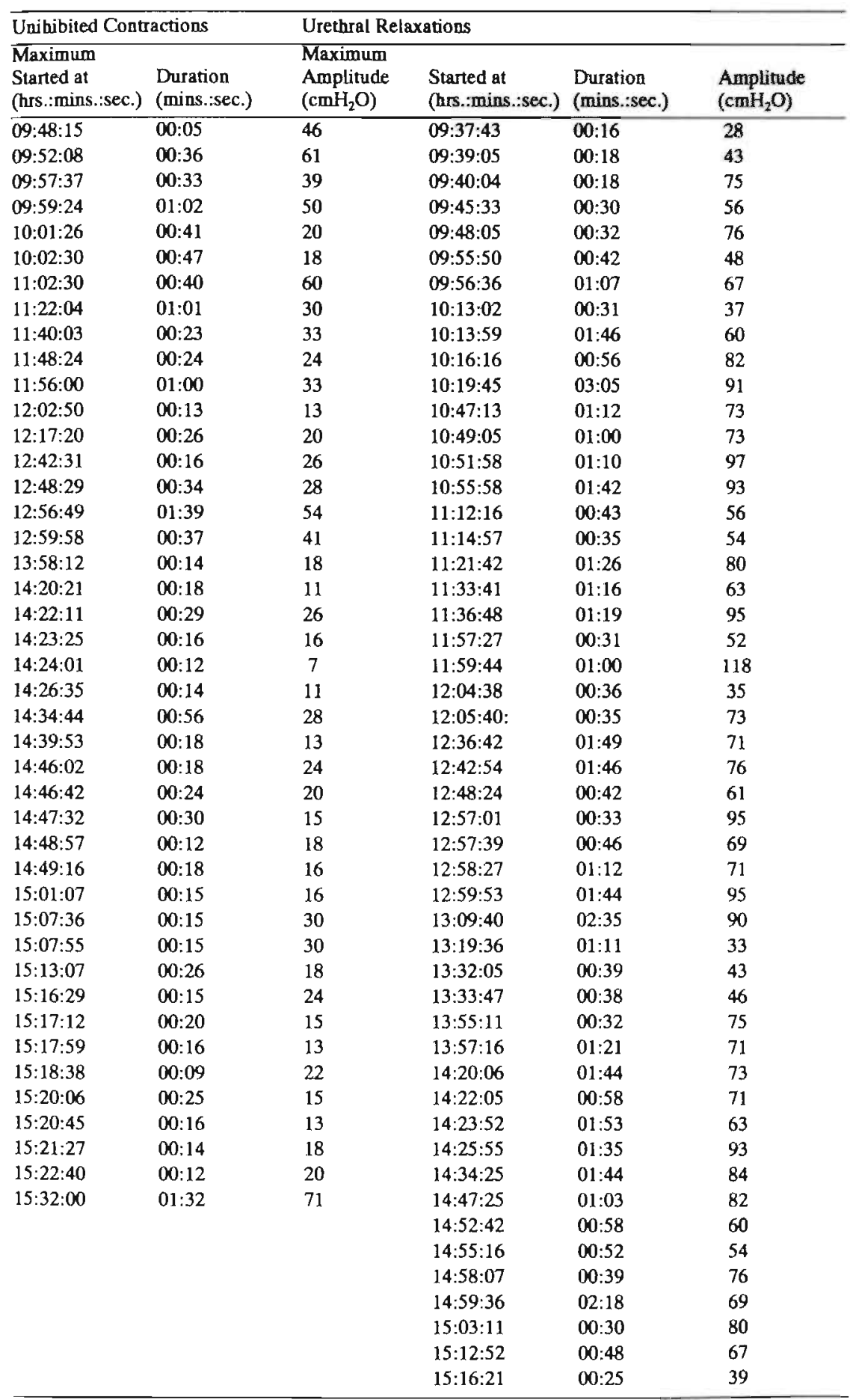

Table 2 List of unihibited detrusor contractions and urethral relaxations. 


\section{Results}

Investigation.

The mean duration of the ambulatory investigation was 5 hours 55 minutes, ranging from 2 hours 30 minutes to 23 hours 42 minutes. An investigation period of 5 to 7 hours seems to be enough to draw diagnostic conclusions in most patients.

Computer-aided analysis of the recorded curves showed that subtraction of bladder and rectal pressures provided a useful trace to interpret detrusor activity both during resting and during periods of physical activity in the studied patients. The same was true for the trace recorded from the urethral sphincter region (fig. 2 and 3, and tables 1 and 2).

After drying the skin thoroughly, brown plaster was used to fix the catheter close to the external meatus. This procedure kept the urethral transducer in position $77 \%$ of the investigation time.

Technical problems (9\%) were mainly limited to the introduction period and they involved mechanical damage of the extension leads from the catheters to the monitor system. Improvement of the leads, combined with more careful handling and a better instruction to the patients, diminished this problem sufficiently. In all cases the investigation could still be evaluated. No microtransducer catheters were damaged. The Gaeltec $6 \mathrm{~F}$ silicon catheters did meet the requirements of ambulatory monitoring satisfactorily; they are robust, easy to fix and flexible.

Of the 100 patients $2(2 \%)$ did not fill in the diary form completely: 1 forgot to mention the amount and time of micturition and drinking, while 1 did not mention the amount and time of drinking only. Analysis still was possible, using the monitored events.

\begin{tabular}{lccc}
\hline preclassification & $\begin{array}{c}\text { mean volume } \\
\text { fluid intake } \\
\text { ml/hour }\end{array}$ & $\begin{array}{c}\text { mean number } \\
\text { micturitions } \\
\text { n/hour }\end{array}$ & $\begin{array}{c}\text { number of } \\
\text { patients } \\
\mathrm{N}\end{array}$ \\
\hline stress inc. & 135 & 0.73 & 14 \\
urge inc. & 125 & 1.22 & 32 \\
mixed inc. & 125 & 0.88 & 31 \\
unclassified inc. & 90 & 0.60 & 9 \\
urgency & 130 & 1.00 & 10 \\
other void. problems & 75 & 0.60 & 4 \\
\hline total group & 120 & 1.02 & 100 \\
\hline
\end{tabular}

Table 3: average values after analysis of micturition and drinking behaviour in the different preclassified groups. 


\begin{tabular}{lcrrrrrr}
\hline preclassification & $\begin{array}{c}\text { mean number } \\
\text { contractions } \\
\text { n/hour }\end{array}$ & $\begin{array}{c}\text { mean amplitude } \\
\text { contractions } \\
\mathrm{cmH}_{2} \mathrm{O}\end{array}$ & $\begin{array}{c}\text { mean duration } \\
\text { contractions } \\
\text { sec }\end{array}$ & $\begin{array}{c}\text { number of } \\
\text { patients } \\
\mathrm{N}\end{array}$ \\
\hline stress inc. & 1.2 & $(0-3.7)$ & 16 & $(0-47)$ & 11 & $(0-18)$ & 14 \\
urge inc. & 2.3 & $(0-8.9)$ & 30 & $(0-57)$ & 30 & $(0-139)$ & 32 \\
mixed inc. & 2.0 & $(0-9.6)$ & 27 & $(0-106)$ & 27 & $(0-197)$ & 31 \\
unclassified inc. & 1.1 & $(0-2.2)$ & 62 & $(0-137)$ & 29 & $(0-69)$ & 9 \\
urgency & $4.0(0.3-14.6)$ & 43 & $(6-128)$ & 32 & $(6-66)$ & 10 \\
other void. problems & 0.3 & $(0-0.5)$ & 14 & $(0-45)$ & 18 & $(0-43)$ & 4 \\
\hline total group & 2.0 & $(0-14.6)$ & 31 & $(0-157)$ & 26 & $(0-197)$ & 100 \\
\hline
\end{tabular}

Table 4: average values after analysis of the pressure curves obtained by ambulatory monitoring in the different preclassified groups.

Analysis.

Drinking and micturition behaviour for the preclassified categories is presented in table 3 . In table 4 a summary is given about abnormal detrusor activity in the investigated patients during extramural ambulatory monitoring. The mean urge component, characterized by stacking the mean number per hour-, the mean amplitude $(\mathrm{cm}$. water) and the mean duration (seconds) of uninhibited detrusor contractions, found during extramural ambulatory monitoring in each preclassified category, is given in figure 4.

In figure 5 results are given of the frequency of each urodynamic diagnosis established from both conventional urodynamic investigation and extramural ambulatory monitoring. In table 5 the occurrence of the symptom incontinence, which is of essential importance to the urodynamic diagnosis, is presented for both methods in each preclassified category. When no incontinence was found in the investigative period, results were distinguished according to the occurrence of detrusor overactivity or underactivity, urethral relaxations and pain.

Table 6 presents the diagnostic results of both methods (conventional urodynamic investigation and extramural ambulatory monitoring) found in each preclassified category. Figure 6 shows the affirmation of the preclassification by each method and by combining both methods. An overall affirmation of the preclassification can be derived for the stress, urge and mixed incontinence, and the urgency groups. The conventional method confirmed preclassified stress incontinence in $36 \%$ of the patients but extramural ambulatory monitoring in only $14 \%$. Combining both methods, preclassified stress incontinence was confirmed in $43 \%$ of the patients. For preclassified urge incontinence these results were $47 \%$, $59 \%$ and $84 \%$, and for preclassified mixed incontinent these 
percentages were $23 \%, 29 \%$ and $55 \%$ using respectively the conventional, extramural ambulatory monitoring method and combined methods, respectively. Conventional urodynamic investigation confirmed the preclassification in $34 \%$ ( 30 of 87 ), extramural ambulatory monitoring in $43 \%$ ( 37 of 87 ) and the combined conventional urodynamic investigation and extramural ambulatory monitoring in $67 \%$ (58 of 87 ) of the patients.

\begin{tabular}{lccccccc}
\hline & results & $\begin{array}{c}\text { incontinence } \\
\text { during } \\
\text { investigation }\end{array}$ & \multicolumn{2}{c}{$\begin{array}{c}\text { norma! } \\
\text { during } \\
\text { investigation }\end{array}$} & $\begin{array}{c}\text { abnormal } \\
\text { without } \\
\text { incontinence }\end{array}$ & sum \\
\hline preclassification & CUI & EAM & CUI & EAM & CUI & EAM & n \\
\hline stress inc. & 57 & 57 & 36 & 7 & 7 & 36 & 14 \\
urge inc. & 50 & 63 & 25 & 0 & 25 & 38 & 32 \\
mixed inc. & 65 & 87 & 26 & 0 & 10 & 13 & 31 \\
other inc. & 11 & 56 & 56 & 11 & 33 & 33 & 9 \\
\hline sum inc. & 52 & 70 & 30 & 2 & 17 & 28 & 86 \\
urgency & 10 & 20 & 50 & 0 & 40 & 80 & 10 \\
other void. problems & 25 & 25 & 25 & 25 & 50 & 50 & 4 \\
\hline sum & 47 & 63 & 32 & 3 & 21 & 34 & 100 \\
\hline
\end{tabular}

Table 5: patients with complaints of incontinence: preclassification versus occurrence of complaints and abnormalities during conventional urodynamics (CUI) and ambulatory urodynamics (EAM).

\begin{tabular}{|c|c|c|c|c|c|c|c|c|c|c|c|}
\hline \multirow{2}{*}{$\begin{array}{c}\text { diagnoses } \\
\text { preciassification }\end{array}$} & \multicolumn{2}{|c|}{$\begin{array}{l}\text { stress } \\
\text { inc. }\end{array}$} & \multicolumn{2}{|c|}{$\begin{array}{l}\text { motor } \\
\text { urge inc. }\end{array}$} & \multicolumn{2}{|c|}{$\begin{array}{l}\text { mixed } \\
\text { inc. }\end{array}$} & \multicolumn{2}{|c|}{$\begin{array}{l}\text { motor } \\
\text { urgency }\end{array}$} & \multicolumn{2}{|c|}{ normal } & \multirow{2}{*}{$\frac{\text { sum }}{\mathrm{n}}$} \\
\hline & $\begin{array}{l}\text { CUI } \\
\%\end{array}$ & $\begin{array}{c}\text { EAM } \\
\%\end{array}$ & $\begin{array}{c}\text { CUI } \\
\%\end{array}$ & $\begin{array}{c}\text { EAMM } \\
\%\end{array}$ & $\begin{array}{c}\text { CUI } \\
\%\end{array}$ & $\begin{array}{c}\text { EAM } \\
\%\end{array}$ & $\begin{array}{l}\text { CUI } \\
\%\end{array}$ & $\begin{array}{c}\text { EAM } \\
\%\end{array}$ & $\begin{array}{c}\text { CUI } \\
\%\end{array}$ & $\begin{array}{c}\text { EAM } \\
\%\end{array}$ & \\
\hline stress inc. & 36 & 14 & ) & 29 & 14 & 7 & 7 & 36 & 43 & 14 & 14 \\
\hline urge inc. & 0 & 3 & 47 & 59 & 0 & 0 & 28 & 38 & 25 & 0 & 32 \\
\hline mixed inc. & 19 & 13 & 26 & 52 & 23 & 29 & 10 & 3 & 23 & 3 & 31 \\
\hline other inc. & 11 & 0 & 0 & 56 & 0 & 0 & 33 & 33 & 56 & 11 & 9 \\
\hline urgency & 0 & 0 & 10 & 20 & 0 & 0 & 40 & 80 & 50 & 0 & 10 \\
\hline other void. & & & & & & & & & & & \\
\hline problems & 25 & 25 & 0 & 0 & 0 & 0 & 50 & 50 & 25 & 25 & 4 \\
\hline sum & 13 & 8 & 24 & 46 & 9 & 10 & 22 & 31 & 32 & 5 & 100 \\
\hline
\end{tabular}

Table 6: preclassification versus diagnosis after conventional urodynamic investigation (CUI) and after ambulatory urodynamics (EAM). 


\section{mean urge component during EAM per symptomatic category}

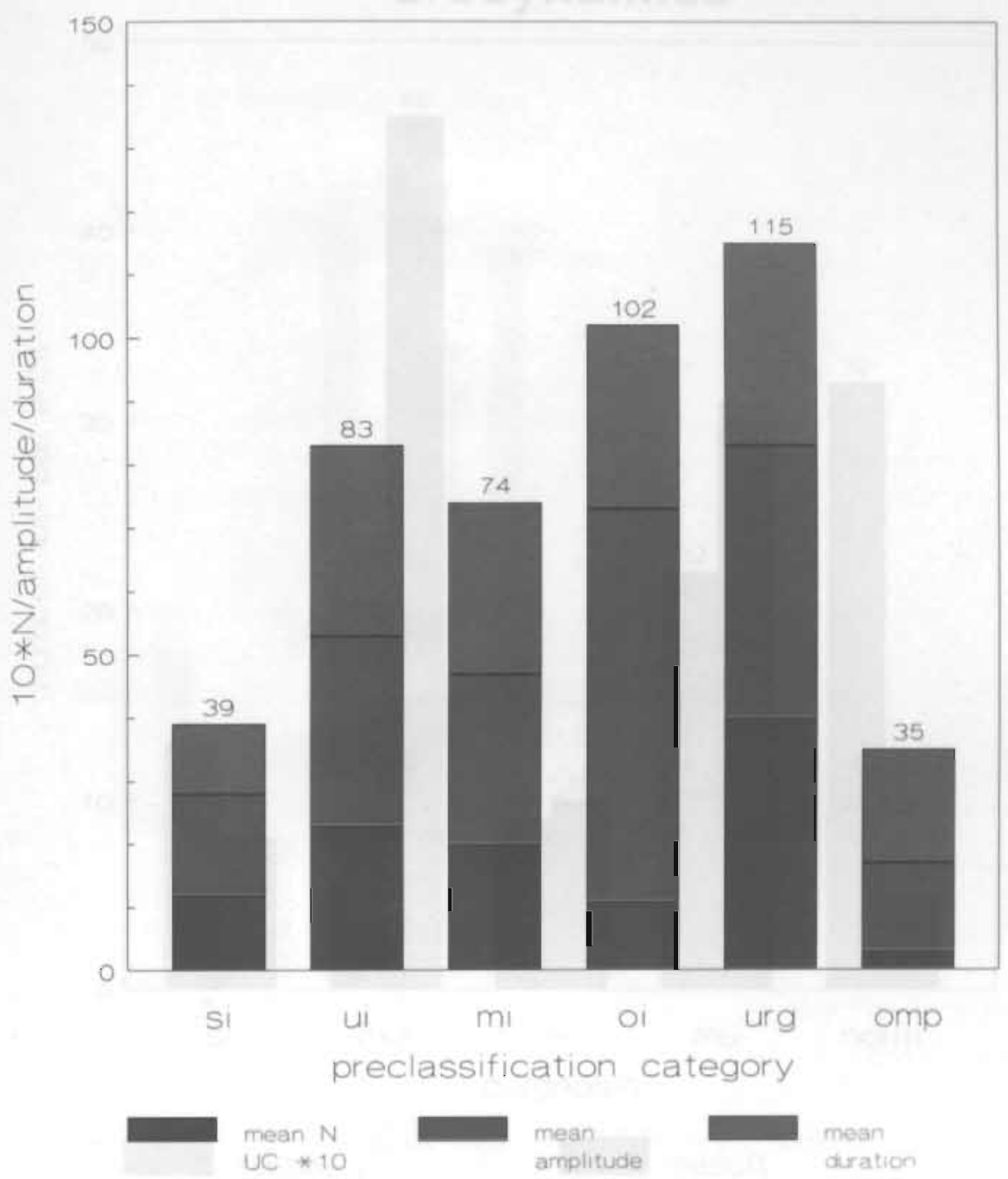

Fig. 4. Mean urge component per preclassified eategory tound during ambulatory urodynamies. Each column represents the sum of number of contractions (NUC). amplitude and duration in different preclassified groups. Differences of sums in stress incontinence (si), urge incontinence (ui), mixed incontinence (mi), other incontinence (oi), urgency (urg) and only micturition problems (omp) groups are clearly shown. 


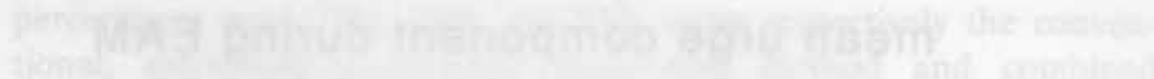

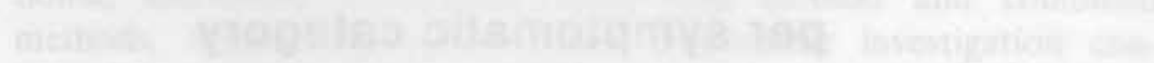
15:-

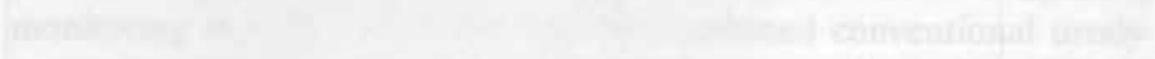

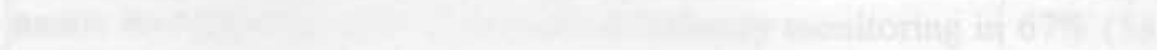

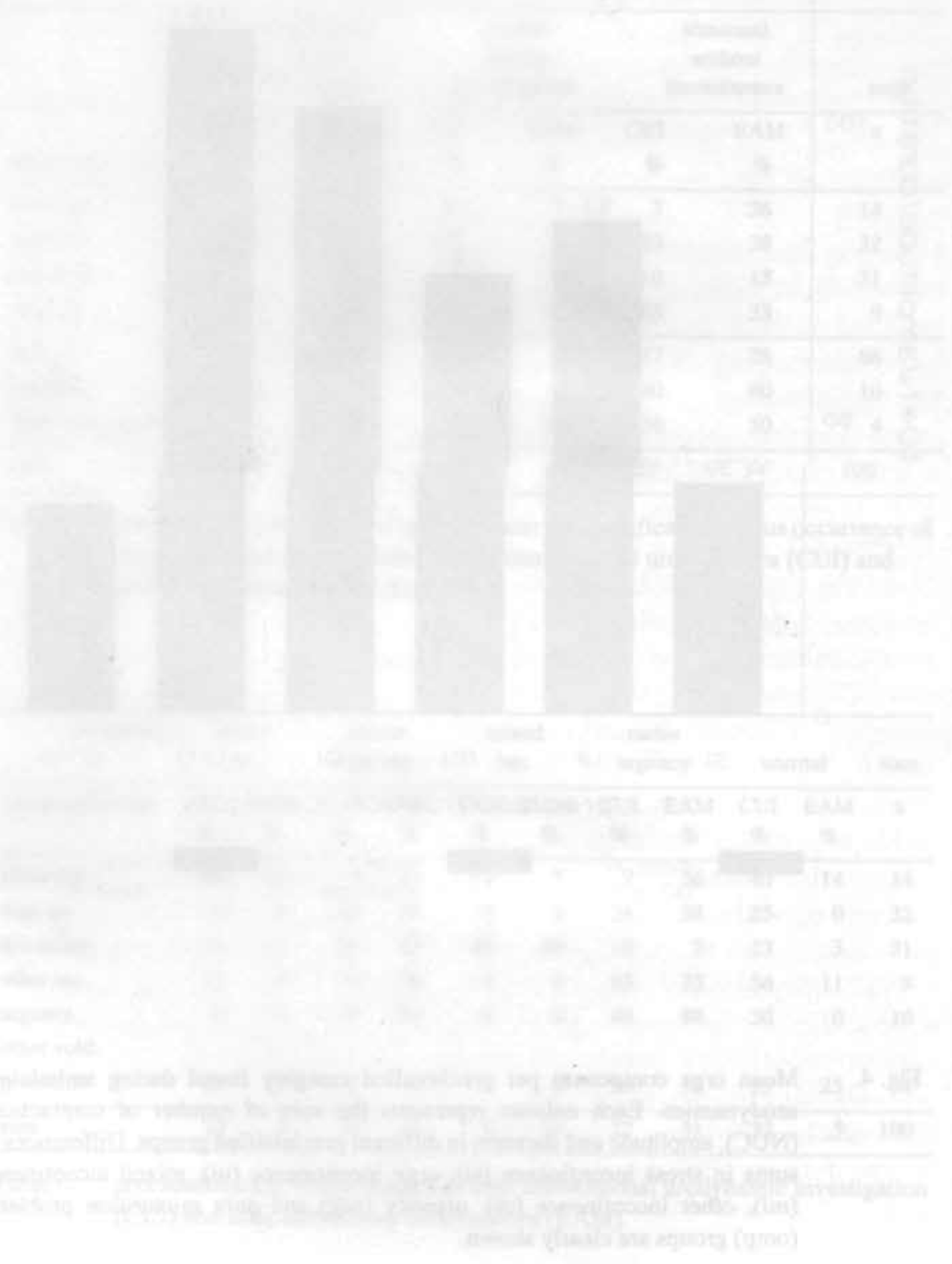




\section{conventional vs. ambulatory urodynamics}

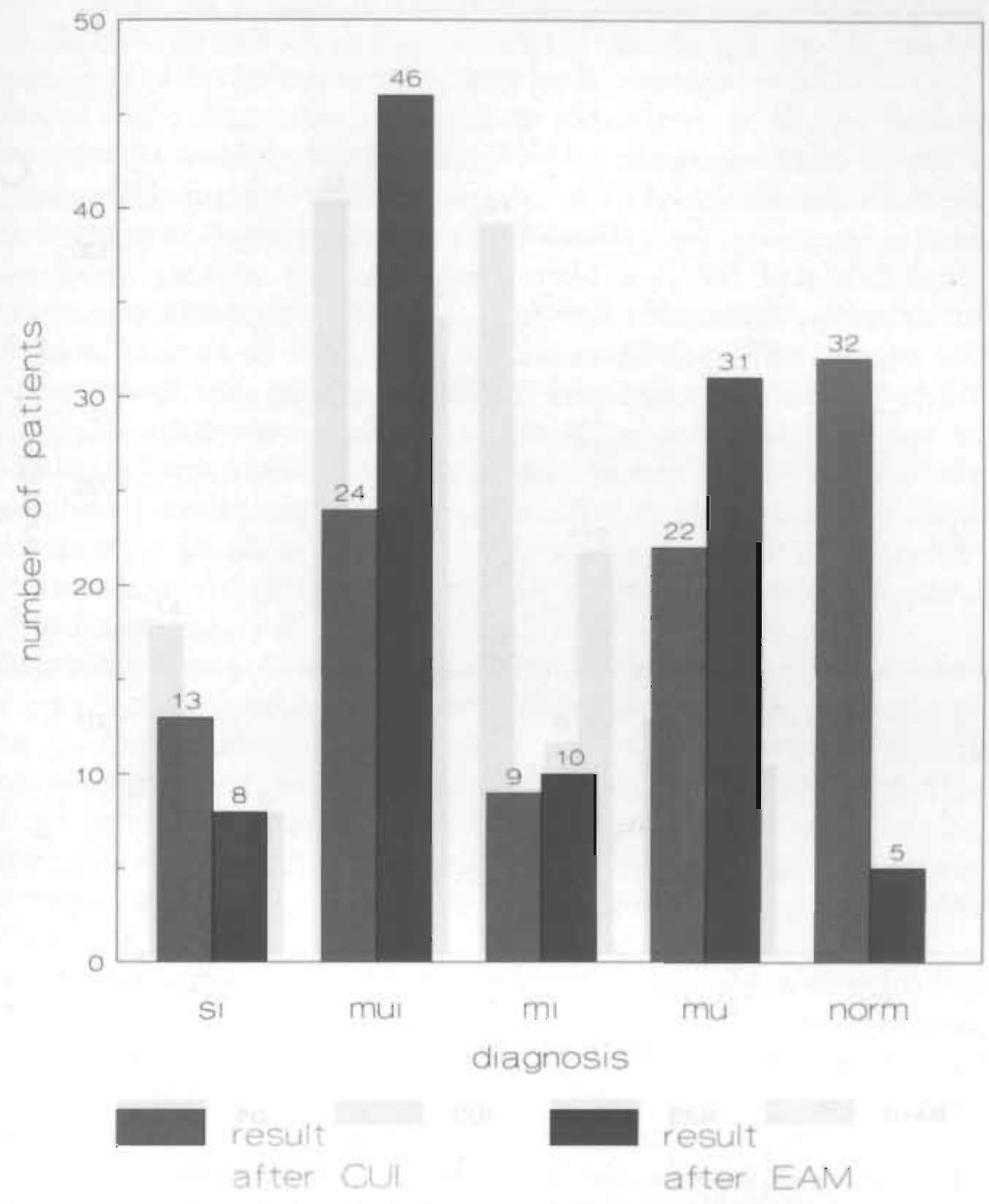

Fig. 5. Diagnostic results after conventiona! urodynamic investigation (CUI) and extramural ambulatory monitoring (EAM). si, stress incontinence. mi, motor urge incontinence. mui, mixed incontinence. mu, motor urge. norm, normal. 
Volaludms .3v lanoilnevnoo

zolmenyboru

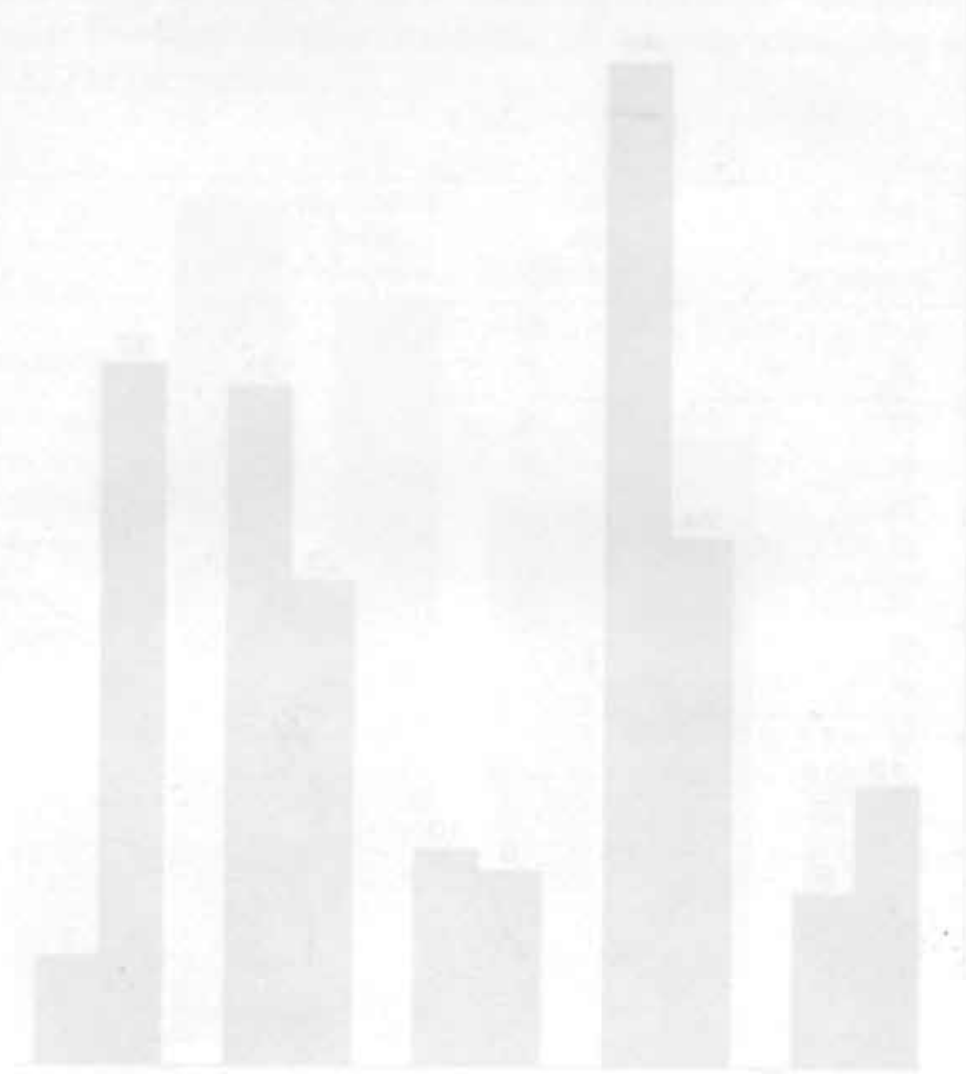

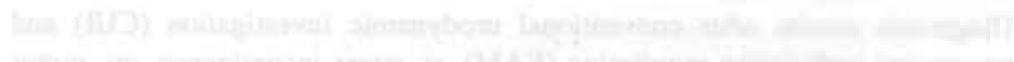




\section{confirmation of the preclas- sification by urodynamics}

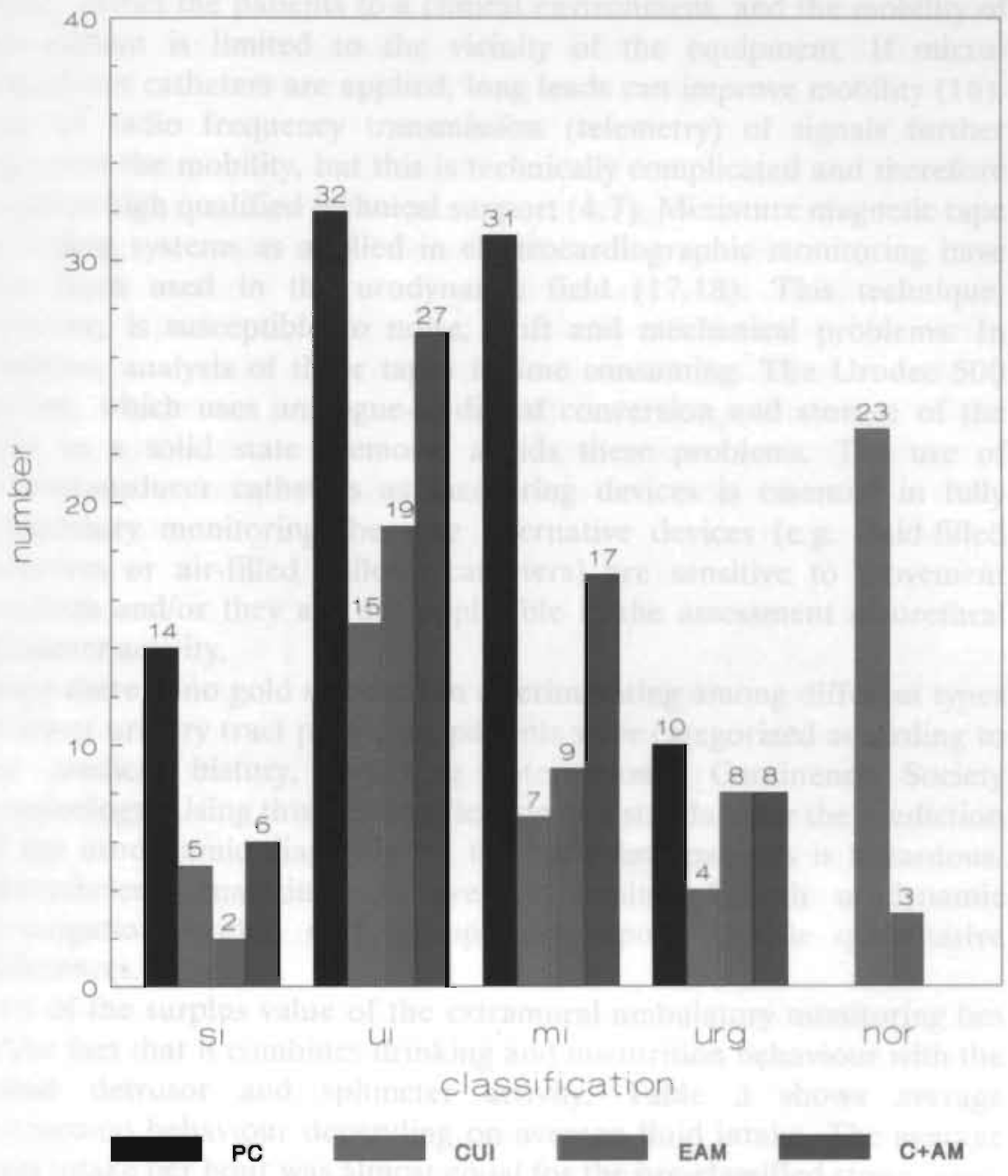

Fig. 6. Affirmation of preclassification (PC) by conventional urodynamic investigation (CUI), extramural ambulatory monitoring (EAM), and combination of both urodynamic investigations ( $\mathrm{S}+\mathrm{AM})$. si, stress incontinence, 14 patients. ui, unge incontinence, 32 patients. mi, mixed incontinence, 31 patients. urg, urgency, 9 patients, nor, normal. 


\section{Discussion}

Various methods have been used to assess detrusor and urethral sphincter behaviour. Conventional urodynamic systems can be used. but these restrict the patients to a clinical environment, and the mobility of the patient is limited to the vicinity of the equipment. If microtransducer catheters are applied, long leads can improve mobility (16). Use of radio frequency transmission (telemetry) of signals further improves the mobility, but this is technically complicated and therefore requires high qualified technical support $(4,7)$. Miniature magnetic tape recording systems as applied in electrocardiographic monitoring have also been used in the urodynamic field $(17,18)$. This technique, however, is susceptible to noise, drift and mechanical problems. In addition, analysis of these tapes is time consuming. The Urodec 500 system, which uses analogue-to-digital conversion and storage of the data in a solid state memory, avoids these problems. The use of microtransducer catheters as measuring devices is essential in fully ambulatory monitoring, because alternative devices (e.g. fluid-filled catheters or air-filled balloon catheters) are sensitive to movement artefacts and/or they are not applicable in the assessment of urethral sphincter activity.

Since there is no gold standard in discriminating among different types of lower urinary tract problems, patients were categorized according to the medical history, following International Continence Society terminology. Using this preclassification as a standard for the prediction of the urodynamic diagnosis for the individual patients is hazardous. Nevertheless, analyzing the average results of both urodynamic investigations within each group may expose specific quantitative differences.

Part of the surplus value of the extramural ambulatory monitoring lies in the fact that it combines drinking and micturition behaviour with the actual detrusor and sphincter activity. Table 3 shows average micturition behaviour depending on average fluid intake. The average fluid intake per hour was almost equal for the pre-classified stress. urge, mixed and urgency groups, while the average number of micturitions per hour differed. Statistical analysis (Wilcoxon rank test with a $5 \%$ level of significance) did not show significant differences in this average fluid intake per hour within the aforementioned preclassified groups. Therefore, conclusions can be drawn about detrusor function and micturition behaviour in these groups. When the micturition frequency per hour was evaluated in stress compared to urge, mixed and urgency incontinence there was a significant difference (level of significance $10 \%$ ) in micturition behaviour between the stress group and each of the 
other groups. Patients with an urge component in the complaints are expected to void more often than patients without this urge component. In the groups other incontinence and other micturition problem groups the statistical analysis showed a significant difference in fluid intake in relation to the other groups. For this reason no conclusions are drawn on the differences in the micturition behaviour of these patient groups (tables 3 and 4 ).

With respect to detrusor function, 3 aspects were considered in the analysis of the motor urge component shown by extramural ambulatory monitoring: 1) the mean number of uninhibited detrusor contractions per hour, 2) the mean maximum amplitude and 3) mean duration of these contractions (table 4). Statistical analysis proves that the mean number of uninhibited detrusor contractions per hour is significantly higher (level of significance 5\%) in the urge and urgency groups compared to the stress group. In the stress and mixed groups the difference is not significant, although the mean number of uninhibited detrusor contractions in the patients complaining of mixed incontinence is higher. The mean amplitude of the uninhibited detrusor contractions is significantly higher (level of significance is 5\%) in the urge and urgency groups than in the stress group. With a significance level of $10 \%$ the mean amplitude in the mixed group is significantly higher compared to the stress group. Finally analysing the mean duration of uninhibited detrusor contractions, the Wilcoxon rank test shows that for the urge, mixed and urgency group the values are significantly higher in comparison to the stress group (level of significance $5 \%$ ).

Figure 4 graphically visualizes the severity of the motor urge component in the different pre-classified groups. It can be seen that patients with complaints of stress incontinence also have uninhibited detrusor contractions. The appearence of these uninhibited contractions in patients in whom one does not expect this finding might be due to misinterpretation of the symptoms or to a triggering effect of the measuring catheter, or it might be physiological. With the urodynamic techniques used presently, it is not possible to distinguish between possibilities 2 and 3. More knowledge about the neuro-anatomy (sensibility) of the urethral and bladder tissue is necessary and a thorough urodynamic investigation of a group of healthy volunteers is advisable to elucidate these aspects. However, it is clear that in the group preclassified as stress incontinent and in the group preclassified as having other voiding problems, the urge component combining the 3 parameters described before is significantly lower than in the clinically suspected groups. The stacked data given in figure 4 show this urge component graphically, and show that the columns of the urge, mixed 
and urgency groups are higher than those of the stress and other voiding problems groups. There is a clear tendency for the combined parameters to provide a measure for diagnosing urge incontinence or urgency.

In conclusion it can be stated that the presented data obtained from the extramural ambulatory monitoring provide objective parameters to distinguish between stress incontinence on the one hand and urge incontinence especially motor urge on the other. Figure 5 shows the urodynamic diagnosis after respectively conventional urodynamic investigation and extramural ambulatory monitoring. Extramural ambulatory monitoring revealed motor urge incontinence alsmost twice as frequently as did conventional urodynamic investigation. Monitoring over a longer period increases the chance that uninhibited detrusor contractions occur. When the diagnostic capability and results are compared from the conventional and the extramural ambulatory monitoring methods, 2 aspects are elucidated (table 5):

1) in $52 \%$ of the patients with incontinence, this complaint occurred during the conventional investigation, compared to $70 \%$ during extramural ambulatory monitoring and

2) in $32 \%$ of the conventional investigations no abnormalities could be demonstrated, compared to only $3 \%$ during extramural ambulatory monitoring.

Investigations are considered normal when no uninhibited detrusor contractions are found at all. Again, we stipulate that it is not known to date whether uninhibited detrusor activity can also be a physiological phenomenon. Therefore, it might be possible that the patient can only be distinguished from the healthy subject by the severity of the urge component defined previously. Figure 6 summarizes the data from table 6 graphically. The correlation of the preclassified patient categories with the outcome of the conventional urodynamic investigation, extramural ambulatory monitoring and the urodynamic diagnosis obtained by combining both investigations is visualized.

Finally, it can be stated that extramural ambulatory monitoring does, as we expected, reveal abnormalities more frequently; the symptom of incontinence occurs more frequently in extramural ambulatory monitoring than in short conventional testing and the over-all correlation with the preclassification is higher than with the conventional method, particularly when an urge component is involved. If the methods are combined the over-all correlation with the preclassification is the highest $(67 \%)$. However, whether extramural ambulatory monitoring is used to complement the conventional test, or is used as a primary 
functional investigation. it is a practical and useful tool to improve the diagnostic abilities of the urologist.

Mr. Vanspauwen and mrs. Geurts-Strauven assisted with this study. Accepted for publication November 30, 1990.

Supported by the ministry of Economic Affairs, department of Industry and BioInterface. 


\section{References}

1. van Venrooij, G.E.P.M., Kamphuis, E.T. and Wolfhagen, M.J.H.M.: Diuresis Cystometry in patients with frequency, urgency and/or urge incontinence complaints.

Neurourol. Urodynam., 6: 29, 1987.

2. Gleason, D.M., Lattimer, J.K and Bauxbaum, C.: Bladder pressure telemetry. J. Urol., 94: 252, 1965.

3. Miyagawa, I., Nakamura, I., Ueda, M., Nishida, H., Nakashita, E. and Goto, H.: Telemetric Cystometry.

Urol. int., 41: 263, 1986.

4. Thüroff, J.W., Jonas, U., Frohneberg, D., Petri, E. and Hohenfellner, R.: Telemetric Urodynamic Investigations in normal Males. Urol. int., 35: 427, 1980.

5. Vereecken, R.L., Puers, B. and Das, J.: Continuous Telemetric Monitoring of Bladder Function.

Urol. Res., 11: 15, 1983.

6. James, E.D.: Ambulatory monitoring in urodynamics. In: Urodynamics: Principles, Practice and Applications. Edited by A.R. Mundy, T.P. Stephenson and A.J. Wein. New York: Churchill Livingstone, pp. 120-126, 1984.

7. Delaere, K.P.J., Kimmich, H.P., van Waalwijk van Doorn, E.S.C., Valcke, A.A.P. and Debruyne, F.M.J.: Basic principles of telemetric urodynamic monitoring.

In: Biotelemetry VIII, Edited by H.P. Kimmich and H.J. Klewe.

Braunschweig: Doering-Druck, pp. 313-318, 1986.

8. Griffiths, C.J., Assi, M.S., Styles, R.A., Ramsden, P.D. and Neal, D.E.: Ambulatory Monitoring of bladder and detrusor pressure during natural filling. J. Urol., 142: 780, 1989.

9. van Waalwijk van Doorn, E.S.C., Bouwmeister, P.P., van Oostendorp, M.E. and Debruyne, F.M.J.: 24h-ambulant monitoring, a reliable method to test on detrusor instability. Proceedings of the European Association of Urology 7th Congress 1986. 
10. van Waalwijk van Doorn, E.S.C., Zwiers, W., Wetzels, L.L.A.N. and Debruyne, F.M.J.: A comparative study between standard and ambulant urodynamics.

Neurourol. Urodynam., 6: 159, 1987.

11. Kulseng-Hanssen, S: Ambulatory urethro-cysto-rectometry in patients with urethral pressure variations.

Neurourol. Urodynam., 6: 156, 1987.

12. Webb, R.J., Griffiths, C.J., Ramsden, P.D. and Neal, D.E.: Measurement of voiding pressures on Ambulatory Monitoring: comparison with Conventional Cystometry.

Brit. J. Urol., 65: 152, 1990.

13. van Waalwijk van Doorn, E.S.C., Bouwmeister, P.P.M., van Oostendorp, M.E., Kimmich, H.P. and Debruyne, F.M.J.:

A retrospective study of the clinical value of telemetric urodynamics compared with standard urodynamics in patients with urinary incontinence. In: Biotelemetry IX. Edited by H.P. Kimmich and M.R. Neuman. Braunschweig: DoeringDruck, pp. 159-160, 1987.

14. International Continence Society Standardisation Committee: The Standardisation of Terminology of lower urinary tract function. Annual International Continence Society meeting, 1987.

15. International Continence Society Working Party on Urodynamic Equipment: technical aspects.

J. Med. Eng. Tech., 11: 57, 1987.

16. James E.D.: The behaviour of the bladder during physical activity. Br. J. Urol., 50: 387, 1978.

17. Murray, A. and Sanders, G.L.: Improving the reliability and accuracy of ambulatory blood pressure recordings. In: ISAM 1979. Proceedings of the 3rd International Symposium on Ambulatory Monitoring. Edited by F.D. Scott, E.B. Raftery and L. Goulding. London: Academic Press, pp. 456-461, 1980 .

18. Bhatia, N.N., Bradley, W.E., Haldeman, S. and Johnson, B.K.: Continuous monitoring of bladder and urethral pressures: new technique. Urology, 18: 207, 1981. 


\section{Chapter VII}

\section{Introduction}

In the course of these studies it became clear that knowledge of urodynamically recorded activity of bladder and urethral sphincter function in normals was missing. Therefore we decided to setup a study with the new ambulatory system in healthy volunteers. This would be the tool to distinguish better between abnormal and normal function of the lower urinary tract.

This study was published in the Journal of Urology, 147: 1319, 1992. 


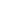




\title{
Conventional and extramural ambulatory urodynamic testing of the lower urinary tract in female volunteers
}

\author{
E.S.C. van Waalwijk van Doorn, A. Remmers, R.A. Janknegt \\ From the Department of Urology, University Hospital Maastricht, \\ Maastricht, The Netherlands.
}

\begin{abstract}
Referential quantitative urodynamic parameters obtained in healthy subjects can rarely be found in the literature. More differentiated and reliable urodynamic diagnoses are essential, since our patient groups and the available therapies are increasingly diversifying. Therefore, a group of 50 healthy female volunteers was investigated urodynamically. After a standardised questionnaire 14 volunteers were excluded: 12 because of lower urinary tract symptoms and 2 because of failure of equipment. Conventional and ambulatory techniques were applied.

Results of the conventional method were compared with the literature: in $18 \%$ of the subjects detrusor instability was noted. During ambulatory monitoring this incidence was 69\%. The mean Detrusor Activity Index (DAI) is introduced. This index contains the number of detrusor contractions in the absence of voiding per hour, the mean amplitude of these contractions and the mean duration. In volunteers and patients with stress incontinence the mean Detrusor Activity Index was significantly lower compared to patients with complaints of urge and/or urge incontinence. As expected, transmission ratios were lower in the distal urethra. At filling volumes of approximately 100 (first sensation) and 300 (strong desire) $\mathrm{ml}$. a decrease in the transmission ratio was noted.
\end{abstract}

Keywords urinary incontinence, urodynamics, urethra, urinary tract. 


\section{Introduction}

Diagnostic testing of lower urinary tract function by performing urodynamic investigations currently is widely accepted. The diagnostic abilities of urodynamics improved after the introduction of ambulatory urodynamic monitoring techniques (1-8). Extended investigation time, physiologic bladder filling, testing under normal daily circumstances and under specific complaint correlated conditions are only some of the advantages of applying ambulatory urodynamic techniques. However, conventional and/or ambulatory test results in healthy persons are rarely reported in the literature. Most previously reported results describing urodynamic data obtained from healthy subjects are limited to free uroflowmetry and urethral pressure measurements (9-13). Jensen et al described the urodynamic findings in elderly male volunteers without prostatic complaints (14). S $\varphi$ renson et al investigated the reproducibility of conventional urodynamics in healthy fertile and postmenopausal women, conventional urodynamics during the menstrual cycle in healthy fertile women and the influence of a urethral catheter and patient age on flow rates (15-18). Objective parameters of conventional and ambulatory investigations, inside and outside the clinic, performed in a group of healthy volunteers are not yet available.

Objective parameters obtained from urodynamic tests, on which functional diagnoses are based should be related to normal standardised reference valucs. The lack of this referral information can cause doubtful urodynamic diagnostic results, especially in patients who have less severe complaints. The admission of these patients into our outpatient clinic has increased during the last decade because urinary incontinence has become a more openly accepted physical and social problem. To enlarge our knowledge of quantitative urodynamic parameters in healthy women we invited volunteers to undergo urodynamic evaluation of the lower urinary tract function. They were asked to undergo a conventional and an ambulatory investigation to provide us an opportunity to study normal detrusor and sphincter function under circumstances inside and outside the clinic. The possible occurrence of uninhibited detrusor activity during the conventional and ambulatory investigations is of special interest. The results can be used to judge detrusor overactivity in different patient groups. In the future, a quantitative description of detrusor overactivity will help to determine the risks of recurrent incontinence after anatomical correction by surgery. In case of mixed incontinence these parameters will be of help to interpret the DAI and to choose a therapeutic strategy. 


\section{Materials and methods}

During a 4 -month period 50 female volunteers 19 to 65 years old (mean age 30.4 years) entered the study. The volunteers were asked to complete a standard questionnaire on lower urinary tract history to judge possible abnormalities. Then, the volunteers underwent supine urethral pressure profilometry followed by an ambulatory urodynamic evaluation. Since detrusor activity in the absence of voiding occurred in the investigated volunteers it was decided to extend the protocol with a conventional urodynamic investigation. For this reason the last 17 of these 50 volunteers underwent a complete conventional urodynamic investigation followed by ambulatory monitoring. All subjects participated in the protocol but those with lower urinary tract symptoms were excluded from the analysis.

Urethra pressure profilometry (UPP). A urethral pressure profile with the subject in the supine position was obtained (withdrawal speed 0.5 $\mathrm{mm} / \mathrm{s}$, micro transducer at a 12 o'clock position). Maximum urethral closure pressure (MUCP), functional urethral length (FUL) and anatomical urethral length (AUL) were calculated.

Conventional urodynamic investigation (CUI). The conventional urodynamic investigation was performed according to International Continence Society standards $(19,20)$. The study included initial uroflowmetry, urethral pressure profilometry, filling cystometry (35 $\mathrm{ml} / \mathrm{sec}$ with the subject in sitting position) and a pressure-flow study. The filling phase was stopped when the volunteer indicated a strong desire to void. To investigate urethral sphincter function an $8 \mathrm{~F} \mathrm{Gaeltec}$ catheter with three urethral transducers $7 \mathrm{~mm}$ apart and 1 tip was applied during the storage and evacuation phases. The catheter was fixed with the urethral transducers approximately at a 12 o'clock position and the medial transducer was fixed the maximum urethral closure pressure region.

Extramural ambulatory monitoring method (EAM). Previous to the ambulatory investigation, the volunteers received an extensive information sheet describing the test and the necessary preparations. Especially with regard to bowel movement, the volunteers were advised to empty the bowel before the investigation.

The same type of catheter-mounted microtransducers that were used with conventional urodynamic investigations were applied but this time with only one urethral transducer. The catheters were connected to a miniaturized microprocessor controlled Holter monitor (BioInterface). The pressure transducers were set at zero automatically after inserting a battery. This was done just before the catheters were introduced in the 


\section{A Pressures}

$P$ bladder

21

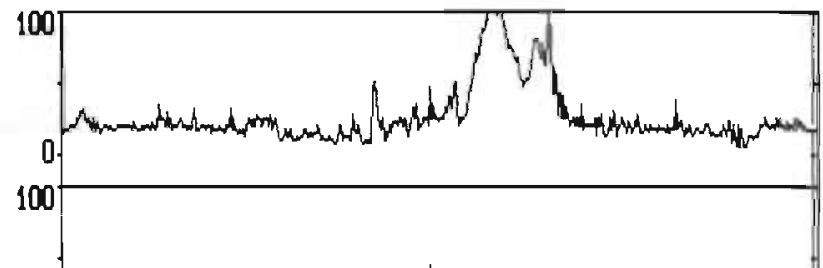

$P$ abdominal 26

P detrusor -5

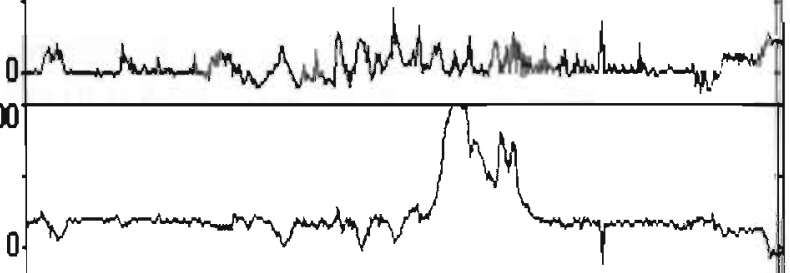

7:30 min $14: 34: 27$

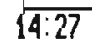

14:30

14:34

Micturition..... [H]]:

Uninhibited Contr

Relaxation / loss[inij:

Liquid intake..... [m] :

Urge / Event

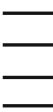

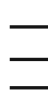




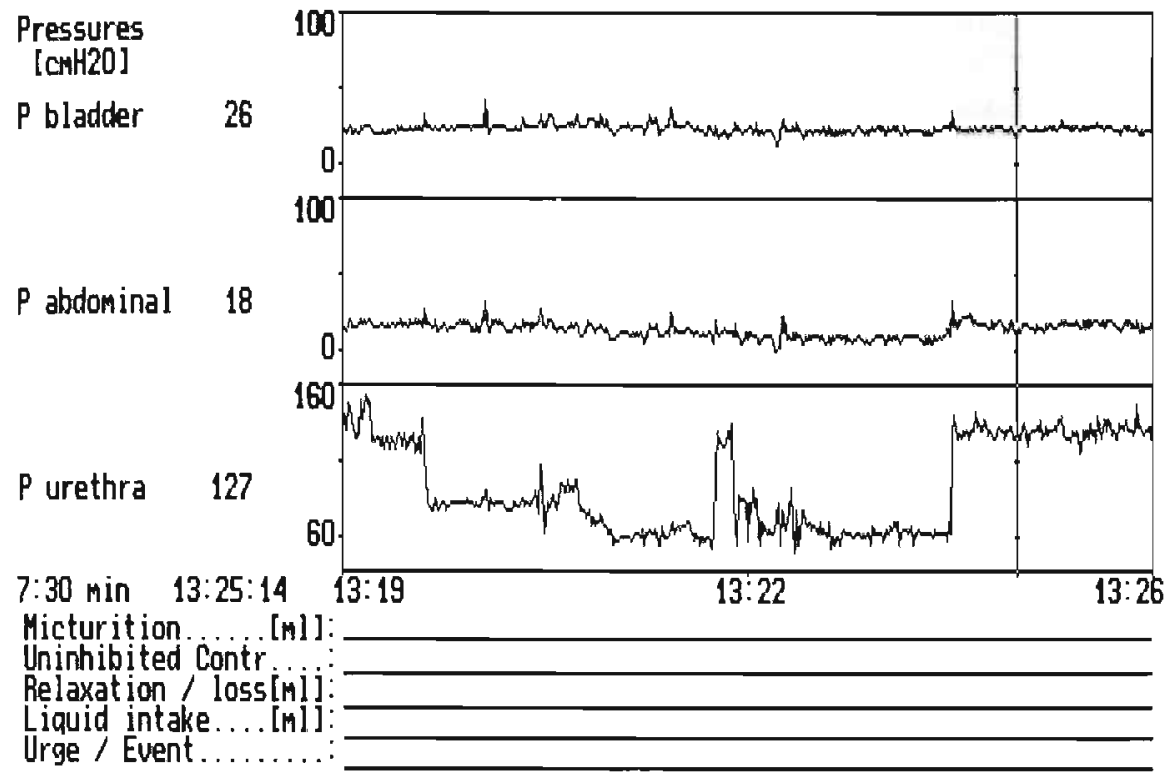

Figure 2. Extramural ambulatory monitoring curves show changes in the urethral pressure curve due to movement of the transducer. Contr, contraction.

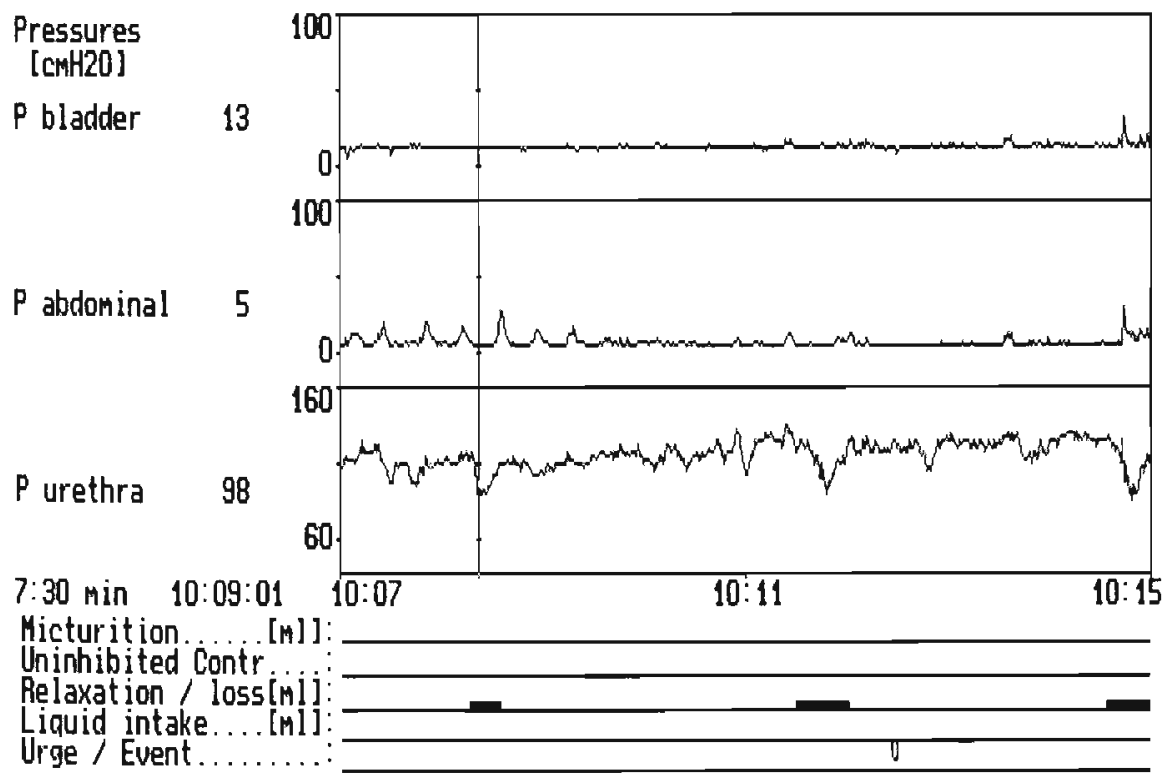

Figure 4. Extramural ambulatory monitoring curves show temporary urethral pressure decreases. $u$, urge as indicated by patient in diary. Decreases are interpreted as urethra relaxations. Contr, contraction. 


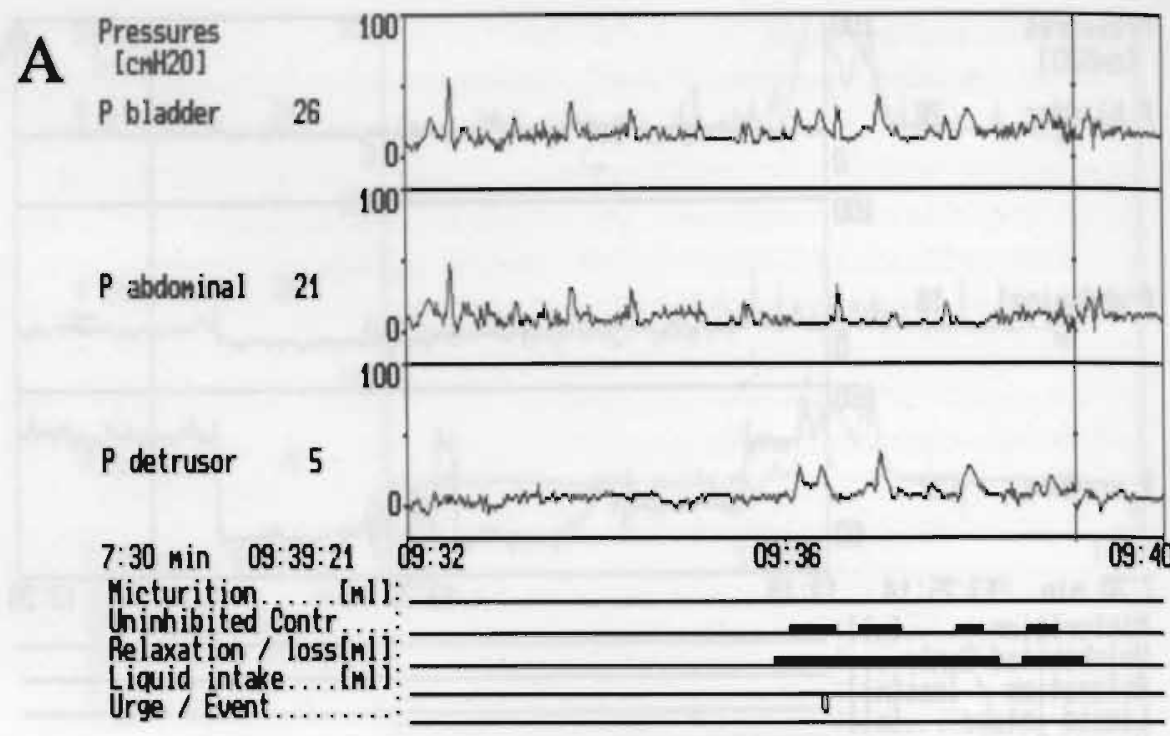

\section{B Pressures \\ [cri20]}

$P$ bladder

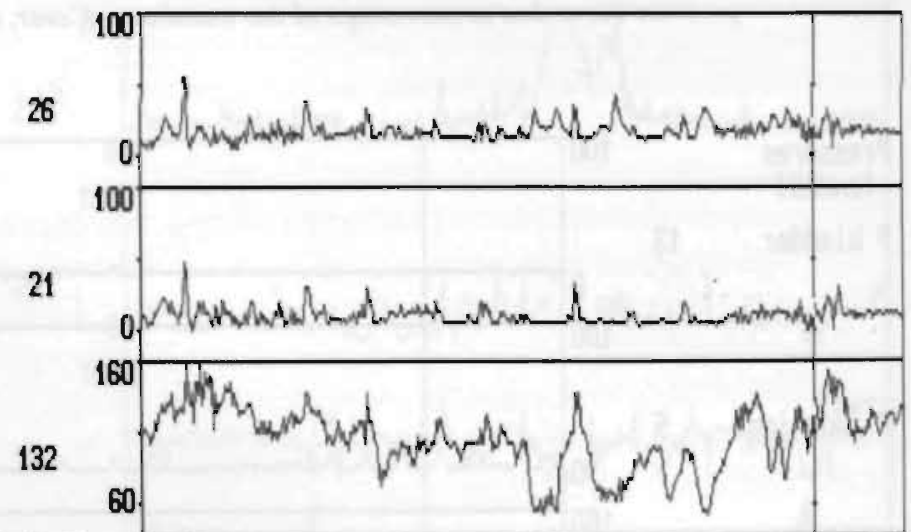

7:30 nin $09: 39: 21$

$0 \overline{9: 32}$

Micturition. [nl]:

Uninhibited Contr Relaxation / loss[n]

Liquid intake.... [nI]

Urge / Event ...........

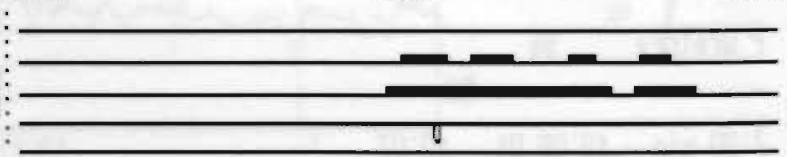

Figure 3. Extramural ambulatory monitoring curves demonstrate interpretation of detrusor and urethral activity in absence of voiding. $u$, indicates urge sensation noted in the diary. A, curve 3 shows subtracted detrusor pressure. B, curve 3 shows urethral activity. Contr, contraction. 


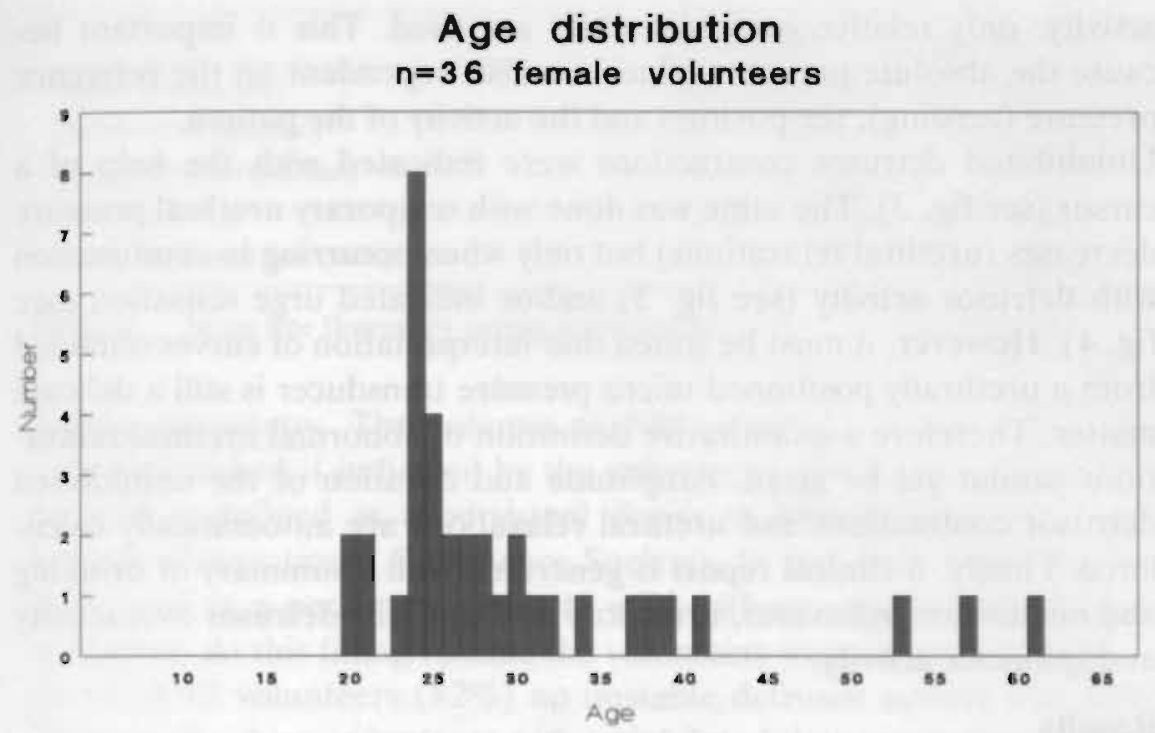

Figure 5. The age distribution of 36 volunteers.

patient. The starting time and end of the procedure were registered. Volunteers were asked to keep a diary of important events, such as micturition (time and volume), drinking (time and volume), urge sensations and remarks. The volunteer was asked to push the event button on the monitor when entering the toilet for voiding. This is of considerable importance in recognizing detrusor overactivity just before voiding. After careful instruction, the volunteers left the hospital and resumed their normal daily activities. They were strongly advised to drink plenty of fluid so as to have 2 or more micturitions during the investigation period. At the end of the investigation period the volunteers returned to the hospital, and the catheters and monitor were removed.

To obtain the measured data the monitor was connected to a personal computer by means of an interface unit. With the help of a software package, the monitor memory was read, after which the diary data were entered via the keyboard. Then the curves were analysed, that is diary data and events were correlated with the measured curves (see fig. 1). During the analysis of ambulatorily monitored pressure curves one must be aware of the possible occurrence of pressure changes due to movement (see fig. 1 and 2). With respect to the analysis of detrusor 
activity, only relative pressure values are used. This is important because the absolute pressure values are also dependent on the reference pressure (zeroing), the position and the activity of the patient.

Uninhibited detrusor contractions were indicated with the help of a cursor (see fig. 3). The same was done with temporary urethral pressure decreases (urethral relaxations) but only when occurring in combination with detrusor activity (see fig. 3) and/or indicated urge sensation (see fig. 4). However, it must be stated that interpretation of curves obtained from a urethrally positioned micro pressure transducer is still a delicate matter. Therefore a quantitative definition of abnormal urethral relaxations cannot yet be given. Amplitude and duration of the uninhibited detrusor contractions and urethral relaxations are automatically calculated. Finally, a clinical report is generated with a summary of drinking and micturition behaviour, urine loss and analyzed detrusor overactivity and sphincter activity.

\section{Results}

Questionnaire. Of the 50 volunteers entering the study 14 were excluded: 12 based on an abnormal urological medical history (incontinence in 6 and urgency/frequency in 6) and 2 because of a defect in 1 of the extension leads, which occurred during the ambulatory test. The recorded pressure curves (EAM) were too short to analyze.

Altogether 36 volunteers remained for analysis (20 to 61 years old, mean age 30.0 years). Figure 5 shows the age distribution of these remaining 36 volunteers. A total of 19 volunteers underwent urethral pressure profilometry and extramural ambulatory monitoring, and 17 underwent a complete conventional urodynamic investigation and extramural ambulatory monitoring.

Urethral pressure profilometry. The results of urethral profilometry are given in table 1.

\begin{tabular}{lccc}
\hline & \multicolumn{2}{c}{ mean (range) } & standard deviation \\
\hline anatomical length $(\mathrm{mm})$. & 34.6 & $(25-53)$ & 6.8 \\
functional length $(\mathrm{mm})$. & 33.0 & $(22-50)$ & 6.6 \\
maximum urethral closure pressure $\left(\mathrm{CmH}_{2} \mathrm{O}\right)$ & 80.6 & $(42-157)$ & 23.0 \\
\hline
\end{tabular}

Table 1. Urethral pressure profilometry in 36 patients.

Free flowmetry. Of 17 volunteers 7 voided more than $100 \mathrm{ml}$. just before conventional urodynamic investigation. Of these 7 subjects 6 (table 2) confirmed the micturition to be the same as at home, 1 of these 6 reported that she always strained with voiding. 


\begin{tabular}{lrrr}
\hline & \multicolumn{2}{c}{ mean (range) } & standard deviation \\
\hline voided volume $(\mathrm{ml})$. & 285 & $(106-538)$ & 171.7 \\
peak flowrate $(\mathrm{mL} . / \mathrm{sec}$ ) & 26 & $(18-31)$ & 5.0 \\
average flowrate $(\mathrm{ml} / \mathrm{sec}$ ) & 15 & $(8-20)$ & 4.8 \\
flowtime (secs.) & 21 & $(7-49)$ & 15.8 \\
time to maximum flow (secs.) & 4 & $(2-9)$ & 2.6 \\
\hline
\end{tabular}

Table 2. Mean free flowmetry values in 6 patients.

Filling cystometry. The volumes at first sensation or first desire were only established if indicated by the volunteer (table 3 ). A strong desire to void is defined as a persistent desire to void without the fear of leakage (Intenational Continence Society). In our study this parameter is defined as a persistent desire to void without any discomfort to the volunteer. At this filling volume the volunteers were allowed to void.

In 14 of 17 volunteers (82\%) no unstable detrusor activity was noted. Data on the three volunteers with uninhibited detrusor activity are presented in table 4 . The mean amplitude of the uninhibited contractions was $8 \mathrm{cmH}_{2} \mathrm{O}$ (range: 3 to 13 ) and the mean duration was $11.3 \mathrm{sec}$ (range: 6 to 24 ).

\begin{tabular}{lcccc}
\hline & \multicolumn{2}{c}{ mean (range) } & standard deviation & n \\
\hline volume first sensation (ml.) & 104 & $(19-205)$ & 56.6 & 11 \\
volume first desire (ml.) & 172 & $(101-320)$ & 66.4 & 12 \\
volume normal desire (ml.) & 263 & $(127-450)$ & 93.1 & 15 \\
volume strong desire $(\mathrm{ml})$. & 294 & $(161-500)$ & 96.1 & 17 \\
compliance $\left(\mathrm{ml} . / \mathrm{cmH}_{2} \mathrm{O}\right)$ & 45.8 & $(11-150)$ & 40.2 & 17 \\
\hline
\end{tabular}

Table 3. Filling cystometry in 17 female volunteers.

\begin{tabular}{|c|c|c|c|c|c|}
\hline subject No. & fill. vol. (ml.) & $\begin{array}{c}\text { duration } \\
\text { (secs.) }\end{array}$ & $\begin{array}{l}\text { amplitude } \\
\left(\mathrm{cmH}_{2} \mathrm{O}\right)\end{array}$ & $\begin{array}{l}\text { Compliance } \\
\left(\mathrm{ml} / / \mathrm{cmH}_{2} \mathrm{O}\right)\end{array}$ & $\begin{array}{l}\text { strong desire } \\
\text { (ml.) }\end{array}$ \\
\hline \multirow[t]{4}{*}{1} & 100 & 9 & 3 & 18 & 347 \\
\hline & 135 & 12 & 5 & & \\
\hline & 173 & 8 & 5 & & \\
\hline & 204 & 10 & 6 & & \\
\hline 2 & 199 & 14 & 12 & 33 & 305 \\
\hline \multirow[t]{5}{*}{3} & 119 & 24 & 10 & 25 & 276 \\
\hline & 200 & 11 & 6 & & \\
\hline & 222 & 6 & 9 & & \\
\hline & 252 & 11 & 13 & & \\
\hline & 260 & 8 & 11 & & \\
\hline
\end{tabular}

Table 4. Cystometric characteristics of 3 volunteers with detrusor instability. 
Transmission ratios. These ratios were calculated as a function of urethral position and as a function of bladder volume. The volunteers were asked to cough every $50 \mathrm{ml}$. of bladder filling. In figure 6 the mean transmission ratio value as a function of urethral position with the standard deviation is plotted. All calculated transmission ratios obtained during filling cystometry are included independently of bladder volume. In figure 7 the mean transmission ratios were calculated in each subsequent range of $50 \mathrm{ml}$. of filling for the proximal, medial and distal positioned urethral transducers, respectively.

Pressure/flow study. In table 5 the results after the pressure/flow study are shown. During conventional urodynamic investigation 6 of 17 volunteers indicated not to void as usual. Therefore, the mean values describing voiding were calculated from 11 volunteers only.

Ambulatory monitoring (36 subjects). The results after extramural ambulatory monitoring are shown in table 6 . From the standardised questionnaire also the normal daily drinking and voiding behaviour is expressed by mean drinking volume per hour and mean number of micturitions per hour. It can be seen that the increased fluid intake during extramural ambulatory monitoring $(182$, normal $70 \mathrm{ml}$.) causes a proportional increase in voiding frequency $(0.7$, normal 0.3 per hour). In 25 of 36 subjects $(69 \%)$ detrusor instability (that is detrusor activity in absence of voiding) was found (table 7). The urethral transducer stayed in position during $75 \%$ of the investigation time. Micturitions were always preceeded and initiated by 1 or more urethral relaxations.

\section{Discussion}

Assessing detrusor and urethral sphincter function in healthy women was done previously. S $\varphi$ rensen et al investigated the reproducibility of urodynamics in healthy fertile and postmenopausal women (15-17). As in our study they evaluated urethral pressure profilometry, free uroflowmetry, filling cystometry and pressure-flowstudy. Comparing their results in 10 fertile women (mean age 34.2 years) with those in our 36 subjects (mean age 30.0 years for those who underwent a urethral pressure profile test and mean age 30.2 years for the remaining 17 who underwent a conventional urodynamic investigation), a statistically significant difference was found only in the maximum urethral closure pressure and maximum detrusor pressure during the voiding phase (Student's t test, level of significance $5 \%$, see table 8 ). We suggest that the difference found in the maximum detrusor pressure during the voiding phase is due to the often occurring late contraction at the end of voiding. Another cause maybe the lower filling volume applied in our study, which in our opinion is more in accordance with normal behaviour. 
transmission ratio along urethra

mean values in 17 volunteera
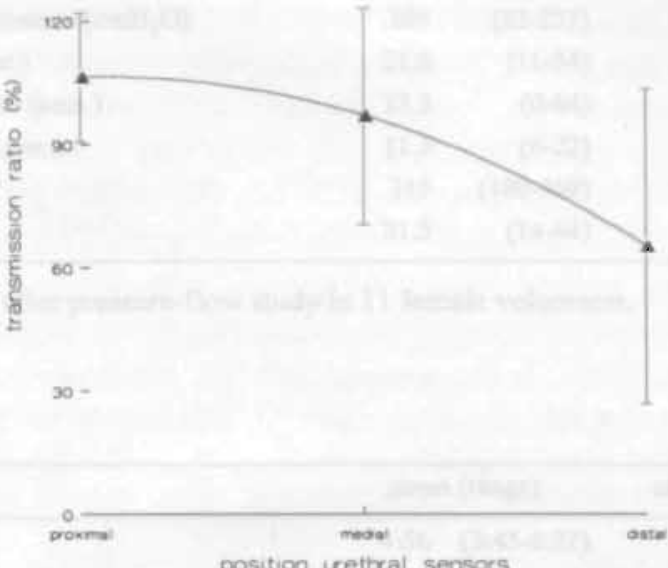

Figure 6. Mean values of the transmission ratio at proximal, medial and distal transducers of urethral catheter in 17 fenale volunteers.

\section{transmission (bladdervolume)}

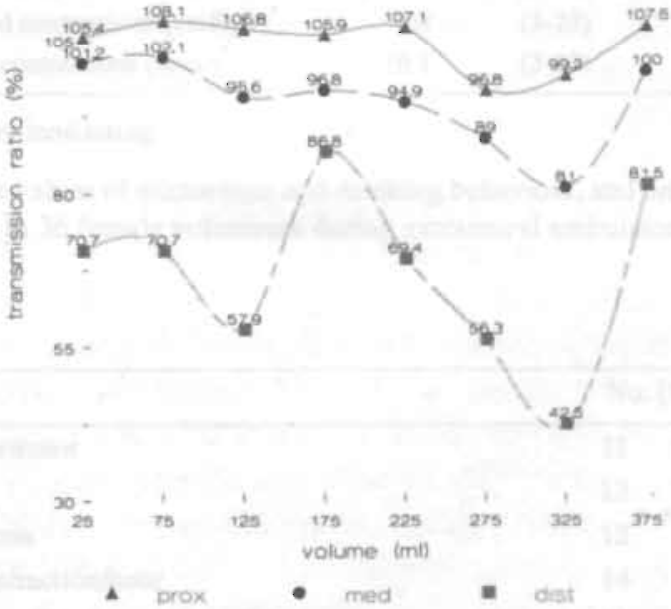

Figure 7. Mean transmission ratio as function of bladder volume in proximal (prox), medial (med) and distal (dist) urethra in 17 female volunteers. 



\begin{tabular}{lrrr} 
& \multicolumn{2}{c}{ mean (range) } & standard deviation \\
\hline opening time (secs.) & 6.5 & $(4-17)$ & 3.9 \\
vesical opening pressure $\left(\mathrm{cmH}_{2} \mathrm{O}\right)$ & 64 & $(49-87)$ & 11.9 \\
Vesical pressure at peak flow $\left(\mathrm{cmH}_{2} \mathrm{O}\right)$ & 63 & $(14-64)$ & 15 \\
maximum detrusor pressure $\left(\mathrm{cmH}_{2} \mathrm{O}\right)$ & 105 & $(22-253)$ & 72 \\
peak flowrate (ml./sec.) & 21.6 & $(11-54)$ & 12.4 \\
time to maximum flow (secs.) & 13.3 & $(0-64)$ & 17.6 \\
average flowrate (ml./sec.) & 11.3 & $(6-22)$ & 4.7 \\
voided volume (ml.) & 315 & $(180-469)$ & 84 \\
flowtime (secs.) & 31.5 & $(14-64)$ & 14.9 \\
\hline
\end{tabular}

Table 5. Results after pressure-flow study in 11 female volunteers.

\begin{tabular}{|c|c|c|c|}
\hline \multirow[b]{2}{*}{ duration (hrs.) } & \multicolumn{2}{|c|}{ mean (range) } & \multirow{2}{*}{$\begin{array}{c}\text { standard deviation } \\
35.6\end{array}$} \\
\hline & $4: 56$ & $(3: 45-6: 22)$ & \\
\hline \multicolumn{4}{|l|}{ No. micturitions/hr.: } \\
\hline - extramural ambulatory monitoring & 0.7 & $(0.2-1.5)$ & 0.3 \\
\hline - normally & 0.3 & $(0.1-0.5)$ & 0.095 \\
\hline voided volume/micturition (ml.) $)^{\bullet}$ & 200 & $(80-360)$ & 78.4 \\
\hline voided volume/hour (ml./hr.) ${ }^{\bullet}$ & 135 & $(30-390)$ & 86.1 \\
\hline \multicolumn{4}{|l|}{ volume fluid intake/hour (ml./hr.): } \\
\hline - extramural ambulatory monitoring & 180 & $(70-530)$ & 90.2 \\
\hline - normally & 70 & $(31-86)$ & 17.0 \\
\hline No. uninhibited contractions" & 4.6 & $(0-22)$ & 5.5 \\
\hline No. uninhibited contractions/hour ${ }^{\circ}$ & 0.9 & $(0-3.8)$ & 1.1 \\
\hline amplitude uninhibited contractions $\left(\mathrm{cmH}_{2} \mathrm{O}\right)^{\circ}$ & 9.8 & $(3-23)$ & 7.3 \\
\hline duration uninhibited contractions (secs.) & 10.1 & $(3-23)$ & 7.8 \\
\hline
\end{tabular}

extramural ambulatory monitoring

Table 6. Average values of micturition and drinking behaviour, and uninhibited detrusor activity in $\mathbf{3 6}$ female volunteers during extramural ambulatory monitoring.

\begin{tabular}{lll}
\hline & \multicolumn{2}{c}{ No. $(\%)$} \\
\hline completely stable detrusor & 11 & $(31)$ \\
$1-4$ contractions & 13 & $(36)$ \\
5 or more contractions & 12 & $(33)$ \\
no to less than 1 contraction/hour & 14 & $(39)$ \\
1 or more contractions/hour & 11 & $(31)$ \\
\hline
\end{tabular}

Table 7. Number of uninhibited detrusor contractions in 36 female volunteers during extramural ambulatory monitoring. 


\begin{tabular}{|c|c|c|c|c|c|c|}
\hline & \multicolumn{2}{|c|}{ present study } & \multicolumn{2}{|c|}{$\begin{array}{c}\text { Soprensen } \\
\text { et aloun }\end{array}$} & \multicolumn{2}{|c|}{$\begin{array}{l}\text { Student's I Test } \\
\text { (2-tailed) }\end{array}$} \\
\hline & No. & $\begin{array}{c}\text { mean } \pm \\
\text { standard } \\
\text { deviation }\end{array}$ & No. & $\begin{array}{c}\text { mean } \pm \\
\text { standard } \\
\text { deviation }\end{array}$ & T-value & P-value \\
\hline \multicolumn{7}{|l|}{ Urethral pressure pron̂lometry: } \\
\hline - functional urethral length (mm.) & 36 & $33.0 \pm 6.6$ & 10 & $32.8 \pm 4.1$ & 0.091 & 0.928 \\
\hline - max. urethral clos. press. $\left(\mathrm{cmH}_{2} \mathrm{O}\right)$ & 36 & $80.6 \pm 23.0$ & 10 & $65.7 \pm 10.8$ & 1.977 & 0.048 \\
\hline \multicolumn{7}{|l|}{ initial fowmetry: } \\
\hline - voided volume (ml.) & 6 & $285 \pm 172$ & 10 & $308 \pm 48.8$ & 0.406 & $>0.5$ \\
\hline - maximum flowrate (ml./sec.) & 6 & $26 \pm 5.0$ & 10 & $30.2 \pm 7.0$ & 1.280 & $0.2<p<0.5$ \\
\hline \multicolumn{7}{|l|}{ filling cystometry: } \\
\hline - compliance $\left(\mathrm{ml} / / \mathrm{cmH}_{2} \mathrm{O}\right)$ & 17 & $45.8 \pm 40.2$ & 10 & $65 \pm 18.7$ & 1.414 & $0.1<p<0.2$ \\
\hline \multicolumn{7}{|l|}{ pressure-flow study: } \\
\hline - opening time (secs.) & 11 & $6.5 \pm 3.9$ & 10 & $10.0 \pm 8.1$ & 1.281 & $0.2<p<0.5$ \\
\hline - ves. opening pressure $\left(\mathrm{cmH}_{2} \mathrm{O}\right)$ & 11 & $64 \pm 11.9$ & 10 & $55.7 \pm 19.4$ & 1.195 & $0.2<p<0.5$ \\
\hline - ves. press, at peak flow $\left(\mathrm{cmH}_{2} \mathrm{O}\right)$ & 11 & $63 \pm 15$ & 10 & $61.3 \pm 17.8$ & 0.237 & $>0.5$ \\
\hline - max. detrusor pressure $\left(\mathrm{cmH}_{2} \mathrm{O}\right)$ & 11 & $105 \pm 72$ & 10 & $44.9+15.9$ & 2.363 & $0.02<p<0.05$ \\
\hline - peak flowrate (ml./sec.) & 11 & $21.6 \pm 12.4$ & 10 & $20.6 \pm 6.9$ & 0.225 & $>0.5$ \\
\hline - average flowrate (ml./sec.) & 11 & $11.3 \pm 4.7$ & 10 & $10.1 \pm 3.8$ & 0.639 & $>0.5$ \\
\hline
\end{tabular}

Table 8. Comparison of conventional urodynamic investigation results in our study and the study of Sфrensen et al ${ }^{15 \cdot 17}$.

When one compares frce uroflowmetry with the voiding phase in the conventional urodynamic investigation the mean values of maximum and mean flow rate are higher in free uroflowmetry (26 and 15 versus 21.6 and $11.3 \mathrm{ml} / \mathrm{s}$, respectively) while the mean voided volume is approximately the same (285 versus 315 . see tables 3 and 6 ). However. using Student's t test does not confirm the mean values from the pressure-flow study to be significantly lower than those from initial uroflowmetry (1-tail p-values $0.1<\mathrm{p}<0.25$ and $0.05<\mathrm{p}<0.1$, respectively).

The mean values of the transmission ratio measured in the proximal, medial and distal urethra decrease as expected (see fig. 6). More astonishing. however, are the data presented in fig. 7 in which the transmission ratio in the proximal, mid and distal urethra as a function of the bladder volume is plotted. At bladder volumes of approximately 100 and $300 \mathrm{ml}$., especially in the distal urethra, a decrease in the transmission ratio can be seen. These volumes match roughly with the mean volumes at first sensation and at strong desire (see table 3 ).

This finding might be coincidental but it is also possible that the transmission ratio might not only be dependent on the anatomy but also on the urethral muscle tension. Applying urethral pressure recording during filling cystometry often shows a temporary decrease in pressure 
combined with a reported urge sensation wave, such as first sensation, first desire and strong desire. To decide on this event, further study is necessary. If the transmission ratio is also dependent on pelvic floor muscle tension, this would also explain the increase in transmission ratio on the right side of the plot, since the bladder volume exceeds 350 $\mathrm{ml}$. and the volunteer is probably squeezing her pelvic floor musculature to postpone micturition.

Syrensen et al did not report on detrusor instability or hyperactivity noted during filling cystometry. In our study detrusor activity in absence of voiding was noted during a conventional urodynamic investigation in $18 \%$ and during extramural ambulatory investigation in $69 \%$ of the subjects. This might be a physiological phenomenon or it might be caused by the application of the transurethral catheter. To test if detrusor activity is provoked by the catheter correlations between subjective sensations during extramural ambulatory monitoring reported by the volunteers, such as continuous awareness of the catheter, increase of urge sensation and increase in micturition frequency were analyzed. Of the volunteers $19(53 \%)$ reported continuous awareness of the urethral catheter, including $10(53 \%)$ who had detrusor activity in absence of voiding. A total of 22 volunteers $(61 \%)$ reported increase in urge sensation, including $12(54 \%)$ with unstable detrusor activity. Although the volunteers were stimulated to drink plenty of fluid, only $14(39 \%)$ reported an increase in micturition frequency and exactly half of them (7) showed unstable detrusor activity during extramural ambulatory monitoring. As a result. we can conclude that none of these subjective parameters showed correlation with unstable detrusor activity. Furthermore, unstable detrusor activity did not occur more frequently during the first hour of monitoring, nor during the period until the first voiding, nor during the second half of the monitoring period. Therefore, it cannot be concluded from these data that unstable detrusor activity is provoked by the urethral catheter.

If detrusor instability is not provoked by the urethral catheter it must be considered as a physiological phenomenon. As in a previous study by our group (8), unstable detrusor activity can be characterized by the number per hour, the mean amplitude and the mean duration of uninhibited contractions. Combining these parameters establishes the mean Detrusor Activity Index (DAI), calculated as the sum of the number of uninhibited contractions per hour multiplied by 10 , the mean amplitude and the mean duration of these contractions (see fig. 8). This parameter reflects the severety of bladder instability (detrusor overactivity). Figure 9 shows the mean DAI for different patient groups and the presented healthy volunteers. Statistical analysis (Student's 
$t$ test, level of significance $2.5 \%$ ) showed that the mean detrusor activity index in the stress incontinence group was not significantly higher than in the normal group $(p=0.08)$. However, in the urge incontinence, mixed incontinence, urgency and other incontinence groups the mean detrusor activity index was clearly significantly higher than in the stress incontinence group (see table 9). Therefore, it can be concluded that in all patient groups with complaints indicating detrusor instability the mean detrusor activity index is significantly higher as compared with the healthy and stress incontinence groups. In conclusion, it can be stated that detrusor instability also occurs in a group of healthy female subjects. However, our data suggest the possibility of a clinically applicable parameter to differentiate between overactive and nonoveractive detrusor function.

\begin{tabular}{lc}
\hline \multicolumn{1}{c}{ hypothesis } & P-value \\
\hline urge component healthy less than urge component stress incontinence & $0.08^{\circ}$ \\
urge component stress incontinence less than urge component urge incontinence & 0.001 \\
urge component stress incontinence less than urge component mixed incontinence & 0.048 \\
urge component stress incontinence less than urge component urgency & $<0.0001$ \\
urge component stress incontinence less than urge component only micturition problems & $<0.01$ \\
\hline
\end{tabular}

'Not significant. All other values indicate significant difference.

Table 9. Statistical evaluation using Student's t test with 1-tailed P-values of the detrusor activity index in the stress incontinence group versus the healthy group and the other patient groups.

Support: Material support by Bio Interface BV, Netherlands.

This study was made possible by a grant from the Ministry of Economic Affairs, The Hague, Netherlands. 


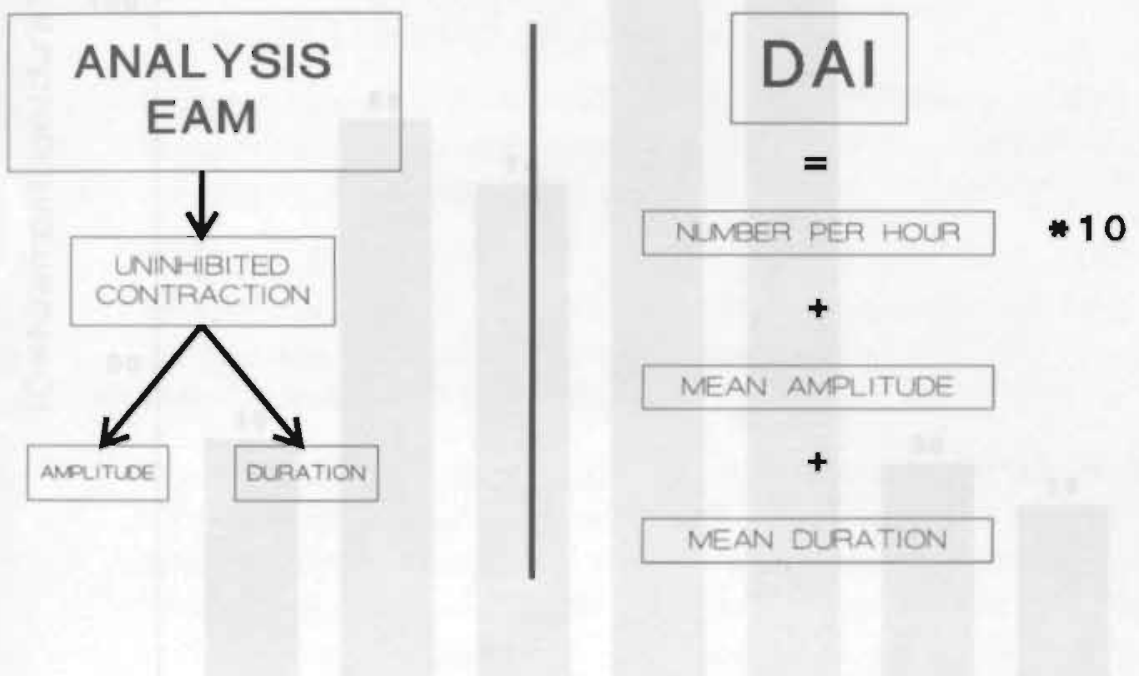

Figure 8. Calculation of the Detrusor Activity Index (DAI) obtained from ambulatory monitoring. 


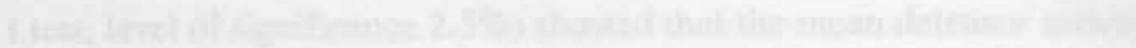

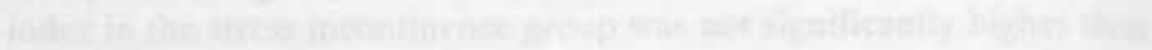

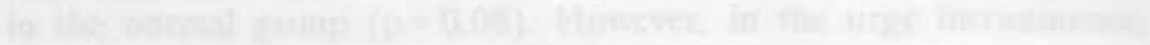

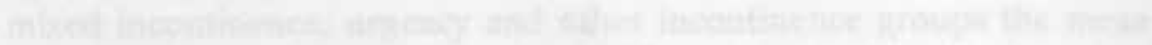

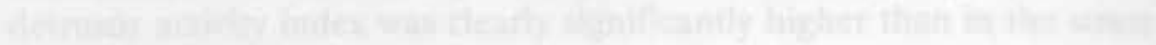

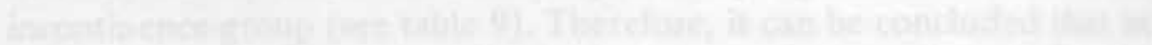

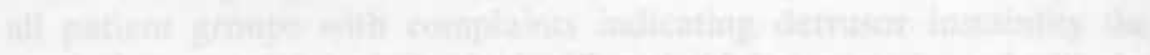

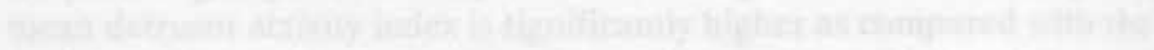

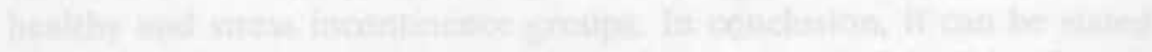

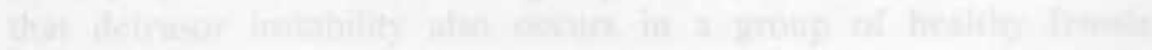

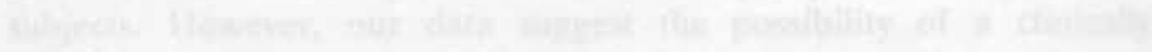

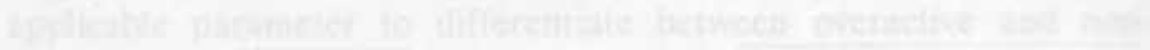

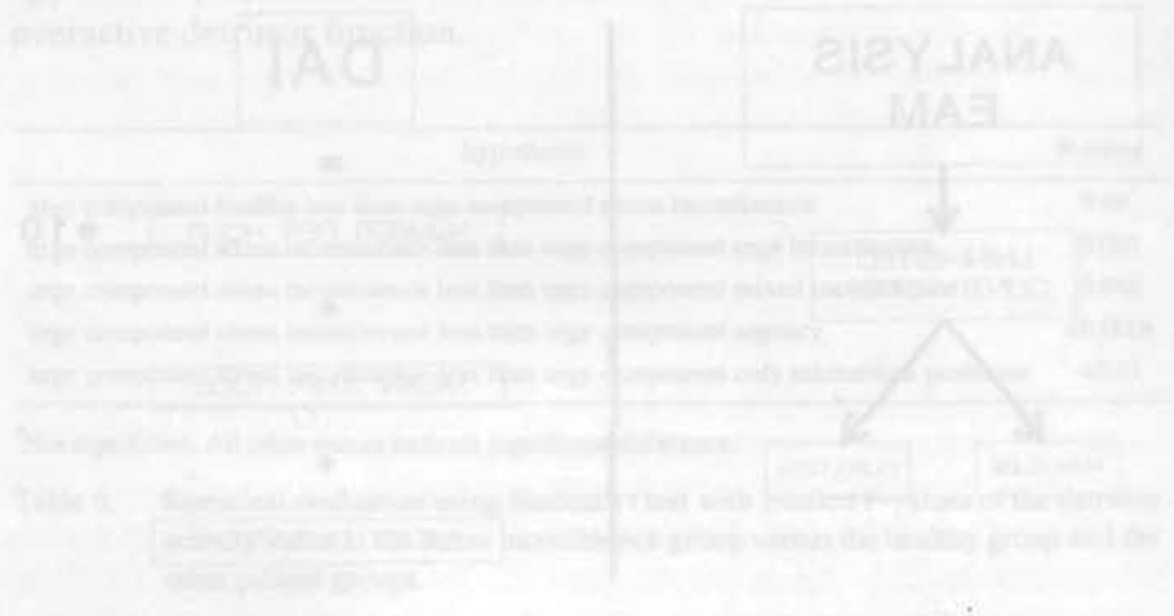

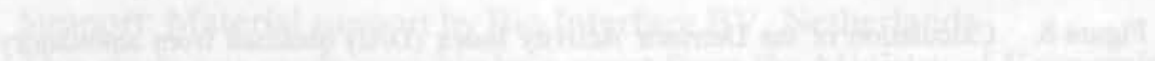

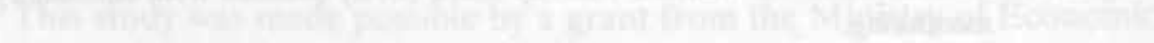

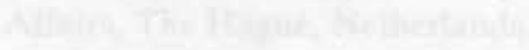




\section{mean "DAI" during EAM per symptomatic category}

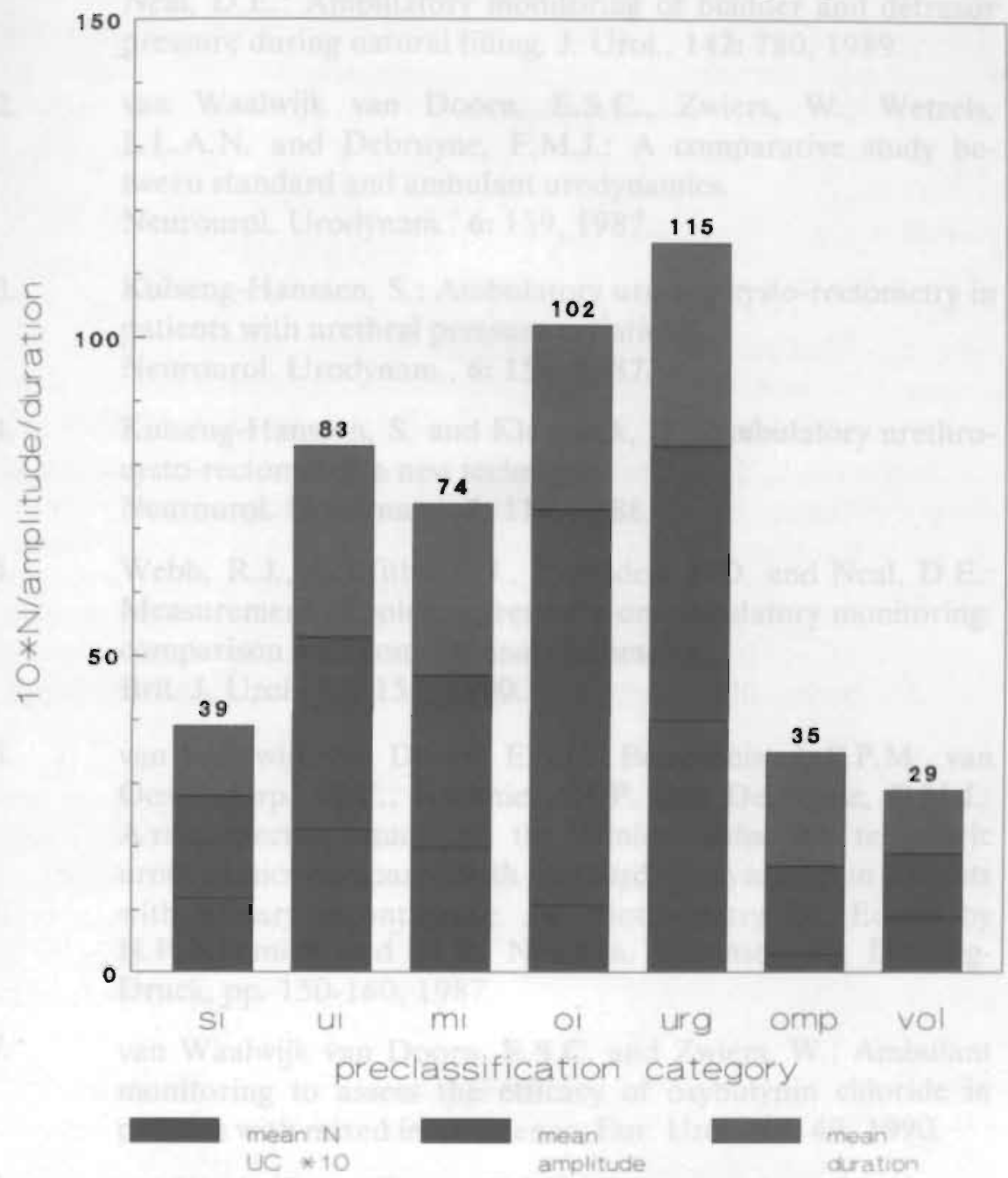

Figure 9. Mean Detrusor Activity Index of 36 female volunteers compared with different patient groups. si, stress incontinence. $u i$, urge incontinence. $m i$ mixed incontinence. oi, other incontinence. urg urgency without incontinence, omp, other micturition problems. vol, volunteers. $N$, number. UC, uninhibited detrusor contractions. 



\section{References}

1. Griffiths, C.J., Assi, M.S., Styles, R.A., Ramsden, P.D. and Neal, D.E.: Ambulatory monitoring of bladder and detrusor pressure during natural filling. J. Urol., 142: 780, 1989.

2. van Waalwijk van Doorn, E.S.C., Zwiers, W., Wetzels, L.L.A.N. and Debruyne, F.M.J.: A comparative study between standard and ambulant urodynamics.

Neurourol. Urodynam., 6: 159, 1987.

3. Kulseng-Hanssen, S.: Ambulatory urethro-cysto-rectometry in patients with urethral pressure variations.

Neurourol. Urodynam., 6: 156, 1987.

4. Kulseng-Hanssen, S. and Klevmark, B.: Ambulatory urethrocysto-rectometry: a new technique.

Neurourol. Urodynam., 7: 119, 1988.

5. Webb, R.J., Griffiths, C.J., Ramsden, P.D. and Neal, D.E.: Measurement of voiding pressures on ambulatory monitoring: comparison with conventional cystometry.

Brit. J. Urol., 65: 152, 1990.

6. van Waalwijk van Doorn, E.S.C., Bouwmeister, P.P.M., van Oostendorp, M.E., Kimmich, H.P. and Debruyne, F.M.J.: A retrospective study of the clinical value of telemetric urodynamics compared with standard urodynamics in patients with urinary incontinence. In: Biotelemetry IX, Edited by H.P. Kimmich and M.R. Neuman. Braunschweig DoeringDruck, pp. 150-160, 1987.

7. van Waalwijk van Doorn, E.S.C. and Zwiers, W.: Ambulant monitoring to assess the efficacy of oxybutynin chloride in patients with mixed incontinence. Eur. Urol., 18: 49, 1990.

8. van Waalwijk van Doorn, E.S.C., Remmers, A. and Janknegt, R.A.: Extramural ambulatory urodynamic monitoring during natural filling and normal daily activities: evaluation of one hundred patients. J. Urol., 146: 124, 1991.

9. Haylen, B.T., Ashby, D., Sutherst, J.R., Frazer, M.I. and West, C.R.: Maximum and average urine flow rates in normal male and female populations-the Liverpool nomograms.

Brit. J. Urol., 64: 30, 1989. 
10. Jensen, K.M., J $\varphi$ rgensen, J.B. and Mogensen, P.: Reproducibility of uroflowmetry variables in elderly males.

Urol. Res., 13: 237, 1985.

11. Kirkeby, H.J., S $\varphi$ renson, S. and Poulsen, E.U.: Urethral pressure variations in healthy male volunteers.

Urol. Res., 17: 191, 1989.

12. Tapp, A.J., Cardozo, L.D., Versi, E. and Studd, J.W.: The prevalence of variation of resting urethral pressure in women and its association with lower urinary tract function.

Br. J. Urol., 61: 314, 1988.

13. Thind, P., Lose, G., J $\varphi$ rgenson, L. and Colstrop, H.:

Variations in urethral and bladder pressure during stress episodes in healthy women. Br. J. Urol., 66: 389, 1990.

14. Jensen, K.M., Bruskewitz. R.C. and Madsen PO: Urodynamic findings in elderly males without prostatic complaints.

Urology, 24: 211, 1984.

15. S $\varphi$ renson, S., Knudsen, U.B., Kirkeby, H.J. and Djurhuus, J.C.: Urodynamic investigations in healthy fertile females during the menstrual cycle. Scand. J. Urol. Nephrol., Suppl., 114: $28,1988$.

16. S $\varphi$ renson, S., Gregersen, H. and S $\varphi$ renson, S.M.: Long term reproducibility of urodynamic investigations in healthy fertile females. Scand. J. Urol. Nephrol., Suppl., 114: 35, 1988.

17. Syrenson, S.: Urodynamic investigations and their reproducibility in healthy postmenopausal females. Scand. J. Urol. Nephrol., Suppl., 114: 42. 1988.

18. S $\varphi r e n s o n$, S., Jonler, M., Knudsen, U.B. and Djurhuus, J.C.: The influence of a urethral catheter and age on recorded urinary flow rates in healthy women. Scand. J. Urol. Nephrol., 23: $261,1989$.

19. International Continence Society; Standardisation Committee: The Standardisation of Terminology of lower urinary tract function. Read at annual meeting of the International Continence Society, 1987.

20. International Continence Society Working Party on Urodynamic Equipment: technical aspects. J. Med. Eng. Tech., 11: 57, 1987. 


\section{EDITORIAL COMMENTS (Journal of Urology)}

This is a fascinating, carefully done study in normal volunteers of relatively young age that demonstrates the frequency of occurrence of detrusor contractility as measured by continuous monitoring.

In addition, the authors recorded normative data for urethral pressure profilometry, voiding pressures and pressure-flow studies. They noted various changes in urethral pressure during continuous monitoring and changes in the transmission of abdominal pressure to the distal urethra associated with increasing bladder volume. This study suggests that we cannot evaluate patients with tests unless we have normative data for those tests so that we know what a finding actually means. At least in this group of young women the authors recorded astonishingly high rates of detrusor instability. They noted maximum urethral pressures that would be considered abnormally low and urethral instability in a group of normal young women. If a test result is often abnormal in a normal patient population we may not use an abnormal result in a symptomatic patient to make a diagnosis with any degree of accuracy. As Blaivas is fond of noting, unless a test duplicates the patient symptoms when an abnormality is recorded the study is not diagnostic.

Edward J. McGuire

Section of Urology

University of Michigan Medical Center

Ann Arbor, Michigan

In their introductory remarks the authors state that ambulatory urodynamic monitoring is intended to enhance the diagnostic accuracy of conventional urodynamics. The data reported in this study convincingly support this contention but only with respect to the diagnosis of detrusor instability. The incidence of detrusor instability increased from $18 \%$ during conven-tional filling cystometry to $69 \%$ during ambulatory monitoring. However, several issues relating to the clinical implications of ambulatory urodynamic monitoring and the interpretation of the results require further discussion.

During ambulatory urodynamic monitoring there is a significant potential for artifact. For example, when microtip transducers are zeroed the position of each transducer is its own zero. For transducers at the bottom of the bladder the weight of the urine above will be additive and will give a falsely elevated pressure measurement when compared to another transducer higher in the bladder. The problem is even more confounded with transurethral transducers, especially in the upright position. This is apparent in figure 2. During the voiding 
contraction detrusor pressure exceeds $100 \mathrm{~cm}$. water, whereas the urethral pressure is only approximately $30 \mathrm{~cm}$. water. It is well documented that urethral pressure is normally isobaric with the detrusor in its proximal portion and lower distally. Moreover, even the slightest movements of the catheter are normally accompanied by changes in urethral pressure. In fact, this is the rationale for performing urethral pressure profiles. For these reasons we believe that urethral monitoring in its present form is of dubious value. There also is the possibility that the presence of the catheter itself may provoke detrusor instability. In the discussion the authors provide arguments against this hypothesis but we believe that the possibility nevertheless exists.

We believe that the enhanced diagnostic ability of ambulatory monitoring to detect detrusor instability relates not only to the increased time frame over which the evaluation is performed (minutes versus hours or days) but also the technique by which filling cystometry is performed. In this study cystometry was performed according to the standards of the International Continence Society, which require that during filling the patient be instructed to try to prevent micturi-tion. No such instructions are given during ambulatory monitoring. We demonstrated previously that approximately $50 \%$ of the patients with involuntary detrusor contractions are able to abort them voluntarily when asked to do so. Accordingly, it would be expected that the incidence of detrusor instability would double simply on the basis of the cystometric technique alone.

Most important is the correlation between symptoms and detrusor instability. In some patients detrusor instability appears to be nothing more than a urodynamic curiosity-the involuntary detrusor contractions are totally asymptomatic and require no therapy. In others it is the proximate cause of incontinence. To evaluate further the relationship between instability and require no therapy. In others it is the proximate cause of incontinence. To evaluate further the relationship between instability and symptoms the authors introduced the term mean detrusor activity index and correlated this with clinical status. They found that the mean detrusor activity index was higher in women with urgency and urge incontinence than in normal subjects and patients with pure stress incontinence. It is noteworthy that the highest values of the detrusor activity index were found not in the patients with urge incontinence but. rather, in those with urgency and other types of incontinence. This is not surprising when one looks at the formula for calculating the detrusor activity index (sum of the number of unstable contractions per hour times 10 plus mean amplitude plus mean duration). If a patient has an unstable contraction and voids the duration of the contraction 
and the amplitude will be lower than if she successfully aborts the contraction. Perhaps it would be better simply to count the number of unstable contractions per hour.

In its present form ambulatory urodynamic monitoring has limited clinical applicability because it is really more of an extended cystometrogram combined with a micturition diary. However, we believe that this is only the beginning. It is to be anticipated that with further technological advances and miniaturization of monitoring devices the goal of enhancement of the diagnostic accuracy of conventional urodynamics may be an understatement. It is not unreasonable to assume that ambulatory monitoring may become the gold standard of the future.

Jerry G. Blaivas

Department of Urology

Columbia-Presbyterian Medical Center

New York, New York

\section{REPLY BY AUTHORS}

We appreciate the positive comments about this study. In general we agree that bladder activity ambulatory monitoring will become the gold standard. However, our detrusor activity index, as indicated by Doctor Blaivas, needs to be developed further. Variables obtained from extramural ambulatory monitoring need to be optimized with respect to their discriminating value.

Our normative data on urethral profilometry obtained in 36 female volunteers showed a mean value of $80.6 \mathrm{~cm}$. water for the maximum urethral closure pressure. In contradiction with the statement of Doctor McGuire, this value was significantly higher than the value of $65.7 \mathrm{~cm}$. water published by Sørensen et al (table 8 in article). We also wish to emphasize that our study does not provide results on the ambulatory recording of urethral pressure, except that the voiding phase begins with a decrease in urethral pressure followed by an increase in intravesical and detrusor pressures, indicating a contraction of the detrusor muscle. Decreases in urethral pressure were frequently noted during a short period just before subjects were to void. Urethral instability is not applicable in this context.

In regard to Doctor Blaivas' comments concerning intravesical and urethral pressure measurement, each microtransducer is zeroed at the level of the external atmospheric pressure because the backside of the sensitive membrane is connected through an open tube inside the cath- 
eter with the open air. The difference in atmospheric pressure at the side of each transducer is less than $1 \mathrm{~cm}$. water and, therefore, it is negligible. Thus, one can consider each transducer to have the same absolute zero pressure level if zeroed outside the patient. Since the applied Gaeltec catheter had the tip and urethral transducer at a distance of $5 \mathrm{~cm}$. the position of the tip transducer in the bladder was reasonably well defined at about 3 to $4 \mathrm{~cm}$. above the bladder neck with a minimal bladder filling of about $35 \mathrm{ml}$. The change in intravesical pressure due to the changing volume of the bladder during the filling phase can be estimated by calculating the diameter of a sphere with a maximum volume of $1,000 \mathrm{ml}$. (none of our volunteers voided more than $600 \mathrm{ml}$.), that is $12.4 \mathrm{~cm}$., causing a theoretical maximum pressure increase of $12.4 \mathrm{~cm}$. water at the site of the bladder neck at the end of the filling phase. Nevertheless, it is obvious that this is a slow process in comparison with pressure increase due to a detrusor contraction.

Urethral pressure recording to monitor activity of the sphincter mechanism is, as stated by Doctor Blaivas, a delicate matter because of the stiffness of the catheter and because of the nonfluidity of the medium during the filling phase. On the contrary, during the voiding phase the mecium is liquid, and urethral pressure depends on other variables, such as intravesical pressure, velocity of the passing urine, urethral properties and so forth. We noted that during voiding the extent of urethral pressure decrease reflected the urethral resistance. In regard to the instruction to prevent micturition, which is not given during ambulatory monitoring. we believe that this instruction will cause direct wetting of the clothes, which is a strong stimulus for inhibition of unstable detrusor activity during extramural ambulatory monitoring. 


\section{Chapter VIII}

\section{Introduction}

In the previous chapter it was demonstrated that detrusor overactivity is one of the most important pitfalls within the urodynamic evaluation of patients with urinary incontinence. A reliable method to quantify detrusor overactivity individually would be of great help. Especially in the group of patients with symptoms of mixed incontinence this would enable optimizing therapy. The mean Detrusor Activity Index, as was presented in chapter VII, figures 8 and 9 was a first attempt to quantify detrusor overactivity. As was stated in the 'editorial comment' this new parameter could probably be improved.

The results in the healthy volunteers and the 100 patients enabled us to improve this urodynamic parameter to an individually applicable quantitative index (DAI).

The results of this study are submitted for publication. 


\section{Detrusor activity index}

Quantification of detrusor overactivity by means of ambulatory monitoring

E.S.C. van Waalwijk van Doorn, A. Remmers, A.W. Ambergen*", R.A. Janknegt

Department of Urology, University Hospital Maastricht, ${ }^{*}$ Department of Medical Informatics and Statistics, University of Limburg, The Netherlands.

Abstract Conventional urodynamic filling cystometry is used to objectify (over)activity of the detrusor by identifying uninhibited contractions during filling. In contrast to patient complaints of urgency and frequency, uninhibited contractions are often not demonstrated during cystometry. On the other hand, the observation of just one uninhibited contraction during the conventional filling cystometry often leads to the diagnosis of an overactive detrusor muscle. A reliable parameter to quantify the grade of detrusor overactivity is not available. Ambulatory urodynamic monitoring has been developed and evaluated during the last decade and its appreciation is growing rapidly. We investigated the usefulness of this technique to quantify detrusor activity. For this purpose we investigated 193 female patients with complaints of urinary incontinence and/or voiding disorders, and a group of 66 asymptomatic female volunteers. Using the medical history as a standard, the subjects were divided into two groups: predicted overactive and predicted non-overactive. The same was done regarding the urodynamic conclusion as a standard. Using statistical analysis and the abovementioned standards, two scoring rules based on variables obtained from ambulatory monitoring were developed to quantify detrusor activity. With these scoring rules extramural ambulatory monitoring alone, can be used as a clinical test to detect and to quantify detrusor overactivity with a sensitivity and a specificity of about $80 \%$. To visualize the results of this complex statistical procedure a nomogram was developed for direct clinical use.

Keywords urinary tract, urinary, incontinence, detrusor, ambulatory, urodynamics 


\section{Introduction}

Since the introduction of urodynamic recording equipment as a tool to diagnose functional abnormalities of the lower urinary tract, filling and voiding cystometry are used to evaluate bladder behaviour. Apart from testing bladder compliance and bladder capacity, filling cystometry is used to investigate detrusor overactivity. However, many studies (1-4) have shown that frequently no detrusor overactivity could be demonstrated in patients despite of their clear symptoms of urgency, frequency, urge or mixed incontinence. On the contrary, the significance of one single objectified uninhibited detrusor contraction during filling cystometry is doubtful. Various provocative tests can help to detect detrusor instability. Nevertheless it is still not possible to derive a reliable parameter from conventional filling cystometry to quantify the grade of detrusor overactivity. Especially in the category of patients with symptoms of mixed incontinence it is difficult to achieve a clear diagnosis, upon which therapy can be based. With the increased variety of possible therapies focusing on detrusor overactivity, a more specific diagnosis is obligatory, not only to optimize but also to evaluate treatment. The severeness of the incontinence component due to detrusor overactivity is of main importance for the choice of therapy.

Ambulatory urodynamic monitoring has been developed and evaluated during the last decade (1-7). Its appreciation is growing rapidly. Ambulatory monitoring has shown compared to conventional filling cystometry and pressure/flow tests clear differences during the filling and voiding phase; i.e.. increased values for bladder compliance and higher voiding pressures at lower physiologic capacities (5). It has also shown a significant increase in the observation of detrusor instability in patients with symptoms of urgency, frequency, urge or mixed incontinence during the filling phase (4). Unfortunately, detrusor overactivity was also detected, using ambulatory monitoring, in a group of female volunteers (8) without urological symptoms and in patient groups with only symptoms of stress incontinence or voiding problems without urgency (4).

We investigated the possibility to objectify and quantify detrusor activity by one parameter, which can be derived from drinking and voiding behaviour combined with an analysis of detrusor activity monitored ambulatorily. This parameter is called the "DETRUSOR ACTIVITY INDEX" (DAI). Since there is no "gold standard" to use as reference, both medical history and urodynamic diagnosis were chosen to develop independently two quantitative rules. Both rules are evaluated and compared. 


\section{Materials and methods}

For this purpose we investigated 193 consecutive female patients (age 9-77 $\mathrm{y}$, mean $44,4 \mathrm{y}$ ) with complaints of urinary incontinence and/or voiding disorders visiting our outpatient clinic. To obtain normal reference values, also a group of 66 asymptomatic female volunteers (age 20-61 y, mean 31,3 y) was investigated. First, all subjects answered an extensive computerized questionnaire on urological symptoms. All patients and volunteers underwent complete conventional urodynamic evaluation, including filling cystometry at a filling rate of $50 \mathrm{ml} / \mathrm{min}$ in sitting position. Unless specified otherwise. the tests were performed according to ICS standards (10). The conventional investigation was followed by extramural ambulatory monitoring during approximately 6 hours, or longer in case of enuresis nocturna, as described previously by Van Waalwijk van Doorn et al. (4). For the conventional urodynamic testing we applied a 10 channel MMS system with flexible Gaeltec micro pressure sensor catheters (6 french rectally and 9 french transurethrally). The ambulatory tests were performed using a 5 channel Bio Interface monitor also combined with flexible Gaeltec micro pressure sensor catheters ( 6 french). During both investigations, intravesical, rectal, and urethral pressures were recorded.

\begin{tabular}{lrcrcc}
\hline groups based on medical history & number & mean age & range & sd & classification \\
\hline stress inc. & 21 & 51,7 & $23-75$ & 14,2 & n.o. \\
urge inc. & 59 & 43,0 & $9-75$ & 14,5 & 0. \\
mixed inc. & 77 & 47,4 & $21-75$ & 11,5 & $?$ \\
enuresis noct. & 12 & 21,8 & $17-55$ & 4,3 & 0. \\
unclear inc. & 3 & 19,0 & $12-25$ & 6,6 & $?$ \\
urgency & 12 & 53,5 & $21-77$ & 18,5 & 0. \\
voiding problems, no urgency & 9 & 38,0 & $17-51$ & 12,2 & n.o. \\
\hline subtotal & 193 & 44,4 & $9-77$ & 16,3 & - \\
asymptomatic volunteers & 66 & 31,3 & $20-61$ & 10,6 & n.o. \\
\hline total & 259 & 41,0 & $9-77$ & 15,0 & - \\
\hline
\end{tabular}

Table 1. Specific subgroups based on computerized medical history taking. Each group is classified as overactive (o.), non-overactive (n.o.) or unknown (?). This classification is used as reference standard for rule $\mathrm{I}$.

Based on the results of the computerized questionnaire all subjects were classified into different symptom groups (table 1). Each specific group, was predicted to have an overactive, a non-overactive detrusor or questionable (table 1). Patients with "unclear" incontinence could not be reliably classified based on medical history. Also patients with 
"mixed" incontinence were excluded from the preclassification because it is our experience that this is from a diagnostical point of view a very difficult group.

The same was done with the specific groups devided according the urodynamic diagnosis, obtained from the conventional and ambulatory urodynamic evaluation (table 2).

\begin{tabular}{lrrrrc}
\hline $\begin{array}{l}\text { groups based on urodynamic } \\
\text { diagnosis }\end{array}$ & number & mean age & range & sd & classification \\
\hline no abnormalities & 7 & 36,6 & $22-51$ & 8,9 & n.o. \\
stress inc. & 24 & 46,7 & $21-73$ & 13,4 & n.o. \\
urge inc. & 85 & 43,9 & $9-77$ & 15,5 & 0. \\
mixed inc. & 38 & 49,6 & $22-71$ & 11,4 & $?$ \\
enuresis noct. & 5 & 41,4 & $21-55$ & 14,3 & o. \\
motor urge & 33 & 40,3 & $12-75$ & 17,5 & o. \\
hypo-active detrusor & 1 & 39 & n.a. & n.a. & n.o. \\
\hline subtotal & 193 & 44,4 & $9-77$ & 16,3 & . \\
asymptomatic volunteers & 66 & 31,3 & $20-61$ & 10,6 & n.o. \\
\hline total & 259 & 41,0 & $9-77$ & 15,0 & . \\
\hline
\end{tabular}

Table 2. Specific subgroups based on clinical urodynamic diagnosis. Each group is classified as overactive (o.), non-overactive (n.o.) or unknown (?). This classification is used as reference standard for rule II.

\begin{tabular}{lcc}
\hline drinking behaviour & volume/hour & $\mathrm{ml} / \mathrm{hr}$. \\
\hline voiding behaviour & number of voidings/hour & $1 / \mathrm{hr}$. \\
& mean volume/voiding & $\mathrm{ml}$. \\
\hline detrusor activity & $\begin{array}{c}\text { number of uninhibited } \\
\text { contractions/hour } \\
\text { mean maximum amplitude of } \\
\text { uninhibited contractions/hour } \\
\text { mean duration of all } \\
\text { uninhibited contractions/hour } \\
\text { mean area under uninhibited } \\
\text { contraction curve/hour }\end{array}$ & $\mathrm{cmH} / \mathrm{hr} / \mathrm{hr}$. \\
\hline
\end{tabular}

Table 3. Different variables obtained from Extramural Ambulatory Monitoring (EAM) that were chosen as being important to discriminate between detrusor over and non-overactivity. 

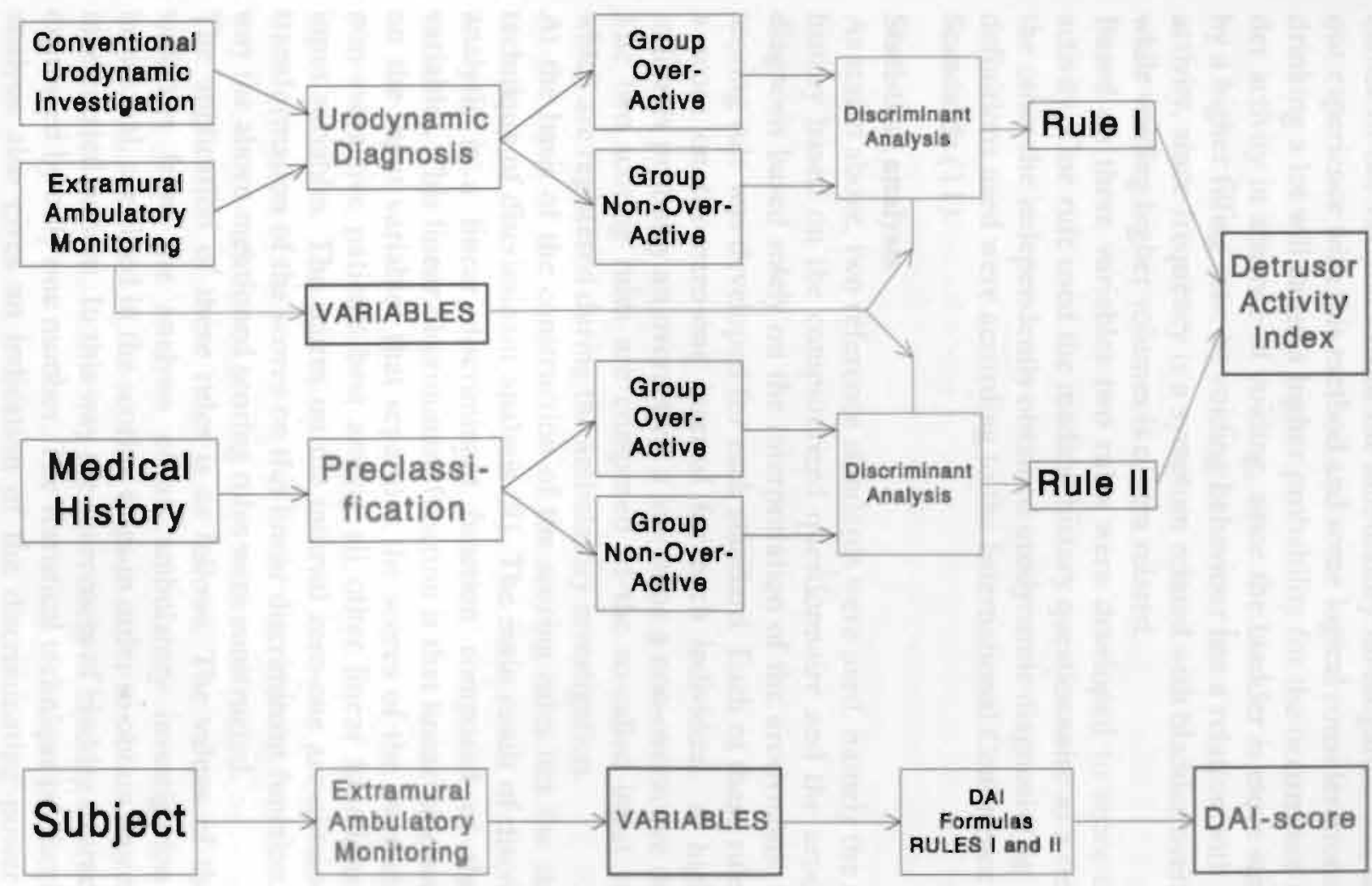

Figure 1. Schematic diagram of the study setup. 

Finally, variables from the extramural investigation were collected and calculated. Three categories of variables were used: drinking behaviour, voiding behaviour, and description of detrusor activity (table 3 ). The choice of the variables from the ambulatory investigation was based on our experience with this method and some logical considerations like; a) drinking a lot will cause a higher probability for the occurrence of bladder activity in absence of voiding, since the bladder is more stimulated by a higher filling rate, $b$ ) voiding behaviour has a relation with bladder activity. since frequency is a symptom related with bladder overactivity, while voiding higher volumes is contra related.

Based on these variables two rules were developed to score detrusor activity. One rule used the medical history questionnaire as a reference, the other the independently obtained urodynamic diagnosis (fig. 1). The definitions used were according to the International Continence Society Standards (11).

\section{Statistical analysis}

As stated above, two reference standards were used, namely the medical history based on the computerized questionnaire and the urodynamic diagnosis based solely on the interpretation of the urodynamic tests. A scoring rule was developed for each standard. Each of these rules yields a score on the zero-one interval for each individual. A high value indicates probably an overactive, a low value a non-overactive detrusor. The two scoring rules are composed of the so-called input variables which are registered during the ambulatory investigation.

At the basis of the construction of the scoring rules lies the statistical technique of discriminant analysis (9). The main result of discriminant analysis is a linear discriminant function composed of the input variables. This linear discriminant function is that linear function based on the input variables that separates the scores of the overactive and non-averactive patients best among all other linear functions of the input variables. The scores on the interval zero-one are obtained by a transformation of the scores on this linear discriminant function. In this way the above-mentioned scoring rules were constructed.

The application of these rules is as follows. The values of the input variables from the analysis of an ambulatory investigation of an individual, are filled in the scoring rules in order to obtain scores of the investigated patient. In this way the severeness of bladder overactivity is expressed by only one number. The statistical technique of discriminant analysis also gives an indication of the discriminating power of the variables which are used in the discriminant function. The so-called loadings are measures of the contribution of the variables to the discriminating power of the scoring rules. High absolute values of the 
loadings indicate high contributions to the discriminating power (loadings are numbers between -1.0 and 1.0.). It should be noted that the order of variables according to their loadings is not necessarily the same as the order of the variables individually considered. However, the scoring rules based on the set of variables mentioned in table 3 . performs better than each variable on its own. The discriminating power of each of the scoring rules themselves can also be evaluated. If there are only two groups (overactive and non-overactive) the sensitivity and specificity are suitable measures to illustrate this power. Sensitivity is the proportion diseased patients which are correctly classified, while specificity is the proportion non-diseased patients which are correctly classified. Of course, the number of persons which will be assigned to either one of the groups by applying these scoring rules will depend on the prevalence of the groups.

According to the two reference standards, patients were divided into three groups (table 1 and 2, last column): the overactive, the non-overactive and the questionable group. However, for the development of the scoring rules only the individuals from the overactive and nonoveractive groups were used, because the diagnoses of these individuals were clear.

\section{Results}

Tables 1 and 2 show the different subject groups according to the computerized medical history and according to the urodynamic diagnosis. Two rules were obtained. One rule approximating the classification of non-overactivity of the detrusor based on the computerized medical history classification and the other approximating the classification based on the urodynamic diagnosis. Table 4 gives for each individual variable from the ambulatory investigation the loading factors (discriminating power) with respect to classification according both reference standards. It can be seen that mean maximum amplitude, and mean area under the curve of the uninhibited contractions are important discriminating variables for both models. Also the mean duration of the uninhibited contractions contributes a lot to the discriminating power. Among the two variables describing the voiding behaviour, the volume per voiding is best. Table 5 give the standardised formula for both rules with the index constants for each variable. With this formula both scores for each individual patient can be calculated after analysis of an ambulatory investigation.

Figures $2 \mathrm{a}$ and $2 \mathrm{~b}$ are the so called Receiver Operating Characteristic curves (ROC-curves). Such a curve plots sensitivity against specificity of 


\begin{tabular}{|c|c|c|c|c|}
\hline 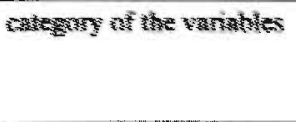 & variable & $\begin{array}{l}\text { variable } \\
\text { code }\end{array}$ & $\begin{array}{l}\text { loadings, } \\
\text { medical } \\
\text { Mustary }\end{array}$ & $\begin{array}{c}\text { loadings, } \\
\text { arodynamic } \\
\text { dsigawais }\end{array}$ \\
\hline 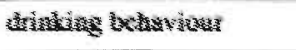 & volume/hiour & trink $\mathrm{hr}$ & $-0,38$ & -0.53 \\
\hline \multirow[t]{2}{*}{ wolding betswivour } & number of woidingshour & michs: & +0.31 & $\div 0.15$ \\
\hline & mean volnmeividing & vol Mie & $-0,6$ & $-1)$ \\
\hline \multirow[t]{4}{*}{ wetrassar activity } & $\begin{array}{l}\text { Fomber we uninhihited } \\
\text { contractions hour }\end{array}$ & nc/hr. & +038 & +0.56 \\
\hline & $\begin{array}{l}\text { mean maximum amplitude of } \\
\text { uninhibited contractions/hour }\end{array}$ & amp/hr. & +0.65 & +137 \\
\hline & $\begin{array}{l}\text { mean duration of uninhibited } \\
\text { contractions/hour }\end{array}$ & $\mathrm{dur} / \mathrm{hr}$. & 70.56 & $+0,71$ \\
\hline & $\begin{array}{l}\text { mesn ares under uninhibited } \\
\text { contraction curve/hour }\end{array}$ & act $/ \mathrm{hr}$. & +0.65 & +0.70 \\
\hline
\end{tabular}

Table 4. The variables from Table 1 and their individual "loadings" (discriminating power) calculated from discriminant analysis.

$$
D A I_{\text {Score }_{j}}=\frac{1}{1+e^{-w w_{j}}}
$$

$$
(j=1,2)
$$

$W_{j}=C_{1}+C_{2} * d r i n k / h r+C_{3} * m i c / h r+C_{4} * v o l / m i c+C_{5} * u c / h r+$ $+C_{6} * a m p / h r+C_{7} * d u r / h r+C_{8} * a c t / h r$

\begin{tabular}{lcc}
\hline variable code & $\begin{array}{c}\text { coefficients }(\mathrm{j}=1) \\
\text { medical history }\left(\mathrm{C}_{\mathrm{i}}\right)\end{array}$ & $\begin{array}{c}\text { coefficients }(\mathrm{j}=2) \\
\text { urodynamic diagnosis }\left(\mathrm{C}_{\mathrm{i}}\right)\end{array}$ \\
\hline constant & 0.6394 & 0.4535 \\
drink./hr. & $-0.3663 \mathrm{E}-2$ & $-0.6227 \mathrm{E}-2$ \\
mic./hr. & 0.5536 & 0.4594 \\
vol./mic. & $-0.5403 \mathrm{E}-2$ & $-0.2930 \mathrm{E}-2$ \\
uc./hr. & $-0.2583 \mathrm{E}-1$ & $-0.5200 \mathrm{E}-1$ \\
amp./hr. & $0.9263 \mathrm{E}-2$ & $0.2612 \mathrm{E}-2$ \\
dur./hr. & $0.1336 \mathrm{E}-1$ & $0.1278 \mathrm{E}-1$ \\
act./hr. & $-0.3832 \mathrm{E}-4$ & $0.5360 \mathrm{E}-4$ \\
\hline
\end{tabular}

Table 5 Standardized formulae with the coefficients $\left(C_{i}\right)$ for the two rules $(j=1,2)$. 
the rule obtained from the ambulatory test. Fig. 2a is the ROC-curve when medical history is used as the reference standard, fig. $2 \mathrm{~b}$ when the clinical urodynamic diagnosis is used as the standard. A clinical test with a sensitivity and specificity of $100 \%$ can hardly be found. Most tests show an overlap in outcomes from healthy and diseased persons. Therefore it is necessary to define a cutoff point in the outcomes or scores to be able to distinguish between predicted healthy and diseased. The dicriminating power of a test gets better when the curve approaches the right upper corner of the diagram, where sensitivity $=$ specificity $=$ $100 \%$. To choose a cutoff point it is important whether the clinician wants to have a highly sensitive or a highly specific test. A highly sensitive test implies that more healthy subjects are classified diseased, whereas a highly specific test favours non-diseased classifications.

The individual scores by both rules are plotted in fig. 3a-d for respectively the learning groups, the mixed inc. groups and the unclear inc. group. Figures 4 and 5 give for both rules the relation of specificity, sensitivity versus the scores. The purpose of such a figure is to define a cutoff point for non-over and overactivity. The rule based on medical history has a cutoff point for bladder overactivity of 0.47 , where specificity equals a sensitivity of $79 \%$. For the rule based on clinical urodynamic diagnosis sensitivity equals specificity $(81 \%)$ at a cutoff point of 0.46. As was expected, the urodynamic diagnosis which also used the subjective interpretation of the ambulatory investigation shows an improvement in sensitivity and specificity at the cutoff point. This difference, however, seems to be negligibly small.

The mean score of the group of overactive patients was 0.63 ( $\mathrm{SD}=$ 0.22 ) for the rule based on the medical history questionnaire, and also $0.63(\mathrm{SD}=0.22)$ for the rule based on the urodynamical evaluation. For the non-overactive group these means were $0.35(\mathrm{SD}=0.17)$ and 0.34 $(S D=0.15)$ respectively. Fig. 6 gives the mean scores by both rules of different symptom groups derived from the medical history. Fig. 7 does the same for the groups derived from the clinical urodynamic conclusion.

\section{Discussion}

Neither medical history nor clinical diagnosis based on urodynamic investigations have proven to be a $100 \%$ reliable "gold standard" to determine whether patients suffer from bladder overactivity (4). These are nevertheless the best options, available. For this reason we chose to use both options in this study. Because medical history was based on a standardised questionnaire and the clinical urodynamic diagnosis was obtained from subjective interpretation without knowledge of the patient's complaints, the "standards" are independent. 
Total group = learning and test group

results with respect to medical history

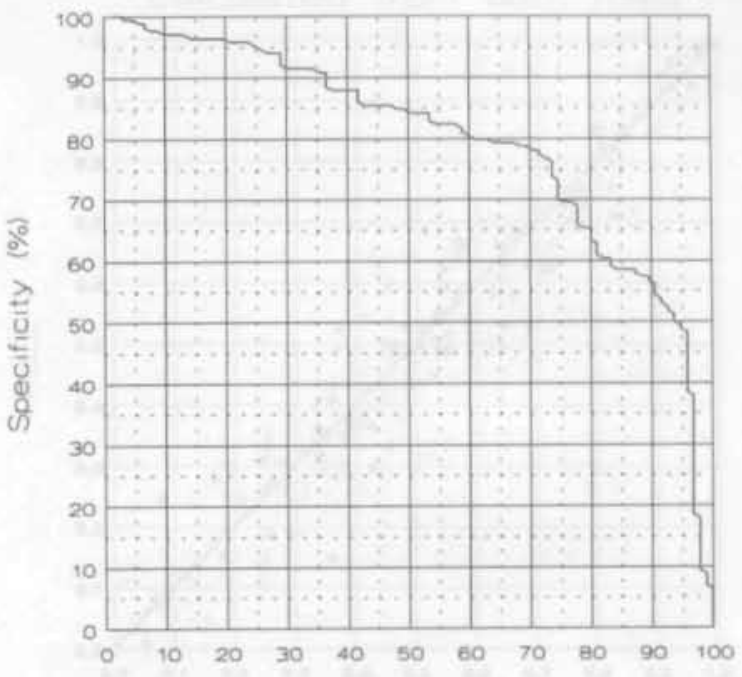

Sensitivity (\%)

\section{Total group - learning and test group}

results with respect to urodyn,diagnosis

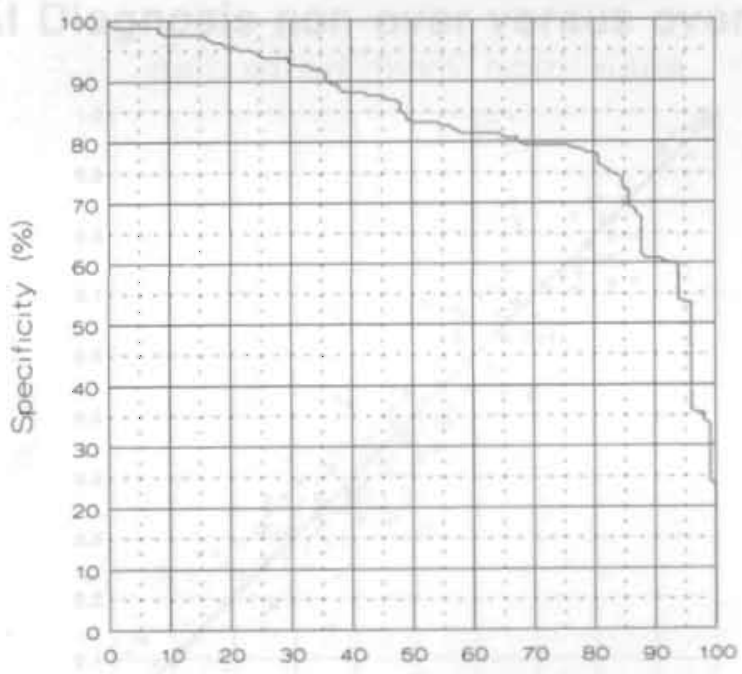

Sensitivity $(\%)$

Figure 2a-b. Receiver Operating Characteristic curves (ROC-curves) of the rule obtained from the ambulatory test, when a) medical history is used as the reference standard and b) when urodynamic diagnosis is used as the reference standard. 


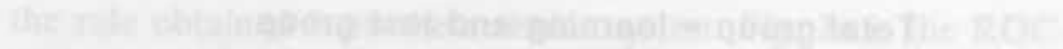

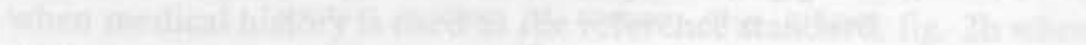

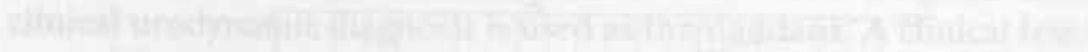

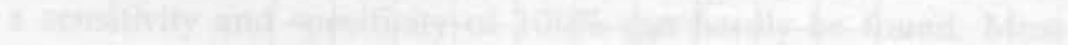

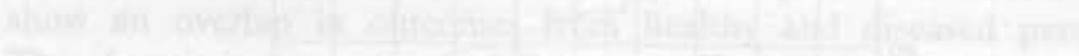

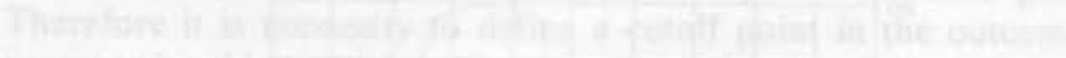

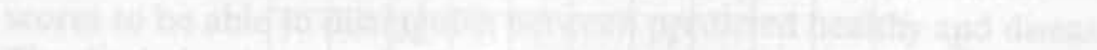

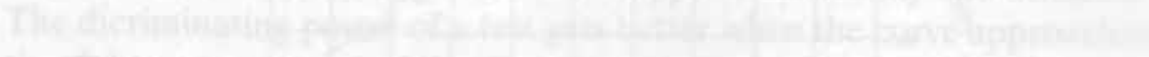

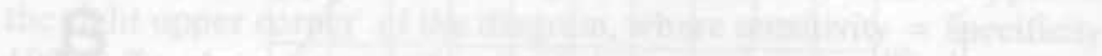

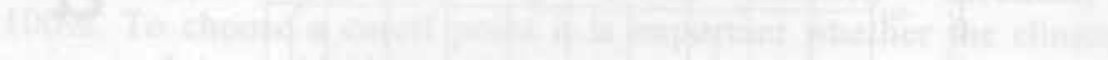

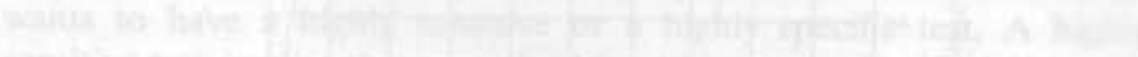

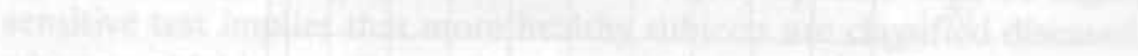

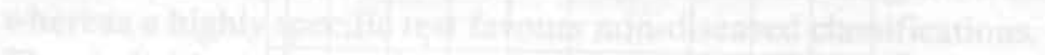

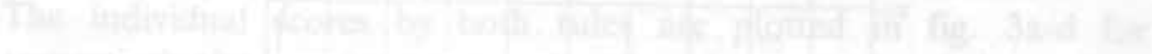

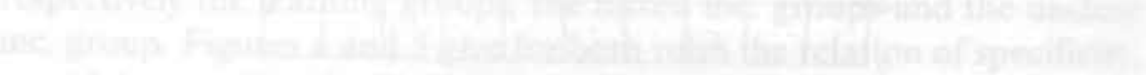

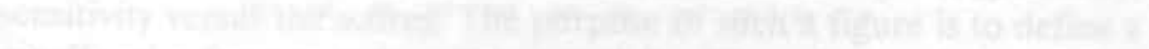

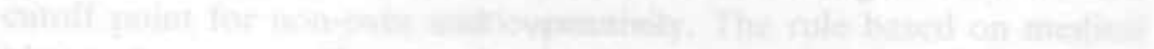

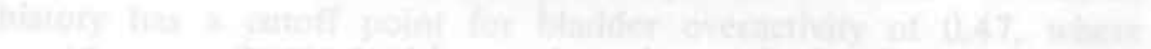

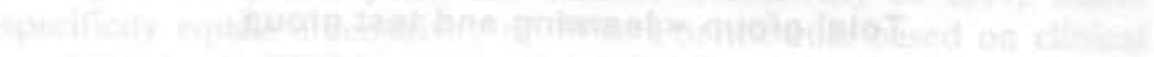

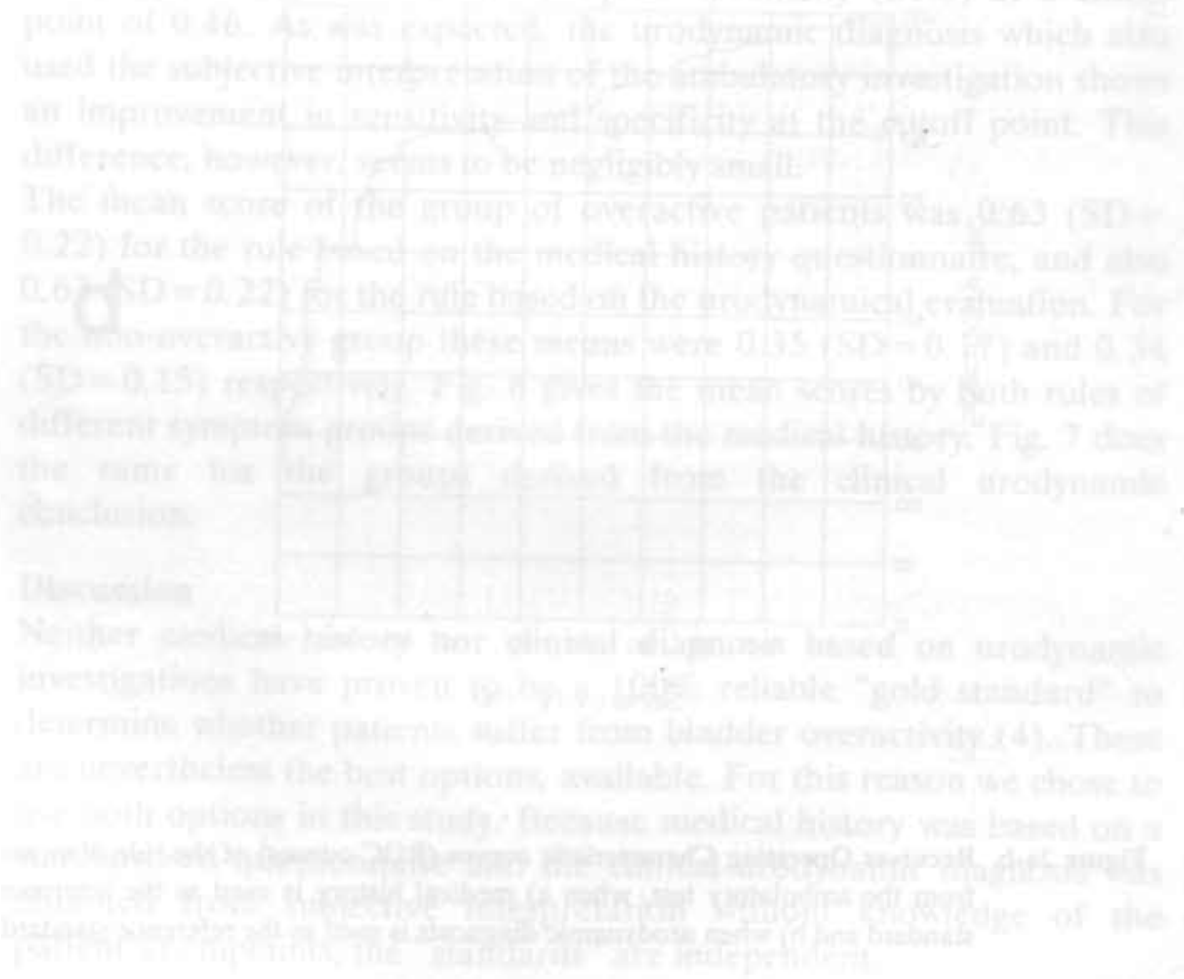


DAI Med. history non-over vs. overactive calculated from both rules

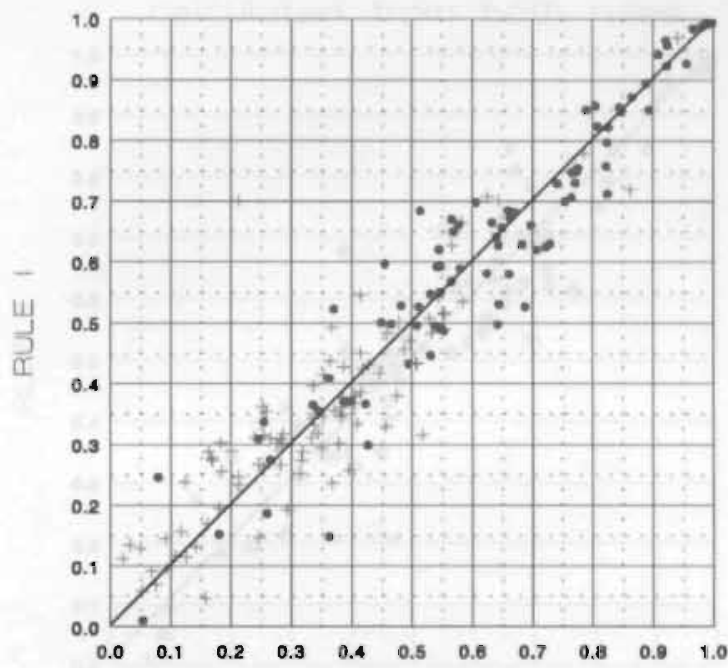

a

RULE II

CLASSIFICATION:

- overactive

DAI Diagnosis non-over versus overactive calculated from both rules
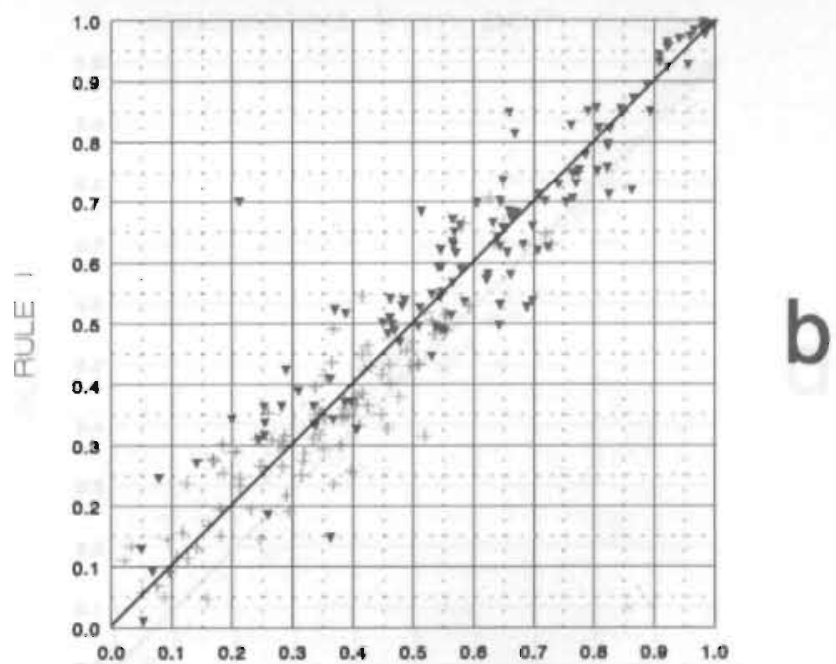

PULE II

CLASSIFICATION:

7 overactive

Figure 3a-b. Individual scores by both rules; a) and b) from both learning groups, 


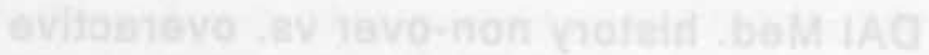

$\sqrt{2}$

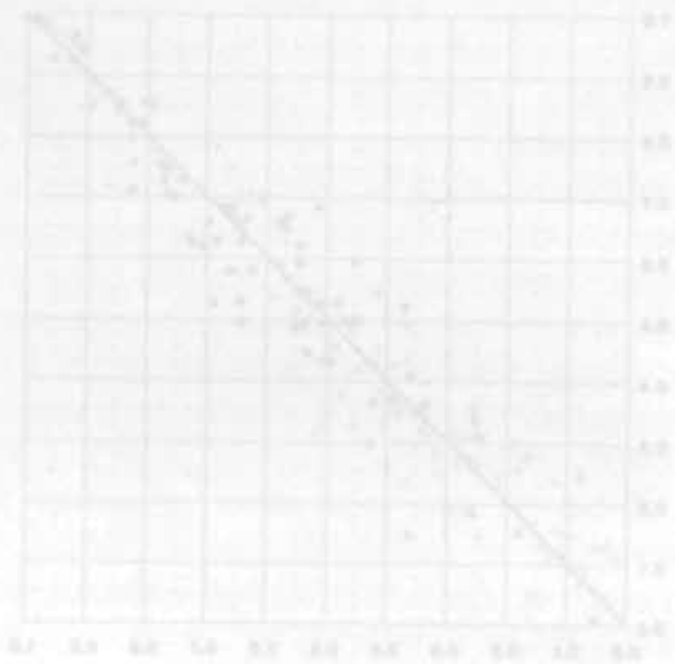

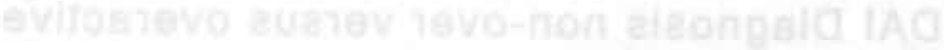

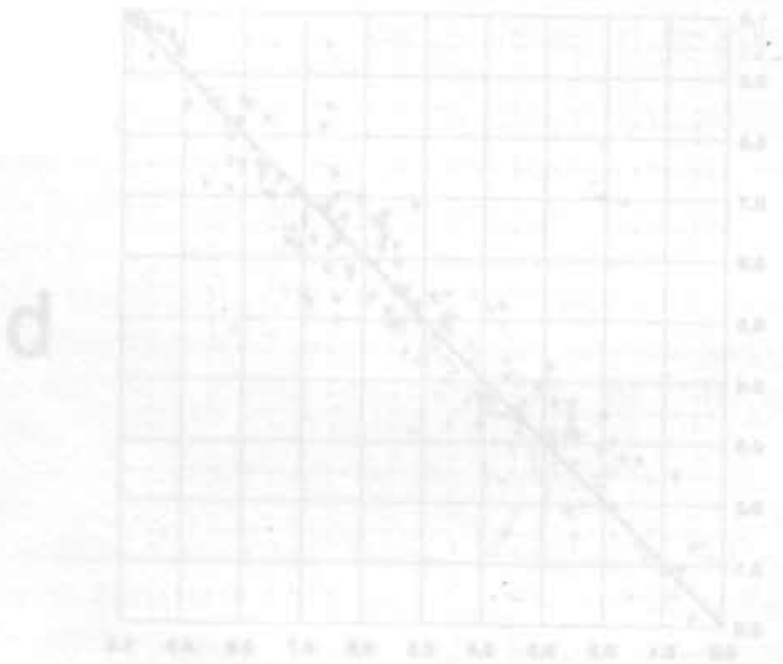

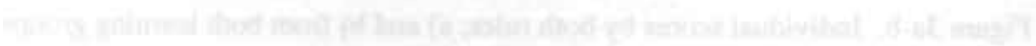


DAI Symptoms Mixed inc. group

calculated from both rules

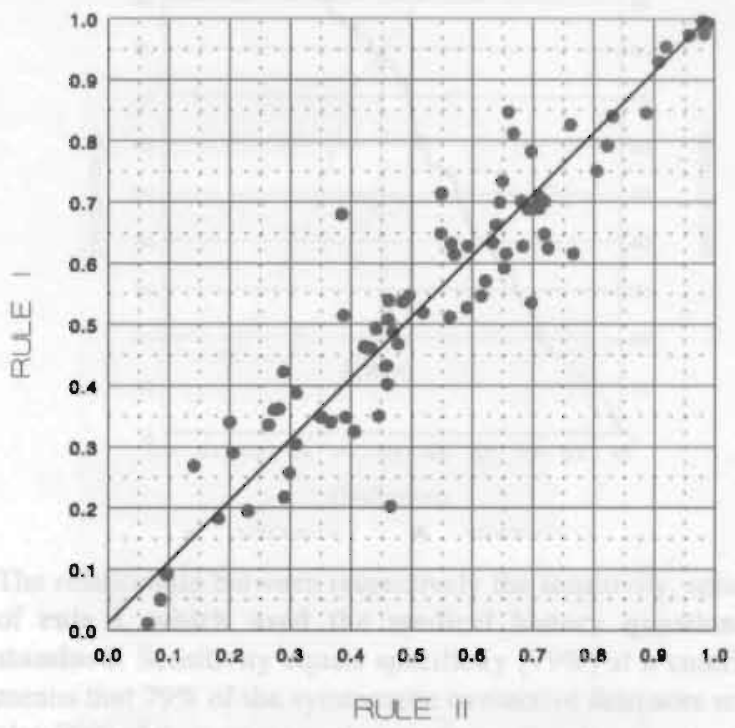

C

\section{DAI Diagnosis urge inc.}

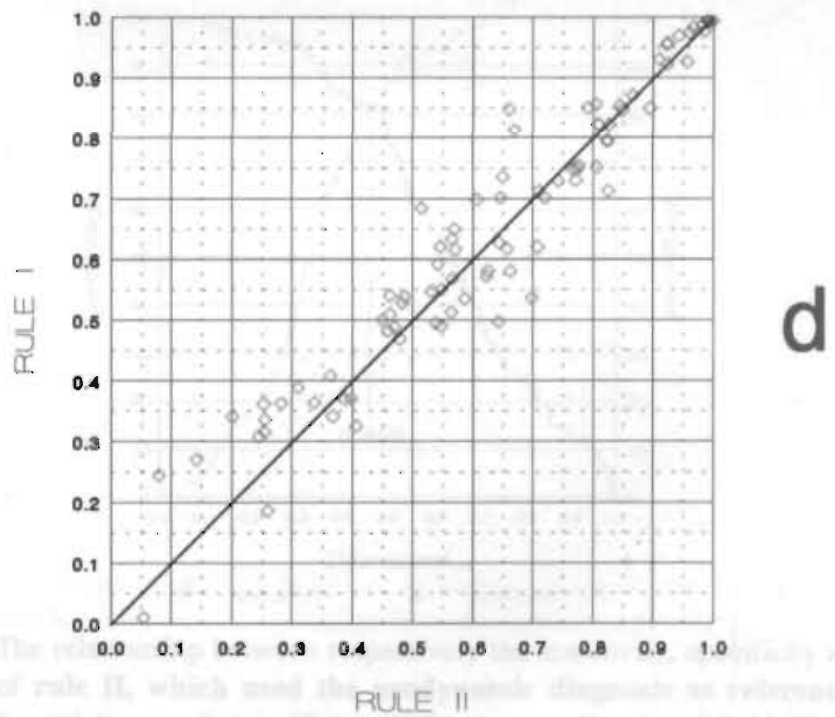

Figure $3 c-d \quad$ c) Individual scores from the symptomatic mixed inc. group and d) from the group diagnosed as urge inc. 
quave ani bexilh amotamye IAO

$\sqrt{2}$

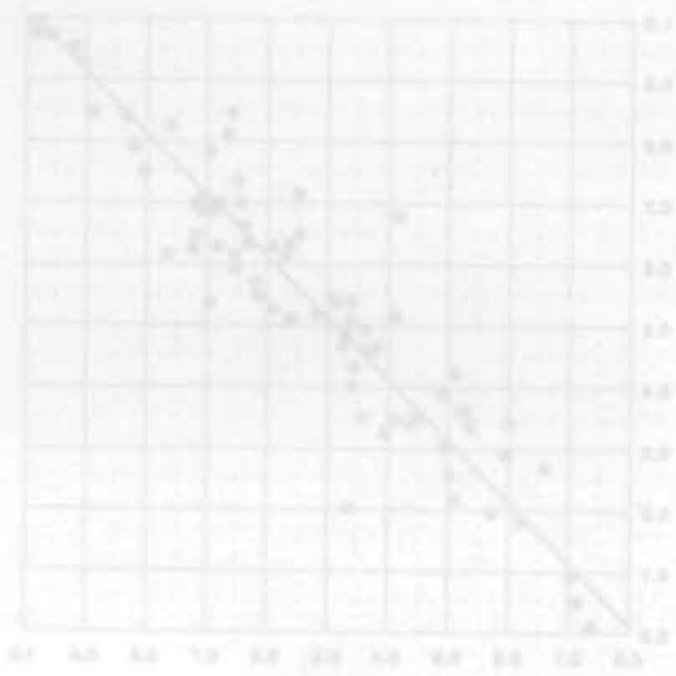

ani Bgut alaonobiO IAO

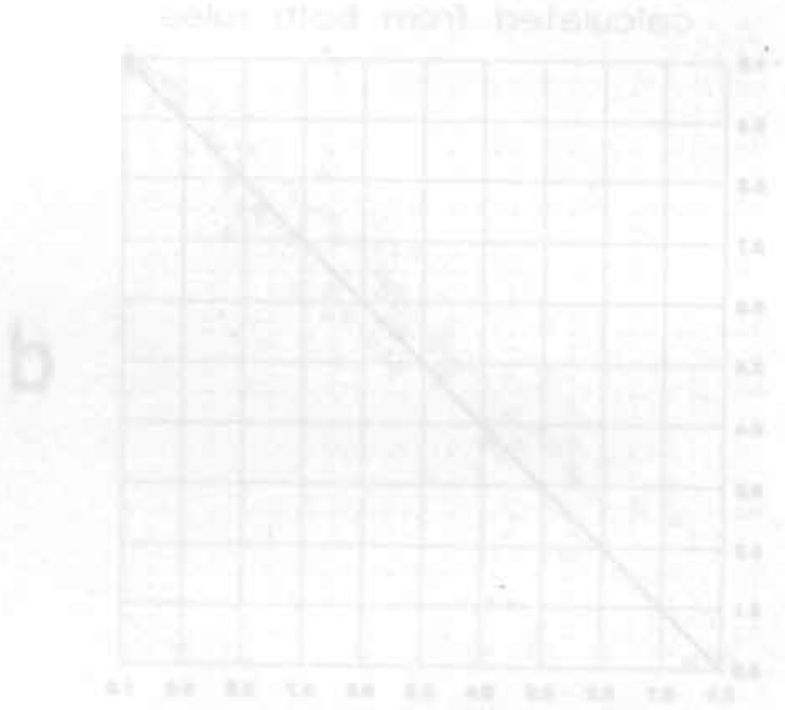

$x^{2}=n^{2}$

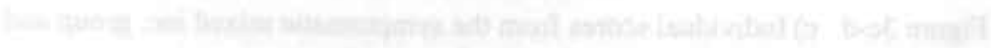

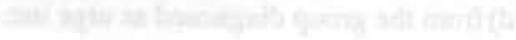




\section{Sensitivity and Specificity vs. Score}

Gold Standard = Medical History

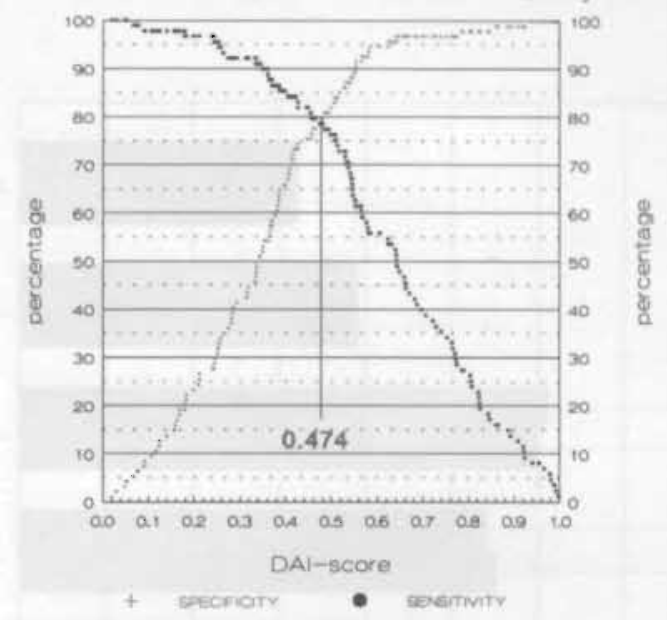

Figure 4. The relationship between respectively the sensitivity, specificity and the score of rule I, which used the medical history questionnaire as reference standard. Sensitivity equals specificity (79\%) at a cutoff point of 0.47 . This means that $79 \%$ of the symtomatic overactive detrusors scored above 0.47 and aiso $79 \%$ of the symptomatic non-overactive detrusors scored below 0.47 .

\section{Sensitivity and Specificity vs. Score}

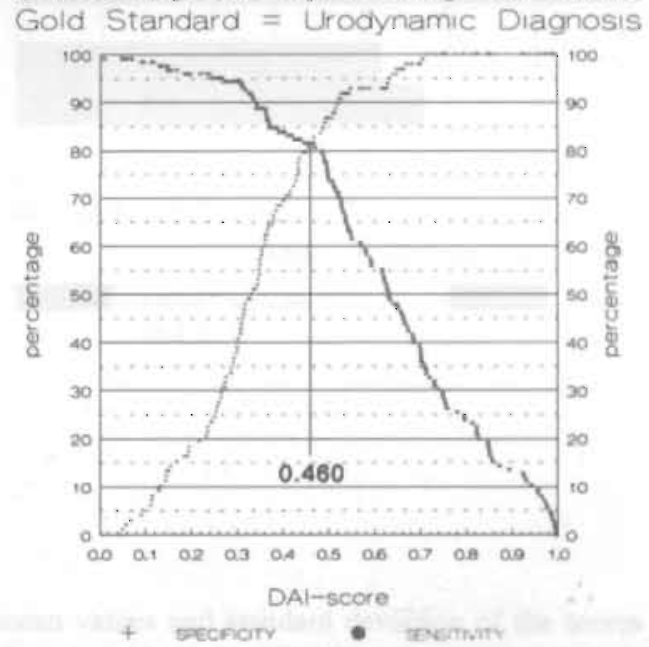

Figure 5. The relationship between respectively the sensitivity, specificity and the score of rule II, which used the urodynamic diagnosis as reference standard. Sensitivity equals specificity $(81 \%)$ at a cutoff point of 0.46 . This means that $81 \%$ of the symtomatic overactive detrusors scored above 0.46 and also $81 \%$ of the symptomatic non-overactive detrusors scored below 0.46 . 


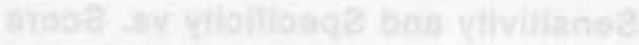

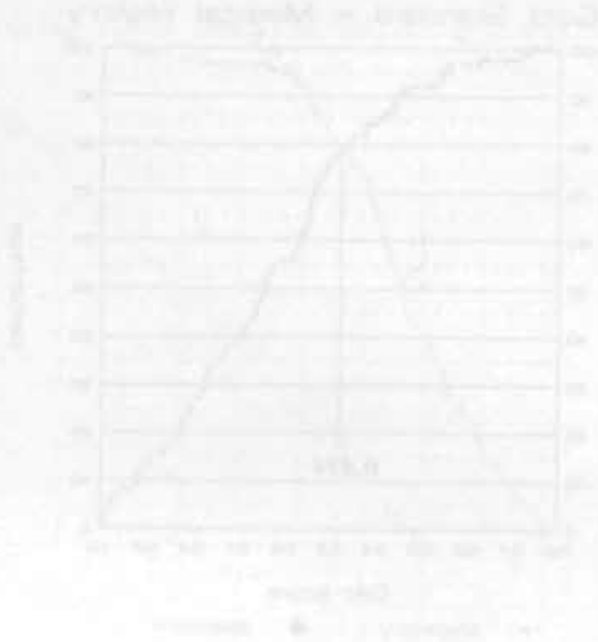

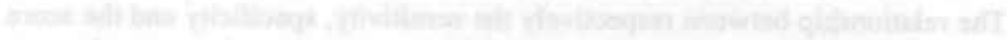

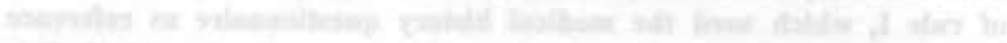

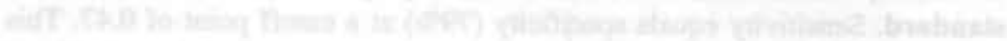

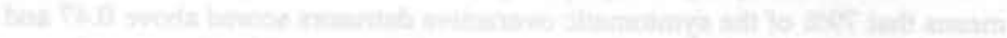

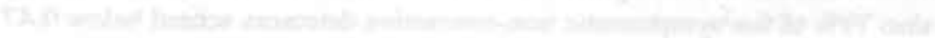

$$
\text { . }
$$

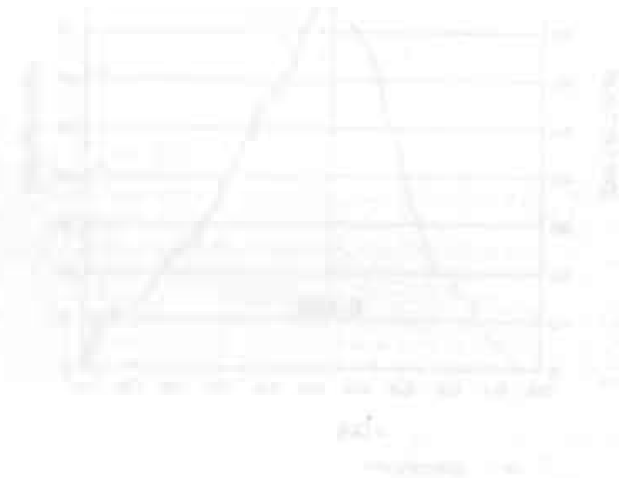

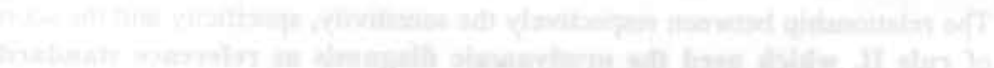

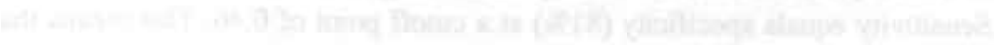
The

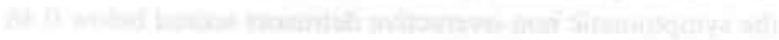




\section{Mean Scores in different symptom groups}

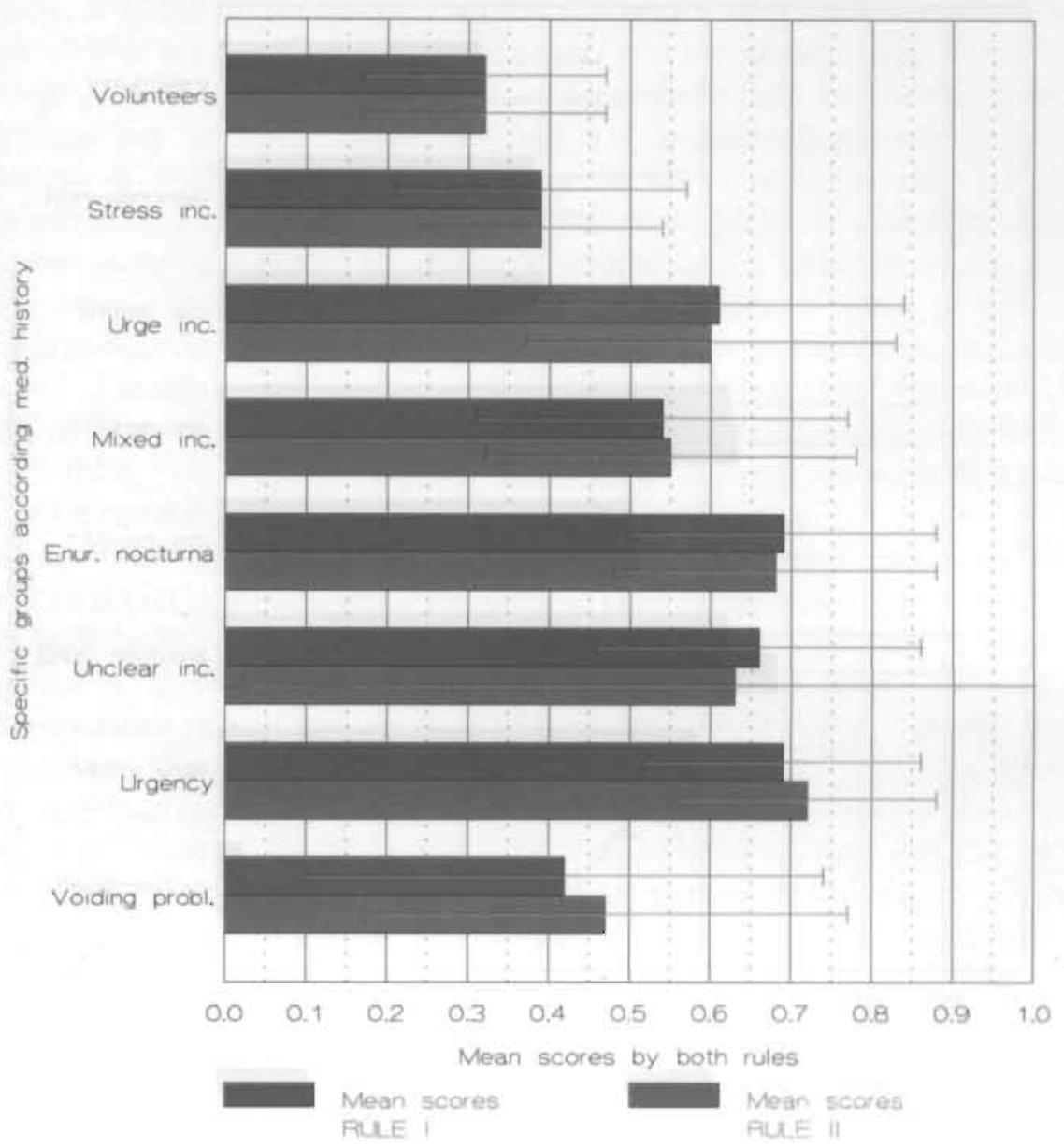

Figure 6. The mean values and standard deviation of the scores by both rules of each specific subgroup as classified from the medical history questionnaire. 


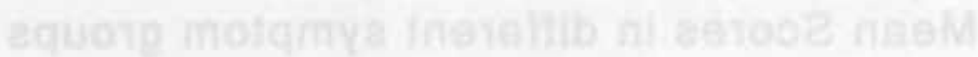

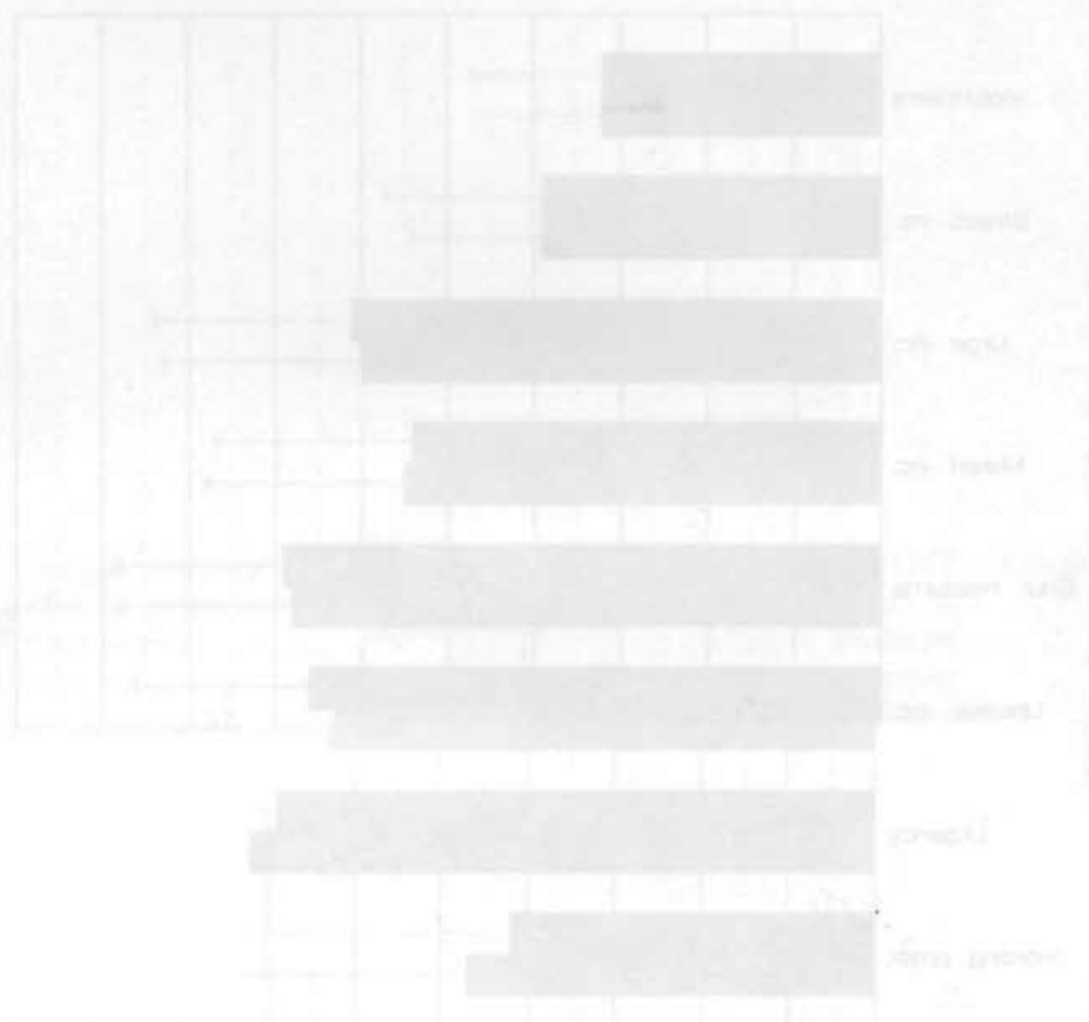




\section{Mean Scores in different diagn. groups}

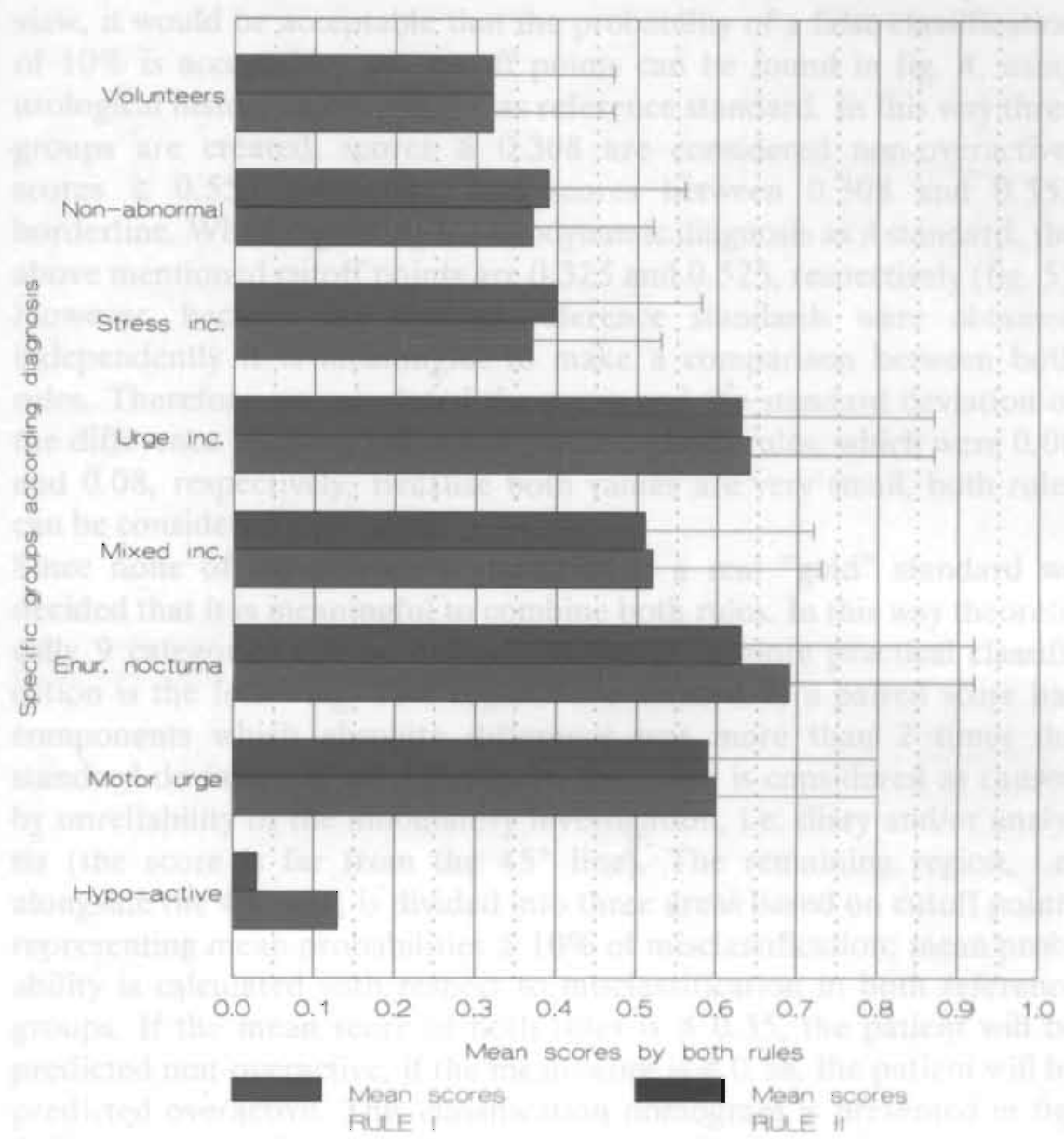

Figure 7. The mean values and standard deviation of the scores by both rules of each specific subgroup as classified from the tirodynamic diagnosis. 
Therefore both figures 4 and 5 can be used to choose clinical significant cutoff points to indicate ranges of scores of non-overactive, borderline and overactive bladder function. If for instance, from a clinical point of view, it would be acceptable that the probability of a false classification of $10 \%$ is acceptable, two cutoff points can be found in fig. 4 , using urological history questionnaire as reference standard. In this way three groups are created, scores $\leqq 0.308$ are considered non-overactive, scores $\geqq 0.555$ overactive, and scores between 0.308 and 0.555 borderline. When regarding the urodynamic diagnosis as a standard, the above mentioned cutoff points are 0.325 and 0.525 , respectively (fig. 5) However, because the applied reference standards were obtained independently it is meaningful to make a comparison between both rules. Therefore we calculated the mean and the standard deviation of the difference between individual scores of both rules, which were 0.00 and 0.08 , respectively. Because both values are very small, both rules can be considered equivalent.

Since none of the reference standards is a real "gold" standard we decided that it is meaningful to combine both rules. In this way theoretically 9 categories can be defined. However, a more practical classification is the following. Five regions are defined. If a paired score has components which absolute difference was more than 2 times the standard deviation of all differences, the score is considered as caused by unreliability of the ambulatory investigation, i.e. diary and/or analysis (the score is far from the $45^{\circ}$ line). The remaining region, i.e. alongside the $45^{\circ}$ line, is divided into three areas based on cutoff points representing mean probabilities $\leqq 10 \%$ of misclassification; mean probability is calculated with respect to misclassification in both reference groups. If the mean score of both rules is $\leqq 0.35$, the patient will be predicted non-overactive, if the mean score is $\geqq 0.58$, the patient will be predicted overactive: This classification nomogram is presented in fig. 8. For each specific subgroup of both standards separately, tables 6 and 7 give the results of the classification using this nomogram.

From the subgroups, obtained by the medical history questionnaire, that were used to construct rule I, 12 subjects (7\%) were classified in the opposite area as was expected based on the questionnaire; 53 subjects (33\%) were classified as borderline and 107 (57\%) in accordance with the questionnaire result. For the groups used from urodynamic diagnosis classification these percentages were respectively $8 \%, 33 \%$ and $55 \%$.

From tables 6 and 7 it can also be seen that the suggestion to include the mixed inc. groups not in the learning groups was valid since only $43 \%$ respectively $34 \%$ of both subgroups were classified as over-active (see also figure $9 \mathrm{a} / \mathrm{b})$. 


\begin{tabular}{|c|c|c|c|c|c|c|c|}
\hline \multirow{2}{*}{$\begin{array}{l}\text { medical history } \\
\text { asymptom. volunteers }\end{array}$} & \multicolumn{2}{|c|}{$\begin{array}{l}\text { non- } \\
\text { overactive } \\
\text { detrusor }\end{array}$} & \multicolumn{2}{|c|}{$\begin{array}{l}\text { borderline over- } \\
\text { activity of the } \\
\text { detrusor }\end{array}$} & \multirow{2}{*}{$\begin{array}{c}\begin{array}{c}\text { overactive } \\
\text { detrusor }\end{array} \\
\mathbf{3}(\mathbf{5} \%)\end{array}$} & \multirow{2}{*}{$\begin{array}{c}\begin{array}{c}\text { unreliable } \\
\text { investigation }\end{array} \\
0\end{array}$} & \multirow{2}{*}{$\begin{array}{c}\begin{array}{c}\text { total } \\
\text { number }\end{array} \\
66 .\end{array}$} \\
\hline & 39 & $(59 \%)$ & 24 & $(36 \%)$ & & & \\
\hline stress inc. & 8 & $(38 \%)$ & 11 & $(52 \%)$ & $1(5 \%)$ & $1(5 \%)$ & 21 \\
\hline voiding problems, no urgency & 4 & $(44 \%)$ & 1 & $(11 \%)$ & $3(33 \%)$ & $1(11 \%)$ & 9 \\
\hline urge inc. & 5 & $(8 \%)$ & 18 & $(31 \%)$ & $33(56 \%)$ & $3(5 \%)$ & 59 \\
\hline enuresis noct. & 0 & & 1 & $(8 \%)$ & $10(83 \%)$ & $1(8 \%)$ & 12 \\
\hline urgency & 0 & & 4 & $(33 \%)$ & $8(67 \%)$ & 0 & 12. \\
\hline unclear inc. & 0 & & 2 & $(67 \%)$ & $1(33 \%)$ & 0 & 3 \\
\hline mixed inc. & 14 & $(18 \%)$ & 25 & $(32 \%)$ & $33(43 \%)$ & $5(6 \%)$ & 77 \\
\hline total & 70 & $(27 \%)$ & 86 & $(33 \%)$ & $92(36 \%)$ & $11(4 \%)$ & 259 \\
\hline
\end{tabular}

Table 6. DAI-classification of the different subgroups from the computerized medical history taking; FAT-printed numbers are subjects classified by the DAI in opposite areas as expected.

\begin{tabular}{|c|c|c|c|c|c|c|c|c|}
\hline \multirow{2}{*}{$\begin{array}{l}\text { urodynamic diagnosis } \\
\text { asymptomatic volunteers }\end{array}$} & \multicolumn{2}{|c|}{$\begin{array}{c}\text { non- } \\
\text { overactive } \\
\text { detrusor }\end{array}$} & \multicolumn{2}{|c|}{$\begin{array}{l}\text { borderline over- } \\
\text { activity of the } \\
\text { detrusor }\end{array}$} & \multirow{2}{*}{$\begin{array}{c}\begin{array}{c}\text { overactive } \\
\text { detrusor }\end{array} \\
3(5 \%)\end{array}$} & \multicolumn{2}{|c|}{$\begin{array}{l}\text { unreliable } \\
\text { investigation }\end{array}$} & \multirow{2}{*}{$\begin{array}{c}\begin{array}{c}\text { total } \\
\text { number }\end{array} \\
66\end{array}$} \\
\hline & 39 & $(59 \%)$ & 24 & $(36 \%)$ & & 0 & & \\
\hline no abnormalities & 3 & $(43 \%)$ & 3 & $(43 \%)$ & $1(14 \%)$ & 0 & & 7 \\
\hline stress inc. & 7 & $(29 \%)$ & 13 & $(54 \%)$ & $3(13 \%)$ & 1 & $(5 \%)$ & 24 \\
\hline hypo-active detrusor & & $(100 \%)$ & 0 & & 0 & 0 & & 1 \\
\hline urge inc. & 8 & $(9 \%)$ & 24 & $(28 \%)$ & $49(58 \%)$ & 4 & $(5 \%)$ & 85 \\
\hline enuresis noct. & 0 & & 2 & $(40 \%)$ & $3(60 \%)$ & 0 & & 5 \\
\hline motor urge & 3 & $(9 \%)$ & 7 & $(21 \%)$ & $20(61 \%)$ & 3 & $(9 \%)$ & 33 \\
\hline mixed inc. & 9 & $(24 \%)$ & 13 & $(34 \%)$ & $13(34 \%)$ & 3 & $(8 \%)$ & 38 \\
\hline total & 70 & $(27 \%)$ & 86 & (33\%) & $6 \%)$ & 11 & $(4 \%)$ & 259 \\
\hline
\end{tabular}

Table 7. DAI-classification of the different subgroups from the urodynamic diagnosis; volunteers were considered healthy with a non-overactive detrusor; FAT. printed numbers are subjects classified by the DAI in opposite areas as expected.

From the 56 patients ( 7 with symptoms of stress inc., 14 with urge inc., 21 with mixed inc., 4 with enuresis noct., 2 with unclear inc., 6 with urency and 2 with voiding problems) with no abnormalities during the conventional urodynamic investigation $24(43 \%)$ were classified as overactive, $19(34 \%)$ as borderline, and $12(21 \%)$ as non-overactive (see fig. 10). These results indicate that conventional urodynamic testing alone is insufficient to detect detrusor overactivity. 


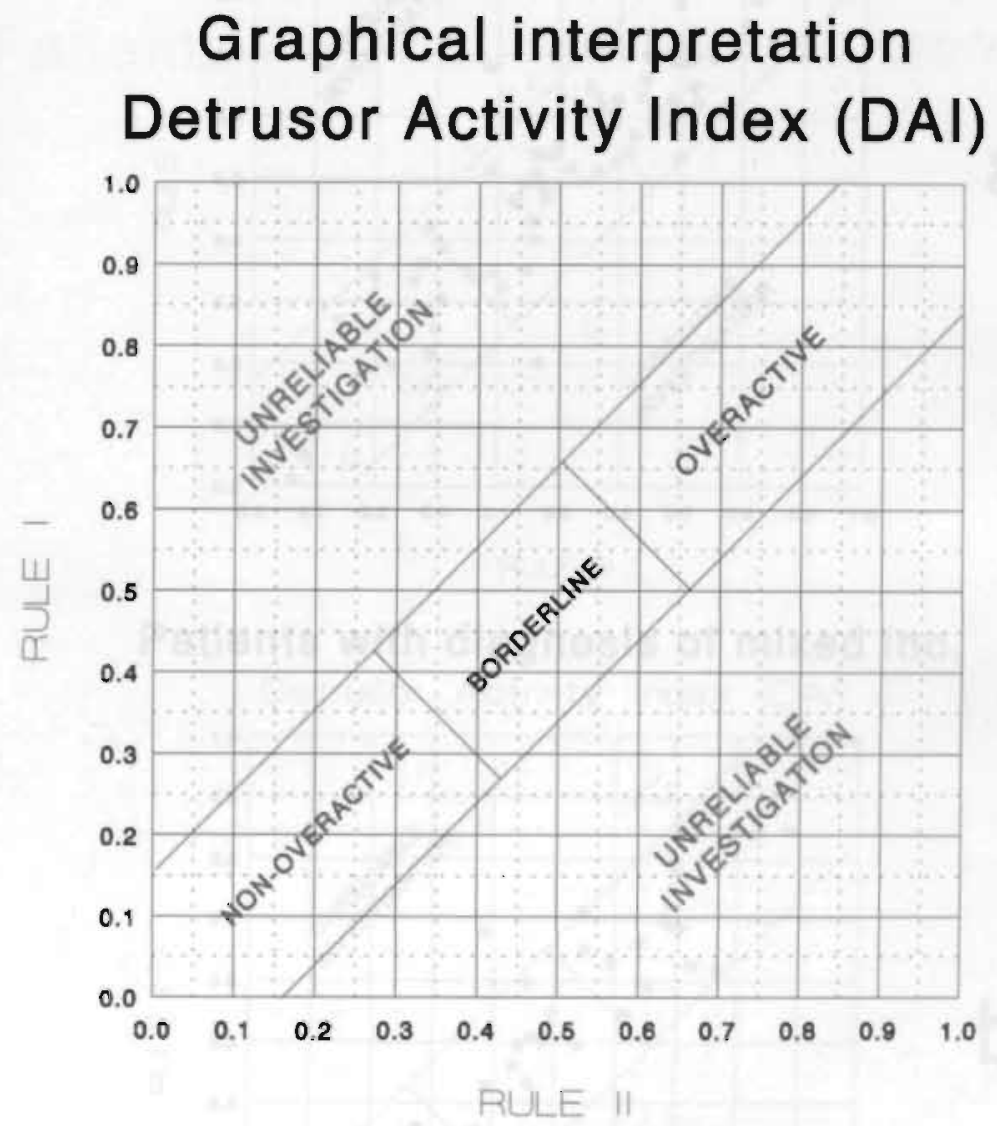

Figure 8. This graph shows the constructed NOMOGRAM representing the DETRUSOR ACTIVITY INDEX (DAI). Scores with the upper and lower triangle are classified as due to unreliable ambulatory investigations. This can be caused by the filling in of the diary or unreliable analysis. 


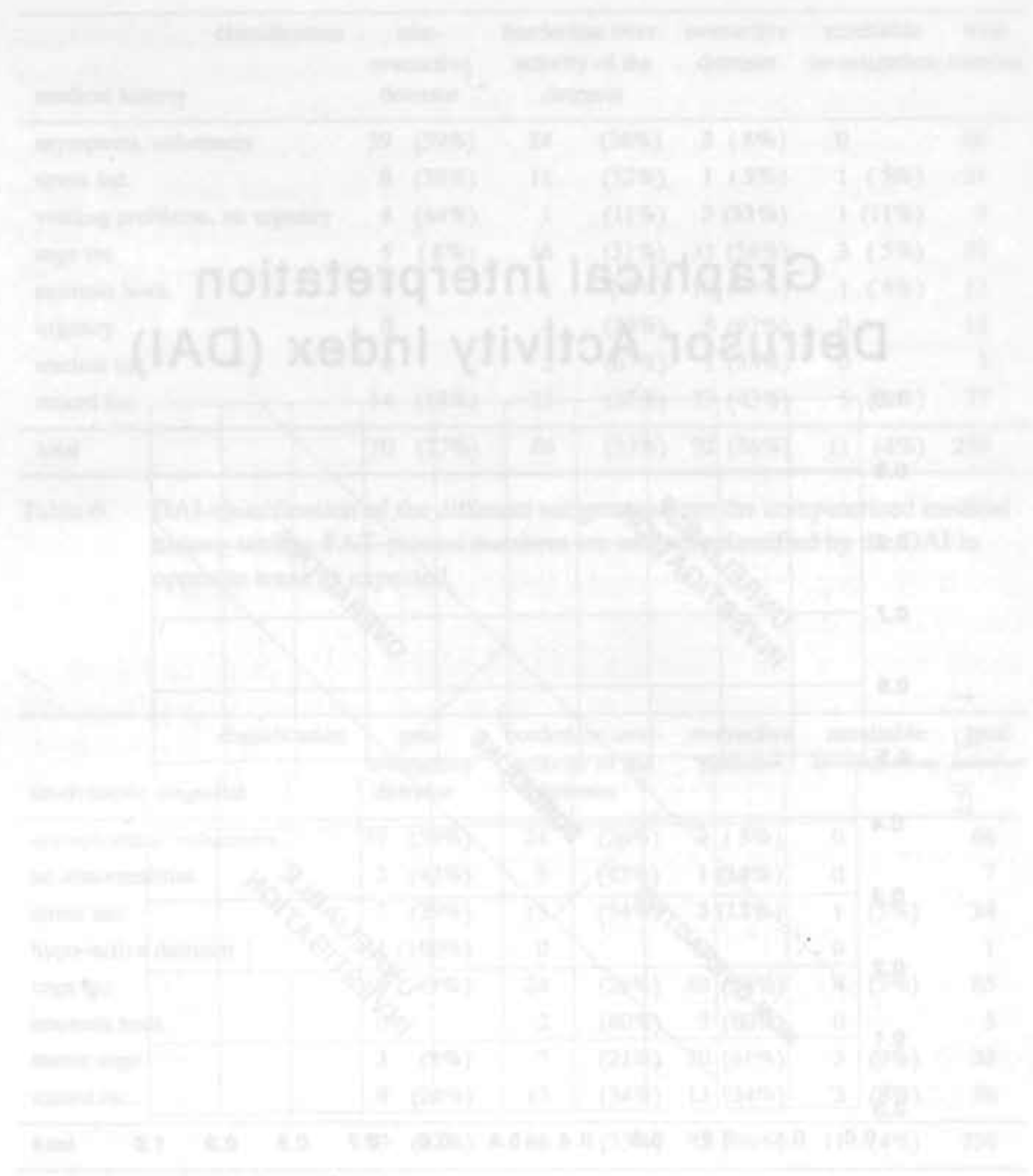

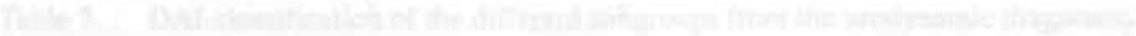

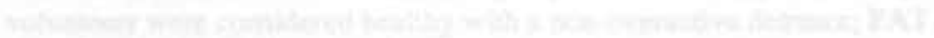

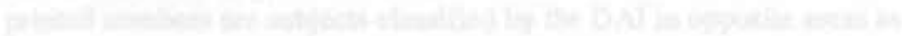

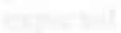

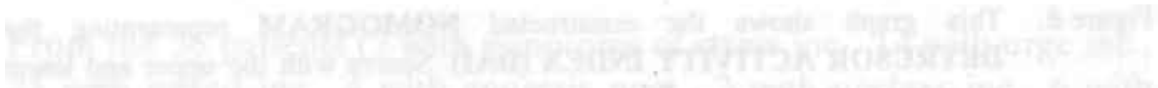

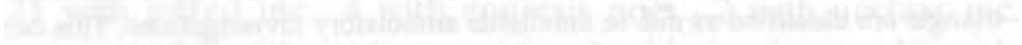

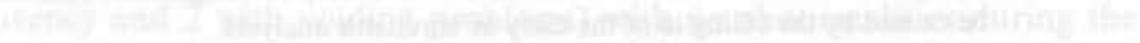

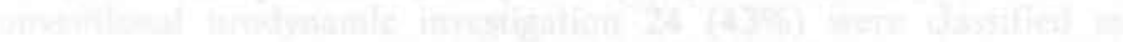

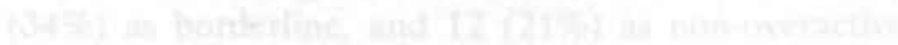

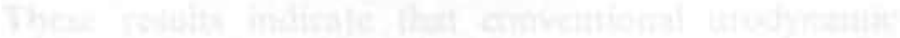


Patients with symptoms of mixed inc.

Detrusor Activity Index (DAl)

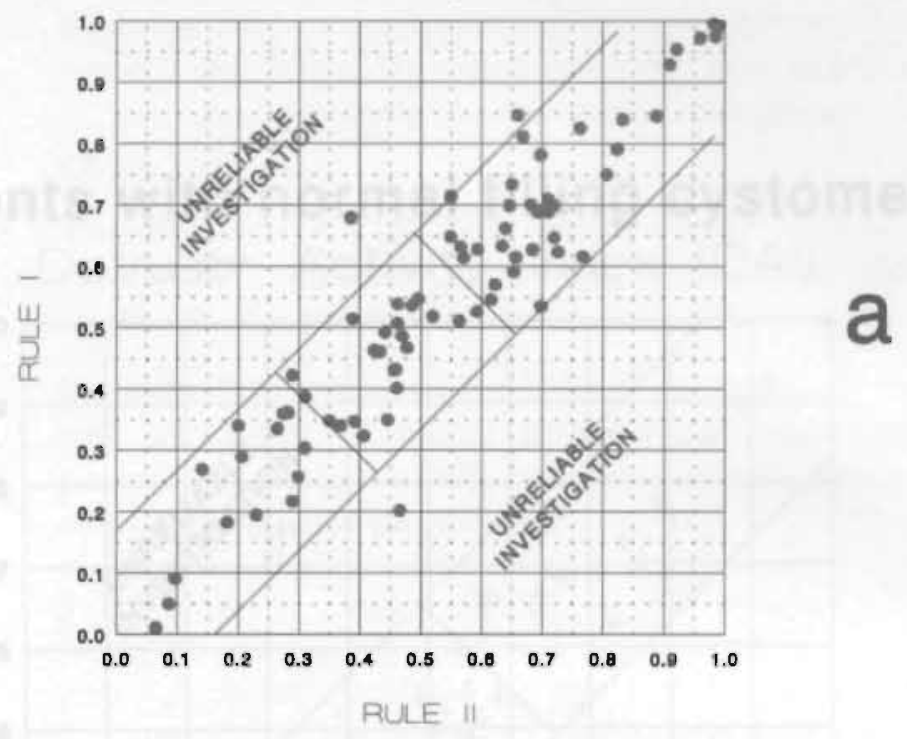

\section{Patients with diagnosis of mixed inc.}

Detrusor Activity index (DAl)

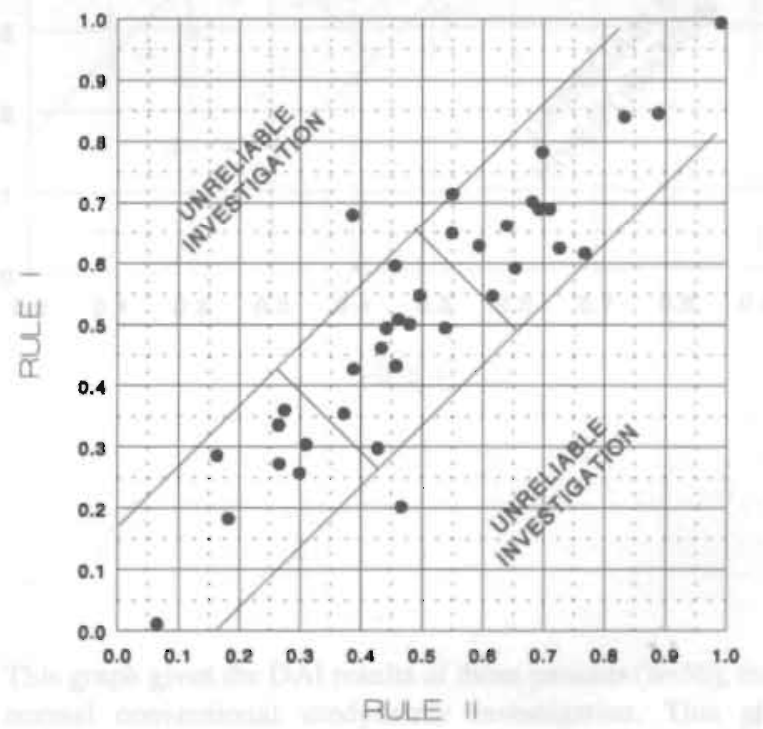

b

Figure 9. Graph a. gives the results of the subgroup with symptoms of mixed incontinence $(\mathrm{n}=77)$. Graph $\mathrm{b}$. gives the results of the subgroup with a urodynamic diagnosis of mixed incontinence. 


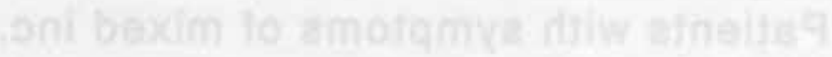
$\sqrt{6}$

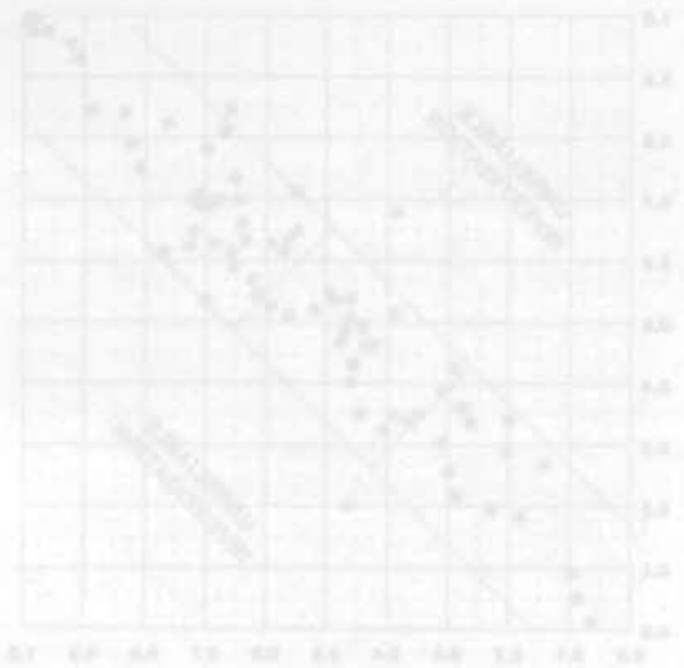

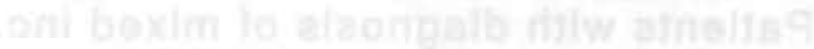
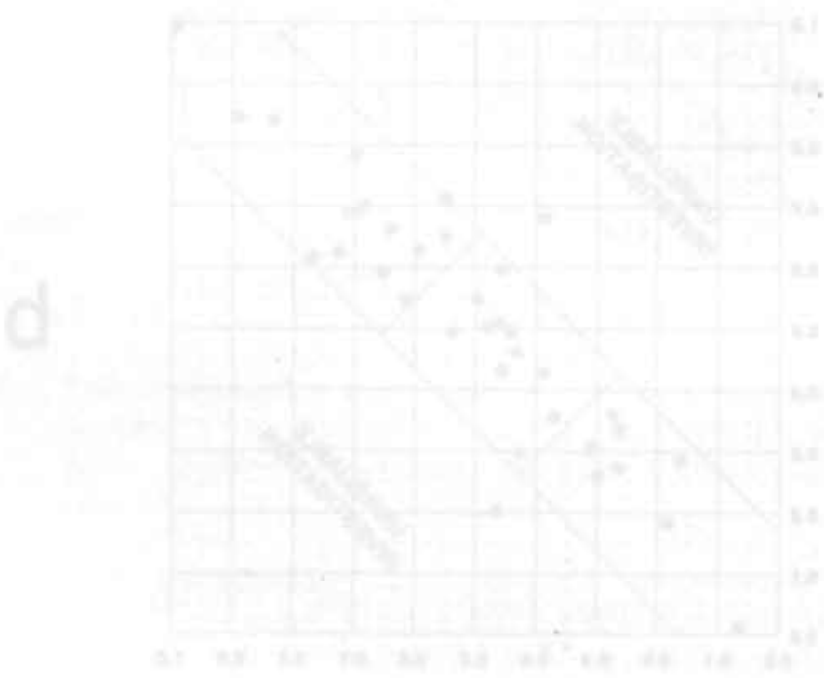

$x^{2}$

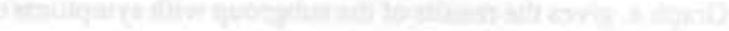

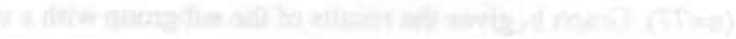

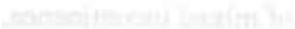




\section{Patients with normal filling cystometry}

\section{Detrusor Activity Index (DAl)}

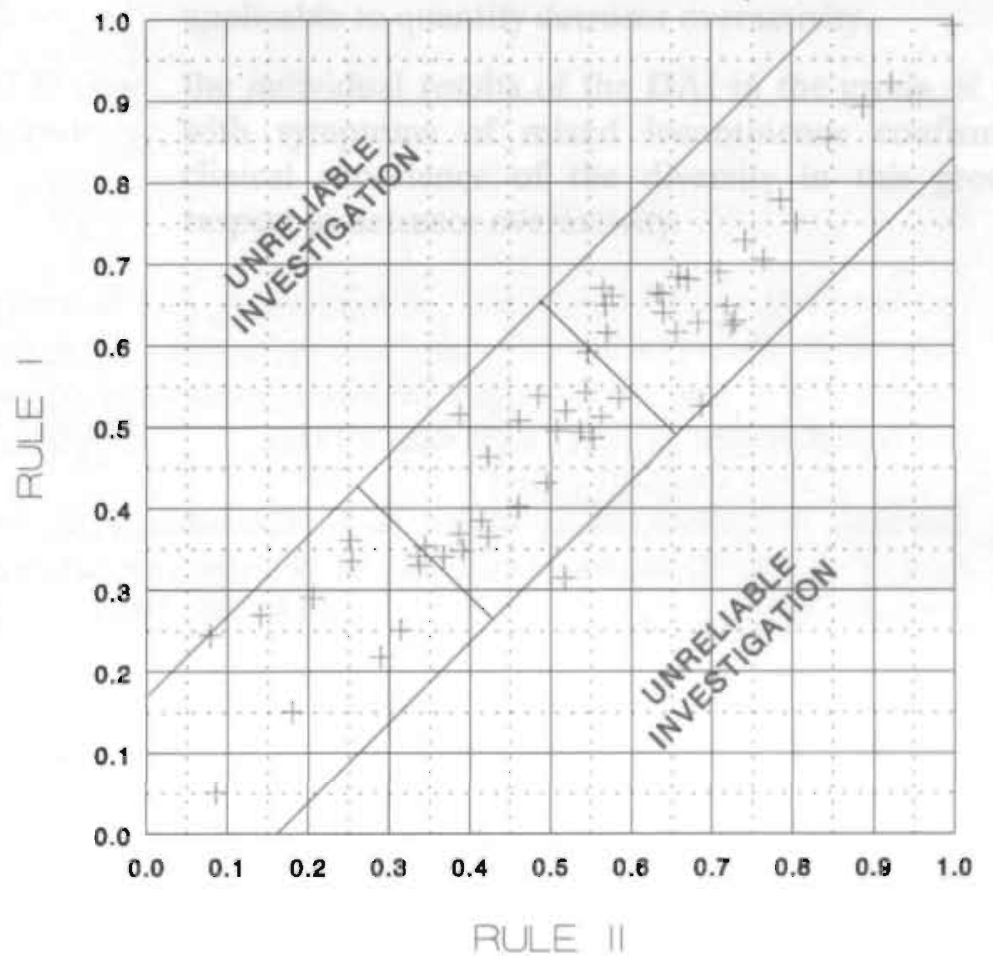

Figure 10. This graph gives the DAI results of those patients $(n=56)$, that had a completely normal conventional urodynamic investigation. This group consisted of, respectively, 7 patients with symptoms of stress inc., 14 with urge inc., 21 with mixed inc., 4 with enuresis noctuma, 2 with unclear symptoms of inc., 6 with urgency and 2 with voiding problems without urgency. The DAI classifies, however, $26(46 \%)$ detrusors as overactive, $16(29 \%)$ as borderline and 13 $(23 \%)$ as non-overactive. 

In conclusion it can be stated that:

- conventional filling cystometry is of minor value for the detection and quantification of detrusor overactivity, because it objectifies detrusor overactivity only in a minority of patients with symptoms of urge incontinence or urgency,

- that the Detrusor Activity Index (DAl) derived from extramural ambulatory monitoring seems to be clinically applicable to quantify detrusor overactivity,

- the individual results of the DAI in the group of patients with symptoms of mixed incontinence confirmed our clinical experience of the diversity in this group with respect to detrusor overactivity. 


\section{References}

1. van Waalwijk van Doorn, E.S.C., Zwiers, W., Wetzels, L.L.A.N. and Debruyne, F.M.J.: A comparative study between standard and ambulant urodynamics.

Neurourol. Urodynam., 6: 159, 1987.

2. Kulseng-Hanssen, S. and Klevmark, B.: Ambulatory urethrocysto-rectometry: a new technique.

Neurourol. Urodynam., 7: 119, 1988.

3. Webb, R.J., Griffiths, C.J., Ramsden, P.D. and Neal, D.E.: Measurement of voiding pressures on ambulatory monitoring: comparison with conventional cystometry.

Brit. J. Urol., 65: 152, 1990.

4. van Waalwijk van Doorn, E.S.C., Remmers, A. and Janknegt, R.A.: Extramural ambulatory urodynamic monitoring during natural filling and normal daily activities: evaluation of one hundred patients. J. Urol., 146: 124, 1991.

5. Griffiths, C.J., Assi, M.S., Styles, R.A., Ramsden, P.D. and Neal, D.E.: Ambulatory monitoring of bladder and detrusor pressure during natural filling. J. Urol., 142: 780, 1989.

6. Kulseng-Hanssen, S.: Ambulatory urethro-cysto-rectometry in patients with urethral pressure variations.

Neurourol. Urodynam., 6: 156, 1987.

7. van Waalwijk van Doorn, E.S.C., Bouwmeister, P.P.M., van Oostendorp, M.E., Kimmich, H.P. and Debruyne, F.M.J.: A retrospective study of the clinical value of telemetric urodynamics compared with standard urodynamics in patients with urinary incontinence. In: Biotelemetry IX, Edited by H.P. Kimmich and M.R. Neuman. Braunschweig DoeringDruck, pp. 159-160, 1987.

8. van Waalwijk van Doorn, E.S.C., Remmers, A. and Janknegt, R.A.: Conventional and extramural ambulatory urodynamic testing of the lower urinary tract in female volunteers.

J. Urol., 147: 1319, 1992 
9. Kleinbaum,D.G., Kupper, L.L. and Muller, K.E.: Applied regression analysis and other multivariable methods. Second Edition. ISBN: 0-87150--123-6. PWS-KENT Publishing Company, Boston, 1988.

10. International Continence Society Working Party on Urodynamic Equipment: technical aspects.

J. Med. Eng. Tech., 11: 57, 1987.

11. International Continence Society; Standardisation Committee: The Standardisation of Terminology of lower urinary tract function. Read at annual meeting of the International Continence Society, 1987. 



\section{Summary}

Urinary incontinence is a major health problem which, although not directly related to mortality, is often a serious handicap. Nowadays it is common sense among urologists that a reliable diagnosis of the causes of urinary incontinence is not possible without the application of quantitative urodynamic investigations like uroflowmetry, urethral profilometry, filling cystometry and pressure/flow tests. For this reason the understanding and mastering of these tests are basic demands to specialists working in a urological or gynaecological practice.

The functioning of the lower urinary tract as a urine storage and evacuation system is normally characterized by time constants, varying from seconds to hours. This causes the occurrence of symptoms during the short conventional quantitative urodynamic tests, which are performed under unphysiological circumstances, to be uncertain. We suggested that this might be the reason that conventional urodynamic investigations often show doubtful outcomes and frequently do not result in a reliable functional diagnosis, while clinical questions remain unanswered.

We investigated this statement by evaluating the sensitivity and specificity of the conventional urodynamic investigation with respect to complaints of urinary incontinence. At the urodynamic laboratory of the university hospital of Nijmegen we found a sensitivity and specificity of the conventional urodynamic investigation using complaints of urinary incontinence as standard in the female patient group of $47 \%$ and $94 \%$, respectively. For the male group these values were $37 \%$ and $95 \%$, repectively.

The results showed furthermore that:

- urinary incontinence is not objectifyed during conventional urodynamic investigation in more than $50 \%$;

- it is more difficult to objectify urge incontinence than stress incontinence:

- if incontinence is objectified during the investigation, there is a high correlation with the medical history in case of stress or urge incontinence;

- the ability of the standard investigation to objectify mixed incontinence is extremely poor $(13 \%)$, with all consequences if surgical treatment is considered. 
The low sensitivity was reason to search for improvements of methodology and technology.

Possibilities to improve urodynamic diagnostic methodology were studied by applying on-line telemetry. This study was performed in 80 females with complex histories of urinary incontinence. Sensitivity to demonstrate incontinence improved to $76 \%$. Sensitivity to objectify abnormalities improved even to $96 \%$. The method showed that the ambulatory aspect, which enabled investigation of the lower urinary tract function under more physiological circumstances caused this dramatic improvement. Nevertheless, this method was time consuming and sensitive to technical problems.

Therefore we decided to set up an experiment applying holter monitoring in stead of on-line telemetry. Advantages were extended recording period ( $24 \mathrm{~h}$.) with repeated filling and evacuation phases. Disadvantage was the lack of on-line information. Testing the method proved clinical applicability to investigate detrusor function. With this method the efficacy of Oxybutynin Chloride to decrease detrusor overactivity could be proven quantatively in a patient group with severe mixed incontinence. The equipment, however, asked for improvement because of technical performance and also because of the extremely time consuming analysis $(75 \mathrm{~min}$.) of 24 meters of paper chart per investigation.

In cooperation with industry a new processor based digital recording system was developed (URODEC 500). Analog replay and analysis of the data was replaced by a PC-computer based interface unit and a software package.

The applicability of this new system was tested in 100 patients and 50 volunteers. Combining this system with robust Gaeltec catheter mounted pressure transducers showed to be working well even under extramural testing circumstances. Analysis resulting in a clinical report with the software package is limited to 10-15 minutes for an 8 hour investigation. Both patients and volunteers judged the new extramural ambulatory method as an acceptable test. The analysis software enabled us to evaluate different variables describing bladder activity during the filling phase quantitatively in different patient groups. With the data from the healthy volunteers we were able to establish a standard for normal bladder activity.

Finally, based on medical history and urodynamic diagnosis, we developed with these data a set of rules using only variables from the 
ambulatory investigation, which give an easily applicable quantitative score for bladder overactivity during the filling phase. This score is plotted in a two-dimensional graph with areas defined as overactive, non-overactive detrusor behaviour, borderline and unreliable to interpret. The senstitivity and specificity to diagnose bladder overactivity of this detrusor activity index (DAI) were approximately $80 \%$, if no borderline area is defined.

In conclusion it can be stated that a new urodynamic method of investigating patients with urinary incontinence has been established, which is a lot more sensitive to abnormal bladder behaviour. The method is now evaluated in other clinics. It is the first time urologists can evaluate therapies to treat bladder overactivity with a totally objective method. The new equipment must be developed further to extent the possibilities. 
. 


\section{Samenvatting}

Urine-incontinentie is, hoewel het geen direkt verband heeft met mortaliteit, een belangrijk probleem binnen de gezondheidszorg.

Patiënten ervaren de incontinentie vaak als een zeer ernstige handicap. Urologen zijn vrij algemeen van mening, dat een betrouwbare diagnose van de oorzaak voor incontinentie niet mogelijk is zonder hulp van kwantitatieve urodynamische onderzoekmethoden, zoals uroflowmetrie, urethrale drukprofilometrie, vullingscystometrie en druk/flowstudie.

Begrip en beheersing van deze urodynamische testen is daarom één van de basale eisen, die aan specialisten, werkzaam binnen een urologische of gynaecologische praktijk, gesteld worden.

Het funktioneren van de lagere urinewegen ten behoeve van de opslagen de ledigingsfase wordt gekarakteriseerd door tijdkonstanten, die variëren qua orde-grootte van seconden tot uren. Dit is er de oorzaak van, dat het optreden van symptomen tijdens de relatief korte conventionele urodynamische test, onzeker is. Bovendien worden die testen onder laboratorium omstandigheden uitgevoerd, waarbij de blaas ook nog een op niet-fysiologische wijze wordt gevuld. Deze aspekten, zo veronderstelden wij, zijn oorzaken voor de vaak onzekere uitkomst van het conventionele urodynamisch patiëntenonderzoek, zodat de klinische vraagstelling dikwijls slechts deels kan worden beantwoord.

De voorafgaande veronderstelling werd onderzocht door de sensitiviteit en specificiteit van het conventionele urodynamische onderzoek met betrekking tot het objectiveren van incontinentie tijdens het onderzoek. In het urodynamisch laboratorium van het St. Radboudziekenhuis te Nijmegen werd een sensitiviteit van $47 \%$ en specificiteit van $94 \%$ van het urodynamisch onderzoek gevonden voor de vrouwelijke patiëntengroep. Voor de mannen was dit $37 \%$ respectievelijk $95 \%$. Hierbij werd de anamnestisch vastgestelde urine-incontinentie als standaard gebruikt voor het indelen van de groepen.

Verder liet het onderzoek zien dat:

- tijdens het conventionele urodynamisch onderzoek werd incontinentie in minder dan $50 \%$ ook daadwerkelijk aangetoond;

- het is moeilijker om urge incontinentie aan te tonen dan stress-incontinentie; 
- indien echter incontinentie tijdens het urodynamisch onderzoek is aangetoond, dan is de overeenstemming tussen de gevonden soort en de klachten van urge- en stress-incontinentie ook goed;

- wat betreft het aantonen van gemengde incontinentie is het conventionele urodynamisch onderzoek echter extreem zwak (13\%) met alle consequenties, indien chirurgische behandeling wordt overwogen.

De lage sensitiviteit van het conventionele urodynamisch onderzoek was de aanleiding om te zoeken naar verbetering van diagnostische methodologie en technologie.

Mogelijkheden hiertoe werden onderzocht door het toepassen van radio-telemetrie, waarbij zowel de laboratorium-omstandigheden, als het niet fysiologisch vullen van de blaas zoveel mogelijk werden vermeden. Hiertoe werd een studie in 80 vrouwelijke patiënten met meestal een ingewikkelde urologische voorgeschiedenis uitgevoerd. De Sensitiviteit voor het aantonen van incontinentie verbeterde hierbij tot $76 \%$. De sensitiviteit voor het aantonen van afwijkingen in het funktioneren van het lagere urinewegsysteem verbeterde zelfs tot $96 \%$. Deze aanzienlijke verbetering van de diagnostische resultaten werd veroorzaakt door het ambulant meten van de patiënt onder normalere omstandigheden. Toch moet gesteld worden, dat het telemetrisch onderzoek te veel tijd kostte, extra personeel vereiste en gevoelig was voor technische storingen.

Om deze redenen werd besloten een experiment te starten, waarbij in plaats van 'on-line' een draagbare 'holterrecorder' wordt gebruikt om de verschillende signalen op te slaan. Voordeel is de verlengde meetduur (24 uur), waarbij de vullings- en ledigingsfasen meerdere malen doorlopen worden. Nadeel is echter, dat tijdens het onderzoek de 'online' informatie ontbreekt. Het testen van dit systeem toonde de klinische toepasbaarheid aan. Vervolgens werd een studie uitgevoerd, waarbij gekeken werd of het remmende effect van Dridase (Oxybutynin Chloride) op de blaas, kwantitatief kon worden aangetoond. Dit onderzoek vond plaats in een patiëntengroep met urodynamisch bewezen gemengde incontinentie. Het resultaat van deze studic toonde inderdaad de remmende werking, waarbij, zoals werd verwacht, de subjectieve verbetering minimaal was. Daarmee werd meteen ook de kracht van deze nieuwe methodiek duidelijk. Het gebruikte 'holtersysteem' was echter duidelijk voor verbetering vatbaar; zowel vanwege technische 
gebreken, als ook door langdurige analyse $(75 \mathrm{~min}$.) van 24 meter papier per onderzoek.

In samenwerking met de industrie werd vervolgens een nieuw digitaal holter-systeem ontwikkeld, dat werd gebaseerd op een geminiaturiseerde microprocessor-gecontroleerde recorder (URODEC 500). Het voorheen gebruikte analoge uitlezen en analyseren, werd vervangen door een pc-interface en een software-programma ter ondersteuning van de analyse en de rapportage.

De toepasbaarheid van dit systeem werd getest in 100 patiënten en 50 vrijwilligers. Combinatie van het URODEC 500-systeem met de robuuste Gaeltec microtip-catheters bleek goed te voldoen, zelfs, wanneer het onderzoek extramuraal werd uitgevoerd. Met het computerprogramma duurt het analyseren en het maken van een klinisch rapport van een 8-uurs meting gemiddeld zo'n 10-15 minuten. Dit is echter zonder uitprinten. Zowel de patiënten als de onderzochte vrijwilligers beoordeelden het extramuraal uitgevoerde ambulante onderzoek als aanvaardbaar wat betreft de belasting. De analyse software maakte het mogelijk verschillende variabelen, die betrekking hebben op blaasspieraktiviteit tijdens de vullingsfase te evalueren in verschillende patiëntengroepen. Met de gegevens van de gezonde vrijwilligersgroep was het mogelijk een kwantitatieve standaard voor normale blaasspieraktiviteit tijdens de vullingsfase te realiseren.

Tenslotte werd gebaseerd op de kwantitatieve data van beide groepen, verkregen tijdens het ambulante onderzoek, de 'Detrusor Activiteits Index' geconstrueerd. Hiervoor werd iedere onderzochte blaas ingedeeld zowel volgens de anamnese gegevens als volgens de klinische urodynamische diagnose. De op basis van deze twee indelingen ontwikkelde regels hadden beide een scheidingslijn (cutoff point), waarbij sensitiviteit en specificiteit beide ongeveer $80 \%$ zijn. Uiteindelijk werd voor de klinische toepassing niet voor één van de regels gekozen, maar werd gebruik gemaakt van een overeenstemmings-voorwaarde van de volgens beide regels berekende DAI-score. Op deze manier was het mogelijk om een eenvoudig af te lezen twee-dimensionale plot te construeren met langs de diagonaal drie gebieden gedefinieerd als 'normaal', 'overaktief' en 'borderline'; daarbuiten blijven dan twee gebieden over, waar de twee waarden zoveel van elkaar verschillen, dat ze als niet betrouwbaar worden geklassificeerd. Het 'normale' gebied en het 'overaktieve' gebied werden zo begrensd, dat de specificiteit, respectievelijk de sensitiviteit $90 \%$ waren. 
Concluderend kan gesteld worden, dat een nieuwe manier voor het diagnostiseren van patiënten met klachten van urine-incontinentie werd gerealiseerd en getest. Dat deze nieuwe techniek veel gevoeliger is wat betreft abnormaal blaasspiergedrag. De methode wordt inmiddels ook geëvalueerd in andere klinieken. Het is voor het eerst, dat urologen hun therapiën voor de behandeling van blaasoveraktiviteit met een duidelijk objektieve methode kunnen evalueren. De ontwikkeling van het draagbare meetsysteem en de analyse programmatuur zullen zeker verder ontwikkeld worden om de mogelijkheden uit te breiden. 


\section{Appendix}

The patient material that was used in chapters II, III and IV originate from the departments of Urology and Gynaecology of the university hospital Nijmegen.

The patient material that was used in chapters V, VI, VII and VIII originates from the department of Urology of the university hospital Maastricht. 


\section{Curriculum vitae}

The auteur was born in Eindhoven on the 8th of februari 1954. In 1974 he finished Grammar-school at the Augustinianum in Eindhoven.

In 1982 he got his masters degree in mechanical engineering at the technical university of Eindhoven. At the end of this education he specialized in Biomedical Engineering with a special study of the concept of an implantable bladder control system. This was done under the supervision of Prof. Schouten. In 1987 he got his registration as Clinical Physicist.

From 1980-1982 he was a coworker at the urodynamic laboratory of the university hospital Nijmegen. From 1982-1987 he was head of the urodynamic laboratory at the same hospital. In 1985 this became a parttime job, which gave him the opportunity to start an engineering company, which still exists. In the same period he teached for one year at the Technical Highschool in Heerlen.

In 1988 he became member of the medical staff of the department of urology at the university hospital Maastricht. In 1990 he won the Dantec Award for his work on ambulatory urodynamics, which was presented that year at the annual meeting of the International Continence Society. 
